\title{
Varieties of Political Consumerism
}

Inauguraldissertation zur Erlangung des akademischen Grades

einer Doktorin der Sozialwissenschaften

der Universität Mannheim

vorgelegt von

Carolin Vanessa Zorell

Mannheim, März 2016 
Dekan der Fakultät:

Erstgutachter:

Zweitgutachterin:

Drittgutachter:

Tag der Disputation:
Prof. Dr. Michael Diehl

Prof. Dr. Jan W. van Deth (Universität Mannheim)

Prof. Dietlind Stolle, Ph.D. (McGill University)

Prof. Dr. Harald Schoen (Universität Mannheim)

24. August 2016 


\section{Contents}

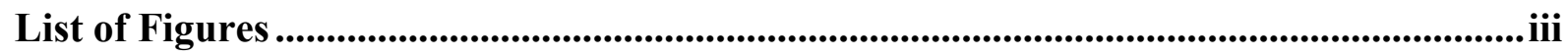

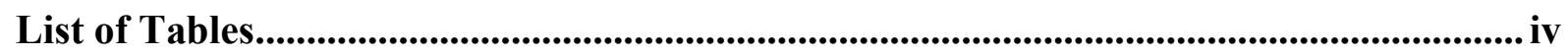

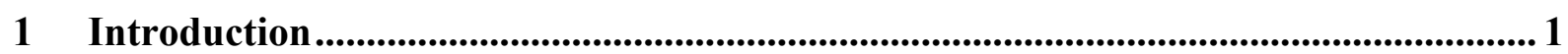

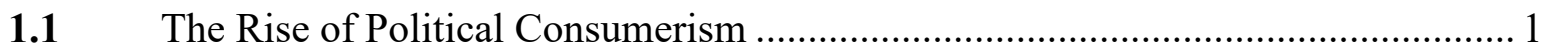

1.2 Explaining Boycotting and Buycotting Involvement ........................................... 3

1.3 Political Consumerism as a Multi-layered Process.............................................. 5

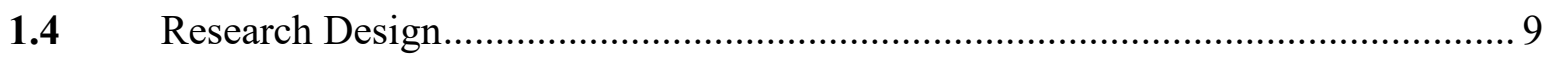

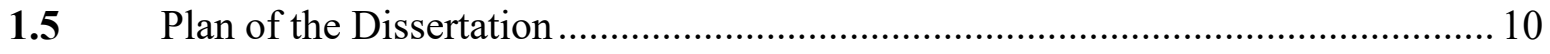

2 Perspectives on Political Consumerism................................................................... 13

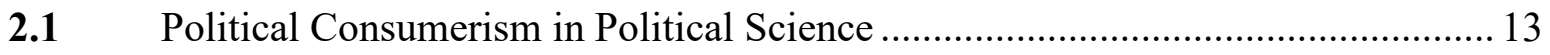

2.1.1 Recognising Consumerism as Political Participation ........................................ 14

2.1.2 Conceptual Varieties of Political Consumerism ................................................ 17

2.2 Sociological Accounts of Political Consumerism: The Citizen-Consumer

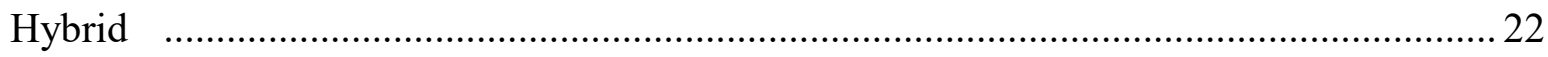

2.3 Political Consumer Behaviour from a Social Psychology Perspective ................ 26

2.3.1 Values, Attitudes and Behaviour ..................................................................... 27

2.3.2 The Use of Cognitive Short-Paths ..................................................................... 31

2.4 Résumé: The Citizen, the Consumer and the Politically Consuming Citizen ....... 34

3 Explaining Political Consumerism ............................................................................. 37

3.1 Evolving Duties and Responsibilities in the Economic-Political Realm .............. 37

3.1.1 New Challenges in a New Environment .......................................................... 38

3.1.2 On the Varieties of Capitalism ......................................................................... 42

3.2 Trust and Confidence in the Citizen-Consumer Sphere.........................................46

3.3 Putting the Pieces Together: A Multi-layered Model on Political Consumerism.. 52

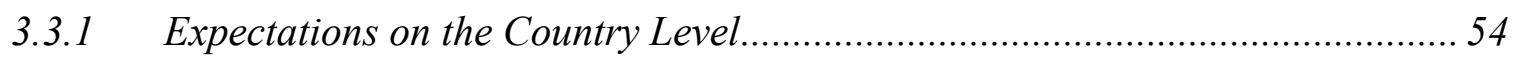

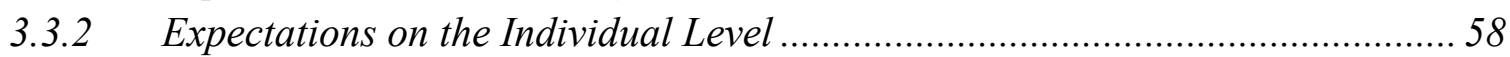

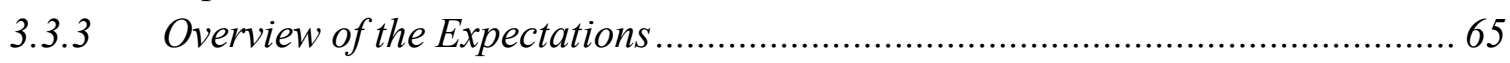

$4 \quad$ Research Design ................................................................................................................69

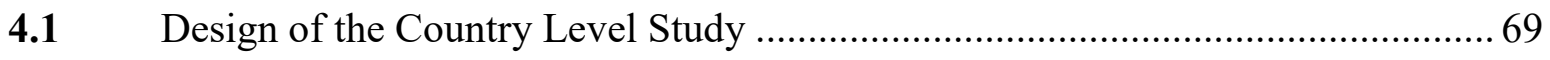

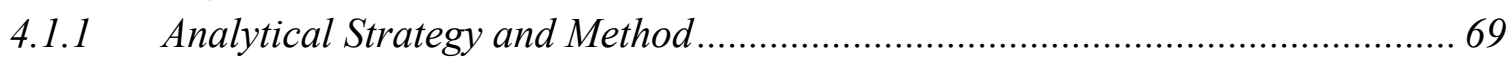

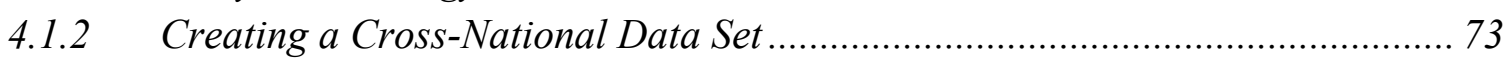

4.2 Design of the Individual Level Study ................................................................... 79

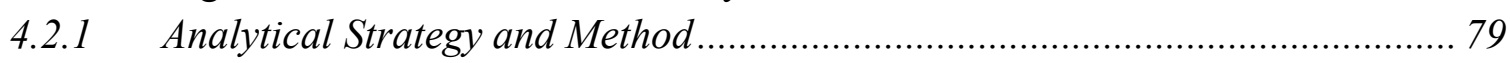

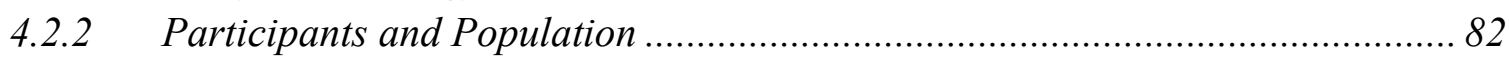

5 Political Consumerism on the Macro-Level ..................................................................8 87

5.1 Investigating the Aims Underlying Political Consumerism Cross-Nationally ...... 87

5.2 The Comparative Prevalence of Political Consumerism, CSR and Labelling

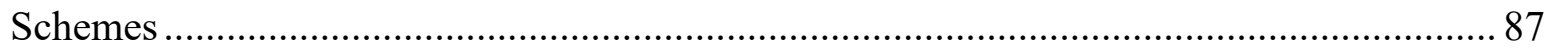

5.3 Varieties of Political Consumerism ……........................................................... 95

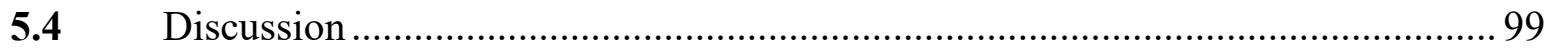


6 Examining Political Consumerism on the Micro-Level ............................................ 101

6.1 Surveying Boycotting and Buycotting Behaviour .......................................... 101

6.2 Socio-Demographic Antecedents of Political Consumerism............................... 101

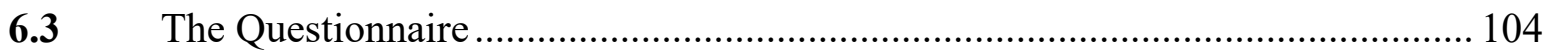

6.3.1 Background and Characterisation ............................................................... 104

6.3.2 Core Aspects of Political Consumer Behaviour ................................................. 104

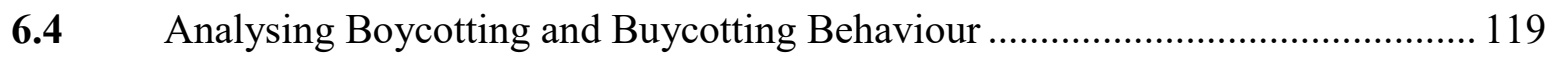

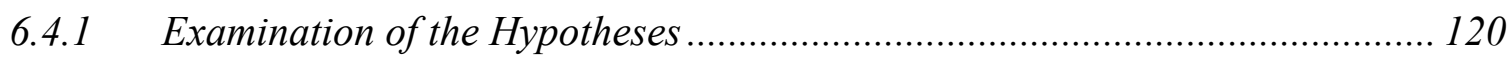

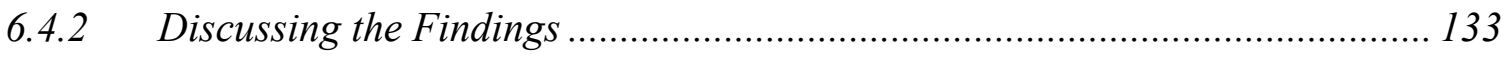

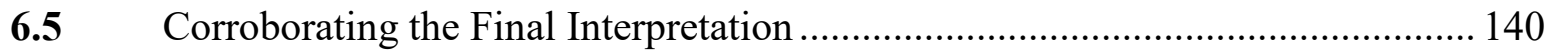

6.5.1 Re-Examination of the Model on Political Consumerism ................................. 141

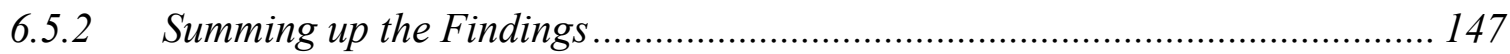

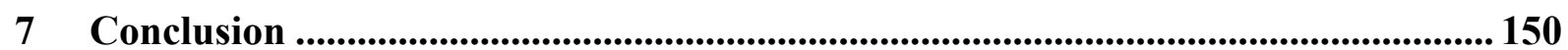

7.1 Investigating the Aims underlying Boycotting and Buycotting.......................... 150

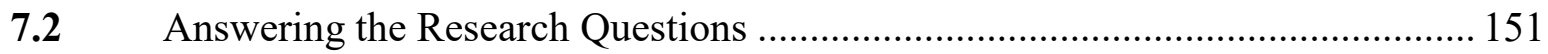

7.2.1 Patterns at the Macro-Level ......................................................................... 151

7.2.2 Political Consumerism at the Micro-Level .................................................... 155

7.3 Integrating the Micro- and the Macro-level Findings ......................................... 158

7.4 Putting the Findings into Perspective .............................................................. 160

7.4.1 Reflecting the Understanding of Political Consumerism in Political Science. 160

7.4.2 Counterbalancing Problematics Expounded by Social Psychology Research 162

7.4.3 From Varieties of Capitalism to Varieties of Political Consumerism .............. 164

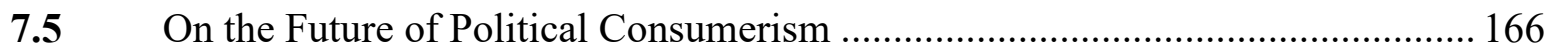

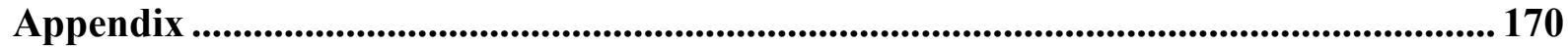

A.1. Questions \& Variables used in the Individual Level Study....................................... 170

A.2. Comparison of the Weighted and the Unweighted Samples with the Microcensus.... 172

A.3. Distribution of the Concept of the State across Age Groups, Gender and Education

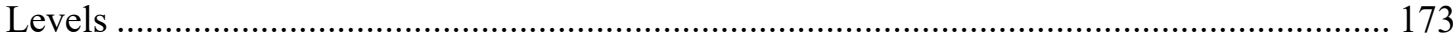

A.4. Distribution of Confidence in Labelling Schemes, Confidence in CSR and General

Trust across Age Groups, Gender and Education Levels .................................................... 174

A.5. Composition of the Corporate Social Responsibility Index ........................................ 175

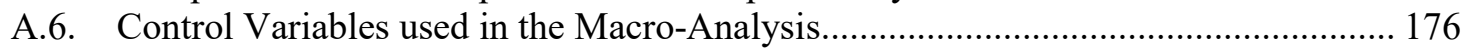

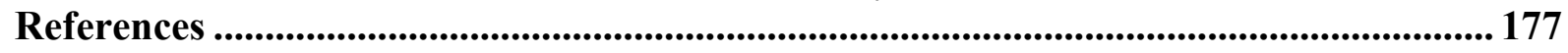




\section{List of Figures}

Figure 1. Labelling Schemes and Corporate Social Responsibility across Countries............................ 5

Figure 2. The Process of Political Consumerism on the Country Level ............................................... 53

Figure 3. The Process of Political Consumerism on the Individual Level ........................................ 53

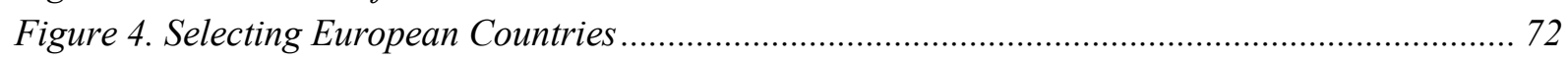

Figure 5. Boycotting and Buycotting across European Countries (in Percent).................................. 74

Figure 6. Fairtrade Sales in Europe (in EUR per capita for the year 2011) ...................................... 77

Figure 7. CSR in Europe (as Index Value for the Year 2003)............................................................. 78

Figure 8. The Spread of Non-Political Consumerism relative to CSR and Sales per Capita of

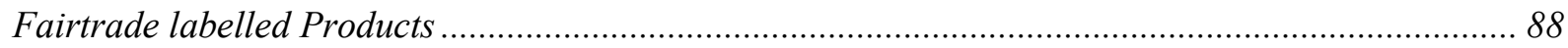

Figure 9. The Spread of Buycotting relative to CSR and Sales per Capita of Fairtrade labelled

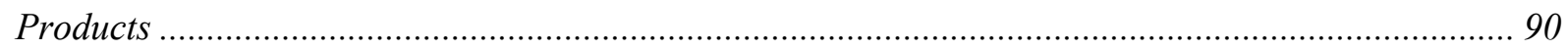

Figure 10. The Spread of Boycotting relative to CSR and Sales per Capita of Fairtrade labelled

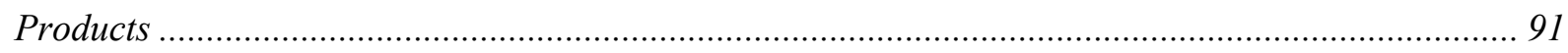

Figure 11. Predicted Percentages of Citizens who have boycotted depending on the Gross

Disposable Income of Private Households...................................................................................... 93

Figure 12. The Spread of Boy-and Buycotting relative to CSR and per Capita Sales of Fairtrade

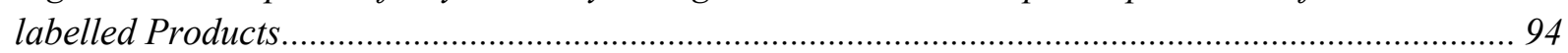

Figure 13. The Relative Spreads of Buycotting and Labelling Schemes across Countries.................. 97

Figure 14. The Relative Spreads of Buycotting and CSR across Countries....................................... 97

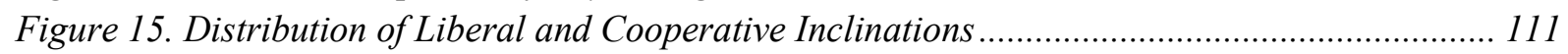

Figure 16. Mean Predicted Probability of Non-Political Consumerism........................................... 122

Figure 17. Mean Predicted Probability of Buycotting Firms ....................................................... 127

Figure 18. Mean Predicted Probability of Boycotting ...................................................................... 130

Figure 19. Mean Predicted Probabilities of Boycotting and Buycotting Products........................... 132

Figure 20. The Effect of Confidence in Labelling Schemes on Boycotting and on Boycotting and

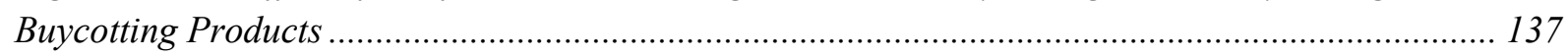

Figure 21. The Process of Political Consumerism....................................................................... 140

Figure 22. Mean Predicted Probabilities of Non-Political Consumerism in the Entire Sample and

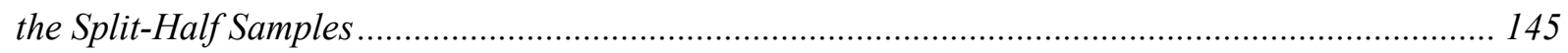

Figure 23. Results for the Process of Political Consumerism ............................................................ 148 


\section{List of Tables}

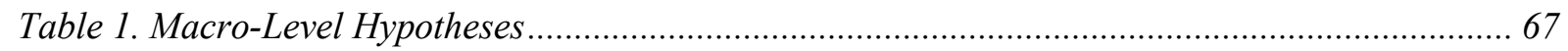

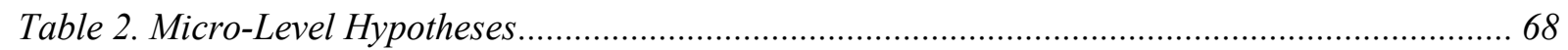

Table 3. Country Classification According to the Concept of the State ............................................... 75

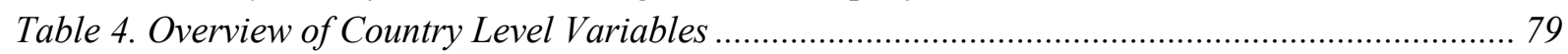

Table 5. Sample Distribution (Age, Gender and Education) …........................................................... 83

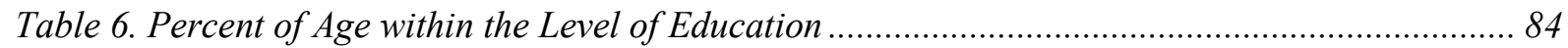

Table 7. OLS Regression of Non-Political Consumerism, Labelling Schemes and CSR ..................... 89

Table 8. OLS Regression of Buycotting, Labelling Schemes and CSR ............................................... 90

Table 9. OLS Regression of Boycotting, Labelling Schemes and CSR ............................................... 92

Table 10. OLS Regression of Boy- and Buycotting, Labelling Schemes and CSR .............................. 95

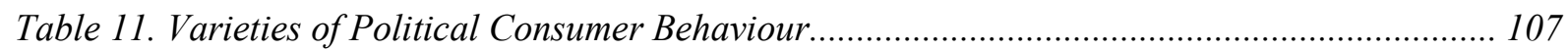

Table 12. Factor Loadings on the Concept of the State ................................................................... 110

Table 13. Absolute and Relative Confidence across Types of Political Consumerism ....................... 114

Table 14. Bivariate Correlations of Non-Political Consumerism with the Concept of the State and

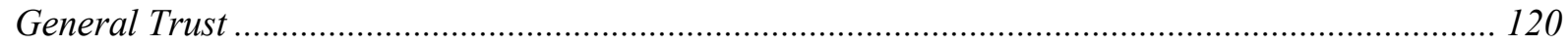

Table 15. Logistic Regression Analysis of Political Consumerism .................................................. 121

Table 16. Logistic Regression Analysis of Non-Political Consumerism ........................................... 122

Table 17. Logistic Regression Analysis of Buycotting Products ...................................................... 124

Table 18. Bivariate Correlations of Buycotting Firms with the Concept of the State and Confidence

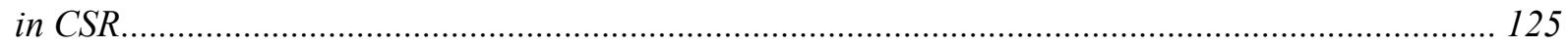

Table 19. Logistic Regression Analysis of Buycotting Firms ...................................................... 126

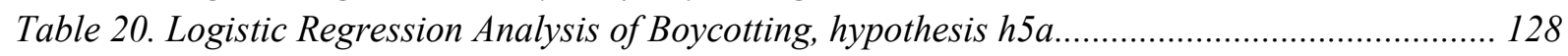

Table 21. Logistic Regression Analysis of Boycotting, hypotheses $h 5 b$ and $h 5 c$............................. 129

Table 22. Logistic Regression Analysis of Boycotting and Buycotting Products ............................... 131

Table 23. Overview of Results of Hypotheses Tests .................................................................... 133

Table 24. Logistic Regressions comparing Political and Non-Political Consumerism ...................... 135

Table 25. Comparative Effects of Confidence in Labelling Schemes and Confidence in CSR........... 136

Table 26. Bivariate Correlations of Non-Political Consumerism with the Concept of the State and

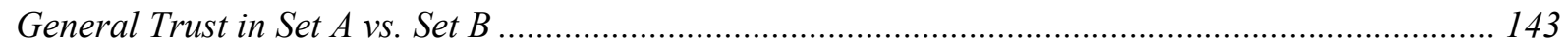

Table 27. Reviewing the Link between the Concept of the State and General Trust with Non-Political

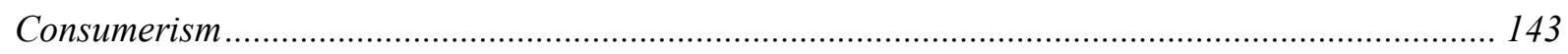

Table 28. Comparative Effects of Confidence in Labelling Schemes and in CSR in Sets A and B .... 147 


\section{Introduction}

"As a rule, no factor acts in a uniquely determined way and, whenever it does not, the necessity arises of going into the details of its modus operandi, into the mechanisms through which it acts."

(Schumpeter 1947, 149)

\subsection{The Rise of Political Consumerism}

Twenty years ago, 123 nations convened to make the world one large entwined political economy. They set up the World Trade Organization (WTO), which since then has been promoting an unpreceded eradication of national barriers to trade and the interweaving of economies worldwide. Half of all goods and services traded today is part of global value chains in which raw materials may be sourced on one continent, assembled on a second, and sold and consumed on a third one (World Trade Organization 2015, 18). This process has furnished a progressively expanding range of consumption alternatives and material comfort all over the world. Yet also, complexity is growing, and as production chains stretch over several countries, the associated problems become of transnational concern as well.

In this context, political, economic and societal concerns have become inextricably intertwined. Decisions taken as a consumer in Europe, for instance, can sustain or impinge on human rights abuses in Bangladesh and environmental pollution in Brazil. The development of the internet, internationalised media and digital communication devices allow for the global diffusion of such concerns. This has transformed political participation considerably. Spreading material prosperity has given rise to individuals desiring to define identity, values and norms by their own actions and practices. Rather than relying on election-centred political participation alone, citizens resort to a customised inclusion of 'politics' in everyday life all across democratic countries (Bennett 2012; Dalton 2006, 2010; Lindén 2005, 208; Norris 2011; Papadopoulos 2013; Stolle, Hooghe, and Micheletti 2003; van Deth 2012). These citizens now encounter a setting where the sphere of influence of national governments is narrowing. Instead, transnationally operating organisations and firms have become key actors and additional addressees for political concerns. Interactions with firms are yielded with political weight. And more and more, individuals appear to recognize the political power therewith resting in their roles as consumers (Bossy 2014; Micheletti 2003, 4; Micheletti and Føllesdal 2007, 169; Neilson 2010, 214; Sassatelli 2008; Spaargaren and Martens 2005, 30).

This has rendered the basis for the rise of the 'political consumer'. A citizen who, being aware of the political embeddedness of consumption, deliberately decides to buy or not to buy a determined product for ethical, environmental or societal reasons (Micheletti 2003, 19). The 
number of politically motivated consumers has steadily increased in the past twenty years and inspired an expanding range of surveys to record its diffusion. In Germany for example, a study series on ethical consumerism conducted by Otto Group charts this rise well. In 2009, 26 percent of the surveyed individuals claimed to buy based on ethical motivations on a regular basis. In 2011, this fraction reached 46 percent, and in 2013, 56 percent (Otto Group 2013). Equally in the UK, this figure rose from 27 percent in 2000 to 42 percent in 2012 (Co-operative Group 2012). Similar tendencies are visible worldwide: a study conducted in 2014 surveyed 30.000 people in 60 countries. On every single continent around half of the respondents declared to have rested purchases on the responsible conduct of a firm (Nielsen 2014). The consistent growth in sales of 'ethical', 'sustainable' and 'organic' goods in spite of economic turmoil (Cooperative Group 2012; Fairtrade International 2014, 2015; Nielsen 2014; Sabbati and Katsarova 2015; Willer and Lernoud 2015) and their more rapid expansion compared to conventional products (Nielsen 2014) further endorse the trend upwards.

The escalating relevance of 'political consumerism' has stirred attention in political science. In distinction to ‘ordinary' consumerism, political consumerism is considered to become an act of political participation if this intention is explicitly expressed. Thus, it classifies as an expressive mode of political participation (van Deth 2014) which encompasses two varieties of action: one of them is 'negative' political consumerism, i.e. the 'boycotting' of buying a particular product with the intention to express discontent with particular practices (Jensen 2005). The second variety is 'positive' political consumerism, that is, the deliberate buying or 'buycotting' of products to approve of a conduct considered as being 'good' (Boström et al. 2005; Stolle, Hooghe, and Micheletti 2003). In both buying and rejecting to buy particular products, the ultimate aim of the political consumer is to express certain values, norms or preferences of political nature with which the respective products are associated (Koos 2012a, 38; Micheletti Føllesdal, and Stolle 2003; Newman and Bartels 2011; Stolle, Hooghe, and Micheletti 2003, 2005). Thus, if political consumerism is depicted as an expression of values, a distinction between the positive and negative variety is not necessary.

Nonetheless, various observations suggest that viewing political consumerism only as a way to express values is too simplistic. Postmaterialist value orientations, for instance, do not appear to be very different for involvement in political consumerism than for other modes of political participation (e.g. Copeland 2014b). Other perspectives advocate that values might rather be the outcome of a political consumer moment than its driver, or even of only little relevance. Quintelier and van Deth (2014), for example, discern a bond where political consumer behaviour appears to much stronger influence attitudes than attitudes behaviour. While 
Mazar and Zhong (2010) find that people feel good by purchasing products that are ethically and environmentally considerate. As an alternative explanation, Boström and Klintman (2009) put forward that political consumerism can serve as a strategy to abridge decision making. So, they argue, some political consumers may be using labelling schemes as a tool for making decisions in uncertain or ambivalent situations simpler. In sum, political consumerism grounds on a far more multi-layered set of influencing factors.

Furthermore, in getting involved in political consumerism, individuals appear to clearly make a distinction between the 'positive' and the 'negative' varieties: Throughout surveys, participants have stated to have either only buycotted or only boycotted, but not both (Baek 2010; Copeland 2014a; Goul Andersen and Tobiasen 2003; Neilson 2010; Stolle and Micheletti 2005). Likewise, on the macro-level, the scope of involvement as well as their distribution across countries varies considerably. The analysis of, for example, the European Social Survey 2002/03 reveals that in most countries buycotting is more widespread than boycotting (see e.g. Koos 2012a; Stolle and Micheletti 2013). In Denmark, Finland, Norway and Sweden, for example, in 2002 between 20 and 30 percent of the citizens stated to be buycotter and no boycotter. But only around 5 percent were boycotter but not buycotter. On the opposite, in France, Greece and Italy, boycotting and buycotting are spread almost equally, with around 9 percent in France, and 3 to 5 percent in Greece and Italy (European Social Survey, Round 1 2002; see also e.g. CID 2000 cit. by Teorell, Torcall, and Montero 2007, 338-9; Copeland 2014a; Holtmann et. al 2015; Stolle, Micheletti, and Berlin 2010).

\subsection{Explaining Boycotting and Buycotting Involvement}

But why is a boycotter not automatically a buycotter, and vice versa? Although most works recognize the two varieties, only a few studies distinguish between buycotting and boycotting in their further analyses (e.g. Baek 2010; Copeland 2014a; Koos 2012a; Neilson 2010; Quintelier 2014). The few which consider them separately mainly focus on the micro-level and, more in particular, on socio-demographic backgrounds. Yet, the findings are ambiguous and provide only limited understanding of the drivers guiding the citizens' decisions on whether to only boycott, only buycott, to do both or to do none of it. For example, whereas women as well as citizens with high levels of education show to be particularly likely to consume politically, the effect is notably stronger on the likelihood to buycott compared to boycott (Koos 2012a, 47; cf. also Stolle and Micheletti 2005, 46). Also, a higher income shows to increase a citizen's likelihood to buycott significantly whereas it exhibits no effect on boycotting (Koos 2012a, 47). 
In contrast, intrinsic factors other than the expression of values appear to provide a more telling explanation. Noteworthy is Neilson's (2010) finding that while boycotter appear to be less trusting than citizens who do not consume politically at all, buycotter show to be more trusting than non-political consumers. So, both their dispositions as well as their underlying intentions seem to be heading into completely opposite directions.

Corresponding to this observation, the aims and drivers underlying buycotting and boycotting seem to be clearly different. Buycotting relates to the idea that a firm is behaving responsibly and thus should be rewarded for this. In so doing, buycotter distinguish between firms or products in which they can have confidence and those they cannot, and they use this as a guideline for their political shopping decisions. On the opposite, boycotters express dissatisfaction with certain market practices and put pressure on firms and regulations to alter a certain conduct. This may be achieved through firms' voluntary self-regulation or be determined by the state or supranational institutions, e.g. through labelling schemes. Hence, boycotters nurture an environment in which (political) consumers can clearly differentiate between 'good' and 'bad' firms, so that 'bad' firms are pressured to change their practices. They can fuel the spreading of reference points or 'guidelines' delivering information on firm and production practices. This may facilitate involvement in buycotting. Consequently, boycotting and buycotting are two opposite and yet complementary modes of political consumerism, interconnected in their relationship with 'guidelines'.

In examining the relationship between political consumerism and political shopping guidelines, political science research has primarily focused on formalised arrangements like labelling schemes (Boström and Klintman 2006; Jordan et al. 2003; Stokke et al. 2005; Stolle, Hooghe, and Micheletti 2003; Stolle and Micheletti 2013; Tobiasen 2005). Labelling schemes shall inform the consumer about a company's or a product's compliance with a certain standard or norm. Compliance is supervised by some (independent) institution other than the company itself (Atkinson and Rosenthal 2014; Berry and McEachern 2005; Lindén 2005; Stolle and Micheletti 2013), while the spreading of the label depends on the consumers' readiness to choose labelled products over others when buying (Rousseau and Vranken 2013). However, a similar key concept that is well known in business research yet seldom considered in political science is Corporate Social Responsibility. It refers to the different ethical, social and environmental practices of companies (European Commission 2011; Lin-Hi 2008; Vogel 2008). Typically, it involves particular projects wherein firms cooperate with other parts of society, such as for example welfare services, governmental institutions or citizens (Berger, Cunningham, and Drumwright 2004; Heidbrink and Hirsch 2008; Koos 2012b; Matten and Crane 2005; Scherer and Palazzo 
2011; Scherer and Smid 2000). By displaying their commitment, firms deliver a clear-cut illustration of their norms, values or principles (Aguilera et al. 2007). Accordingly, they deliver a guideline for distinguishing between market practices comparable to labelling schemes. Yet, whereas labelling schemes usually involve formalised market-based approaches, Corporate Social Responsibility relates to relatively loose voluntary engagements built on cooperation between firms with other actors of civil society. Which means, the two ground on different styles of solving socio-political concerns moving at the interface of politics and the 'market'.

Similar to boycotting and buycotting, the two types of guidelines are different in nature and relate to distinct underlying intentions. Equally, the spread of both Corporate Social Responsibility and labelling schemes is different across countries (Figure 1). In Ireland and in the UK,

\section{Figure 1. Labelling Schemes and Corporate Social Responsibility across Countries}

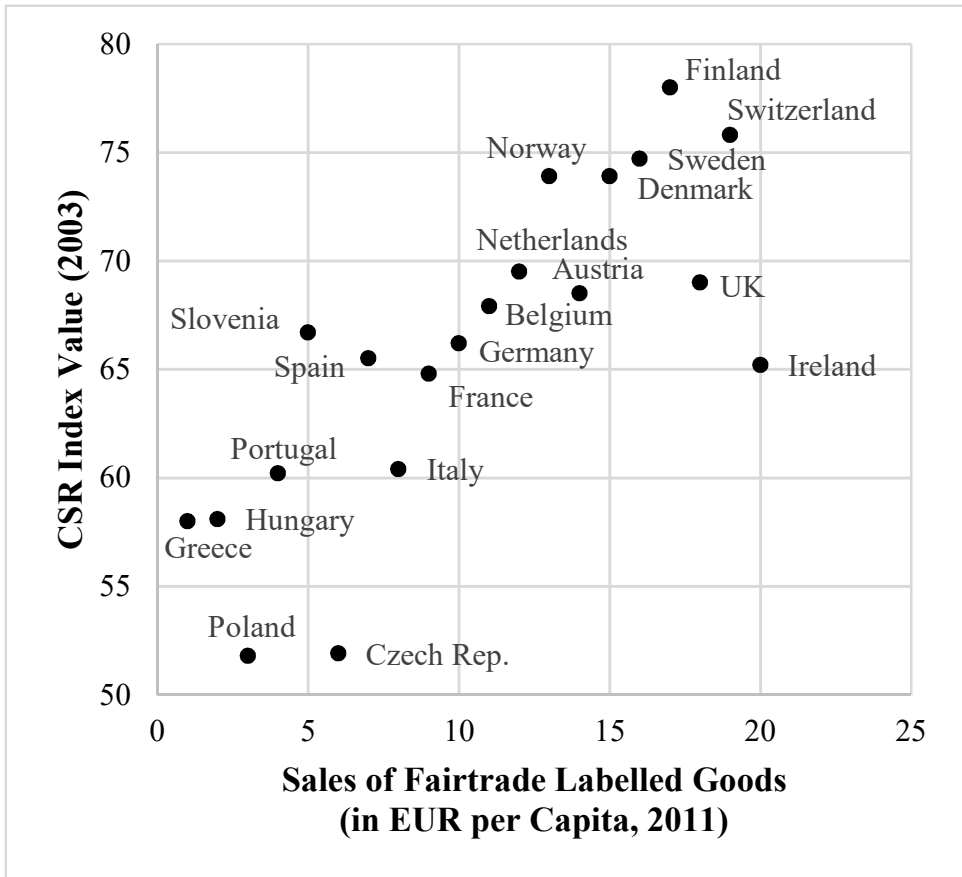

for example, labelling schemes seem to be of greater relative importance than the voluntary involvement of firms. In the reverse, in Middle Europe, Corporate Social Responsibility appears to be comparatively more widespread. Only in Scandinavia the two are equally well established. The main goal of the present study is to examine the relationship of boycotting and buycotting behaviour with labelling schemes compared to Corporate Social Responsibility. The obser-

vations give rise to the idea that boycotting and buycotting involvement interacts differently with Corporate Social Responsibility and labelling schemes, and across countries.

\subsection{Political Consumerism as a Multi-layered Process}

The central idea investigated in this dissertation is that political consumerism is a process which develops on two levels in parallel and interacting. At the individual level, citizens have distinct preferences for how political concerns ought to be tackled. The fundamental proposition is that these preferences influence citizens' choice of whether and on how they get involved in 
political consumerism, too. In the absence of responsible conduct, citizens may be encouraged to start boycotting in order to pressure for more responsible practices in firm operations and production processes. In so doing, they may stimulate the creation of different types of guidelines which provide information. This can render confidence in particular purchases supporting political concerns and facilitate buycotting involvement. Likewise, at the country level, prevailing attitudes towards which responsibilities belong to 'the market' and which ones to the state vary. This can give rise to varying macro-level patterns, where more or fewer citizens get involved in boycotting and/or buycotting, as well as where some firms tend to act more responsibly and others less. Furthermore, labelling schemes and Corporate Social Responsibility relate to different conceptions of the manner in which companies should comply with demands regarding their societal responsibilities and duties. Also, they entail different distributions of responsibilities between the state and the market. In view of that, responses to demands for more responsible conduct may differ across countries depending on prevailing preferences. They may rather involve cooperative approaches like Corporate Social Responsibility or market-based tools like labelling schemes.

As a result, different country level patterns evolve wherein political consumerism, again, develops differently. Boycotting and buycotting involvement as well as the spreads of labelling schemes and Corporate Social Responsibility vary across countries, and the assumption is that their variation is linked. This being the case, their comparative prevalence in and across countries can be expected to exhibit systematically different configurations. The enquiry therefore begins with a primary question concerning the country level:

(Q1) Do specific 'patterns' in boycotting and buycotting involvement vary in conjunction with certain 'patterns' in the distribution of labelling schemes and/or Corporate Social Responsibility?

Simultaneously, these patterns reflect a sum of individual level choices. Political consumers deal with political concerns moving at the interface of politics and the 'market', and citizens have distinct preferences on how to approach such political concerns. Put differently, the citizens' 'concept of the state' varies, that is to say, their attitudes concerning the state, the market and civil society and their view about who is responsible for what, how the cooperation between the three actors should look like, and which role each of them should take over (cf. Almond and Verba 1996; Kim et al. 2012; North 1990; Pickel and Pickel 2006). Correspondingly, the citizens' strategy followed when using their consumption for political participation may be guided by these preferences as well. If citizens prefer broad cooperation and solidarity between the different parts of society (the state, citizens, profit and non-profit organisations, etc.) in order 
to solve challenges of socio- and economic-political relevance, they may rather follow a strategy in political consumerism that allows for addressing the problems in a way that focuses on cooperation and solidarity, too. Other people tend to rely on free market competition. They count on that the consumer will automatically choose the 'right' products as long as the market provides the 'right' choices, and that, thereby, they will drive firms to adapt to shifting demands in society. These citizens may hold the view that there is no need for further intervention or assistance of others (e.g. the state or NGOs) for promoting the solution of given challenges. The aims and drivers underlying buycotting and boycotting seem to be clearly different. Distinct preferences may then translate into a preference for one or the other of the two modes:

(Q2) Is having a specific concept of the state related to the individuals' involvement in boycotting and/or buycotting?

Besides, labelling schemes reflect market-based approaches while Corporate Social Responsibility relates to engagements built on cooperation between various actors in society. They rely on different approaches used for solving challenges of socio-political concern. As a consequence, depending on their concept of the state, citizens may either prefer labelling schemes or Corporate Social Responsibility:

(Q3) Is having a specific concept of the state related to individuals purchasing based on labelling schemes or Corporate Social Responsibility?

But labelling schemes and Corporate Social Responsibility also share one characteristic: both of them supply information about the backgrounds of a product or firm behaviour. Therewith, they may furnish confidence in products and/or firms. According to previous research on political consumerism, an important factor in deciding whether to buycott and/or to boycott appears to be trust. This suggests that preferences may translate differently into political shopping behaviour depending on the individuals' level of trust in co-citizens, companies and labelling schemes. In their roles as political consumers, citizens primarily interact with firms. Rather than trust in general, confidence in particular firms and/or products supporting a political aim seems to be important. Having confidence may then facilitate buycotting. On the opposite, if they lack confidence, citizens might want to express their discontent and push for the creation of guidelines which can render confidence. For doing so, they may deliberately refuse to buy, i.e. boycott certain firms and/or products. Thus, boycotting and buycotting are two opposite and yet complementary modes of political consumerism. Confidence may constitute the bonding mechanism between citizens' attitudes and their choice for getting involved in one or the other of the two variants: 
(Q4) Is having high or low levels of confidence in labelling schemes and/or in Corporate Social Responsibility related to the individuals' involvement in boycotting and/or buycotting?

In summary, the citizens' involvement in a boycott and/or in a buycott may vary with their concept of the state, and it may be contingent on their level of trust and confidence. However, it will also depend on whether the guidelines which a citizen is looking for are available in a country. Put differently, individual political consumer behaviour is directly influenced by the framework provided for political consumerism in a country, and vice-versa.

In their theory on the „Varieties of Capitalism“, Hall and Soskice (2001) assume that countries can be differentiated according to predominant strategies which actors in single nations typically follow in solving economic and socio-political challenges (Hall and Soskice 2001, $8,13)$. In their view, institutional structures condition the patterns according to which actors behave, and they view these structures, in turn, as 'nation-specific', i.e. shaped by national circumstances like culture, history, etc. (Hall and Soskice 2001, 15). Further, the authors assume that this leads to systematic differences in the approaches across countries and they distinguish two main strategies (Hall and Soskice 2001, 15): in so called 'coordinated market economies', non-market forms of cooperation between the state, market and civil society prevail as means to deal with tasks of socio- and economic-political significance. In contrast, in so called 'liberal market economies', actors rely on free market competition and that this will most effectively lead to the fulfilment of the intended objective. Finally, they distinguish a 'mixed' category of countries which appear to be moving in between the two extremes (Hall and Soskice 2001, 21). There, Hall and Soskice discern the prevalence of structures that favour cooperative approaches in the sphere of interfirm relations and rather liberal approaches in concerns affecting other actors in society than firms (Hall and Soskice 2001, 21).

Applied to political consumerism, this leads to the supposition that countries exhibit different magnitudes of political consumerist activities, of Corporate Social Responsibility and of labelling schemes depending on the way in which coordination problems in interactions are typically solved there. Hence, analogous to the individual level and therewith closing the circle in a multi-layered process, the last two questions to be answered are:

(Q5) Is boycotting and buycotting involvement distributed differently across countries depending on the prevailing concept of the state?

(Q6) And are labelling schemes and Corporate Social Responsibility distributed differently across countries depending on the prevailing concept of the state? 


\subsection{Research Design}

Guided by these research questions, the dissertation combines two empirical studies: a macro- and a micro-level analysis. In due consideration of $Q 1$, the study begins at the country level and firstly examines the comparative prevalence of boycotting and/or buycotting involvement, Corporate Social Responsibility and labelling schemes. In reference to $Q 5$ and $Q 6$, it then reviews to what extent this comparative prevalence varies systematically relative to the concept of the state across countries. To this end, the study compares a selection of 20 European liberal democracies on the basis of different indicators for the year 2003. The countries have relatively similar standards of living, institutional settings, and a common (cultural) heritage. Still, views on the roles of the state and the market vary. That is, the underlying structures diverge little. Instead, what varies is the notion of how interactions within these structures should be dealt with, i.e. the core variable, which is the concept of the state.

The second part considers the micro-level. Q2, Q3 and $Q 4$ ask whether individuals with a certain concept of the state and level of trust and confidence in labelling schemes and/or Corporate Social Responsibility are particularly likely to be engaged in singular varieties of political consumerism. To examine these questions, the investigation relies on data of an own online survey conducted in March 2014 in cooperation with the University of Siegen. The sample comprises 1.350 citizens at the ages of 14 to 69 living in Germany. ${ }^{1}$ The questions centre on citizens' political shopping behaviour and their attitudes concerning the role of government, companies and co-citizens. The survey includes different questions developed specifically for the purpose of this dissertation. Centrepieces constitute a battery of items to gather the individuals' concept of the state, as well as a combination of questions assessing the level of confidence in societally involved firms and labelling schemes compared to non-involved firms and nonlabelled products, respectively. Besides, the survey distinguishes between boycotting and buycotting involvement; and, what is more, it further distinguishes between two varieties of buycotting: the buycotting of firms and the buycotting of products. This separation parallels the differentiation drawn between Corporate Social Responsibility, which relates to firm conduct, and labelling schemes, which are rather product related. So, it allows for a thorough examination of how varying types of guidelines may act upon political consumer behaviour.

As Schumpeter notes, whenever factors do not act in one way only, "the necessity arises of going into the details of its modus operandi [...]" (1947, 149). In a world where politics,

\footnotetext{
${ }^{1}$ In this regard, I would like to thank Prof. Dr. Baringhorst and Dr. Yang from the University of Siegen for the great cooperation in this survey project.
} 
economics and societal concerns become progressively more entwined, where shared natural resources are depleting and media are disseminating information and awareness, politically motivated consumption can gain further bearing. But to be able to study the impacts, developing an appropriate understanding of the concept itself is essential. Contradictory results obtained when studying political consumerism as one concept underline the necessity of unravelling the concept and drawing a distinction between single variants. The fundamental idea guiding this dissertation therefore is to make the explicit distinction between boycotting and buycotting. This will facilitate a more precise comprehension of the concept, and it will allow for an accurate appreciation of the relevance of political consumerism in the future world of politics and, with it, in political science research.

\subsection{Plan of the Dissertation}

With this ambition, the dissertation proceeds in five chapters. Chapter two provides a conceptualisation of political consumerism, and it reflects upon its positioning in the realm of political participation modes. In so doing, the chapter describes the notion of the concept upon which the later chapters will rest upon. This defined, it turns to the various perspectives on political consumerism. Political consumers mix their role of being a citizen with that of being a consumer, making it a hybrid and highly ambivalent phenomenon. It embraces the act of deciding to boycott or to buycott a product. These decisions are again shaped by processes that develop and are developed both 'within' as well as 'outside' the individual and in multiple spheres of life. Political science, sociology and social psychology research provide various explanations for how such decision-making processes develop. A thorough approach should consider the logics applied in these respective areas and combine them in an explanatory model. Correspondingly, the chapter interweaves the logic of the different fields touched and presents insights of sociology and social psychology on the drivers and the intentions inspiring political consumer involvement. Integrating the different explanations, the chapter closes with proposing two key criteria as a basis for an efficient investigation of the underlying dynamics of boycotting and buycotting.

The rise of political consumerism is placed on the background of a profoundly evolving macro-environment. The third chapter seeks to elaborate on the implications which these processes engender for the relationship between politics and the business sector, and it seeks to describe how the changes and the rise of political consumerism are connected. The chapter begins with a concise delineation of the currently evolving macro-environment. Based thereon, 
it strives to disentangle single constants in this context which affect the course of development of the citizen-consumer. Drawing on a theory on attitudes concerning the relationship between the state, firms and civil society, the chapter drafts an explanation for how in similar contexts individual political consumer behaviour evolves into distinct directions. Specifically, it delineates the main concepts which inspire the research questions presented: the concept of the state and confidence in guidelines for the (political) consumers, i.e. labelling schemes and Corporate Social Responsibility. Bringing together the ideas for the micro- and the macro-level, the last section drafts an explanation for the dissertation's puzzle and derives two sets of hypotheses to investigate the questions: one set of hypotheses concerning the country-, and one concerning the individual level.

The data and methods employed for testing the hypotheses are presented in chapter four, the empirical evaluations follow in chapters five and six. Chapter four introduces the approaches applied for examining each of the two levels. The first section sketches the details of the country level analysis, which comprises a cross-country study of 20 European democracies. It outlines the selection of countries, the variables as well as the methods used in the study. The second section lays out the details of the research strategy undertaken to assess individual level attitudes and behaviour. Next to the methods, the section presents and briefly discusses the sample used in the enquiry, which stems from a survey conducted among 1.350 citizens living in Germany.

The examination of the macro-level hypotheses follows in chapter five. In line with the three research questions raised for the country level $(Q 1, Q 5, Q 6)$, the research strategy involves two stages and a methodological approach built on three concerted pillars: the first section of the chapter covers stage one and explores whether the levels of prevalence of CSR, labelling schemes and single types of political consumer behaviour display paralleling tendencies from country to country. To this end, the investigation combines bivariate correlation analyses with OLS regressions. In the subsequent stage, the study seeks to discern a systematic clustering of countries with a particular concept of the state by recurring to hierarchical cluster analysis. The chapter closes with integrating the results of the two stages and discussing the findings.

Turning to the individual level, chapter six firstly reviews the socio-demographic antecedents of political consumerism in the sample and then proceeds by presenting the core variables used in the analyses together with their measurement. In the second part the examination of the hypotheses follows. The methodological approach deployed in testing the hypotheses involves a combination of bivariate correlation analysis with a generalised linear model (GLM) research 
design: catering to $Q 2$ and $Q 4$, the correlation examination permits to single out whether variables are at all noticeably related. Afterwards, in reply to $Q 3$, regression analysis permits to study more accurately whether the individuals' concept of the state and their confidence in labelling schemes and in CSR are linked to being more or less likely to consume politically in a specific way. The analyses are followed by a brief discussion of the results, whose conclusions in turn build the point of departure for the third part: this last section of the chapter intends to corroborate the findings by means of using a split-half method applied on the sample. That is, the sample is split at random into two halves. Then, the tests are performed for a second time. The ensuing results are put in comparison with those obtained for the entire sample and are altogether discussed.

The fundamental proposition of the dissertation is that developments on the macro- and the micro-levels are interrelated. Chapter seven finalises the investigation by bringing together the findings of the respective studies. In getting back to the research questions, the chapter compares the results gained in the country and the individual level studies with the ideas presented at the outset of this work, and it elaborates on what findings and ideas the dissertation delivers. Further, the chapter gauges the degree to which the findings obtained for the individual level appear to replicate and underpin observations previously found for the country level, and viceversa. A sketch of their consequences and an outlook for future endeavours to investigate political consumerism complete the dissertation. 


\section{Perspectives on Political Consumerism}

2.1 Political Consumerism in Political Science

For more than two decades a vibrant discussion has surrounded the question whether political participation in modern democracies is in decline or not (cf. Abramson and Aldrich 1982; Blais 2010; Crouch 2004; Dalton 2006, 2008; Putnam 2000). Whilst political scientists generally agree upon that traditional forms of political participation such as voting and political party membership are in decline indeed, the updated conception is less dark. Instead, citizens, and especially younger people, appear to increasingly be turning to new means to express their political preferences and as ways to tackle sensed problems (Lindén 2005, 208; cf. also Acik 2013; Bauman 2008; Blais 2010; Boström et. al 2005; Dalton 2006; Hooghe and Marien 2012; Inglehart and Catterberg 2002; Kaase 1999; LeDuc, Niemi, and Norris 2010; Micheletti 2003; Micheletti, Føllesdal, and Stolle 2003; Norris 2011; Papadopoulos 2013; Stolle, Hooghe, and Micheletti 2003; Stolle and Micheletti 2013; van Deth 2001, 2013). One of these newly emerging phenomena of political engagement is political consumerism.

Within this variegated context it is ever more important to clearly define and (de)limit the single varieties of political participation (see e.g. Hooghe, Hosch-Dayican, and van Deth 2014; van Deth 2014). Otherwise, by putting it under the label of 'unconventional mode of political participation' nearly everything could be regarded as a form of political participation and blur the notion of the political (cf. van Deth 2014, 351). Furthermore, conclusions can vary depending on the conceptualisation a scientist is basing research on (van Deth 2014, 350). Therefore, also a clear delineation of the understanding on which the ensuing examination rests is essential for avoiding erroneous comparisons and deceitful conclusions.

This section intends to provide a precise conceptualisation of political consumerism and the notion of the concept upon which the following chapters will rest on. To do so, the first part asks for when political consumerism may be considered to be political participation, and it reflects upon its respective positioning in the realm of political participation modes. The second part in turn looks at the underlying character of the concept. In looking at the various varieties of words which have been used in talking about politically natured purchasing behaviour and their conceptual meaning, the section proposes that rather than being further modes of political consumerism, these varieties are sub-aspects of an equal concept. The section then closes with the proposition that, instead of looking at the aspects which individuals intend to express, when studying political consumerism in its guise as a variant of political participation the focus should 
rather lie on the different modes of action which individuals may apply: positive and negative buying, i.e. the buycotting and boycotting of products and/or firms, respectively.

\subsubsection{Recognising Consumerism as Political Participation}

In the constitutive book on the politics of products, Micheletti, Føllesdal, and Stolle (2003) define political consumerism as the

"consumer choice of producers and products with the goal of changing objectionable institutional or market practices. It is based on attitudes and values regarding issues of justice, fairness, or non-economic issues that concern personal and family well-being and ethical or political assessment of favorable and unfavorable business and government practice. Regardless of whether political consumers act individually or collectively, their market choices reflect an understanding of material products as embedded in a complex social and normative context which may be called the politics behind products” (Micheletti, Føllesdal, and Stolle 2003, xiv-xv).

Thus, political consumerism relates to the deliberate decision to buy or not to buy a specific product out of politically natured reasons. Consequently, it actually encompasses two varieties of action: one of them is 'positive' political consumerism or 'buycotting' (Jensen 2005; Stolle, Hooghe, and Micheletti 2003). It consists of the intentional buying of a determined product or service with the aim of thereby making a political statement (Jensen 2005; Stolle, Hooghe, and Micheletti 2003). The second variety is 'negative' political consumerism, i.e. the boycotting of buying a determined product or service based on the objective to make a political statement (Jensen 2005). In both cases, the aim of the political consumer generally is to express certain values, norms or preferences of political nature with which the respective products are associated (Stolle, Hooghe, and Micheletti 2003). The underlying motives range from ethical and social concerns to ideological issues or more individual-centred motives such as health preservation (cf. Kroeber-Riel and Gröppel-Klein 2013, 757ff.; Micheletti 2003, 11f.; Micheletti and Stolle 2012, 104ff.; see also Stolle, Hooghe, and Micheletti 2005, 246). The targets of the pleas typically are governments and firms, and in approaching these targets, political consumers can act collectively (e.g. in the framework of a collective mass-boycott) or individually, as well as in private (i.e. making no mention of it vis-à-vis other people) or alluding to it in a public dimension (cf. Kroeber-Riel and Gröppel-Klein 2013, 746ff.; Micheletti 2003, 14, 24ff.; Micheletti, Stolle, and Berlin 2012; Stolle, Hooghe, and Micheletti 2005, 246; Stolle and Micheletti 2013, 39ff.). 
But consumption is more than only the purchase of goods and their physical consumption. Individuals may as well consume brands and the images they involve, or advertising and media (messages). As a result, individuals may be considered to consume nearly persistently (cf. Ariely and Norton 2009, 476; Harrison, Newholm, and Shaw 2005, 4-5; Koos 2012a; Rasmussen 2014, 9; see also Barnett, Cafaro, and Newholm 2005, 18; Soper and Trentmann 2008, 8). To clearly distinguish between everyday shopping and political consumerism is thus indispensable. However, the multiplicity of aims, motives, targets and dimensions makes it difficult to recognize when a purchasing activity may be considered to be a political action. ${ }^{2}$ Two perspectives are thinkable from which the action may be assessed on whether it is political or not: the outsiders' view and the individual's own perception.

In assessing a purchase from the outside, what matters is that a particular act of consumption is recognized in public as a political act. Neilson (2010) for example defines political consumerism as "[p]ublicly motivated consumption [...]" $(2010,214)$. In this account, individuals act based on the prospect that their purchase is understood as a political statement. As a consequence, the assessment would largely depend on the outsiders' conception of a purchasing act. The individuals' understanding of the own doing alone would not suffice for determining when it may be considered to be an act of political relevance. Yet, defining political consumerism from this perspective raises the problem that when the targets are not undoubtedly related to political matters, as for example firms, the act may not be immediately recognised as a political act. Instead, a firm may take the purchase or non-purchase for something else, e.g. as the approval or rejection, respectively, of the quality or the brand which the firm delivers. This may render it problematic to discern political participatory acts in the consumer realm and, with it, to assess these activities' relevance and political consequences (cf. Newman and Bartels 2011, 804; Sassatelli 2006, 225). At the same time, it deviates from the more common approach in political participation research which focuses on the individual and the own definition of when an activity is meant to be one of political expression. Consequently, focusing on the targets' perception would also complicate comparisons across types of political participation.

\footnotetext{
${ }^{2}$ In part of political science literature, it is even questioned whether political consumer action can in fact be considered to be a type of political action (see discussions in e.g. Copeland 2014b; Micheletti and Stolle 2012; Schlozman 2012; Schudson 2007; van Deth 2012).
} 
Focusing on the individual judgement makes this problem less pertinent. ${ }^{3}$ According to the classic understanding of political participation which emanates from Verba and Nie (1972), political participation is something which citizens make use of in order to communicate certain preferences to government officials (Teorell 2006, 788-9). It as any attempt by the citizens "aimed at influencing the selection of governmental personnel and/or the actions they take" (Verba and Nie 1972, 2). So, Verba and Nie do not centre on how government perceives and processes citizens' demands. But they expressly focus on the citizens and on what modes of activities they state to have embarked on in attempting to influence government (1972, 3 \& 57). Correspondingly, political consumerism is also typically assessed from the individuals' perspective. For Newman and Bartels $(2011,805)$, for example, consumerism becomes political as soon as the individual gives a shopping decision a subjective political meaning and follows political purposes. ${ }^{4}$ What matters is thus the person's own conception of what the respective act constitutes (cf. also Shaw et al. 2005; Stolle, Hooghe, and Micheletti 2005; van Deth 2012, 124). Likewise, van Deth (2014) develops a conceptual map where citizens' intentions and aims serve as the distinctive features for defining when an act is a variant of political action (2014, $360-2)^{5}$. According to this conceptualisation, political consumerism classifies as a motivational mode of political participation. That is, it is the political meaning i.e. the underlying motivation what matters for that a purchase may be considered to be an act of political participation. Furthermore, this motivation needs to also be explicitly expressed as being one based upon political ambitions $(2014,359)$.

In sum, if the aim of research is to develop a precise elementary understanding of the political consumer, viewing political consumerism as a matter of the persons' subjective conception of what the own act constitutes appears to be a suitable and efficient proceeding. On the one hand, relying on the individuals' own conception of what an act constitutes allows for a clear delineation of when an act of consumerism is to be regarded as one of communicating a political preference. On the other hand, it facilitates the comparative positioning of political consumerism in the realm of political participation. Lastly, focusing on the individual's own

\footnotetext{
${ }^{3}$ The difficulty of a political acts' recognition and the proposed solution to it by focusing on the individual is well illustrated in the procedure of the British Co-operative Bank's Ethical Purchasing Initiative project. The project gathers data on the development and magnitude of ethical consumer activity, and in doing so it rests on two pillars: the first pillar grounds on data on sales of goods and services that are explicitly ethical; the second pillar rests on surveying consumers on their motivations to follow so called 'ethical invisibles', that is, activities that may or may not be done for expressly ethical reasons, e.g. using the bus. Thus, aware of the two possible perspectives, the project actually relies also on both the 'outsiders view' and the individuals' own perspective (see Clouder and Harrison 2005, 96-7).

${ }^{4}$ Their definition is based on Dalton (2008), and they call it "a citizen-centred view of participation" (Newman and Bartels 2011, 805).

${ }^{5}$ Thus, the mapping of what constitutes a political participation action rests on an operational definition instead of a nominal definition focused on terminology, since according to him, what matters is less the label but the content of an action, i.e. the purpose or targets of it (van Deth 2014, 360).
} 
assessment permits also to assess the entire extent to which individuals are involved in positive and negative political consumerism and thus it allows for distinguishing individuals who do either only one of the two or both. Thus, for studying the underlying character of the two sides of political consumerism, this approach is in fact essential.

\subsubsection{Conceptual Varieties of Political Consumerism}

The diversity of motives, aims and approaches which may compose a political consumerist action has another side-effect: The use and understanding of the concept as well as the focus of enquiry varies widely across publications. Basically, the distinction extends on two dimensions: one related to the content of the concept, i.e. the type of attitudes which individuals want to express by their action; and one related to the concept's placement on the repertoire of political participation modes, i.e. the peculiar 'shape' of the action.

On the first dimension, the variation consists in the use of several alternative terms next to 'political consumerism'. Examples of prevalent terms in use are 'sustainable consumption', 'ethical consumerism' or 'green buying behaviour' (cf. Harrison, Newholm, and Shaw 2005, 2; Hoffmann 2008, 6; Micheletti 2003, 2; Smith 2008, 283-4; see also Andorfer 2015; Bossy 2014; Micheletti and Stolle 2012). Yet, not only the word varies but also the underlying understanding attached to these modes of expression. Some authors use a seemingly specialised term and look at this specific issue alone indeed (e.g. Fraj and Martinez 2006b, 2007; Mazar and Zhong 2010) whereas others may use the same word but base it on a general understanding, i.e. one which actually comprehends all the various forms of ethical, ecological, etc. consumerism (e.g. Andorfer 2015; Barnett, Cafaro, and Newholm 2005; Harrison, Newholm, and Shaw 2005; Ozcaglar-Toulouse 2007; Shaw et al. 2005; Tallontire, Rentsendorj, and Blowfield 2001). A closer look at the underlying understandings reveals that, ultimately, all these terms are rather specialized sub-concepts which allude to the characteristics of a product, but they are no truly distinct types of actions used for communicating a political preference. Put differently, buying based on ethical or sustainable or green considerations classifies on a range next to drivers of buying decisions such as price, quality or brand. As a consequence, using such sub-concepts entails the risk of sliding with the focus of enquiry from the act of political participation as such to the content of it. The global mode of expression 'political consumerism' in turn associates all subaspects in one and rather compares to political participation types like demonstrating or voting. In the view of that, when studying political consumerism and why individuals get involved in 
it in the wider context of the repertoires of political participation, the global term appears to be the more reliable and efficient option.

In contrast, on the second dimension the handling of buycotting and boycotting, i.e. of the distinction between the positive and the negative forms of political purchasing behaviour varies. In difference to the previous dimension, this variation does not relate to the type of products the individual is buying but to the way in which the individual is acting. Hence, the distinction relates to political consumerism in its guise as a mode of political participation. Nevertheless, although most works recognize the two sides of political consumerism, most of them do not distinguish between the two in their analyses (Bossy 2014; Copeland 2014b; Micheletti, Stolle, and Berlin 2012; Newman and Bartels 2011; Stolle and Micheletti 2003, 2005). Only a few examine both buycotting and boycotting separately (e.g. Baek 2010; Copeland 2014a; Koos 2012a; Neilson 2010; Quintelier 2014). ${ }^{6}$ Depending on the researchers' purpose, recurring to the global term may be sufficient. Specifically, if political consumerism is depicted as an expression of values, a distinction between the positive and negative varieties of political consumerism may not be necessary. Newman and Bartels (2011), for example, take political consumerism as one all-encompassing phenomenon and study it "[...] as a means of expressing policy preferences and achieving political objectives" $(2011,804)$. Thus, what matters for them is its positioning as an expression of values in the array of political participation repertoires relative to the other variants rather than its underlying drivers.

Different observations put forward that citizens recognize political consumerism not only as a way to express values but also as a strategy to abridge decision making or to feel better. Boström and Klintman (2009), for example, highlight the role of labelling schemes to some political consumers as a tool for making decisions in uncertain or ambivalent situations simpler (Boström and Klintman 2009, para. 21). Mazar and Zhong (2010) in turn find that purchasing green products can incite licensing effects; that is, people feel good by purchasing products that are ethically and environmentally considerate. The varying motives and drivers may in turn influence behavioural choices: behaviour psychologists like Tversky and Kahneman (1981) emphasize how the nature and framing of a decision can influence individuals' risk propensity

\footnotetext{
${ }^{6}$ Micheletti, Stolle, and Berlin (2012) go as far and discern four modes of political consumerism: next to the boycott and the buycott they distinguish "discursive actions" and "lifestyle choices" $(2012,146$; see also Micheletti and Stolle 2010; Stolle and Micheletti 2013, 27 \& 39ff.). The first they define as "the expression of opinions about corporate policy and practice and even consumer culture in a variety of communicative efforts and venues" $(2012,146)$. The second embraces for them the individual decision to incorporate responsible action and certain values of political nature consistently in daily life $(2012,145$; see also Micheletti and Stolle 2010, 126; Stolle and Micheletti 2013, 41-2). Hence, the first focuses on how openly an individual propagates an action, the second relates to the constancy and action's bearing on an individual's life. Yet, regardless of whether an individual acts in public or private and whether he or she does it once or frequently, the act per se must consist in either rejecting to buy or deliberately buying a certain product or from a certain firm. Thus eventually, rather than constituting additional categories next to buycotting and boycotting, discursive and lifestyle political consumerism seem to be sub-aspects of the two.
} 
and therewith come with very different preferences over options, which may affect behaviour. Likewise, buycotting and boycotting ground on fundamentally different conceptions: the act of buycotting consists in the deliberate decision to buy a specific product or from a certain firm based on the idea that the purchase relates to a conduct which should be rewarded. Thus, it rests on the willingness to make an investment in support of a product or firm. In contrast, boycotting consists in the deliberate rejection of buying and expresses discontent with certain market practices. Accordingly, it rather rests on a desire to ward off a certain conduct which e.g. may be irreconcilable with the own ethical convictions, and to push for a change in these practices (cf. Friedman 2003; Hoffmann 2008, 59ff.; Neilson 2010, 214-5; Smith 2008). Given this distinct underlying nature, individuals might regard the two as tools suited for very different purposes. For that reason, as soon as the concept itself turns to be the object of analysis rather than its relation vis-à-vis other forms of political participation, using the global term may run the risk of understating and even missing important features which define the concept as well as facets framing and explaining involvement in it.

In fact, the findings concerning the motivations of citizens to consume politically, their socio-economic characteristics, etc., are typically all understood as defining a single politically consuming citizen rather than distinguishing between only buycotting or only boycotting individuals and those who do both (cf. also Neilson 2010, 225-6). However, differing results obtained in studies that consider political consumerism as one concept compared to studies that differentiate between the two sides challenge this notion. On the macro-level, analyses of past surveys exhibit rather different distributions of boycotts and buycotts across countries. According to the global figures on general involvement, political consumerism is most popular in northern European countries and in the United States, and the percentages of the involved have steadily increased over the past decade (cf. Copeland 2014a; Goul Anderson and Tobiasen 2003; Koos 2012a, 46; Micheletti, Stolle, and Berlin 2012; Stolle, Hooghe, and Micheletti 2005; Stolle and Micheletti 2005). Nevertheless, distinguishing between buycotting and boycotting reveals that for example boycotting is more popular in the United States than generally in Europe (cf. Copeland 2014a, 180), and not so much lower in the Middle European Countries (i.e. France, Germany, Switzerland, UK, etc.) compared to the Scandinavian Countries (cf. Koos 2012a, 46; Micheletti and Stolle 2012, 105). The most recent comprehensive cross-national surveys that cover both buycotting and boycotting are the Citizenship, Involvement, Democracy Study (CID) conducted in 2000 and the 2002/03 wave of the European Social Survey (round 1; see European Social Survey 2002b). The analysis of both surveys clearly suggests that in most countries buycotting is more widespread than boycotting. More specifically, for buycotting the 
figures vary between 4 to 11 percent in Southern and Central-European countries ${ }^{7}$ and 25 to 48 percent in Middle and Northern European/Scandinavian countries ${ }^{8}$. In contrast, for boycotting the figures vary between 3 to 5 percent in Southern and Central-European countries and 10 to 32 percent in Middle and Northern Europe. Also more recent data from smaller studies and surveys that were conducted in single countries (e.g. Copeland 2014a; Holtmann et. al 2015; Otto Group 2013; Stolle, Micheletti, and Berlin 2010) continue maintaining that the scope of involvement as well as the distribution across countries differ for buycotting and boycotting. Hence, altogether, preferences for the two seem to vary across countries, clearly underscoring the importance to draw a distinction between the two.

Similarly, on the micro-level numerous participants in surveys have stated to have either only buycotted or only boycotted, but not both (Neilson 2010; Stolle and Micheletti 2005, 45). At the same time, when looking at the influence of various demographic and socioeconomic characteristics on political consumerism taken as a whole, results suggest that individuals who are female, young of age, highly educated and/or interested in politics are most likely to be political consumers (cf. Acik 2013, 9-11; Copeland 2013, 14; Goul Andersen and Tobiasen 2003; Micheletti and Stolle 2004; Newman and Bartels 2011, 810-2; Quintelier and van Deth 2014; Stolle, Micheletti, and Berlin 2010; Strømsnes 2005; Tobiasen 2005, 132). Besides, having high generalised trust and, on the contrary, low trust in political institutions appears to be linked to being involved in political consumerism, too (Copeland 2014b; Goul Andersen and Tobiasen 2003; Stolle, Hooghe, and Micheletti 2005; Stolle and Micheletti 2005). Lastly, counter to some normative apprehensions which regard political consumerism as an elitist type of political participation where not everyone could have access to (Stolle, Hooghe, and Micheletti 2005, 258; cf. also Sørensen 2005; Stolle and Micheletti 2013, 45; Tobiasen 2005), income appears to be of only minor bearing or none at all (e.g. Acik 2013; Copeland 2014b; Goul Andersen and Tobiasen 2003; Tobiasen 2005). ${ }^{9}$ However, in considering the differences of the influence of the various micro- and macro-level factors on the likelihood to boycott compared to buycott, Koos (2012a), for example, finds that a higher income significantly increases a citizen's likelihood to buycott whereas it exhibits no effect on boycotting (Koos 2012a, 47). Similarly, he reveals that females as well as citizens with high levels of education are particularly

\footnotetext{
${ }^{7}$ In the European Social Survey 2002/03, the Czech Republic builds an exception, reaching 22.6 percent who indicate to have buycotted. The CID does not include the country (see Westholm, Montero, and van Deth 2007 , 17).

${ }^{8}$ In both surveys, Sweden reaches the highest percentages, with 48 percent in the CID Study (see Teorell, Torcall, and Montero 2007, 338-9) and outstanding 55 percent in the European Social Survey.

${ }_{9}^{9}$ Stolle, Hooghe, and Micheletti (2005) observe even a reverse effect, that is, in their study students coming from wealthier households were less likely to consume politically. With a coefficient of -.100 the negative influence is weak though.
} 
likely to consume politically, yet with a notably stronger effect on the likelihood to buycott compared to boycott (Koos 2012a, 47; cf. also Stolle and Micheletti 2005, 46). In keeping with that, Baek (2010) observes that more men than women are involved in boycotting $(2010,1073$ 4).

In sum, the analyses suggest that buycotters are not automatically boycotter, too, and that their demographic and socioeconomic backgrounds are not necessarily the same. Yet, the comparative results for the socioeconomic and demographic characteristics are ambiguous and, in the end, provide only a limited understanding of the drivers that guide the individuals' decisions on whether to only boycott, buycott or to do both.

Considering intrinsic factors other than the expression of values in turn provides more telling results. More concrete, Neilson (2010) has considered the psychological differences between boy- and buycotters more closely. Noteworthy is her finding that compared to the individuals who buycott, those who boycott show to have much lower mean levels of trust in institutions and in co-citizens $(2010,220)$. What is more, while individuals with very low levels of trust appear to rather be boycotter than to not consume politically at all, it is when having high levels of trust that citizens tend to be buycotters rather than non-political consumers (Neilson 2010, 220-2). Thus, both their dispositions as well as their underlying intentions seem to be heading into completely opposite directions. Baek (2010) discerns a similar pattern (2010, 1074-5), and Copeland (2014a) for political trust as well (2014a, 182). However, this finding is plausible bearing in mind that buycotts are usually private in form, which means that others than the politically consuming individual only get to know about the political action if the individual informs them about it (Neilson 2010, 216; cf. also Tobiasen 2005, 126-7). As a consequence, given that individuals cannot recognize who else is buycotting the same product and/or company they need to be more trusting than boycotters need to be: they need to be able to rely on others doing the same so that firms actually become aware of who is being buycotted - and who is not. Boycotts in turn usually are coordinated public actions aiming at generating public attention to certain issues. Moreover, they entail the withdrawal of (cash) support, and thus they do not involve a monetary or other type of investment that could entail the risk of a loss. Accordingly, involved individuals can observe whether others do the same and thus require less 'blind trust' (cf. Neilson 2010, 215-6).

To sum up, on the one hand, in studying political consumerism in its guise as a mode of political participation, using the global understanding of political rather than alone e.g. ethical or green consumerism allows for a more precise focus on the activity rather than its content. The subsequent chapters therefore rest on this comprehensive notion. On the other hand, the 
results of existing research suggest that the way in which citizens engage in political consumerism varies with their underlying intentions and attitudes. The deliberate decision to buy a product clearly seems to be driven by other factors than the intentional decision to reject buying a product for political reasons. As a consequence, in treating positive and negative political consumerism (i.e. buycotts and boycotts) as two interchangeable concepts, analyses run the risk of concealing differences across the different types of political consumers, that is, the different 'approaches' ${ }^{10}$ political consumers follow. Relationships between single factors and political consumers may be assigned to being valid for all politically consuming citizens when, in fact, they may only be valid for one 'strategic variety' of political consumerism. Also, effects may be underestimated in their size or, if being negative for one and positive for the other, even overlooked because they may cancel out each other. The contradictory results obtained in studying political consumerism as one concept underline the need for treating and exploring boyand buycotting as two separate elements. This will permit to avoid deceitful attributions and, with it, it will allow to find out where the two modes are alike and where they diverge. In tying in with this idea from the political science perspective, this dissertation develops and studies a theory that views boycotting and buycotting expressly as two separate elements, pursuing the aim of exploring their underlying character more in depth.

\subsection{Sociological Accounts of Political Consumerism: The Citizen-Consumer Hybrid}

The distinction traditionally drawn between the 'homo politicus' and the 'homo oeconomicus' (cf. Faber, Petersen, and Schiller 2002) illustrates the general perception of the individual as being 'divided' into several identities whose applicability depend on the specific situation in which one is acting (cf. Sørensen 2005). In this perspective, consumer decisions and political opinions are formed and applied independently from each other. As Sagoff puts it: "As a citizen, I am concerned with the public interest, rather than my own interest; with the good of the community", whereas "as a consumer [...] I concern myself with personal or self-regarding wants and interests" (1988, 8; emphasis in original).

However, this independence is fading. Whereas formerly a persons' job and the ensuing position on the social stratum would almost automatically define party affiliation on the one hand, and style of fashion, food, etc. on the other hand (cf. Bourdieu 1987), these stable bonds are not prevalent any longer today. Fundamental changes are taking place in both the citizen

\footnotetext{
10 'Approach' shall refer here to the citizen's choice between boycotting, buycotting, doing both, or not consuming politically at all depending on which option appears to him or her as to be most suitable to achieve goals.
} 
and the consumer spheres: In the former sphere, formal political identity and party identification are no longer closely tied to class belonging and life-long loyalties. Instead, material prosperity and existential security have shifted many peoples' attention on pursuing non-physical goals or so called postmaterialist values, which comprise aims such as e.g. the conservation of the environment or the protection of individual freedoms and rights (cf. Inglehart 1977, 1990; Inglehart and Abramson 1994; Inglehart and Baker 2000; Papadopoulos 2013, 22). The larger spectrum of demands has enlarged the fragmentation of interests and, with it, party affiliations (cf. Kim 2012; Papadopoulos 2013, 1 \& 20ff.; see also Crouch 2004, 63-4 \& 73). Next to this, a loss of importance of traditional structures and institutions and a following loss of institutionally set values, norms and ideal types of behaviour have come along with an increased recurrence to alternative means for expressing an individualised set of values and norms; election-centred political participation is extended or even replaced by a customised inclusion of 'politics' in everyday life based on a personal and 'flexible' set-up of varying political participation modes and group belonging (cf. Bennett 2012, who ref. also to Giddens 1991; Dalton 2006, 2010; Papadopoulos 2013; van Deth 2012).

This flexible set-up is also the point of connection to the second sphere, i.e. the sphere which touches on the role as a consumer: there, as Jäckel (2006) puts it, focus is shifting from the standard of living to the lifestyle ${ }^{11}(2006,270)$. Specifically, economic developments have allowed for an assimilation of general living conditions, thus leaving little room for defining the self ${ }^{12}$ within social interactions - as it was traditionally the case - by the mere amount one is able to spend or the luxury a purchase reflects (Jäckel 2006, 270). In the view of that, individuals are seeking alternatives for differentiating themselves. These alternatives they may find in the increasing bandwidth of products that are distinct from each other not (only) in their physical nature but in the identity which they confer to their beholder (cf. Jäckel 2006, 260-3 $\&$ 269-70). That is, consuming particular products or 'styles' provides both a critical source for defining the self and a means for conveying the own self in public (cf. Dittmar 2008; LlopisGoig 2013; Ozcalgar-Toulouse 2007; Sommer 2007, 26ff.; see also Ariely and Norton 2009; Belk 1988; Bennett 2003; Jubas 2007; Kim 2012; Stolle and Micheletti 2013, 19-20). In sum then, in the citizen as well as in the consumer roles, identity, values and norms are no longer

\footnotetext{
${ }^{11}$ Translated from German, termed by Jäckel as "Lebensstandard” and "Lebensstil" (2006, 270).

12 As Leary and Tangney (2012) advise, the term 'self' is a fuzzy and delusive concept which may be attached to a variety of understandings, including the self as personality, as a total person, as the person in awareness of oneself as subject or as an executing agent (Leary and Tangney 2012,4-5). The understanding in this dissertation though is precisely an integrated conception of the self as the combination of the conscious experience of the own person and personality, the perceptions and beliefs about oneself, as well as what one displays to the external world (cf. also Leary and Tangney 2012,6 ). Therefore, the term self will be used and based throughout this work on this integrated understanding unless otherwise noted.
} 
attributes almost automatically connected to the job or income class one belongs to. Instead, individuals may increasingly set-up and define a 'personal' set of values and norms by their own actions and practices. ${ }^{13}$

A third development enters as a crucial bonding mechanism, which is the ever more overlapping of issues and the simultaneously shifting of responsibilities in both citizen and consumer regards. The interconnectedness in today's world not only accrues to communication, media or the mere exchange of goods and services, but it also entails an interconnectedness of associated problems that touch upon the political and consumer spheres at once (cf. LlopisGoig 2013; Spaargaren and Martens 2005, 28-9; Stolle and Micheletti 2013). Environmental degradation, overfishing, polluted food as well as the exploitation of the poor in manufacturing relate both to the individual in its role as a consumer as well as in its role as a citizen who recognises that democratic citizenship confers not only rights but also a number of substantial responsibilities (Zakaras 2009, 9; see also e.g. Faber, Petersen, and Schiller 2002, 329). These responsibilities relate to public and private commitments alike and, as Zakaras points out, they entail the obligation (or at least the option) to not only reflect upon public commitments in private, but to act on these principles openly in the public sphere, too $(2009,29,33 \& 214$; see also e.g. Woodward, Skrbis, and Bean 2008). Further, the freedom to define one's own values and norms obliges the individual to deliberately deal with the own surroundings and the self, at least to a certain extent. In so doing, individuals may attain a clearer picture of what ethical and political principles they value and which they should act for (Zakaras 2009, 27ff.; see also Kim 2012). At the same time, more and more individuals appear to start recognizing that they as "[...] consumers have power to influence a fair and moral marketplace" (Neilson 2010, 214; see also e.g. Bossy 2014; Micheletti 2003, 4; Micheletti and Føllesdal 2007, 169; Sassatelli 2008; Spaargaren and Martens 2005, 30). Together, the desire to feel and act free and selfdetermined, the wish to convey a particular 'self' in public, the focus on new issues, and the recognition of consumer power seem to lead to a fundamental shift: The entangling of the citizen and the consumer roles (cf. Bennett 2012; Johnston 2008, 238 \& 242; Kim 2012; Micheletti 2003, 2; Micheletti and Stolle 2010, 126-9; Ozcalgar-Toulouse 2007; Sassatelli 2008, 36; Soper

\footnotetext{
${ }^{13}$ It should be noted that social identity theory (Tajfel and Turner 1979, see Hogg and Abrams 1999, 10) as well as self-categorization theory (Turner 1985; see also Turner et al. 1987, cit. by Hogg and Abrams 1999, 11; Abrams 1999, 197) advocate that in dealing with a social environment, to simplify interaction and behaviour individuals categorise objects as well as subjects, including themselves. Moreover, this (self-)categorisation is flexibly dependant on the specific context and the type of people present (Abrams 1999). Thus, even in times of declining pre-determined group belongings, individuals continue to assign themselves to certain social groups and this is going to influence the definition of the self (cf. Turner and Oakes 1986). Rather than having disappeared, the possible alternatives of groups to which an individual may belong to have simply widened and made general social group membership more fragmented.
} 
and Trentmann 2008, 6; Spaargaren and Martens 2005; Stolle and Micheletti 2013, 21; Wheeler 2012).

The entangling of these roles into one hybrid form of existence as the 'citizen-consumer' has two important implications. On the one hand, it bears the potential to nurture a mutual reinforcement between the different ambits, namely between political developments, capitalist interests and consumers' rights. That is, concerns in one sphere may foster debate in the other sphere and lead to changes and developments (intellectually as well as in practice) which had not been possible if the spheres would not be in touch (cf. Soper and Trentmann 2008, 6; see also Bennett 2012, 31; Micheletti 2008, 122-3; Trentmann 2007). On the other hand, several ideological contradictions and critiques have been raised (cf. e.g. Johnston 2008; Jubas 2007; Sassatelli 2008; Soper 2008; Spaargaren and Martens 2005, 35) which in their core all point to the idea that the citizen-consumer entails some air of 'schizophrenia': as a consumer, individuals typically strive for utility maximisation or simply the lowest price; the citizen, in contrast, pursues 'moral maximisation' and the public good (cf. Faber, Petersen, and Schiller 2002, 3246 \& 329; Johnston 2008, 243-4). Yet, these are two frequently opposing goals (cf. Sagoff 1988, $8 \& 10-1)$. In addition, the citizen-consumer is embedded in a social context where beliefs about normative expectations as well as the desire to display a particular self in public, among other things, may interact and shape goals and eventual behaviour, too. As a result, individuals may express certain attitudes and sublime political intents, yet when it comes to the act of deciding what to purchase, the outcome may diverge from the initial statements (Spaargaren and Martens 2005, 35; Wheeler 2012).

Hence, political consumerism is a highly ambivalent phenomenon and studying it requires care. The sociological narrative unfolds a citizen-consumer hybrid that merges the private with the public realm and politicises purchasing decisions. The character of the hybrid advocates that the study of political consumerism should interweave the logic of the different touched fields, too: Political consumerism embraces the act of deciding to boycott or to buycott a product. These two types of decisions are again shaped by processes that develop and are developed both 'within' as well as 'outside' the individual and in multiple spheres of life. Political science, economic and psychological research on consumer behaviour provide various explanations for how such decision-making processes develop. A thorough approach should consider the logics applied in these respective areas and combine them in an explanatory model. Thus, emanating from the insights delivered by the sociological narrative, this dissertation integrates the different explanations into one comprehensive framework for sharpening the understanding of the decision-making process underlying boycotting and buycotting behaviour. 


\subsection{Political Consumer Behaviour from a Social Psychology Perspective}

Political consumerism unites being a citizen and being a consumer. Correspondingly, the concept touches on two main strands of behavioural psychology research: consumer psychology and behavioural psychology in the realm of social and political science research. Traditional assumptions on consumer behaviour in economics suggest that individuals have stable and consistent preferences, know about their preferences, follow these preferences actively, and that in decision-making processes individuals use all information available to them (Bazerman and Malhotra 2006, 264). However, (social) psychology research has provided extensive support for assuming the contrary. Instead, preferences appear to be rather volatile and they seem to be influenced by contextual factors (see e.g. Bettman, Luce, and Payne 2008; Kahneman and Tversky 1979; Schimank 2005, 195ff.; Wyer 2008) as well as by conscious and subconscious strategies which individuals take on in order to make decisions simpler or more consistent in terms of needs, wants, ought's, and cans (cf. Boström and Klintman 2009; Simon 1978; Valor 2007)

Social and political science research suggests that political consumerism is in particular tightly connected to values, norms and attitudes (see Andorfer 2015, 27-8). Yet, attitudes are not unambiguously connected to actual behaviour either (cf. Kollmuss and Agyeman 2002; Quintelier and van Deth 2014). Specifically, psychological facets play a vital role in this process, and thus they are also a key element that shapes political consumer behaviour. Moreover, as the previous section has shown, attitudes appear to play a vital role in the course of getting involved in either boycotting or buycotting. To comprehend the psychological complexities underlying political consumerism there are two principal questions to answer: first, what defines the relationship between values, norms, attitudes on the one hand, and behaviour on the other hand; and second, what circumstances can lead to an incongruent translation of values, norms and attitudes into behaviour. To answer the former question, the first part of the section provides a concise overview of key models that try to explain the link between norms, values, attitudes and behaviour. The second part of the section then turns to the latter question and considers different strategies or 'cognitive short-paths' that have been identified as sources of deviations between attitudes and actual behaviour. The section closes with a discussion of the global observations and their consequences for studying political consumerism. 


\subsubsection{Values, Attitudes and Behaviour}

As in any politically infused activity, norms, values and attitudes are crucial elements that play a part in defining the eventual political consumerist behaviour (cf. van Deth 1995). Norms may be understood as "standards of behaviour that are based on widely shared beliefs how individual group members ought to behave in a given situation" (Fehr and Fischbacher 2004, 185; see also Kallgren, Reno, and Cialdini 2002, 1002). ${ }^{14}$ Values, in contrast, are “[...] conceptions of the desirable which are not directly observable but are evident in moral discourse and relevant to the formulation of attitudes" (van Deth and Scarbrough 1995, 46). They are hypothetical constructs that give rise to notions about "a specific mode of conduct or end-state of existence" (Rokeach 1973 cited by van Deth and Scarbrough 1995, 29). Thus, whereas norms are rather objective standards that individuals observe and attain from the surroundings, values are subjective, individually defined notions. Ideally, values are something an individual defines as personal guidelines based on which behaviour is then constrained or adjusted depending on what is perceived to be necessary in order to coherently incorporate these values in one's life (cf. Fraj and Martinez 2006a; Fritzsche 1995; Vermeir and Verbeke 2006). Together, these notions and social experiences shape individuals' attitudes, that is, their predispositions to react in a certain manner when being faced with a given object (cf. Fishbein and Ajzen 1975, 10). ${ }^{15}$ Considering this, as also Quintelier and van Deth (2014) note, theoretically "[...] political consumerism is the attitude-driven mode of participation par excellence" $(2014,156)$ since it deeply relies on ethical and other political stances which individuals hold and base their consumer decisions on. Similarly, Micheletti and Stolle (2010) concede the consumption of only vegetarian or vegan groceries a political character based on the view that such individuals "have developed a consistency between values, attitudes, and consumer action" $(2010,144)$. Nevertheless, social and consumer psychology research suggests that this consistency is not always fully applicable. Other factors intervene and may alter choices, such as e.g. the perceived attitudes of others and their perceived relevance, situational features, habits or past experiences (cf. Ariely and Norton 2008, 13-4; Jones and Fazio 2008, 443-4; Katona 1967, 220; Nelson 2004, 37; Roberts and Lilien 1993, 31; Soper and Trentmann 2008, 7; Spaargaren and Martens 2005, 35-6; Vermeir and Verbeke 2006; Wheeler 2012). Furthermore, research also suggests that attitude judgements are not automatically the same towards an issue or object in a similar

\footnotetext{
${ }^{14}$ For a more extensive discussion of norms see Kroeber-Riel and Gröppel-Klein 2013, 579ff.

15 The reactions may be positive or negative in nature, and they may consist of affective, behavioural and cognitive elements (Bohner and Wänke 2002, 5; Hines, Hungerford, and Tomera 1987, 4; Shapiro 2000, 9).
} 
situation but may be influenced by the subjective experience at the time of judgement formation (Bohner and Wänke 2002, 89 \& 107; cf. also Nelson 2004).

Various models try to describe the decision processes and the complex set of factors that play in (see e.g. Kollmuss and Agyeman 2002, who provide a general review of models on specifically environmental behaviour). One of the most widely acknowledged frameworks emanates from the Theory of Reasoned Action by Fishbein and Ajzen (1975). In its enhanced extension this model is known as the Theory of Planned Behavior (Ajzen 1991), with the core assumption that attitudes and behaviour are not immediately connected but that behavioural intentions mediate between the two. These behavioural intentions are again influenced by various other factors (Ajzen 1991, 181; Fishbein and Ajzen 1975, 348 \& 351) and they are not persistent over time (Fishbein and Ajzen 1975, 375). Specifically, Ajzen (1991) proposes three main components that influence intentions: (1) attitudes toward the behaviour, (2) subjective norms, and (3) the perceived degree to which the behaviour in question is within the own sphere of control (Ajzen 1991, 181-2 \& 188; 2008, 537-8). These three components are in turn all bonded with different beliefs concerning the behaviour. ${ }^{16}$ Moreover, even if the intention to act is formulated, constraints in for example time, finances or product availability may still shape the perceived behavioural control such that it facilitates or impedes the actual culmination in the respective behaviour (Ajzen 1991, 182-3; 2008, 538). That is, the perceived behavioural control influences both the intention to perform a behaviour as well as the performance of the behaviour directly.

Yet, importantly, beliefs do not necessarily match the true attributes of an object or issue in evaluation, that is, they may be biased (Ajzen 2008, 531; Fishbein and Ajzen 1975, 42). Therefore, Ajzen (1991) concludes that in looking at beliefs one can in particular "learn about the unique factors that induce one person to engage in the behavior of interest [...]" $(1991,206-$ 7; see also Sagoff 1988, 9). They are the very foundation of the considerations that shape intentions to act and actual behaviour. Consequently, in starting with understanding a persons' beliefs it is how one may start to learn to understand the underlying factors inducing a person to perform a specific behaviour. In today's sphere of consumption brands, certain types of products and advertisement reflect types of behaviour which are proposed to be a societal ideal; using particular products is promised to permit the individual to live up to these ideals (cf.

\footnotetext{
${ }^{16}$ Belief is defined in the understanding of Ajzen (2008) and Fishbein and Ajzen (1975) as "the subjective probability that the object has a certain attribute" (Ajzen 2008, 531; see also Fishbein and Ajzen 1975, 12). The relationship of beliefs with attitudes, according to the authors, is reciprocal and includes the beliefs about the consequences of performing a specific behaviour (cf. also Fishbein and Ajzen 1975, 15-6). Subjective norms are shaped by normative beliefs i.e. the beliefs regarding what behaviour is perceived to be expected from one's social surroundings. And lastly, they assume the perceived degree of behavioural control to be influenced among other things by the belief that factors exist which may hinder or facilitate behavioural control (Ajzen 2008, 538).
} 
Sommer 2007, 26; see also Dichter 1964; Fournier 2009; Jubas 2007; Sassatelli 2008, 27; Sirgy 1982). Single brands, for example, may be associated with beliefs of attaining a particular status, quality or security by their purchase, though these ascriptions must not necessarily be true (Ajzen 2008, 540; see also Allison 2009; Roberts and Lilien 1993, 31). Still, by shaping beliefs these publicly proposed ideals may influence attitudes and their translation into behavioural intentions (cf. Ajzen 2008, 540). In political consumerism, buying organic products or vegetarianism, for example, are often regarded as an attempt to coherently integrate certain ethical or political values into the own state of existence (cf. e.g. Lindén 2005; Micheletti and Stolle 2010, 2012; Shaw 2005, 140-1; see also Ariely, Bracha, and Meier 2009). Thus, looking at the respective beliefs that underlie these forms of behaviour may allow for the closest approximation to grasping the 'real' sources of involvement in political consumerism (cf. Ajzen 1991, 206). In line with this idea, two propositions for extensions of the Theory of Planned Behavior model shall be highlighted. First, Vallerand et al. (1992) emphasize the interactive link between normative beliefs and attitudes in moral behaviour. In their view, an individual's perception and response to an object or issue is influenced also by what is perceived to be expected from the surrounding people. Therefore, they recommend to include a linkage from norms to attitudes (Vallerand et al. 1992, 104-5; cf. also Noel 2010, 16-7). Tightly connected to it is the conception that values and norms are mirrored in symbols and symbolic behaviour (Sommer 2007, 25). Hence, secondly, to consume in one or another manner is also connected to an individual's selfperception and self-image: what behaviour and what symbols reflect best how I expect ' $m e$ ' to be and to behave? (cf. also Sirgy 1982). Emanating from this idea, Shaw (2005) extends the theoretical model by including among others the factors 'self-identity' and 'ethical considerations'. Her findings advance the idea that people need to perceive that they are acting in line with a certain ethical obligation for upholding a consistent self-image; and this appears to influence their intentions to engage in ethical consumerism.

Notwithstanding, political consumerism seems to be more than an expression of values and attitudes. Along these lines, Hines, Hungerford, and Tomera (1987) depart from this focus and put emphasis on the relevance of knowledge and actual ability to act in determining behavioural intentions. Based on a meta-analysis of 128 studies, the authors put forward a model that comprises four factors which influence the intention to act environmentally responsible. The first they call personality factor or desire to act, and it basically agglomerates all elements of the Theory of Planned Behavior: attitudes, sense of personal responsibility, and the sense of capability to bring about the intended change through individual actions (Hines, Hungerford, and Tomera 1987, 6-7). The other three factors relate to knowledge of the issues at stake, knowledge 
of action strategies, and action skills. Thus, they propose that next to the individuals' inner perceptions of what is desired and what is feasible, capabilities and knowledge are equally of importance in formulating intentions to act.

Finally, as Quintelier and van Deth (2014) observe, values and attitudes must not necessarily precede behaviour. Instead, they discern a reverse relationship where political consumer behaviour appears to influence (political) attitudes much stronger than attitudes behaviour. Hence, political consumer behaviour may take place without holding previously a corresponding attitude. Instead, the activity may come first and lead towards a renewal of one's set of values and attitudes. Observations in social psychology research support this idea, where depending on the incentives and perceptions in relation to a behaviour attitudes could be improved or worsened as a result of engaging in a particular behaviour (see Bohner and Wähnke 2002, 165-8; see also Ariely and Norton 2009, 489). Likewise, Faber, Petersen, and Schiller (2002), for example, observe that human beings " [...] want to receive approval from their fellow citizens for what they say and for what they do" (2002, 328; see also Wyer 2008). Hence, individuals may behave in a specific manner because friends, family or other people behave in this style (cf. Sommer 2007, 25; see also Lindén 2005). In so doing, they get acquainted with the behaviour, cotton up to it and start incorporating the values and attitudes that are related to the behaviour.

Taken together, the various observations entail four conclusions. Firstly, values and attitudes are not directly related to behaviour. Instead, behavioural intentions enter as intermediaries. Secondly, these behavioural intentions are influenced by more than only politically infused values and attitudes. Precisely, ones perceived capabilities to act including background knowledge, prevailing norms and opinions in the immediate social environment as well as ones self-image play in and shape intentions to act, too. Thirdly, situational features may interfere and incite that intentions do not necessarily result in corresponding behaviour. And, fourth and lastly, the link between predispositions to act and actual behaviour is not unidirectional but rather interactive. That is, political consumer behaviour shapes the predispositions to act and these may again shape intentions and subsequent behaviour.

Considering this, in basing explorations of political consumer engagement on values and attitudes only, research would risk leaving out an important fraction of explanatory variables. At the same time, whensoever focusing on values and attitudes, given the unsteadiness of behavioural intentions over time and context and given the ongoing reciprocal relationship between attitudes and behaviour, reliable predictors for involvement in political consumerism 
may best be found in such underlying values and/or norms that relate to fundamental issues in life and therefore are comparatively stable over time.

\subsubsection{The Use of Cognitive Short-Paths}

In converting behavioural intentions into actual behaviour, various factors may intervene and distort or strengthen a previous consistency between attitudes and behavioural intentions. Decision making is largely processed at the subconscious and, often without taking notice, individuals recur to various types of strategies and cognitive short-paths that permit them to cope with specific situational features (Ajzen 2008, 540). Moreover, biases, priming and framing effects, as well as values and the influence of context and surrounding people may shape and direct actual behaviour (cf. Ariely and Norton 2008; Bettman, Luce, and Payne 2008; Bohner and Wänke 2002; Fraj and Martinez 2006b; Kahneman 2003; Poffenberger 1942; Schoen 2006; Wyer 2008). In this framework, to reliably discern and objectively assess peoples' impulses is difficult if not impossible both for the individuals themselves as for their counterparts (Sommer 2007, 37; cf. also Kroeber-Riel and Gröppel-Klein 2013, 185ff., 192-4, 333-5 \& 382). Bettman, Luce, and Payne (2008) advocate four meta-goals which individuals generally strive to realize in any decision-making situation: (1) maximizing the accuracy of the decision, (2) minimizing cognitive effort needed to take the decision, (3) minimizing the amount of negative emotions while deciding, and (4) maximizing the ease of justifying why the final decision has been taken $(2008,590)$. Depending on the specific situation and issue at stake (i.e. salience, time, motivation) one or the other goal may be more or less relevant than the others. Corresponding to it, individuals may apply different decision strategies and varying cognitive shortcuts. Applied to political consumerism this entails that depending on the specific framework and the approaches selected for making a decision, political attitudes may not translate congruently into the respective political behaviour.

In striving for ease of justification, incentives to behave in a certain way may vary depending on whether a decision is made in private or in the presence of others; similarly, if the decision is taken in private but its outcome will be known to others afterwards, the decision-making process as such may also differ from when it is entirely kept private. As Ariely, Bracha, and Meier (2009) have shown, decisions taken in the presence of others are much determined by the desire to satisfy a certain image (cf. also e.g. Friedrichsen and Engelmann 2013; Sirgy 1982). Privately taken decisions in turn require justification 'only' towards oneself. Consequently, the focus therein lies more on behaving in such a way as to maintain a consistent self- 
image (Bettman, Luce, and Payne 2008; see also e.g. Mazar and Ariely 2006). However, to maintain this is not as simple either. Valor (2007), for example, discerns 'cognitive' and 'emotional' ambivalences which may distort decision making. In situations of cognitive ambivalence, individuals perceive a lack of knowledge and that they therefore cannot behave in such way as they think it would be their ethical obligation $(2007,686)$. In contrast, emotional ambivalence occurs when individuals perceive a mismatch between different dimensions of their personality $(2007,687)$. Both types of incongruities may complicate ease of justification and, as a consequence, incite 'cognitive dissonance' (Festinger 1957, see Valor 2007, 686). Hence, Valor (2007) concludes, consumers who find themselves in an ambivalent situation may recur to different neutralisation strategies that serve them to reduce the dissonance between their felt obligation and what they want or can do. Related to political consumerism, individuals may for example lower the level of their perceived ethical obligation or consider it as being beyond their power to act in line with their political ideals (cf. Valor 2007, 687-8). That is, they may alter attitudes held initially. Another finding which proves the ambivalent nature of behaviour is provided by Mazar and Zhong (2010). They observe that while the mere exposure to green products may trigger altruistic behaviour, actually purchasing these ethically and environmentally considerate products makes people more prone to engage in dishonest behaviour than the purchasing of conventional products. This illustrates how values related to ethical commitment are not necessarily persistent, and acting according to certain (ethical) values in one case may alter an individual's predispositions to act for other activities. Hence, their finding actually supports both the notion that preferences are volatile over time and context as well as the notion that attitudes and behaviour are linked in a continuous reciprocal process in which they shape each other.

The concept of cognitive dissonance implies that next to easy justification, individuals typically strive for a decision making that is as effortless as possible and yet maximally accurate. As Simon (1978) notes, people are in many situations simply not capable to search and process the vast amount of information they could theoretically take into consideration before making a decision. Frequently, individuals face a large array of purchasing options while simultaneously being surrounded by multiple media and other environmental influences. Although in theory they may have access to all relevant information, the complex system is little transparent and keeping track of new developments is difficult while factual time-pressure often is high (cf. Boström and Klintman 2009; Kroeber-Riel and Gröppel-Klein 2013, 747; Schimank 2005, 161 \& 168-9). These circumstances make prone to depend on expert advice and other tools that 
allow for making decisions in uncertain or ambivalent situations simpler (Boström and Klintman 2009, para. 21) while maintaining a high enough level of security that the 'right' decision is taken (cf. Kroeber-Riel and Gröppel-Klein 2013, 469 \& 476ff.; see also Poffenberger 1942, 95; Ybarra, Lee, and Gonzalez 2012).${ }^{17}$ One major strategy to cope with this ambivalence consists in using so-called heuristics, that is, simplified rules that facilitate and abridge decisionmaking (cf. Bohner and Wänke 2002, 153; Noel 2010, 146; Schoen 2006, 22). Such heuristics may entail straightforward strategies of selecting only based on price or brand, or they may as well entail more complex procedures where individuals compare, evaluate and ultimately rate various aspects of the alternatives (cf. Kurz-Milcke and Gigerenzer 2007, 50; Wyer 2008, 57). As Nelson (2004) observes, also in political consumerism " [...] many decisions are made rather simply" $(2004,37)$, grounding on screening processes or the activation of particular subsets of images which the individual holds in relation to the product or producer $(2004,29)$. Thus, again, political consumerism appears to be clearly driven by more than mere values and attitudes, and the translation from behavioural intentions into actual behaviour shows to be possibly interfered by the simple desire to find a quick path towards a decision.

The remaining fourth meta-goal relates to the desire to minimize the amount of negative emotions experienced while deciding. This aim is of particular relevance in political consumerism since high-stake concerns build the very core of political consumer activity (e.g. product security, individual and/or the family's health, ecology or animal welfare or employee safety; see e.g. Lindén 2005; Micheletti and Stolle 2010; Stolle and Micheletti 2005; Tallontire, Rentsendorj, and Blowfield 2001). Accordingly, the risk of negative emotional and/or cognitive consequences in the case of taking a 'wrong' decision in politically infused purchasing situations may be perceived as being relatively high. However, when salience is high whereas the situation is not a matter of routine, individuals have shown to be particularly prone to either over- or underestimate relevant information (see for an overview Bettman, Luce, and Payne 2008, 601; Kroeber-Riel and Gröppel-Klein 2013, 483), and even to deter or abstain from choosing (Ariely and Norton 2009; see also Jäckel 2004, 277-8). Thus, despite holding political values and attitudes, depending on the evaluation of a situation's level of risk individuals may deter from converting the intention to engage in political consumerism into the respective behaviour. Furthermore, as Bohner and Wänke (2002) highlight, also the ease of information retrieval may have a relevant impact on the assessment of a situation or object; that is, being able to rate a situation without much effort comes along with more positive emotions, which in turn

\footnotetext{
${ }^{17}$ This idea relates to Herbert Simon's famous notion of ‘bounded rationality’ (1955; see Simon 1978).
} 
appears to lead to a more favourable assessment (Bohner and Wänke 2002, 107). As a consequence, the presence of e.g. labels or other easily recognisable criteria that allow for evaluating a product or producer may facilitate the conversion of intentions to engage in political consumerism into actual behaviour. Finally, moods and impulses, past personal experiences or the mere presence of habits which are difficult to overcome may play in, too, and influence which attitudes are being relied on in a situation and how they are translated into behavioural action (cf. Ajzen 2008, 541; Bohner and Wänke 2002; De Vries, Aarts, and Midden 2011; Kroeber-Riel and Gröppel-Klein 2013).

Altogether, the findings highlight the complex processes that underlie decision making and the mere impossibility of predicting political consumer behaviour by relying only on values and attitudes. Too many factors may interfere alongside and result in an incoherent relationship between attitudes and behaviour. Nevertheless, as mentioned above, focusing on attitudes which are comparatively unchanging over time may be one part of an approach to predict behaviour and thus to further explore involvement in political consumerism. Moreover, the observations of this section emphasize that outside conditions heavily condition behaviour as well. In this regard, information provision appears to be a particularly important factor: information can deliver knowledge about issues and action possibilities whereas reliance on the information provided can promote a feeling of security. Together, the presence of these two aspects can facilitate involvement, their absence hinder it. As a consequence, in looking at individuals' degree of familiarity with information providing phenomena and their confidence in them means moving focus onto criteria that are less a subject of individuals' fickleness. Instead, familiarity and confidence should be relatively steady across varying contexts. In conclusion, then, information provision appears to be a second piece to be included in a promising tactic designed to better comprehend political consumers.

\subsection{Résumé: The Citizen, the Consumer and the Politically Consuming Citizen}

The perspectives on political consumerism vary, yet they all ground on a common origin: the invisible frontier between the citizen and the consumer domains is vanishing. All across Europe individuals make use of their consumer decisions as vehicles to convey political demands and to tackle sensed problems which touch upon the two spheres. That is, they combine their citizen with their consumer role and become political consumers. 
In doing so, the political consumers express a multifaceted array of political demands, and, along with the varying contents also the terms used in talking about this phenomenon in research differ. But named 'ethical consumerism', 'sustainable shopping' or 'green purchasing' - the review of these terminological variants suggests that they allude to distinct characteristics of a product but, essentially, they all deal with a variant of political participatory action taking place in the sphere of consumption. That is, they all centre on one idea: the attempt to express a concern relating to the public good by means of purchasing. In contrast, a second terminological variation appears to actually cover distinct modes of action employed across individuals: the distinction between boycotting and buycotting behaviour. Some individuals appear to only boycott, some to only buycott, and some are involved in both boycotting and buycotting. Existing research suggests that the way in which individuals get involved in one or the other varies with their underlying intentions and attitudes. In view of that, boycotting and buycotting appear as two essentially different variants of political participation which require to be studied as separate modes.

But where to look for explanations why boycotter are not automatically buycotter, and viceversa? So far little is known about the concrete background and the underlying factors that influence individuals to get involved in a boycott and/or a buycott. The sociological drawing of the activities' background shows a citizen-consumer hybrid which unifies the own consumption desires with self-transcending societal interests and acts based on the global appraisal of the respective concerns. In this process, the aspiration for constructing an own identity and to differentiate oneself interacts with civic aspirations and political aims. This mixed background suggests that a thorough examination of the underlying drivers of boycotting and buycotting should assume an interwoven approach, too. It should seek for explanations within the consumer sphere as well as in the political domain. Likewise, it should combine insights and methods from both strands of research.

Tying in with this, one striking insight is the frequent incongruence of attitudes, intentions and behaviour. Several factors shape and promote the development of their relationship, consciously as well as subconsciously, and many of them are subjected to the individuals' fickleness and contextual vicissitude. In order to circumvent the risk of misattributing and overstating explanatory links, the examination strategy needs to build on criteria which are relatively unchanging across time and context. Integrating the political, sociological and psychological perceptions on the backgrounds of the citizen and the consumer proposes two broader classes of concepts as promising points of departure for such an endeavour. Firstly, underlying values 
and/or norms that relate to fundamental issues in life; and, secondly, the degree of familiarity with information provisions and the confidence individuals have in them. 


\section{Explaining Political Consumerism}

3.1 Evolving Duties and Responsibilities in the Economic-Political Realm

A bundle of concurrent developments has deeply affected the relationship between the political and the economic spheres. For the political realm, these developments involved a declining stable electoral basis in a situation where, simultaneously, political tasks were becoming more complex and national budgets tighter. This context facilitated the penetration of particular interests articulated by political advocacy groups and lobbies which claim to be experts on specific subjects (cf. Cox 1997; Crouch 2004). In the economic sphere in turn, liberalisation of global trade and a trend among firms to maximally increase their regional flexibility promoted the evolving of production processes into globalised chains of cross-border collaboration where raw materials may be sourced on one continent, assembled on a second, and sold on a third continent (cf. Crouch 2004, 35ff.). In a political atmosphere shaped by economic rationales, this flexibility gave economic actors ample negotiation power vis-à-vis governments (cf. Crouch 2004; Haufler 2001; McGrew 1997; Thompson 1997). The greater power of the business sector combined with the sway of economic arguments and 'expert' advices in the public sector supported a wave of privatisation and the increasing take-over of public tasks by private businesses. Together with the concurrently declining power of constituencies, the context stimulated a reorganisation of responsibilities and duties between the political and the business spheres and their closer intertwining.

This reshuffle entails important consequences for the citizen-consumer. In blurring the frontier between the public and private domains (Scherer, Palazzo, and Matten 2009, 332), the individual also is immersed deeper into the struggle between the role as a cosmopolitan consumer and a customer of a firm, and the role as an astute and conscientious citizen of the world. To better understand the differences between boycotting and buycotting behaviour requires attention to these macro-societal changes, too. Therefore, the section begins with a concise delineation of the currently evolving macro-environment. In doing so, it seeks to elaborate on the implications which these processes of change engender for the relationship between politics and the business sector. Moreover, it seeks to describe how the macro environmental changes and the evolving of the citizen-consumer are connected. The second part of the section then strives to disentangle single constants in this context which affect the course of development of the citizen-consumer. Drawing on a theory on attitudes concerning the relationship between the state, firms and civil society, the section closes with explaining how in similar contexts individual political consumer behaviour evolves into diverse directions. 


\subsubsection{New Challenges in a New Environment}

Since roughly the end of the 1970 s, several concurrent developments have led to a transformation of the relationship between politics, the business sector, and society. Economic growth in the post-war era had brought about a general increase in wealth and material prosperity as well as expanding social welfare systems in industrialised countries. Over the years, this instigated a decline of traditional, relatively static social class structures. In the political sphere it entailed the dwindling of traditional, class related political party belongings. Analogously, in the economic sphere the coverage of basic material needs induced a more differentiated consumption structure. Ultimately, this fragmentation and the loosening of individuals' ties to particular social groups provided a new environment with important consequences for the tasks of political decision makers (cf. Papadopoulos 2013).

One consequence is a less reliable basis for political action due to the more fickle electorate (Crouch 2004, 63-4 \& 73-4). More precisely, as Crouch notes, fragmentation entailed two important adverse consequences for society at large. On the one hand, the fragmentation of interests and individualisation render it difficult to build up interest groups. Hence, in the new environment constituencies face a greater difficulty to articulate their common political demands. On the other hand, the electorates' unpredictability encourages or may even force political office-holders to open up to alternative support. In such a setting, well organised advocacy groups and lobbies could find it relatively easy to gain strength and outweigh the constituencies' influence on political decision makers (Crouch 2004, 64). Hence, social fragmentation cleared the way for a growing influence on politics of well-organised subgroups including the business sector (cf. Crouch 2004; Papadopoulos 2013).

While social welfare state systems had been expanding in times of economic growth, the oil-crises of the 1970s and the following economic stagnation brought national budgets into struggling (Crouch 2004, 9). In the wake of growing unemployment, inflation and economic stagnation, governments had to refocus and increased their attention to economic rationales (Cox 1997, 53ff.). As a result, the public sector retreated from its former course of expanding welfare provisions. Instead, social welfare spending was downsized and in the course of a wave of privatisation various public sector duties were gradually transferred to the private sector (Scherer, Palazzo, and Matten 2009; see also Micheletti 2003, 6ff.; Shaw and Black 2010, 388).

This directly connects to a third crucial development on the international level, which may be subsumed under the umbrella term 'globalisation' ${ }^{18}$ : liberalisation of trade, financial markets

${ }^{18}$ See Held (1997), McGrew (1997) and Ritzer (2007) for a more detailed delineation of the multifaceted concept of globalisation. 
and communication, and the growing number of transnational institutions and partnerships promoted the interweaving and interdependence of countries worldwide (cf. Cox 1997; Held 1997; McGrew 1997). With it, the recognition rose that challenges crossing national frontiers, such as trade, migration or climate change, demand transnational problem-solving processes (cf. McGrew 1997). Issues of formerly national concern became subjects of transnational negotiation processes. On the one hand, these global issues are numerous and given their cross-linked character the subjects are often highly complex. As a consequence, without specialists' advice and assistance politicians may find it difficult to precisely assess an issue. Combined with the pressure of a fickle electorate, this further promotes the opening up of political office-holders to advocacy groups and lobbies which assert to be able to deliver expert knowledge on specific subjects (Crouch 2004; Papadopoulos 2013). Moreover, Everson, and Joerges (2008) point to the tendency to de-politicise procedures. More specifically, they highlight the trend (with particular reference to the EU) to rest political decision making on a technocratic-scientific and market-driven logic, that is, grounding e.g. protection and regulation decisions on scientific arguments and 'expert' advice (2008, 164-171). This, they assert, equals consciously moving responsibility out of the political sphere. Yet, despite these deliberate attempts of political institutions to cope with the greater array of challenges, the global reach of the issues combined with short public budgets complicates coping with all of it. Thus, on the other hand, the globalised tasks leave a "regulatory vacuum in global governance" (Scherer and Palazzo 2011, 899; Vogel 2008, 266; see also Micheletti 2003, 9; Stolle and Micheletti 2013, 8, ref. to Young 2006, 2010). Here, firms come in and fill the vacuum by taking up political and social responsibilities that formerly belonged to the public sector, including the very provision of public goods such as education or health care, or contributing to official regulations (Haufler 2001; Heidbrink and Hirsch 2008, 15ff.; Scherer and Palazzo 2011, 900-1; cf. also Matten and Crane 2005; Scherer and Smid 2000). With it, the traditional distinction does no longer hold that political and social responsibilities belong to the state while economic ones belong to the business sector. Instead, as Scherer, Palazzo, and Matten $(2009,332)$ note, under the conditions of globalisation "the nation state is losing part of its regulatory power, [...and], the private-public distinction gets blurred" (cf. also Matten and Crane 2005; Offe 2000; Palazzo 2009; Scherer and Smid 2000). It is further intensified by the more favourable environment to shift operations from one country to another which is provided by the global decline of country barriers as to trade, investments and communication (Held 1997, 5-6). The greater regional flexibility reduces governmental capabilities to regulate firms (Vogel 2008, 266). At the same time, the settling of a firm promises to bring jobs, tax payments and in some cases the settling of further firms to a country. As 
a result, firm's regional detachment fosters intergovernmental competition to attract businesses (Hall and Soskice 2001, 55-6; Scharpf 1997), and this desire to attract firms in turn prompts the sway of the business sector on public decision making (Jensen 2005, 444; see also Held 1997; Scherer and Palazzo 2011). Ultimately, with taking over tasks and influencing decisions in politics, firms have become "political actors" whose, as Jensen expresses it, "decisions and actions considerably influence economical, social, cultural, political, and environmental affairs in society" $(2005,444)$. In sum, in decreasing the assertiveness of national interests while increasing the power of the private business sector, globalisation has further intensified already developing changes in the sphere of national government power (Micheletti 2003, 4ff.).

The growing power of the business sector in particular and the broad array of reliance on expert advice in general entails two risks. Firstly, some firms (as well as other advocacy groups and lobbies) might take advantage of the regulatory weaknesses and try to foster their own interests without considering the possible adverse consequences for the social and natural environment in which their operations are embedded (Scherer, Palazzo, and Matten 2009, 332-3, ref. to Banerjee 2007; see also Crouch 2004; Haufler 2001; Papadopoulos 2013). More generally, reliance on the counselling of asserted experts can be treacherous since in its position of being an 'expert', the counselling agent possesses per definition greater knowledge than the political decision makers (see Arrow 1985; Petersen 1993). This asymmetric spread of information places politicians into a disadvantaged position, which experts may exploit. What is more, lobbies and political advocacy groups tend to be experts on issues where the decisions eventually taken have a direct effect on themselves. Thus, they are not impartial on the final decision outcome. This in turn may incentivise them to withhold or highlight particular aspects of information on the issue depending on what is expedient for inciting the desired outcome (cf. Milgrom and Roberts 1988, 156). Secondly and related to this first aspect, the political weight of the business sector and the resulting spread of asymmetric political power can endanger democracy: firms are gaining significant influence on the tasks which actually belong to democratically elected actors, and are gaining influence on processes which should be subjects of public deliberation and scrutiny (Scherer, Palazzo, and Matten 2009, 339-340; cf. also Cox 1997; Crouch 2004; Matten and Crane 2005; Haufler 2001; Papadopoulos 2013). As a result, firms may actually get into the position to promote outcomes that are skewed to their interests and, possibly, undermine, elide or even act counter to general societal interests.

Notwithstanding, in addition to the gain in flexibility, power and tasks for firms, their responsibilities and duties have moved more into the public focus, too: the freer operating range provides firms with a greater ability to steer their own behaviour. Yet, this also enables the 
viability of a wider range of types of behaviour and, with it, a greater distinction and more differentiated evaluation of firm behaviour by the public. Besides, with the business sector gaining more influence on politics, individuals and the environment worldwide on the one hand, and the narrowing capability to regulate firms' activities through politics on the other hand, societal expectations on firms to assume moral and legal responsibility have gained both strength and attention (Haufler 2001; Micheletti 2003, 13-4; Vogel 2008).

Lastly, new developments in communication technologies make it easier to control whether companies are adhering to societal expectations or not (Shaw and Black 2010, 388; see also Valor 2007). The internet in particular has become an important platform where individuals cannot only get hold of (political) information but also use it as a crucial space for political participation and organisation (Bauman 2008, 143-5; Saunders 2009; Stolle and Micheletti 2013, 38-9). This includes the expression of facts, opinions and assessments of firm conduct and their products (cf. Berry and McEachern 2005, 84-5; Gil de Zúñiga, Copeland, and Bimber 2013, 493; Stolle and Micheletti 2013, 41-3). In this environment, companies are becoming progressively attentive to societal demands for moral and legal responsibility and the need to respond to these demands. Numerous firms go beyond compliance to legally set standards and engage in self-regulation (Haufler 2001; Scherer and Smid 2000, 368). Likewise, some use their power as well to influence the political processes which seek to redefine or to establish new standards (Scherer, Palazzo, and Matten 2009, 328; Scherer and Smid 2000, 354) and thereby further engender a new 'balance of power' between state and markets.

Taken together, actors and addressees of political concerns can vary widely from issue to issue and they may be found in multiple spheres. Besides, redefined duties and responsibilities between the state and the business sector are transforming the ideas of which actors are responsible for what issues and who should be directly held accountable in each situation. As a consequence, the changing environment is bringing along the need to find adequate mechanisms which allow citizens for coping with these shifting responsibilities and addressees of political concerns (cf. Micheletti 2003, 13-5).

However, both the attribution of duties and responsibilities as well as the preferred mechanisms for keeping this 'balance of power' intact differ from country to country and across individuals (cf. Bair and Palpacuer 2012; Boström and Klintman 2006; Hall 2007; Hall and Soskice 2001; Hoffmann 2014). Therefore, comparable developments may have very different effects on individual behaviour depending on the national contexts and the personal backgrounds. In the view of that, the developments described provide an important starting point for the study of boycotting and buycotting behaviour: they delineate a comparable set of conditions, i.e. a 
'frame' in which political consumer behaviour as a whole could evolve. Simultaneously, the processes described raise the question how mechanisms for tackling the new challenges develop, and how this results in different types of boycotting and buycotting behaviour despite similar circumstances.

\subsubsection{On the Varieties of Capitalism}

Which duties and responsibilities belong to the state, to the business sector and to the citizens, and the preferred style in which this allocation is kept in balance differ from country to country. Within each country, certain preferences tend to persist and underlie the citizens' views on duties and responsibilities and respective mechanisms for ensuring (political) answerability (cf. Inglehart 1988; Kim et al. 2012; Pickel and Pickel 2006; Swidler 1986). Hofstede identifies national patterns or, as he calls it, a "collective mental programming" according to which citizens exhibit similar patterns of behaviour and attitudes depending on the country they come from (Hofstede 1996, 388). This mental programming includes, among other things, their ,,political culture“, which Almond and Verba defined as ,the particular distribution of patterns of orientation toward political objects among the members of a nation" (Almond and Verba 1963, 14-5). It consists of the individuals', ,[... [ attitudes toward the political system and its various parts" and their "attitudes toward the role of the self in the system" (Almond and Verba 1963, 13). The particular attitudes are considered to be the result of (political) socialisation during childhood, education, media influence as well as personal experiences with political, economic and social circumstances in adulthood (Almond 1990, 143-4). They develop on the individual level, therein being influenced by society specific events and peculiarities. Simultaneously, they constitute the grounds on which specific attitudes in society as a whole develop (Almond and Verba 1980, 27-8; Eisenstadt 1996, 451; Hofstede 1996, 388; Reisinger 1995, 335). Hence, Almond and Verba delineate a concept which immediately links micro-level conduct with macro-level developments and vice-versa. They explicitly focus on culture in its meaning as a "psychological orientation" towards socio-political objects and processes (Almond and Verba 1963, 14; emphasis in original). In this vein, they connect individual dispositions with generic patterns, and the dispositions and patterns with institutional processes. Although they demarcate a conception whose underlying idea provides a crucial starting point for studying the citizenconsumer, the particular concept of political culture relates explicitly to the sphere of politics, policy and the polity (cf. Almond and Verba 1963, 12-3; Ersson and Lane 2008). The peculiar encounter of the newly evolving environment though is that it challenges precisely this clearcut differentiation of the political from other spheres of life when it comes to define individual 
behaviour. That is, rather than the structures, actors and procedures of the immediate political system, the crucial 'object of orientation' is the state and its relation to firms, and the mode in which duties and responsibilities are solved and shared among them.

A corresponding understanding inspires the idea of the 'concept of the state'. It refers to citizens' attitudes concerning the state, the market and civil society and the relationship between the three. That is, it denotes the view about who is responsible for what, how the cooperation between the three actors should look like and which role each of them should take on (Almond and Verba 1996; cf. also Kim et al. 2012; North 1990). Accordingly, the concept of the state also comprises the balance between collaboration and free competition that from an individual's point of view appears to be desirable (cf. Esping-Andersen 1990, 80). This conception in turn builds the basis of what Swidler calls a "repertoire or 'tool kit' of habits, skills, and styles from which people construct 'strategies of action"' (Swidler 1986, 273), that is to say, preferred approaches to solve socio-political tasks (Swidler 1986, 276-7; cf. also Wahlström and Peterson 2005, 240). Hence, in a context where new tasks are arising and duties and responsibilities in society are reorganised, these preferences guide the establishment of mechanisms that serve to secure political accountability, both as preferences of the individual citizens and in society as a whole.

Along the lines of these thoughts, Hall and Soskice (2001) propose in their theory on the 'Varieties of Capitalism' concrete patterns according to which actors in single nations typically solve economic- and socio-political challenges (Hall and Soskice 2001, 8 \& 13). ${ }^{19}$ Hence, in the vein of Almond and Verba, Hall and Soskice describe a certain distribution of patterns of orientation towards how cooperation problems should be tackled among the actors in a country. In their view, institutional structures condition these patterns according to which actors ${ }^{20}$ behave. These structures they view in turn as "nation-specific", i.e. shaped by national circumstances like culture, history, etc. (Hall and Soskice 2001, 15-6). Further, the authors assume that this leads to systematic differences across countries and distinguish two main strategies (Hall and Soskice 2001, 8 \& 16): in so called 'coordinated market economies', non-market forms of cooperation between the three actors state, market and civil society prevail as means to deal with tasks of socio- and economic-political significance. The strategic approach focuses

\footnotetext{
${ }^{19}$ Also Hall und Soskice refer to Swidler and her suggestion that societies develop 'behavioural repertoires' that serve as a basis for solving coordination problems concerning society (Hall and Soskice 2001, 13).

${ }^{20}$ In Hall and Soskice's theory, the term 'actors' refers to companies (Halls and Soskice 2001, 15). The reason for this is that, in their theory, it is companies that are those central interacting actors which find themselves confronted with a coordination problem. Nevertheless, also citizens constitute actors who interact in the framework of specific institutional structures and therein need to coordinate their actions. Correspondingly, the presented ideas may as well serve as point of departure for analysing the behaviour of individuals in the context of coordination problems.
} 
on consensus finding and the establishment of and reliance in interfirm networks and sectorial associations. In line with it, corresponding policies centre on further enabling non-market coordination and cooperation (Hall and Soskice 2001, 46-7). In contrast, in so called 'liberal market economies', actors rely on free market competition as means for coordinating their undertakings. They reject institutional intervention and, instead, rely on formal contracts to ensure successful collaboration (cf. also Nölke and Vliegenthart 2009, 675). At the same time, any policies which are set up are then compatible with the systemic structure when designed such that they "[...] sharpen market competition" (Hall and Soskice 2001, 46). In addition, the authors distinguish a third category of countries which appears to be moving in between the two extremes, and they refer to them as 'Mediterranean' cluster (Hall and Soskice 2001, 21). The countries in this cluster deviate from both the liberal and the cooperative countries in some aspects and match some of them in other cases. A main common characteristic Hall and Soskice differentiate for this cluster is the prevalence of structures that favour cooperative approaches in corporate relations, and rather liberal approaches in concerns that affect the interaction of firms with other actors in society (Hall and Soskice 2001, 21). They mainly attribute these structures to similar historical backgrounds. Broad influence of the state on the economy provided for structures facilitating non-market cooperation. Besides, several of the countries have only recently left behind autocratic state structures. This has resulted in a large state controlled business sector and the high relevance of family ties and informal networks (see e.g. Hancké, Rhodes, and Thatcher 2009, 290-1). Given the mixed features and to facilitate a straightforward and yet generically applicable understanding, this cluster will in the following be referred to as 'mixed economies'.

Generally speaking, according to the underlying principle different types of institutional regimes and (political) culture prevail across countries and shape the predominant attitudes in society concerning the roles of the state, the market and the citizenry in matters of socio- and economic-political relevance (cf. Almond and Verba 1996; Kim et al. 2012; Hall and Soskice 2001; North 1990; Pickel and Pickel 2006). On the macro-level, political culture or 'varieties of capitalism' constitute a dominant and quite time-invariant response pattern to shifts and newly emerging challenges. That is, they constitute a contextual constant which shapes the mechanisms and approaches developed for coping with 'coordination problems' (cf. Hall and Soskice 2001, 6 \& 9). These coordination problems involve different actors who enter into a joint interactive relationship. Correspondingly, the classification of countries according to patterns of conducting such relationships essentially stems on the conception of how each actor 
should behave, including the individual actor itself (Hall and Soskice 2001, 13). Hence, equivalent to Almond and Verba $(1963,1980)$, the concept ties country level patterns to individual level behaviour. With it, these general understandings of preferred individual behaviour would also be expected to directly reverberate on the behaviour of the individuals involved in respective interactions. Breaking down the varieties of capitalism theory to the individual level, it then means that the mode of operation of a country's market economy may shape the inhabitants' notion on what balance between the state, the market and civil society is considered to be desirable in one of two directions: either they may be pleased with the balance prevailing in the country and therefore regard it as an appropriate mode of operation; or they may rather oppose it, due to perceived weaknesses or injustices for instance, and instead strive for an alternative mode of operation. Additional factors influencing the view may be e.g. political interest or individual social position. ${ }^{21}$ Yet, assuming that the citizens of countries with a democratic political system ideally are satisfied with the prevailing system ${ }^{22}$, citizens who are living in a country with a liberal market economy would be expected to also tend to have a liberal concept of the state; they are used to the general belief that the free market mechanism leads to the optimal outcome, and this general belief may both reflect and resonate on individual behaviour. In contrast, individuals who are living in and formed by a system founded on cooperation and coordination would be expected to rather tend to have a concept of the state which relies upon coordination, too. Finally, citizens coming from countries with a 'mixed' concept are used to the role of the state as regulating element (Molina and Rhodes 2007, 225), but also to informal networks in subspaces of the economic sphere. Accordingly, citizens may generally perceive less responsibility to get involved, yet where interactions take place, they would be expected to prefer informal, collaborative approaches (cf. Nölke and Vliegenthart 2009, 678; see also Molina and Rhodes 2007, 225ff.).

In sum then, macro- and the micro-levels are tightly entwined in there being "systemic differences in [behavioural] strategy across nations" which "parallel the overarching institutional structures [...]" (Hall and Soskice 2001, 15). Political culture in general and the varieties of capitalism approach in particular appear as connectors of the two levels (Almond and Verba

\footnotetext{
${ }^{21}$ On the one hand, the politically interested may rather look into the subject and deal with the political system than the disinterested, what in turn increases the likelihood to find weaknesses. On the other hand, an individual's social position may be important since the sense of how fair or unfair a system is will vary also with the personal experiences; that is, someone who e.g. cannot find a job and is therefore dependant on welfare aid may compare the own life with that of others who are better off and develop a sense of being treated unfairly. Thus eventually, the individual may perceive the entire prevailing system as being unjust and therefore strive for an alternative.

${ }^{22}$ In a democracy, by means of elections and other forms of democratic political participation (e.g. involvement in political parties), citizens are theoretically able to influence the prevalent political system and with it the resultant balance between the state, the market and civil society. In the long run, the existing balance should normally correspond to the expectations of a majority of the country's citizens.
} 
1963, 32; Hall and Soskice 2001, 14): they furnish the concept of the state, which in its guise as a nation-specific conception builds the fundament on which general response-patterns in the country for coping with socio-economic and political matters develop; in its guise as a personspecific conception it builds in turn the basis on which an individual acts in socio-economic and political concerns. In connecting the two levels, the theory of the concept of the state delineates the translation of macro-societal developments into individual behaviour and provides a concrete name for the long-term, underlying notion which influences this translation. Besides, stemming on the observation that the conceptions vary systematically across countries yet should be relatively stable among individuals and within a single country, the theory sketches a possible explanation for why boycotting and buycotting behaviour develop differently.

\subsection{Trust and Confidence in the Citizen-Consumer Sphere}

The theory on the varieties of capitalism focuses on firms as actors and on the countries' systemic structure for solving coordination problems (Hall and Soskice 2001, 6-7). Inherent to coordination problems is that actors with different interests interact and must arrange this interaction such that neither of both may be exploited or deceived (Hall and Soskice 2001, 5; Milgrom and Roberts 1992; Morgan and Hunt 1994). Put differently, they require a framework which provides them with security as well as confidence in that counterparts will not delude.

Applying this notion to (political) consumerism, the principal parties involved are firms and individuals: firms deliver a product and want to sell it, whereas individuals want to buy a product if they conceive that the purchase can fulfil a need or provide another type of added value to them. In this realm of classic consumerism, trust is considered to be a decisive factor that influences buying decisions: a lack of trust can deter from buying, its presence encourage a buy (cf. Atkinson and Rosenthal 2014, 33-4; Chaudhuri 2006, 116; Kroeber-Riel and Gröppel-Klein 2013, 484; Morgan and Hunt 1994; Pivato, Misani, and Tencati 2008, 5-6; see for an overview also Hoffmann 2008, 88). Depending on the particular person, different criteria may be more or less relevant in providing trust. Yet, common criteria relate to the expectation that the use or consumption of a good is secure on the one hand; and, on the other hand, that the firm fulfils what it promises to the customer, e.g. a certain usability or a determined priceperformance ratio (Chaudhuri 2006, 121; Crane 2005, 227; see also Ariely and Norton 2009). The provision of information, brands and other (symbolic) anchors are viewed to be tools which can promote the establishment of a trusting relationship of firms with their customers and encourage a purchase (cf. Atkinson and Rosenthal 2014, 34; see also Aguilera et al. 2007, 847; Chaudhuri 2006, 130-1). The expectations on the duties and responsibilities firms must fulfil 
have increased as well as the scrutiny with which their activities are assessed by the public (see e.g. Scherer and Palazzo 2011, 907; Stolle and Micheletti 2013, 139-41). Simultaneously, with the growing complexity of production processes and an expanding number of product alternatives available to consumers, individuals can hardly fully assess the origins and characteristics of their purchases (Atkinson and Rosenthal 2014, 34). Periodic reports of adverse company conduct and misleading information provision further obstruct the creation of trusting relationships (Atkinson and Rosenthal 2014, 33-4; Valor 2007; see also Lin-Hi 2008, 3; Muthuri, Matten, and Moon 2009, 87). So, consumers are said to be losing trust in companies (Crane 2005, 227; see also Stolle and Micheletti 2013, 141).

Trust has been defined as a 'phenomenon of reciprocity' between two parties, (Offe 1999 and 2001 cit. in Seubert 2009, 112; see also Kaase 1999, 3 \& 12): 'I trust you because I believe that you will reciprocate this trust when interacting with me' (Newton 2008, 242-3). Applied to the interaction between individuals and firms and in the context described, this entails three ambivalences: firstly, dealing with firms and their activities does not take place between two persons but a person and an organisation. Therefore, the counterpart a person should put trust in is difficult if not impossible to ascertain. Secondly, the spreading of firm operations worldwide and the typical division between producer and seller positions has increased the factual distance between producer and consumer. Instead of interacting with the firm which actually commands the circumstances in which a product is produced, individuals are typically interacting with firm-alien sales representatives. Accordingly, there is no direct interaction with the counterpart one requires to put trust in, i.e. the 'you', and thus no process in which the individual could actually learn whether the counterpart may reciprocate the trust. Third and lastly, usually the firm's activities undertaken in response to the demands of political consumers are not directed straight to 'me' (cf. Friedman 1996, 443-4). Instead, the typical targets of the respective ethical, ecological or socio-political concerns are e.g. a firm's own employees, the natural environment or communal institutions. The individual is therefore not able to actually verify whether the firm fulfils the demands or criteria to which trust is being subjected. In sum, the missing immediate interaction between 'me' and 'you' makes it difficult to evaluate the firm's intentions and credibility and requires different strategies for deciding whether to cooperate or not. For such reason, Newton (2008) and Offe (1999) differentiate between social trust and confidence in institutions:

"Trust in people is based upon personal knowledge of people, social types, or social situations, whereas confidence in institutions is based on knowledge of structures and systems, and 
the rules and practices that govern their operation, irrespective of whether we know personally the people who happen to run the institutions." (Newton 2008, 243)

Social trust (also known as 'generalised trust in people'; Seubert 2009, 192; see also Newton and Zmerli 2011, 171) applies in situations where the trustee reciprocates directly to the truster, that is, 'where I can check the outcome'. Confidence in turn applies in impersonal dealings 'where I can only infer from the best of my knowledge how a relatively anonymous counterpart will behave' (cf. Offe 1999, 43-44 \& 63). As an institution, a firm is not a person but an anonymous organisation. Individuals cannot gain intelligence about the true underlying intentions of a firm's activities through personal communication. But they can observe the firms' doings and acquire general knowledge about the rules, practices, and structures governing the firms' operations. Then, based on this, individuals can construct a feeling or belief about what a firm's intentions might be and how it will behave. The result is a relationship defined by confidence rather than trust.

For Rossteutscher $(2008,210-1)$, trust is "the precondition of any kind of collective behaviour". In the same vein, trust and confidence are commonly regarded as being core dimensions of social capital (cf. Brehm and Rahn 1997; Coleman 1990; Newton and Zmerli 2011; Onyx and Bullen 2000; Putnam 1993), i.e. a society's 'stock' of structural and cultural elements which relate to the individuals' willingness to get involved into collective action also with relative strangers (cf. Esser 2008; Onyx and Bullen 2000; Rossteutscher 2008; van Deth 2008). The actual character and strength of the relationship between trust and the willingness to get involved is subject to discussions. ${ }^{23}$ However, applying the differentiation between trust and confidence permits to disentangle and structure this relationship and opens up an alternative perspective on (political) consumerism: Newton (2008), for example, notes that " [...] trust is a core personality syndrome, and since trust is all of a piece, social and political trust necessarily go together" (2008, 249; see also Uslaner 2002, 7); that is, having high trust in fellow citizens should mirror an overall trusting character. This in turn relates to a willingness to get involved and to get in touch with strangers. Thus, individuals with a high level of generalised trust should

\footnotetext{
${ }^{23}$ For some scientists, trust is a prerequisite for getting involved in collective action: any party has to be able to trust that the other party involved will contribute its part to achieve the collective ambition; otherwise, they assume, due to the fear of being exploited, the first party won't be willing to cooperate (Rossteutscher 2008; see also Ahn and Ostrom 2008; Fafchamps 2004). In contrast, a large strand of social capital research views this also from the reverse: they put forward that the repeated interaction between actors, i.e. essentially civic involvement, is a central means to establish trust (Offe 1999; Putnam 2000, 137). In getting involved, the participating actors can observe each other for a set period of time and based on their observations they then can better evaluate the trustworthiness of the counterpart (Putnam 1993, 172ff.; 2000, 137). Some other authors question that involvement actually generates trust (cf. Seubert 2009, 112ff. \& 192ff.). Instead, one fraction argues that involvement depends on personality (e.g. Uslaner 2008, 108ff.), whereas a second advocates the characteristics of an individual's social environment (e.g. Newton and Zmerli 2011, 25). All taken together, the theories suggest that in the end trust depends on a combination of personality, experiences (involvement), and the precise object that is to be trusted.
} 
be more willing to get involved at all than individuals with little trust. If, in principle, they are willing to engage in political consumerism, they may also be more willing to ponder information concerning the business sector. In so doing, although not being able to directly 'check' whether a firm fulfils what it promises, they can match what they observe against what they consider to be plausible and credible in view of the system in which the firm is operating. The structure of a system as well as the prevalent rules and practices delimit to a certain extent what is feasible for a firm (cf. Aguilera et al. 2007, 843; see also Hall and Soskice 2001, 5; Morgan and Hunt 1994, 20, ref. to Solomon 1992, 26). ${ }^{24}$

So, if the behaviour of a firm deviates remarkably from how companies in the country generally behave citizens may find it hard to give credence to a firm's asserted commitment. But given the case a firm can plausibly deliver its conduct and the values and principles guiding it therein, citizens may gain confidence in it. To convey its conduct, the firm can supply specific information which individuals may then observe and utilise, and from what they observe the individuals can infer whether they may have confidence in the firms' assertions (cf. Pivato, Misani, and Tencati 2008; see also Muthuri, Matten, and Moon 2009). Corresponding to this conception, companies resort to approaches and 'tools' which aim at informing the consumer about firm conduct and/or particular product characteristics. ${ }^{25}$ In the midst of the shift in demands on firms to take over responsibility, this renders knowledge of evolving structures and new practices in the business sector based on which individuals may assess and amend what they should generally expect of the firms, and so gain confidence (cf. Degli Antoni and Sacconi 2011).

These approaches and tools may be relatively loose voluntary engagements, generally falling into the category of so called 'Corporate Social Responsibility' (CSR) or they may entail the adherence to externally set and supervised general standards, typically known as 'Labelling Schemes'. CSR refers to the different ethical, social, and environmental practices of companies and is typically understood as voluntary company action (European Commission 2011; Lin-Hi 2008; Vogel 2008). More specifically, CSR comprises manifold issues including a company’s commitment to ecological production, environmental protection, 'fair' payment and 'fair' working conditions for their employees, as well as the carrying out of projects that promote e.g.

\footnotetext{
${ }^{24}$ Ahn and Ostrom (2008) even regard the 'rules of the game' as institutions $(2008,74)$, that is, as per se a structure of formal as well as informal rules on "what may, must, or must not be done" $(2008,74)$ which shapes collective interaction and the outcome of it. Hence, even though it not entirely compares to the understanding of institutions as is followed in this dissertation, their view underlines the relevance of such 'prescriptions' which guide, structure and delimit behaviour in activities where different actors cooperate.

${ }^{25}$ See, in a similar vein, Stolle and Micheletti, who discuss the facilitating and mobilising role of an information infrastructure or "choice architecture" for involvement in political consumerism. Therein, they especially refer to the presence of labelling schemes and similar informative claims for conferring that information and confidence (2013, $111 \mathrm{ff} . \& 135 \mathrm{ff}$.$) .$
} 
social welfare. Some also initiate community projects or host charity events (cf. Aguilera et al. 2007; Bhattacharya and Sen 2004; Berger, Cunningham, and Drumwright 2004; Koos 2012b). Furthermore, firms increasingly take over political and social responsibilities which traditionally belonged to the state, including the provision of public goods (e.g. education, cultural projects or health care) or the contribution to official regulations (cf. Heidbrink and Hirsch 2008, 15ff.; Scherer and Palazzo 2011, 900-1; cf. also Matten and Crane 2005; Scherer and Smid 2000). By displaying their commitment to concerns beyond their ordinary operations, companies try to differentiate themselves from competitors (Becker-Olsen, Cudmore, and Hill 2006; Pivato, Misani, and Tencati 2008; Smith 2008) and deliver a clear-cut illustration of their norms, values or principles (Aguilera et al. 2007). At the same time, in their doing firms are typically not acting alone. Instead, most projects involve the cooperation with other parts of society, such as for example welfare services, governmental institutions or citizens. In contrast, labelling schemes are mostly regulated by institutions, non-governmental organisations or, in some cases, introduced by companies themselves. They shall inform the consumer about a company's or a product's compliance with a certain standard or norm which is supervised by some (independent) institution other than the company itself (cf. Atkinson and Rosenthal 2014; Berry and McEachern 2005; Lindén 2005; Stolle and Micheletti 2013, 112). However, apart from the introduction and the supervision of the labelled products, these actors are not involved in any further stage. As soon as the labelled products are introduced onto the market it is up to the consumers whether they choose to buy a labelled product, to reject products because they are not labelled, or to disregard the labels (cf. Rousseau and Vranken 2013, 32).

In line with this, labelling schemes are commonly regarded as a market-based approach (Berry and McEachern 2005, 71; Jordan et al. 2003, 162-3; Shaw and Black 2010, 391; Shreck 2002, 14; Stokke et al. 2005, 292; Vogel 2008, 265): labelling schemes work like a 'sign' that is placed on the product comparable to a brand. They refer to certain characteristics or a quality standard and thus are designed to provide additional knowledge about single features of the labelled product (Atkinson and Rosenthal 2014; Shaw and Black 2010). Correspondingly, they line up on the range of purchasing criteria next to brand, price, etc. which are present in the moment of purchase and may guide the buying decision. On the opposite, CSR by definition is not yet a tool that delivers information on product characteristics. Rather, it refers to firm activities precisely beyond the core business (cf. e.g. Aguilera et al. 2007), which need not necessarily touch on the product. Therefore, involvement in CSR is typically not 'visible' in the moment of purchase (cf. Bhattacharya and Sen 2004). Companies usually divulge their engagement and employ it as a means for informing and furnishing confidence in them (Vogel 2008; 
see also Pivato, Misani, and Tencati 2008). But to know about it requires the individual to have actively pursued, perceived and processed information about the respective activities before the moment of purchase. Hence, the individual needs to be interested in getting involved actively and 'cooperate' with a firm beyond the mere market transaction.

Altogether, this entails three central conclusions. Firstly, labelling schemes and CSR relate to very different conceptions of the manner in which companies could comply with demands that regard their environmental, ethical and/or societal responsibilities and duties. Besides, they entail different degrees to which the citizen-consumer itself takes an active part in collaborating with a firm. Similarly, the concept of the state involves distinct conceptions of how responsibility and cooperation in the economic and socio-political context are to be organised. Consequently, the personal concept of the state should influence the preference for one or the other. Secondly, labelling schemes come as externally set and supervised instruments; that is, a party other than the firm (e.g. public institutions, NGOs) is presumed to verify whether the firm actually complies with the standards which the label advocates to certify. The typically voluntary and self-standing nature of CSR in turn does not allow for such an external verification. Instead, individuals can rely only on what they observe and their assessment of it. As a consequence, recurring to CSR or labelling schemes will vary with the confidence one has in firms' voluntary involvement on the one hand, and in labelling schemes and their genuine enforcement on the other hand. As a final point, thirdly, the different backgrounds of labelling schemes and CSR may also translate into different decisions for what or for whom to buycott: labelling schemes are related to the nature and production backgrounds of the product (e.g. organic, eco-friendly, etc.). Accordingly, buying based on labelling schemes means to buycott a product for a particular reason. In contrast, CSR is company related. So, if a citizen decides to buy something because the producing company is acting responsibly it is based on the aim to support the particular firm. In other words, the citizen is buycotting a firm. Finally, in the absence of labelling schemes and CSR where individuals rely in, they may actually desire to express their discontent with the situation. Additionally, they might seek to encourage or pressure firms to implement it. To achieve that, individuals may decide to boycott (cf. Baek 2010, 1066; Hoffmann 2008, $55 \mathrm{ff}$.$) .$

Departing from the notion that trust between individuals and firms is vanishing, this section portrays a more nuanced picture. In conceptually distinguishing between trust and confidence in the sphere of the citizen-consumer it introduces an alternative consideration grounded on two core conceptual dimensions: the notion of confidence, and the view of means which aim at furnishing confidence; respectively, labelling schemes and CSR. So, while trust in firms might 
be vanishing, they resort to labelling schemes or CSR to deliver confidence instead. The structure of the two suggests that preference for one or the other varies with the concept of the state and the individuals' degree of confidence in them. This may affect their comparative prevalence in and across countries, whereas the different character and underlying aims of labelling schemes and CSR may translate also into different types of individual boycotting and buycotting behaviour. ${ }^{26}$

\subsection{Putting the Pieces Together: A Multi-layered Model on Political Consumerism}

The deliberate decision to buy a product clearly seems to be driven by other considerations than the intentional decision to reject buying a product for political, environmental or social reasons: Boycotters want to express their discontent with certain market practices and put pressure for more responsible behaviour. In contrast, buycotting relates to the idea that a firm or a product is behaving 'responsibly' and should be rewarded for this. Simultaneously, despite relatively similar socio-political developments in and across countries, the tendency with which citizens recur to either of the two and the manner how companies as well as the state respond, varies. This advances the central assumption that political consumerism is a process which develops on the country- and the individual levels simultaneously and interacting. Depending on their concept of the state, individuals have different preferences for how concerns in the citizenconsumer realm should be tackled. This resonates on their choice of whether and on how they should get involved in political consumerism. The sum of the individuals' decisions in turn raises singular patterns in a country, in which the process of political consumerism may develop very differently. ${ }^{27}$ Figure 2 and Figure 3 outline the theoretical framework for the development of political consumerism at the country- and at the individual levels.

\footnotetext{
${ }^{26}$ In considering how varieties of capitalism affect product production choices in single countries, Trumbull (2006) discerns a similar mutual process: market institutions influence the decisions and preferences of consumers; yet, in the reverse, prevailing consumer institutions and structures have an important impact on the eventual choices as well $(2006,5-6)$. As a consequence, he points out the paralleling variation of peculiarities of (consumer) demand and product types on offer (Trumbull 2006, 5, ref. also to Kogut 1991).

${ }^{27}$ In a similar vein, Lüdemann (1997) alludes to a 'feedback-process' between supply and demand: companies will be willing to produce (in his case) ecological products if they can expect to sell a satisfactory amount. This depends on the demand which they perceive on the market. However, if such products are not available yet, the demand may neither exist or be readily observable; instead, individuals might need to first make out a possible offer so to then formulate an interest i.e. potential demand. This makes initiating the process difficult (Lüdemann 1997, 23-4; see also Trumbull 2006) - and may lead to comparable but varying developments across countries.
} 
Figure 2. The Process of Political Consumerism on the Country Level

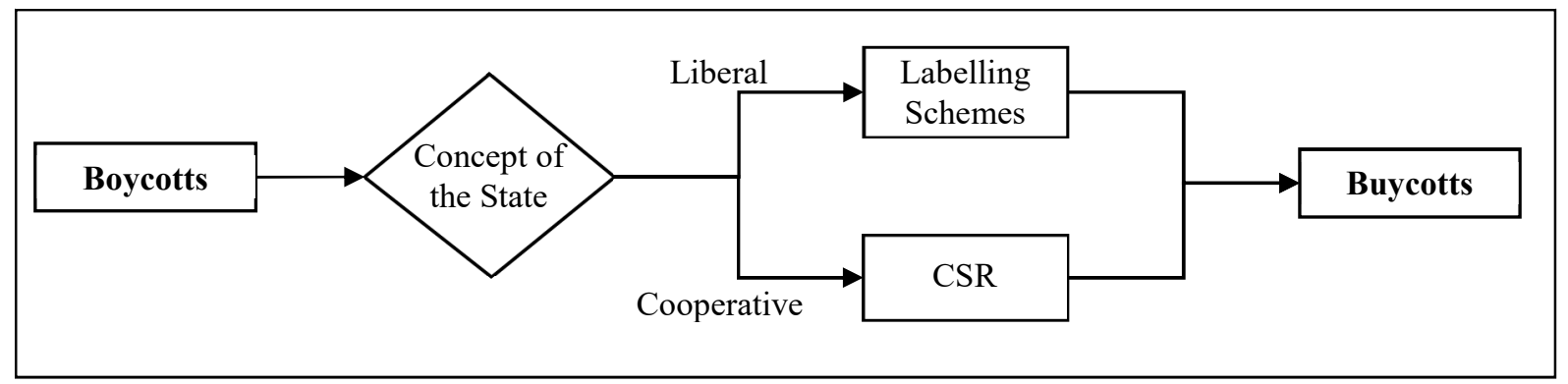

Figure 3. The Process of Political Consumerism on the Individual Level

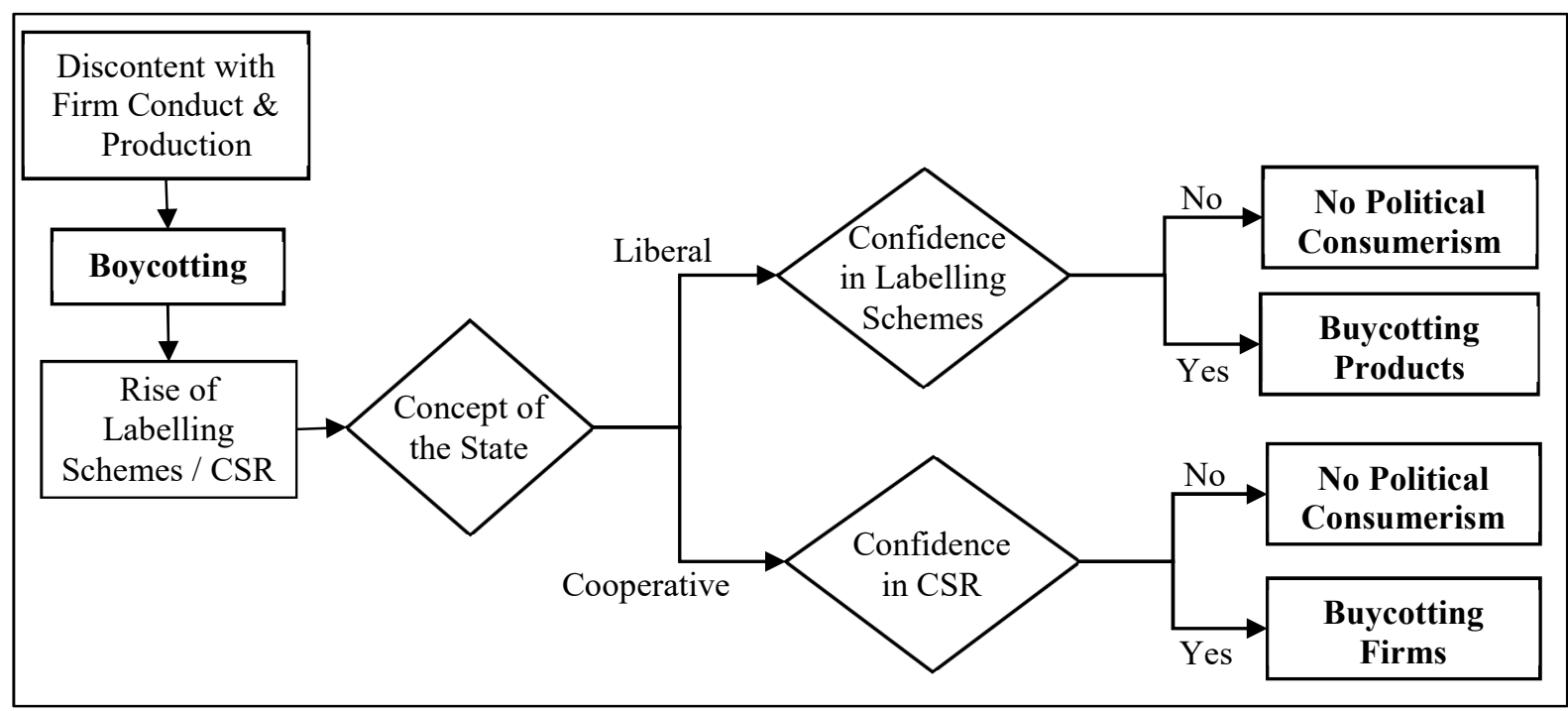

In a first stage, at the individual level (Figure 3), in the absence of responsible conduct citizens may be encouraged to get involved in boycotts to pressure for more responsible practices in firm operations and production processes. Therewith, they may stimulate the creation of labelling schemes and comparable standards. The resulting guidelines allow for differentiating between 'good' and 'bad' firms and/or products. Hence, in a second stage, if the guidelines delivered (1) match the individual citizens' notion of how challenges in the socio-political and economic spheres should be approached, (2) and if they have confidence in the information which these guidelines deliver, individuals may base on it their buycotting decisions. More precisely, some boycotter may get involved in buycotting in addition to the boycott. Alongside them, further citizens might be encouraged to get involved into political consumerism, too. The sum of the individuals' decisions in turn lead to different patterns across countries (Figure 3): In countries with wide-spread involvement in political consumerism, the prevalence of responsible conduct and respective guidelines may be higher than in countries with little involvement. Likewise, depending on which concept of the state predominates in a country, the spread of either labelling schemes or of CSR may be comparatively higher. Accordingly, the comparative 
prevalence of labelling schemes and CSR would vary across countries with different concepts of the state. These distinct macro-level patterns then, again, reverberate on the developments of individual boycotting and buycotting behaviour.

Thus, the core theoretical framework comprises a two-level model on boycotting and buycotting behaviour, where individual preferences and behaviour develop in relation to (1) the general understanding in a country of how cooperation between government, the market and civil society should look like; and to (2) the general spread of CSR and labelling schemes. Consequently, it leads to two related sets of expectations: one with regard to the developments on the country level and a second set concerning the process on the individual level.

Grounded on this, the ensuing subsections develop a more elaborate description of the different connections and integrate them into a thorough explanatory framework. The first subsection outlines the ideas and ensuing expectations which the model propounds on the macro-level, the second subsection centres on the micro-level. Each of the two begins with the most basic consideration of when citizens can be expected to be involved in political consumerism in the first place, and when not. Following this, succeeding hypotheses focus on types of active political consumerism, considering one variety after another. Finally, to close the theoretical part of this dissertation, a third subsection briefly presents an overview of the resultant hypotheses as they will be examined in the subsequent chapters.

\subsubsection{Expectations on the Country Level}

According to the varieties of capitalism, countries can be divided according to predominant types of strategies that are followed in managing the collaboration between actors with different interests in economic- and socio-political matters (Hall and Soskice 2001, 8 \& 13): cooperative, liberal, and 'mixed' approaches, where the last one unites elements of the former two. Analogous to this distinction, two major tools that are typically associated with political consumer actions - labelling schemes and CSR - relate to different conceptions of how cooperation between the state, firms and civil society should look like, and which role corresponds to each of the three actors. The spread of both CSR and labelling schemes is somewhat different across countries. Similarly, the analysis of the European Social Survey 2002/03 reveals varying patterns of buycotting and boycotting involvement across countries (see Figure 1, Chapter 1.2). Taken together, this suggests that the different prevalence of political consumerist activities, of CSR and of labelling schemes are linked to the way in which coordination problems in interactions are typically solved there, that is to say, to the prevailing concept of the state. 
Specifically, the coinciding variations suggest that involvement in the different varieties of political consumerism is varying in parallel and systematically relative to CSR and labelling schemes. In the absence of CSR and labelling schemes, there are no 'anchors' available which may serve individuals as an orientation for political consumerism. Therefore, citizens would remain non-political consumers. Still, the link is not entirely clear-cut: it needs an impetus for the spreading of CSR and/or labelling schemes which active political consumers might give. From this perspective, non-political consumerism would (also) be a source of low CSR and/or labelling schemes prevalence. Nevertheless, the central idea underlying the proposed process of political consumerism is that in their presence, CSR and labelling schemes convey information concerning company conduct and/or product characteristics (Atkinson and Rosenthal 2014; Bhattacharya and Sen 2004; Rousseau and Vranken 2013; Valor 2007). CSR provides clear-cut illustrations of the fact that some firms exhibit a certain concern and commitment for society, while others do not. It facilitates the distinction between the value-sets different companies hold and makes the nature of these differences obvious (i.e. what is 'good' vs. what is 'bad'). Labelling schemes inform about the e.g. environmental or ethical backgrounds of products. Therewith, CSR as well as labelling schemes allow for distinguishing which purchase may support a particular political endeavour and furnish confidence. In creating the option to support firms with clear value-sets and certain types of products, both CSR and labelling schemes make sending political signals easier. Moreover, they render knowledge and so may raise awareness on political concerns relating to consumption (cf. Lindén 2005, 209; Stolle and Micheletti 2013, 166-7). Consequently, their existence is proposed to facilitate buycotting and, overall, to come along with lower fractions of non-political consumers. This leads to the following first expectations:

H1a. ${ }^{28}$ The greater the prevalence of CSR is, the lower is the percentage of non-political consumers.

$\mathrm{H} 1 \mathrm{~b}$. The greater the prevalence of labelling schemes is, the lower is the percentage of non-political consumers.

H2a. The greater the prevalence of CSR is, the higher is the percentage of buycotter.

$\mathrm{H} 2 \mathrm{~b}$. The greater the prevalence of labelling schemes is, the higher is the percentage of buycotter.

\footnotetext{
${ }^{28}$ The set of hypotheses is divided into a fraction which relates to the macro-level and another fraction relating to the micro-level. The word 'macro' comes from the Greek makros, meaning 'long, large'. Therefore, the first set of hypotheses is marked with a capital 'H'. 'Micro' in turn comes from the Greek word mikros, meaning 'small'. Accordingly, the second set is enumerated with a lowercase ' $h$ '. (Oxford Advance Learner's Dictionary, "micro," http://www.oxforddictionaries.com/de/definition/learner/micro\#micro_2, "macro," http://www.oxforddictionaries.com/de/definition/learner/macro).
} 
In lack of CSR and labelling schemes, some citizens may want to pressure and encourage firms to 'do better' and to disclose their conduct. To do so, these citizens may express their demands by rejecting to buy specific products, that is, they may resort to boycotting. A low incidence of CSR and labelling schemes would thus be expected to come along with relatively high numbers of individuals who only boycott. However, this relationship can vary: once citizens have become boycotter, they may not stop doing so as soon as first labelling schemes and CSR have spread out in the country. Hence, at later stages, a large magnitude of boycotting activity can come along with a high incidence of CSR and/or labelling schemes. The actual prevalence of boycotting compared to CSR and labelling schemes can thus be different depending on the stage at which the country under consideration is.

Across countries, political consumerism has started to develop at different times. Accordingly, countries can be at different stages. Therefore, they may exhibit different spreads in spite of having the same concept of the state. Where political consumerism is only recently developing, boycotting may come with little CSR and labelling. In contrast, in countries where political consumerism has already been developing for a longer period of time, firms have had time to respond to political consumer demands. As a result, a high percentage of boycotter may come with high prevalence of CSR and/or labelling schemes there. In view of that, overall, countries are not expected to reveal general bonds: ${ }^{29}$

\section{H3a. The prevalence of CSR exhibits no general bond with boycotting.}

$\mathrm{H} 3 \mathrm{~b}$. The prevalence of labelling schemes exhibits no general bond with boycotting.

Lastly, once CSR and/or labelling schemes are better disseminated, some boycotter may decide to become buycotter, too. In addition, other citizens might consider the 'successes' of boycotter i.e. that firms and other (public) institutions respond to political consumer actions. For that reason, they may decide to join in boycotting and to engage in buycotts based on the labelling schemes and CSR available. In other words, they may become both boy- and buycotter:

\footnotetext{
${ }^{29}$ Specifically, the bonds are expected to be different when comparing the countries at a particular point in time. The framework build up here concentrates on such a point-in-time comparison. Nevertheless, when comparing the progress of boycotting vis-à-vis CSR and labelling schemes across time, the theory would instead expect that countries with an equivalent concept of the state followed a similar course of development. Therefore, in a timeseries analysis, CSR and/or labelling schemes can be expected to exhibit a comparable, general pattern of development in relation to boycotting.
} 
$\mathrm{H} 4 \mathrm{a}$. The greater the prevalence of CSR is, the higher is the percentage of boy-and buycotter.

$\mathrm{H} 4 \mathrm{~b}$. The greater the prevalence of labelling schemes is, the higher is the percentage of boy-and buycotter.

Central to the theoretical framework though is the idea that there is an antecedent to these links: CSR and labelling schemes relate to different types of approaches to deal with sociopolitical concerns. So, each is supposed to be preferred by citizens with different concepts of the state. Similarly, labelling schemes and/or CSR are assumed to facilitate buycotting. As a result, depending on the prevailing concept of the state, buycotting is expected to be more closely related to either labelling schemes or CSR. Countries with similar concepts of the state should exhibit a similar level of involvement in buycotting with respect to the spread of labelling schemes and CSR. More in detail, in countries where a liberal concept of the state prevails, approaches tend to rely on formal contracts and free market competition (Hall and Soskice 2001, 46; Nölke and Vliegenthart 2009, 675). Thus, citizens there should rather prefer formal arrangements like labelling schemes. In contrast, in countries where a cooperative concept of the state predominates approaches typically centre on non-market coordination and cooperation in dealing with socio-political challenges (Hall and Soskice 2001, 46). Citizens there are therefore expected to prefer the rather collaborative CSR. Correspondingly, the magnitude of buycotting should vary relative to either the prevalence of labelling schemes or of CSR depending on whether the prevailing concept of the state in a country is liberal or cooperative, respectively:

\section{H5. In countries where a liberal concept of the state prevails, compared to CSR labelling schemes exhibit a greater relative importance for buycotting than in countries where a cooperative or a mixed concept of the state prevails. \\ H6. In countries where a cooperative concept of the state prevails, compared to labelling schemes CSR exhibits a greater relative importance for buycotting than in countries where a liberal or a mixed concept of the state prevails.}

Lastly, for the so called mixed economies it is more complex to provide expectations. Given the described structures as favouring a separation of the private from the public realm and the presence of a strong state, citizens there might be used to primarily focus on issues that concern the private realm. Moreover, if the state is supposed to already control a large part of business activities, citizens might feel less in charge to intervene and put firms under pressure to change their practices. The result is, on the one hand, less 'pioneers' that set in motion political consumerism and with it the introduction of labelling schemes and/or the increased involvement of firms in CSR. But on the other hand, they are used to rely on informal networks in interactions 
that take place in the economic sphere. Therefore, citizens who have yet decided to buycott should prefer the more informal CSR to labelling schemes. As a consequence, it is expected that:

H7a. In countries where a 'mixed' concept of the state prevails, both labelling schemes and CSR are less present than in countries where a cooperative or a liberal concept of the state prevails.

$\mathrm{H} 7 \mathrm{~b}$. In countries where a 'mixed' concept of the state prevails, CSR is of greater relative importance for buycotting than labelling schemes.

\subsubsection{Expectations on the Individual Level}

\subsubsection{Getting Involved or not in Political Consumerism}

The central proposition of the theoretical framework is that depending on their concept of the state, citizens have distinct preferences on how to approach political concerns. And given that political consumerism is an act of political participation, the citizens' strategy followed when using their consumption for political participation should be guided by these same preferences, too. Accordingly, there are actors focused on broad cooperation between the different parts of society in solving challenges of socio- and economic-political relevance. Correspondingly, they are expected to follow a strategy in political consumerism that allows for addressing the problems in a way that focuses on cooperation and solidarity, too. That is, they deem it the firms' duty to assume societal responsibility as well as their own duty to cooperate with these firms, e.g. by means of purchasing from them. On the opposite there are actors who tend to rely on free market competition and on its ability to yield optimal outcomes. This implies a reliance on that one will automatically choose the 'right' products as long as the market provides for the 'right' choices. Their reliance in the 'market' suggests that it is in particular among the citizens who have a liberal concept of the state where a high level of general trust is decisive for being willing to get involved at all: they need to be able to rely in their co-citizens acting alike, so to together be able to incite a noticeable shift in demand and thereby send a signal to producers. ${ }^{30}$ Thus, general trust can permit them to rely in that the political consumer action can advance political aims through the market. ${ }^{31}$ This, in turn, can nurture the willingness to engage in po-

\footnotetext{
${ }^{30}$ Although the interaction between citizens normally is not one of direct communication, generalised trust applies here given that it entails a direct reciprocity between persons: it is in the best interest of each citizen involved that the other citizen(s) behave the same, since only then they can together fulfil their mutual aim of exerting pressure on a firm. Hence, the persons cooperate in a concrete issue and the outcome directly relates to the respective citizens' behaviour, not to that of an institution.

${ }^{31}$ Otherwise, the level of earnings might not reach a level that is high enough for incentivising to produce the product (cf. Lüdemann 1997, 23-4).
} 
litical consumerism. In contrast, among citizens with a cooperative conception the level of general trust might make little difference for engaging in political consumerism. Their cooperative understanding entails a willingness to collaborate with others in the framework of societal problem-solving processes. In the citizen-consumer domain, this relates in particular to interactions with firms. In consequence, it is also firms which for the individuals are the most relevant counterpart. To be willing to get involved they thus require above all to rely in companies and their societal involvement whilst trust in co-citizens is of minor importance. This leads to the following two first hypotheses:

h1a. Individuals with a liberal concept of the state and a high level of general trust are more likely to be political consumers than individuals with a liberal concept of the state and a low level of general trust.

$\mathrm{h} 1 \mathrm{~b}$. Individuals with a cooperative concept of the state and a high level of general trust are equally as likely to be political consumers as individuals with a cooperative concept of the state and a low level of general trust.

Similarly, it follows that it is the citizens with a liberal concept of the state but little general trust who can be expected to be more likely than any other individuals to neither engage in a buycott nor in a boycott. As they rely on the market as a means for promoting political concerns they must be able to rely on that their purchase can send a signal to the producer. But their individual purchase alone may not incite a noticeable shift in demand. Instead, it requires other citizens to act alike. Thus, to be willing to get involved citizens with a liberal concept of the state require to have trust in co-citizens and be able to rely on them acting alike. If they do not have this general trust, they may rather remain non-political consumers:

$\mathrm{h} 1 \mathrm{c}$. Individuals with a liberal concept of the state and a relatively low level of general trust are more likely than other individuals to be non-political consumers.

\subsubsection{Buycotting Products or Firms}

If the citizens' concept of the state guides the strategy they follow when using their consumption for political purposes, it should also resonate on their choice among the varieties of 
active political consumerism: ${ }^{32}$ Hence, the first line of argument further implies that, depending on the concept of the state, citizens may engage in different varieties of political consumerism.

A cooperative conception entails a focus on cooperation and solidarity. Likewise, a firms' societal involvement reflects such an engagement and thus may be regarded as a collaborative, solidarity-focused approach. In contrast, actors with a liberal conception rely on free market competition and on that one will automatically choose the 'right' products as long as the market provides the 'right' choices. Therefore, they might hold the view that it is by buying based on product characteristics and influencing revenues how they can best induce firms to adapt to shifting demands in society. Labelling schemes are corresponding market-based approaches that allow for differentiating such 'right' products. Following this line of thought, individuals with a liberal concept of the state are expected to rather buycott based on product characteristics i.e. to buycott products. ${ }^{33}$ Citizens with a cooperative concept of the state are in turn expected to be more likely to buycott based on the firm's activities i.e. to buycott firms. Respectively, the expectations are that:

\section{h2a. Individuals with a liberal concept of the state are more likely to buycott products than individuals who have a cooperative concept of the state.}

$\mathrm{h} 2 \mathrm{~b}$. Individuals with a cooperative concept of the state are more likely to buycott firms than individuals who have a liberal concept of the state.

The second line of argument is that confidence, rather than trust, facilitates a positive purchasing decision and that labelling schemes and CSR can deliver such confidence. They are means that permit citizens to distinguish the products and firms which correspond to particular political values or notions from those which do not. Therewith, they allow for distinguishing firms and products in which one can have more confidence compared to the others. ${ }^{34}$ More in

\footnotetext{
${ }^{32}$ In a similar vein, Hoffmann (2014) theorises that cross-country variation of boycotting prevalence is linked to the cultural characteristics, that is, the magnitude of boycotting activity varies with the singular culture. Specifically, he too points to the distinct preferences of people across countries for either individual or collective action taking. And in fact, he finds a positive effect for a culture that emphasises 'institutional collectivism' (i.e. collaborative action and resource distribution) on boycotting prevalence, that is, that culture affects people's view of boycotting as an appropriate means for tackling political concerns. Also, Bair and Palpacuer (2012) stem on the theory of the varieties of capitalism and analyse to what extent different national institutional settings affected the development of anti-sweatshop politics. They, too, observe distinct shapes and ways of framing the approaches depending on the peculiar national institutional environments and political cultures.

${ }^{33}$ See also Boström and Klintman (2006). Though they centre alone on labelling schemes, Boström and Klintman's central proposition rests on the distinction between state- and non-state driven 'symbols' which permit to distinguish products and firms that conform to particular political standards. Thus, their line of argument actually mirrors the proposition presented here: they observe differences in the setups of labelling schemes in Sweden compared to the U.S. and link it to the preference for cooperative approaches in the first case, and a need for fixed standards which can then be integrated in the market-structure in the second.

${ }^{34}$ This idea rests on findings of a former analysis of survey data collected in the framework of my Master Thesis in $2012(\mathrm{~N}=336)$. More concrete, the analysis shows that politically consuming individuals do not necessarily have high trust in societally involved firms, yet more than in firms which are not involved. This excess of trust and, with it, the familiarity with single firms' social involvement suffices as 'anchor' for their positive political buying.
} 
detail, labelling schemes "[...] empower consumers to make informed choices based on the information presented to them on product labels" (Bellows et al. 2008, 4), that is, they convey information relating to the purchase. This can furnish the security that the purchase conforms to its promise of supporting a particular political aim. ${ }^{35}$ In general, labelling schemes touch upon features that directly relate to the product as such and less to the firm and its activities beyond the product. Therefore, confidence in labelling schemes should encourage the involvement in specifically product-based buycotts:

\section{h3a. Individuals who have more confidence in labelled than in non-labelled products are more likely to buycott products than individuals who have no more confidence in labelled compared to non-labelled products.}

CSR in turn typically relates to enterprise activities rather than to product features. It serves as a display of the norms, values or principles a company follows and delivers a clear-cut illustration of the fact that some firms exhibit a certain concern for society and other matters beyond their ordinary operations, while others do not. Thereby it facilitates the distinction between the value sets different companies hold and makes the nature of these differences obvious (i.e. what is 'good' vs. what is 'bad'). Besides, it can be used to verify whether a firm behaves in line with its promises. This alleviates the comparison between companies one can have confidence in and those one cannot (cf. Muthuri, Matten, and Moon 2009; Degli Antoni and Sacconi 2011). CSR thus constitutes a straightforward option to support firms with specific value sets and to send political signals. So, when having more confidence in societally committed firms as compared to in non-involved firms, this can underpin the decision to buycott firms:

$\mathrm{h} 3 \mathrm{~b}$. Individuals who have more confidence in firms that are involved in CSR than in firms that are not involved are more likely to buycott firms than individuals who have no more confidence in involved firms.

From these considerations, it follows that, on the one hand, individuals with a liberal concept of the state and higher confidence in labelled products might be more likely to buycott products than individuals with a liberal conception but no higher confidence. On the other hand, individuals with a cooperative concept of the state and higher confidence in societally involved firms might be more likely to buycott firms than individuals with a cooperative conception but no higher confidence. Nevertheless, citizens with a liberal view precisely rely on the ability of

\footnotetext{
${ }^{35}$ Analogous to this idea, Stolle and Micheletti, for example, observe a close correlation between market shares and sales volume of Fairtrade coffee and organic foods with the percentage of individuals who indicate to have buycotted in a country $(2013,98)$. In line with it, they, too, view labelling schemes as being a crucial element facilitating buycotting by rendering information and transparency. However, they also highlight that in order to be able to 'make use' of labelling schemes, the citizens need to regard the labels as being credible and trustworthy $(2013,111-2)$.
} 
the free market to provide and make visible the best offer. Hence, their conception entails per definition that the comparative features of products allow for discerning the 'right' purchase among the alternatives at hand. This does not necessarily demand for the presence of special labelling schemes. Therefore, having a liberal concept of the state and having confidence in labelling schemes may operate independently from each other as two distinct factors which can influence an individual in the decision to get involved in buycotting. As opposed to it, buycotting a firm implies that individuals enter an interaction in which they reward a company based on its typically self-set societal engagement. This requires the individual to have confidence in the firm. However, in addition it requires the individual to be willing and/or to sense the need for entering a cooperative relationship with the firm. Consequently, having confidence may indeed not suffice to buycott a firm. Instead, whether or not one engages in it might concurrently depend on the individual concept of the state. This leads to the following expectation:

\section{$\mathrm{h} 4$. Individuals with a cooperative concept of the state and a higher confidence in firms that are involved in CSR than in firms that are not involved are more likely to buycott firms than individuals with a cooperative concept of the state but no higher confidence in involved firms.}

\subsubsection{Boycotting}

Neither labelling schemes nor CSR have always existed in a country. The third line of argument thus stems from the observation that it first needs an impetus for their spreading. It needs 'pioneers' who are (1) eager to promote the introduction of such schemes and initiatives, and, for doing so are (2) willing to get involved in political consumerism also in their absence. ${ }^{36}$ Some individuals may in theory have confidence in informative guidelines, yet not in the existing ones. For that reason, they might desire to promote the creation of guidelines and marker in which they can in practice have confidence. This hypothetical confidence might then nurture the willingness to get involved.

Corresponding to this idea, boycotts, on the one hand, serve for expressing discontent with the absence of responsible practices and regulations. Hence, they reflect this lookout for schemes and proofs which may bolster further political consumer activities (cf. Hoffmann 2008, 73-4; Neilson 2010, 223). On the other hand, unlike the buycott, boycotting is geared to the

\footnotetext{
${ }^{36}$ Similarly, Stolle and Micheletti speak of the "small vanguard of committed activists" $(2013,116)$ whose demands give rise to institutions which in turn provide the infrastructure that may facilitate the broader, more widespread political consumerism. Even so, based on their observations of the two organisations standing behind fair trade (Fairtrade International Organization, FLO) and organic labelling (International Federation of Organic Agriculture Movements, IFOAM), they basically conclude with the assertion that the infrastructure, i.e. the existence of institutions providing information, awareness and security, is the more decisive element than the "vanguard activists" in setting in motion political consumerism (Stolle and Micheletti 2013, 116-7; see also 135ff.).
} 
missing or negative information about products and firm behaviour. Accordingly, citizens can make use of it without requiring the existence of labels or similar guidelines as a basis for their action. However, previous studies suggest that boycotter have particularly low levels of general trust (cf. Baek 2010; Neilson 2010). This advances the idea that boycotter must be driven by 'something else' that in the face of low general trust warrants them to be willing to get involved. In its place, it lends support to the suggestion that boycotter want to promote guidelines which can deliver confidence and therewith somewhat compensate for little general trust.

Labelling schemes and CSR represent two types of standards. Labelling schemes are formal guidelines which usually are supervised by multiple institutions (Boström and Klintman 2006). Thus, discontent citizens with little general trust may perceive them as a stringent and credible response to their boycott. By contrast, CSR reflects a mode of societal involvement where firms set the frame of action more or less themselves and devoid of a stern external supervision (Vogel 2008; Aguilera et al. 2007). CSR may thus be perceived as a less 'strict' and reliable variant than labelling schemes. Consequently, it should expressly be labelling schemes which can serve as a potent substitute for low general trust.

Hence, in sum, citizens might pursue to advance the availability of labelling schemes when holding the view that such schemes can inspire confidence. That is, citizens are expected to engage in a boycott in spite of little general trust when having more confidence in labelled than in unlabelled products:

h5a. Individuals who have little general trust yet more confidence in labelled products than in non-labelled products are more likely to boycott than individuals who have little general trust and no more confidence in labelled than in non-labelled products.

Yet, individuals with a liberal concept of the state rely on free market forces. Therefore, they should generally tend to reckon no need for further intervention in the market. Instead, they should have faith in that prevailing market processes would by themselves advance more responsible behaviour and produces (cf. Kang and Moon 2012, 92). ${ }^{37}$ In contrast, having a cooperative conception entails per definition the idea that all actors involved in a process regard it as their responsibility to cooperate and to be willing to invest " [...] in competencies based on relations with others that entail coordination problems" (Hall and Soskice 2001, 22). Correspondingly, citizens with this conception should deem it a duty to assume responsibility and be willing to engage in a collaborative problem-solving process, both of themselves as well as of

\footnotetext{
${ }^{37}$ That is, in the framework of free market competition, responsible practices may turn to be a competitive advantage and a criterion guiding demand similar to e.g. a determined quality or product feature (see Aguilera et. al 2007, 844).
} 
firms. If they perceive products or firm behaviour to oppose certain values or political principles they might sense the need to adjust their own consumption practices respectively and to pressure firms to assume responsibility, too. As a consequence, citizens with a cooperative view are expected to generally be more likely to engage in a boycott to express their claims than citizens with a liberal conception:

$\mathrm{h} 5 \mathrm{~b}$. Individuals with a cooperative concept of the state are more likely to boycott than individuals with a liberal concept of the state.

Nonetheless, a boycott must not only be regarded as a vehicle to express discontent and to influence company practices. Labelling schemes constitute a market based approach (Berry and McEachern 2005, 71; Jordan et al. 2003, 162-3; Shreck 2002, 14) which allows for distinguishing the 'good' from the 'bad' products and thus helps selecting the best offer (cf. Stokke et al. 2005, 292). Hence, as consumers who intend to encourage firms to introduce a new, higherlevel product, citizens with a liberal concept of the state may as well regard boycotting as a means to express a demand for the offer of 'better' products and the creation of labelling schemes that differentiate these products from others. In this case, if the citizens have a sense of confidence in labelling schemes indeed being able to serve the intended goal and to provide a 'superior product' conforming to particular expectations of political nature, they should be willing to act respectively. That is, of the individuals with a liberal view, those having a greater level of confidence in labelled than in non-labelled products might also be interested in promoting the offer of labels and express this by means of boycotts:

h5c. Individuals with a liberal concept of the state and a higher confidence in labelled as compared to non-labelled products are more likely to boycott than individuals with a liberal concept of the state but no higher confidence in labelled versus non-labelled products.

\subsubsection{Boycotting and Buycotting Products}

Finally, the ideas drawn purport that it is especially individuals with a cooperative conception who are most likely to be engaged in both a boycott and a buycott: for citizens who prefer cooperative solutions between the involved parties it is a tacit understanding to take an active role in problem-solving processes among diverse societal actors and to demand the state and firms to act on behalf of these principles, too. Likewise, a consistent finding in previous studies is that boy- and buycotters have an equally low level of trust in institutions as boycotter; lone buycotter in turn appear to have a comparatively high level of trust in institutions (Baek 2010; Copeland 2014a; Neilson 2010). This advances the idea that boycotter and boy- and buycotter 
are actually the same or similar persons. Therewith, it leads to the final line of argument: once boycotters have set the ground by promoting the creation of the marker strived for, boycotter as well as other citizens can make use of those and engage in a buycott in addition to a boycott.

Two aspects tie in here: firstly, the desire to promote guidelines which can furnish confidence and may compensate for little trust is proposed to encourage involvement in boycotting. Thus, citizens first engage in boycotts. Therein they cooperate with other citizens and NGOs to together pressure for more institutional regulation by means of laws, labelling schemes and comparable standards. The resulting schemes allow for distinguishing more clearly the products that correspond to the desired standards from those that do not. Hence, boycotts generate an environment conducive to the buycotting of specifically products, where on the one hand (some) boycotter 'become' boy- and buycotter. On the other hand, further citizens will get to know about the successes and resultant labels and might be encouraged to act alike.

Secondly, labelling schemes usually are the result of a co-operative process. In view of that, citizens involved in the process may not perceive the labels as a device associated with the free market mechanism but as an emblem of collaboration. Citizens guided by a cooperative concept of the state may be willing to make use of the labels. Likewise, from the liberal point of view, this process would reflect too much proactive intervention into market practises.

In conclusion, in boycotting citizens promote the establishment of labelling schemes. Given their partaking in this process, their level of confidence in labelled products generally can be of little relevance. Instead, individuals should be more or less likely to then further engage in a buycott depending on their conception of the role and responsibilities of the self as a citizenconsumer. Specifically, seeking the 'full bandwidth of cooperation', individuals with a cooperative concept of the state are expected to be more likely to boycott and to buycott products than individuals with a liberal concept of the state. This leads to the following, concluding hypothesis:

h6. Individuals with a cooperative concept of the state are more likely to both boy-and buycott products than individuals with a liberal concept of the state.

\subsubsection{Overview of the Expectations}

The theoretical framework propounds 24 hypotheses which consider why individuals get involved in political consumerism in general, and which line of action they might be following more in particular. To close the theoretical section, Table 1 and Table 2 summarise these hypotheses developed. 
The central idea of the drafted model is that particular patterns of labelling schemes, CSR, general trust and concept of the state furnish certain tendencies to be involved in one or another variety of political consumer behaviour. Likewise, in the reverse, single behavioural repertoires are suggested to also nurture the development of certain patterns. In line with it, the hypotheses are organised according to the particular variety of political consumer behaviour that is being considered. In addition, the country level hypotheses are split in two blocks: the first block considers the bivariate correlations of the prevalence of single varieties of political consumerism with the spread of labelling schemes on the one hand, and with CSR on the other hand. This can reveal country-specific 'patterns' of distributions. Based on that, the second block centres on discerning whether particular patterns are steadily associated with a specific concept of the state across countries.

With the development of this set of hypotheses the theoretical part of the dissertation closes. The next step consists in testing the hypotheses. Yet prior to it, the subsequent chapter presents the details of the empirical approach taken, including the methods and data that are going to be employed. 


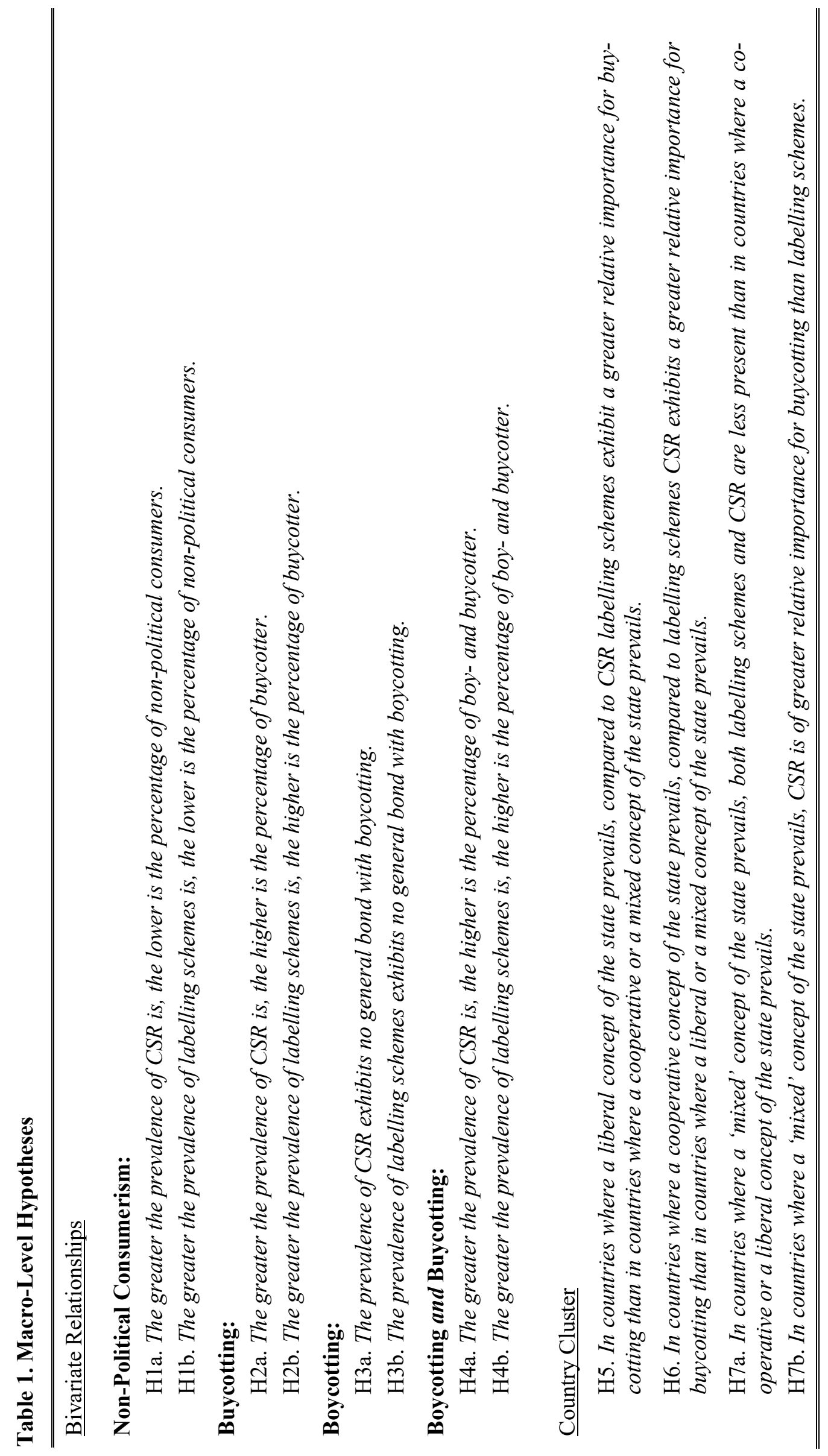




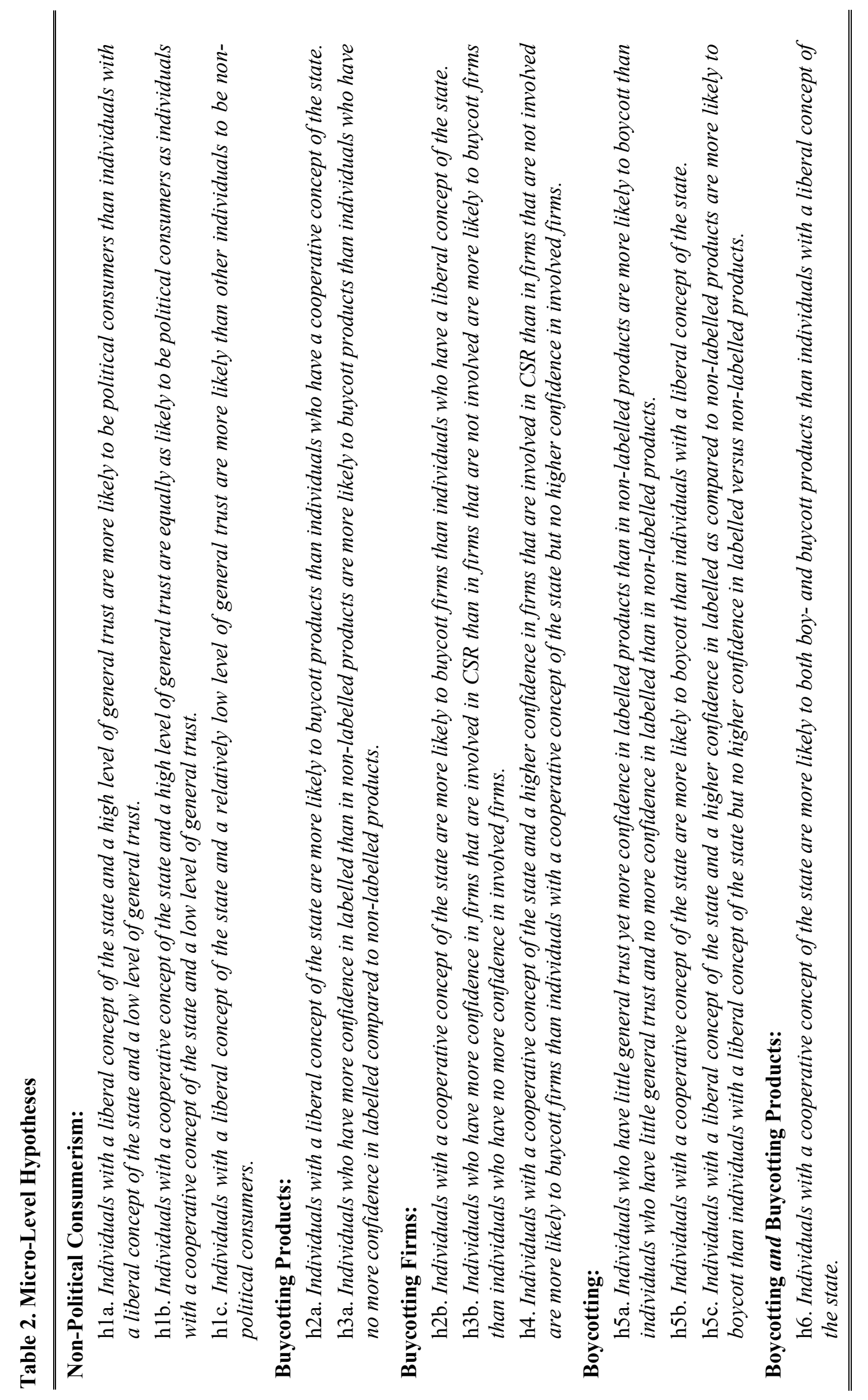




\section{Research Design}

The previous chapter outlined the theoretical backgrounds and drafted an explanation for the dissertation's puzzle. The subsequent chapters now consider empirical data and match it with the explanation proposed. The theoretical model puts forward that political consumerism develops simultaneously and interrelated on two levels. Corresponding to it, the empirical investigation comprises two major parts: a macro- and a micro-level analysis. More specifically, the model emanates from the observation of cross-national differences, and the examination begins at the macro-level with studying the links between the spread of boy- and buycotting, CSR and labelling schemes across countries with different concepts of the state. The second analytical part then turns to the individual. The aim therein is to examine whether individuals with a certain concept of the state and level of trust and confidence are particularly likely to be engaged in singular varieties of political consumerism. Besides, it further reviews whether the conclusions drawn based on country level data can be replicated when using individual level data.

Before turning to the analyses, the subsequent sections introduce the approaches applied for examining each of the two levels. In line with the examination proceeding, the first section sketches the details concerning the country level analysis, including the country selection, the variables and the respective data sources employed. The second section lays out the details of the research strategy undertaken to assess individual level attitudes and behaviour. Furthermore, it presents and briefly discusses the resulting sample used for the examination of the hypotheses at the individual level.

\subsection{Design of the Country Level Study}

\subsubsection{Analytical Strategy and Method}

The theoretical assumptions for the macro-level expect country-specific 'patterns' of distributions in labelling schemes, CSR and political consumer behaviour as well as particular patterns to be associated with a specific concept of the state. These patterns are understood as collective general characteristics prevailing in a country. Thus, the unit of analysis is the country (cf. Graeff 2014). Further, the assumptions relate involvement in single varieties of political consumerism to factors extending on two dimensions: the spreads of labelling schemes and CSR in a country; and, second, the varying predominance of either labelling schemes or CSR across countries depending on the prevailing concept of the state. These assumptions in turn comprise two considerations: the existence of a bond as well as the direction of the connection. 
Taken together, this puts forward a research strategy involving two stages and a methodological approach built on three concerted pillars.

The opening eight macro-level hypotheses deal with bivariate relationships (H1a-H4b). Accordingly, a first pillar covers bivariate correlation analyses which explore whether the levels of prevalence of CSR, labelling schemes and single types of political consumer behaviour display paralleling tendencies from country to country. Building on the respective findings, the second pillar examines the relationships in OLS regressions. Regression models permit to discern to which extent one variable influences the development of another variable (cf. Agresti and Finley 1997, 303; Woolridge 2003, 22-3). Thus, this approach allows for appraising whether labelling schemes and CSR relate to single varieties of political consumerism in the expected sequential mode or whether these variables may only happen to coincide or develop differently than expected.

In the next stage, to examine the hypotheses expecting systematic alignments of countries (H5 to $\mathrm{H} 7 \mathrm{~b}$ ) in relation to the prevailing concept of the state, a third pillar involves clustering countries according to visible patterns. Specifically, the theory assumes that the prevailing concept of the state in a country influences the spread of labelling schemes and CSR and that their spread in turn constitutes the basis for buycotting. In view of that, the analysis explicitly centres on buycotting. Its comparative prevalence relative to labelling schemes and CSR can, firstly, reveal whether patterns indeed are similar within clusters of countries with a same concept of the state, and different across them. Secondly, it may tell to what extent buycotting prevalence varies more strongly with respect to either the presence of labelling schemes or CSR depending on the concept of the state. To this end, hierarchical clustering is applied relying on 'Ward's Method'. Corresponding to the hypotheses, this technique centres on internal cohesion and therewith allows for systematically discerning and clustering countries according to the relative similarity of their patterns (cf. Brosius 1998, 711; Everitt et al. 2010, 76ff.; Zaki and Meira 2014, 366ff.). ${ }^{38}$

To be able to compare the relationships throughout countries, the study relies on a crosssectional set-up. To cover variability, testing the hypotheses requires a selection of two or more

\footnotetext{
${ }^{38}$ Using an agglomerative clustering algorithm, the hierarchical cluster analysis following Ward's method begins with $\mathrm{n}$ cluster comprising one 'member' and then joins them step by step according to proximities (or similarities) until all members are included in one cluster. Proximities are therein defined in terms of the degree to which the within-cluster sum of squared errors increases when merging two clusters; this increase shall be held minimal at each merger (cf. Brosius 1998, 711; Everitt et al. 2010, 76ff.; Zaki and Meira 2014, 366ff.). The hypotheses propose that the relative importance of labelling schemes/CSR for buycotting is comparatively higher in some countries depending on the concept of the state. Thus, countries within a cluster are expected to exhibit similar (i.e. close) bonds. In line with it, Ward's method seeks to keep in-group variance minimal; therewith, it delivers the basis for systematically aligning countries according to such proximities.
} 
countries for every variety of the concept of the state. ${ }^{39}$ However, to minimise the risk of attributing findings of patterns across countries to the concept of the state mistakenly, the selection may concentrate on countries which exhibit comparable underlying structures but different conceptions of how cooperation within these structures should be managed. This advances three criteria which the selection of countries needs to fulfil: firstly, the countries should all be liberal democracies; there, individuals may be considered without reservation as being able to freely and deliberately decide to get involved in political consumerism or not. ${ }^{40}$ Likewise, labelling schemes and CSR can develop rather freely as well. Secondly, all countries included should classify as 'developed' economies with a corresponding middle to high standard of living. More specifically, the citizen-consumer arises a setting in which basic material needs are satisfied and an immense freedom to define the 'self' persists (see Chapter 2.2). Hence, financial leeway is one important aspect in opening up in the first place the possibility to make use of consumption as a tool to express the 'self' and one's political ambitions. Thirdly, the countries should share a relatively close common (cultural) heritage. Indeed, the concept of the state flows from the idea that institutional structures condition the distribution of patterns, and the structures are in turn shaped by national circumstances like culture, history, etc. Different circumstances thus frame the variation in the concept of the state (see Chapter 3.1.2; Hall and Soskice 2001, 15). However, a large difference in the countries' background can easily blur the sources of possible differences found across countries. 'Controlling' for a somewhat common (cultural) background allows for separating more clearly the underlying structures of the views on how cooperation within these structures should be managed. If patterns exist, this separation permits to more confidently attribute visible variances to the concept of the state.

A respective composition constitutes a subset of European states. The geographical area of Europe covers the largest number of countries which fulfil all three criteria: 37 countries or 88 percent of European countries classify as free democratic states, comprising 86 percent of the population living on the continent (cf. Freedom House 2015, 13). Of these 37, 33 are so-called developed or high-income economies while only 4 range within the upper-middle income category (cf. World Bank Group 2015; see also e.g. Gallup 2013; UNDP 2014, 220). Excluding very small autonomous (city) states ${ }^{41}$ leaves out of the 33 free democratic countries with comparable standards of living, 29 countries. Given their geographic proximity and entangled history, among others, they all share a relatively close common heritage (cf. Stratenschulte 2014,

\footnotetext{
${ }^{39}$ Accordingly, it requires for the minimum two countries which may be classified as liberal, two cooperative and two with a 'mixed' concept of the state.

${ }^{40}$ See in this regard also Stolle and Micheletti 2013, 24-5.

${ }^{41}$ Andorra, Liechtenstein, Monaco and San Marino.
} 
7). Still, the countries differ in important aspects surrounding the views on how cooperation between the state, the market and civil society should look like and which preferred balance between collaboration and free market competition predominates (cf. Esping-Andersen 1990; Hall and Soskice 2001). The concentration on Europe may limit the generalisability of the findings. Yet, in systematically combining countries from various European regions into a final set allows for covering a relatively broad range of countries. This leads to the choice to combine 20 countries: four Central-, four Middle-, four Northern-, four Southern and four Western (i.e. Benelux and the British Isles) European countries (encirclements in Figure 4).

\section{Figure 4. Selecting European Countries}

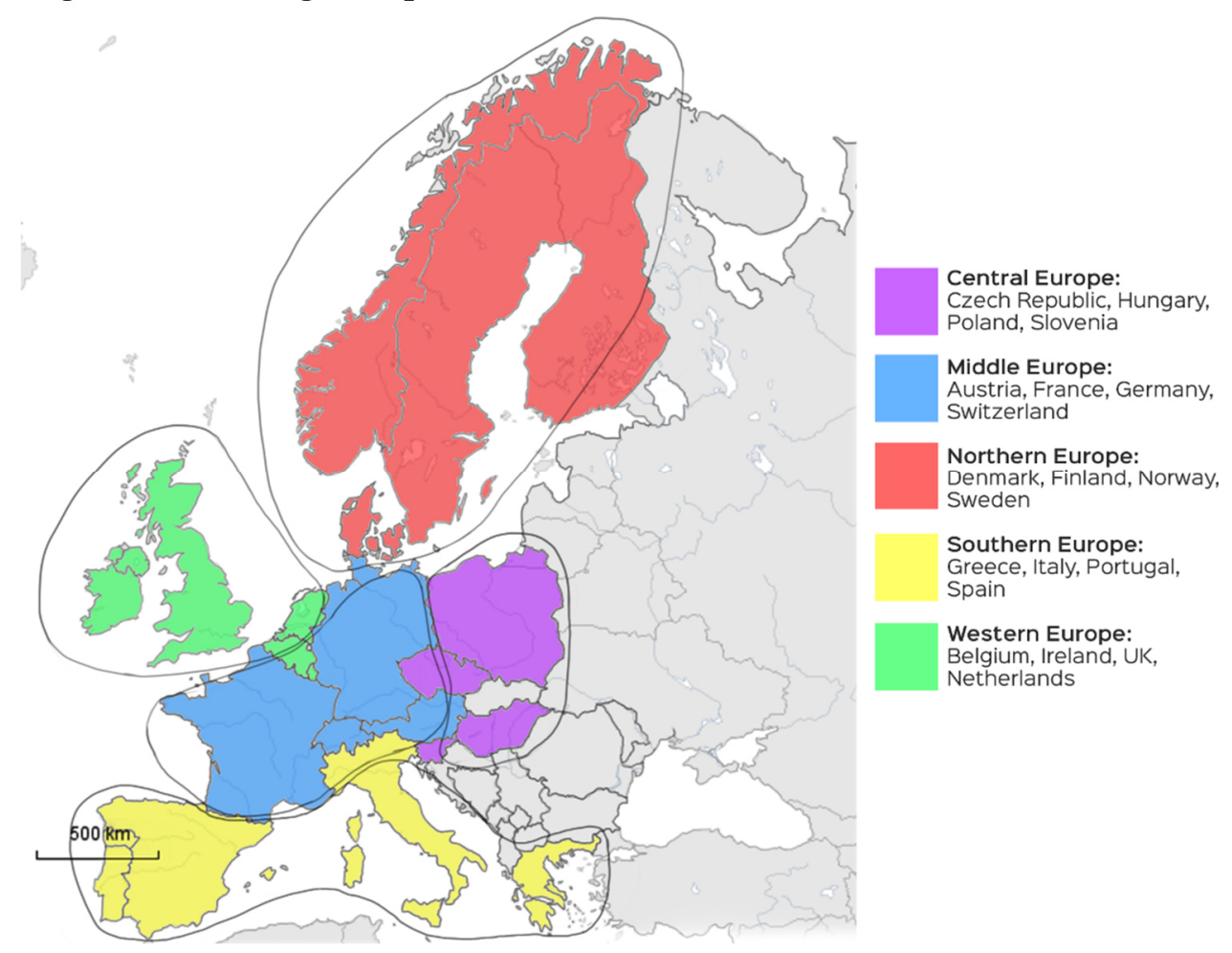

The European Social Survey (ESS) provides a corresponding data set. It covers 36 European countries from various regions across several years. The first round $(2002 / 03)$ shares the advantage that it offers data for the central variables of the analysis, i.e. boycotting and buycotting behaviour on a corresponding number of European countries of the designated regions. ${ }^{42}$ Figure 4 depicts the four countries chosen for each region of the ESS data set. This selection of countries yields a wide ranging sample which encompasses variability in the conceptions on how cooperation shall be managed. But at the same time, it renders a practical as well as efficient approach for gathering an impression of the theoretical assumptions' plausibility.

\footnotetext{
${ }^{42}$ The data set covers 22 countries in total. Since not belonging to Europe, Israel is excluded. Furthermore, also Luxembourg is excluded as it is neither covered by varieties of capitalism theory nor by the employed CSR-Index (see Chapters 4.1.2.2 and 4.1.2.4). In the result remain 20 countries.
} 
This specified, four main aspects need to be operationalised and gathered in one comprehensive data set: (1) political consumerism, or more specifically, buycotting, boycotting, boyand buycotting, and not consuming politically at all; (2) the spread of labelling schemes in a country; (3) the magnitude of firm involvement in CSR in a country; and (4) the concept of the state. The particular combination of variables could not be acknowledged as being united in an existing data set. Therefore, the data employed rest on different sources. The subsequent section presents the variables and their sources more in detail.

\subsubsection{Creating a Cross-National Data Set}

\subsubsection{Boycotting and Buycotting}

The central assumption of this dissertation is that boycotting and buycotting constitute two inherently different types of activities. Selecting a proper source for this variable thus hinges on the availability of data that covers the two as separate aspects. Further, emanating from this idea, the theoretical framework considers the relative extent to which citizens have deliberately bought or rejected to buy out of political considerations within a country as well as in comparison with other countries. Accordingly, additional criteria for selecting a proper indicator are that it delivers information (1) about the relative number of individuals who are engaged in it in a country and (2) for the European countries selected.

Few sources provide data on boycotting and buycotting behaviour as two separate variables and cover multiple countries. The first round of the European Social Survey (ESS) fielded in 2002/03 is one of the very few larger scale surveys which includes such two separate questions and covers various European countries. Therefore, this round serves as the source for the dependent variables. The two separate questions on boycotting and buycotting behaviour ${ }^{43}$ permit to create a variable for each of the four basic varieties of political consumerism: boycotting only, buycotting only, doing both boy- and buycotting, and non-political consumerism. The values of the variables denote the percentages of survey respondents per country who indicated to have engaged in the respective type of political consumerism. Figure 5 displays the percentages of individuals who have buycotted, boycotted or both boy- and buycotted across countries.

\footnotetext{
${ }^{43}$ The specific wording is: "There are different ways of trying to improve things in [country] or help prevent things from going wrong. During the last 12 months, have you done any of the following? [B21] Boycotted certain products/ [B22] Deliberately bought certain products for political, ethical or environmental reasons"; see the ESS1 Source Main Questionnaire (European Social Survey 2002a) and ESS1 Appendix A3 ed. 6.4 (European Social Survey 2014, 16-7).
} 
Figure 5. Boycotting and Buycotting across European Countries (in Percent)

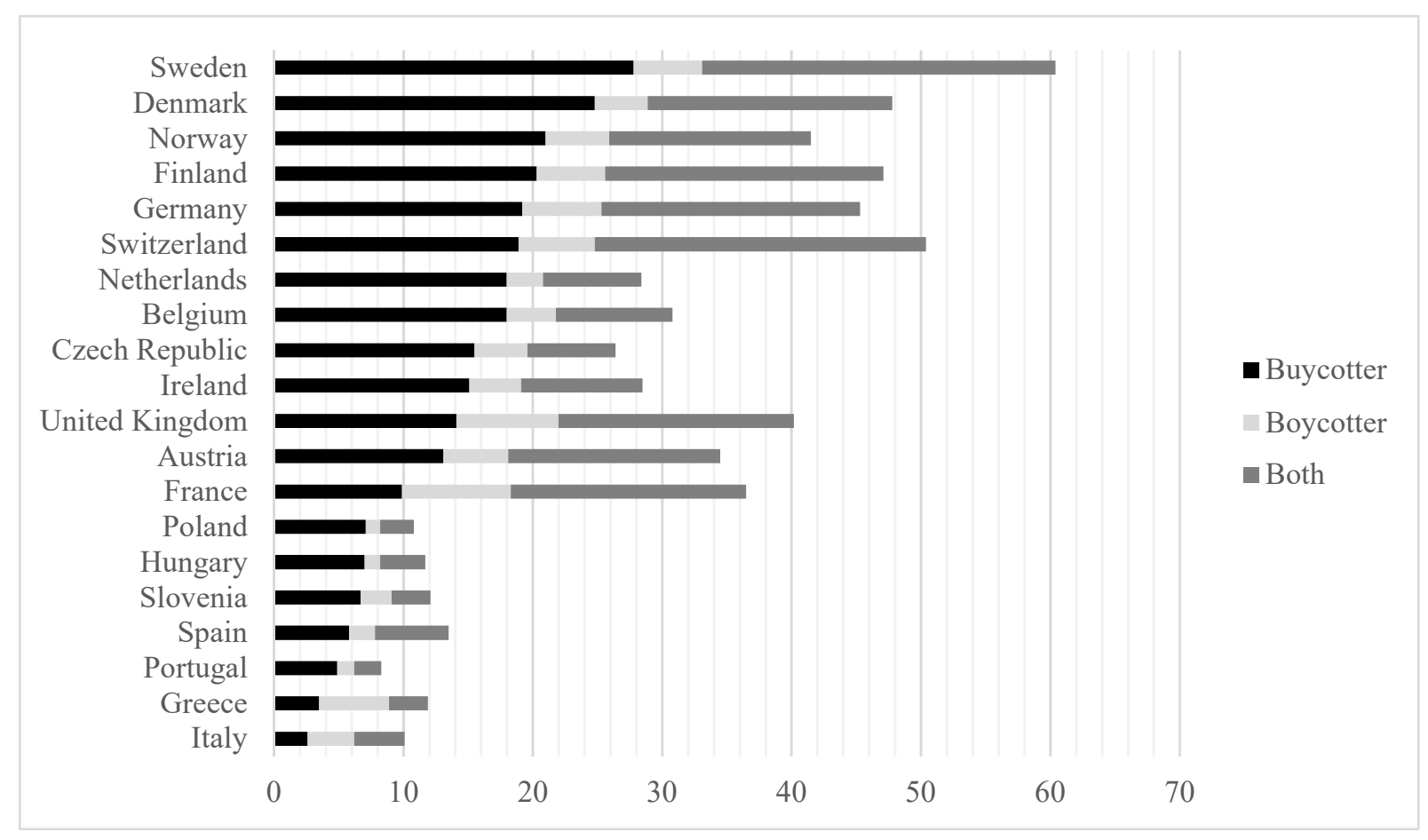

\subsubsection{The Concept of the State}

The concept of the state refers to the view on how cooperation between the state, the market and civil society should be managed. For the country level, a suitable variable would thus gather whether these actors in a country overall appear to rather follow collaborative or more liberal and market-logic driven approaches towards solving challenges of socio-political and economic relevance. Seeing that the concept stems from Hall and Soskice's theory on the Varieties of Capitalism, their theory also serves as reference for classifying countries according to the prevailing concept of the state (cf. Hall and Soskice 2001, 19-21).

All but four countries included in the analysis (the Czech Republic, Hungary, Poland and Slovenia) are already considered by Hall and Soskice (2001). The countries which Hall and Soskice classify as 'liberal' market economies are introduced in the data set as countries where a liberal concept of the state predominates (the UK and Ireland); 'cooperative' market economies as countries with a 'cooperative' concept of the state (Austria, Belgium, Denmark, Finland, Germany, Netherlands, Norway, Sweden, and Switzerland); and their 'Mediterranean' market economies are included as countries having a 'mixed' concept of the state (France, Italy, Spain, Portugal, Greece).

The Czech Republic, Hungary, Poland and Slovenia are not classified yet. However, alike several of the 'Mediterranean' economies, these countries have only recently left behind autocratic state structures. This has resulted in the prevalence of structures that favour a highly- 
interwoven relationship between the state and the business sector as well as a high relevance of informal networks. In managing societal processes, rather than relying on market competition and formal contracting, the different actors rely on coordination and cooperation; yet, as in the case of the 'Mediterranean' economies, this cooperation takes place in a narrow realm among a private subsample of actors (cf. Nölke and Vliegenthart 2009, 677-8). That is, the focus rests on the private and the informal. Accordingly, these four countries overall display close parallels to the 'Mediterranean' economies and, for the purpose of this analysis, they are placed into the cluster with a 'mixed' concept of the state. In the end, the data set includes two countries with a 'liberal', nine with a 'cooperative' and nine with a 'mixed' concept of the state (Table 3 ).

Table 3. Country Classification According to the Concept of the State

\begin{tabular}{cc}
\hline \hline Concept of the State & Countries Included \\
\hline Liberal & Ireland, the UK \\
Cooperative & Austria, Belgium, Denmark, Finland, Germany, \\
& Netherlands, Norway, Sweden, Switzerland \\
Mixed & Czech Republic, France, Greece, Italy, \\
& Hungary, Poland, Portugal, Slovenia, Spain \\
\hline \hline
\end{tabular}

\subsubsection{Labelling Schemes}

The macro-level hypotheses (H1b, 2b, 3b and H4b as well as $\mathrm{H} 5$ to H7) relate to labelling schemes in terms of their spread in a country. A proper indicator therefore needs to reflect the comparative degree to which labelling schemes are available and purchased in a country. Specifically, looking at the mere number of existing labelling schemes per country does not necessarily tell whether citizens actually 'make use' of them, i.e. purchase the labelled products. More telling can be comparing sales data for one or more equivalent labelling schemes across countries: at comparable levels of economic development and disposable private income, higher/lower sales in one than in another country may indeed reflect a comparatively greater/smaller spread. Next to that, a second important criterion is the capped breadth. That is, the label(s) should apply on multiple types of products so as to be able to absorb possibly from country to country differing consumption preferences.

A labelling scheme which applies on a wide range of products is the 'Fairtrade Label' (cf. Fairtrade International 2013). Four more reasons underpin the choice of this label as a general indicator for labelling schemes: first, its requirements (i.e. the standards it stands for) are uniform in all participating countries. Second, these standards are not set by the state or other public institutions but by a private global organisation. The labelling operates independently 
from national structures such that it rather compares to how 'conventional' products are introduced and managed on international markets. Therewith, the label works as a good proxy of a market-based approach. ${ }^{44}$ Third, it is available in nearly all countries that shall be included in the analysis, and in those countries where it is not available this appears to merely be due to the fact that labelling schemes are still little popular there. Fourth and most important, precise data in terms of retail sales per country ${ }^{45}$ per year are available. ${ }^{46}$ This assures a systematic, objective comparison.

To account for the distinctive population distributions across the countries covered, the label is operationalised as per capita retail sales of Fairtrade-labelled goods in a country in the year 2011 (in Euro) ${ }^{47}$ As can be seen in Figure 6, the values of the resulting variable for labelling schemes range from zero (representing no sales volume) in Greece, Hungary, Poland, Portugal and Slovenia up to roughly 34 Euro per capita spent by citizens in Ireland and Switzerland. In between, rather than gathering at singular clusters, per capita sales rise quite continuously from country to country, extending from 5 to 19 Euro per capita.

\footnotetext{
${ }^{44}$ See the organisation's self-concept in Fairtrade Labelling Organizations International 2011.

${ }^{45}$ Sales data refer to the estimated retail sales values of both consumer retail sales (i.e. sales in stores and supermarkets) and the out-of-home sales (i.e. in sales in e.g. cafés, restaurants) in sum. For more information, see Fairtrade International 2013, 13.

${ }^{46}$ Unfortunately, country-wise data on retail sales is not available for the years 2002/03 i.e. when the here employed data on political consumerism was collected. Nevertheless, according to the theory it is the national concept of the state which influences political consumers in their behaviour and thus a concept that should be expected to remain stable over the years. As a result, the tendency of an individual to prefer labelling schemes or CSR should remain mostly the same, too. Still, to minimise the risk of a possible bias a good alternative constitutes using the data available for 2011: it is the (1) most recent annual data available on Fairtrade sales which at the same time surges a (2) general economic state across Europe that compares very well to that in 2002/03 (in terms of real GDP growth; cf. Eurostat 2014). So, when disregarding GDP growth, the most recent data is available for the year 2013, yet the economies of most of the countries included in the analysis were shrinking in that year. By contrast, economic growth in 2011 compares very well to that in 2003 (cf. Eurostat 2014). Considering this comparability is important, seeing that labels in general and the Fairtrade Label in particular come with a price premium (cf. Stolle and Micheletti 2013, 71 \& 108ff.; see also Shreck 2002; Stokke et al. 2005) which may avert consumers from buying it in economically difficult times (cf. Flatters and Willmott 2009, 7). Therefore, using data on sales of years in which comparable economic circumstances to the situation in $2002 / 03$ prevailed provides a more reliable alternative for observing the relative tendencies which the different countries exhibit. ${ }^{47}$ Population as of January $1^{\text {st }} 2011$, based on the EU Census carried out in specifically that year (Eurostat 2015a).
} 
Figure 6. Fairtrade Sales in Europe (in EUR per capita for the year 2011)

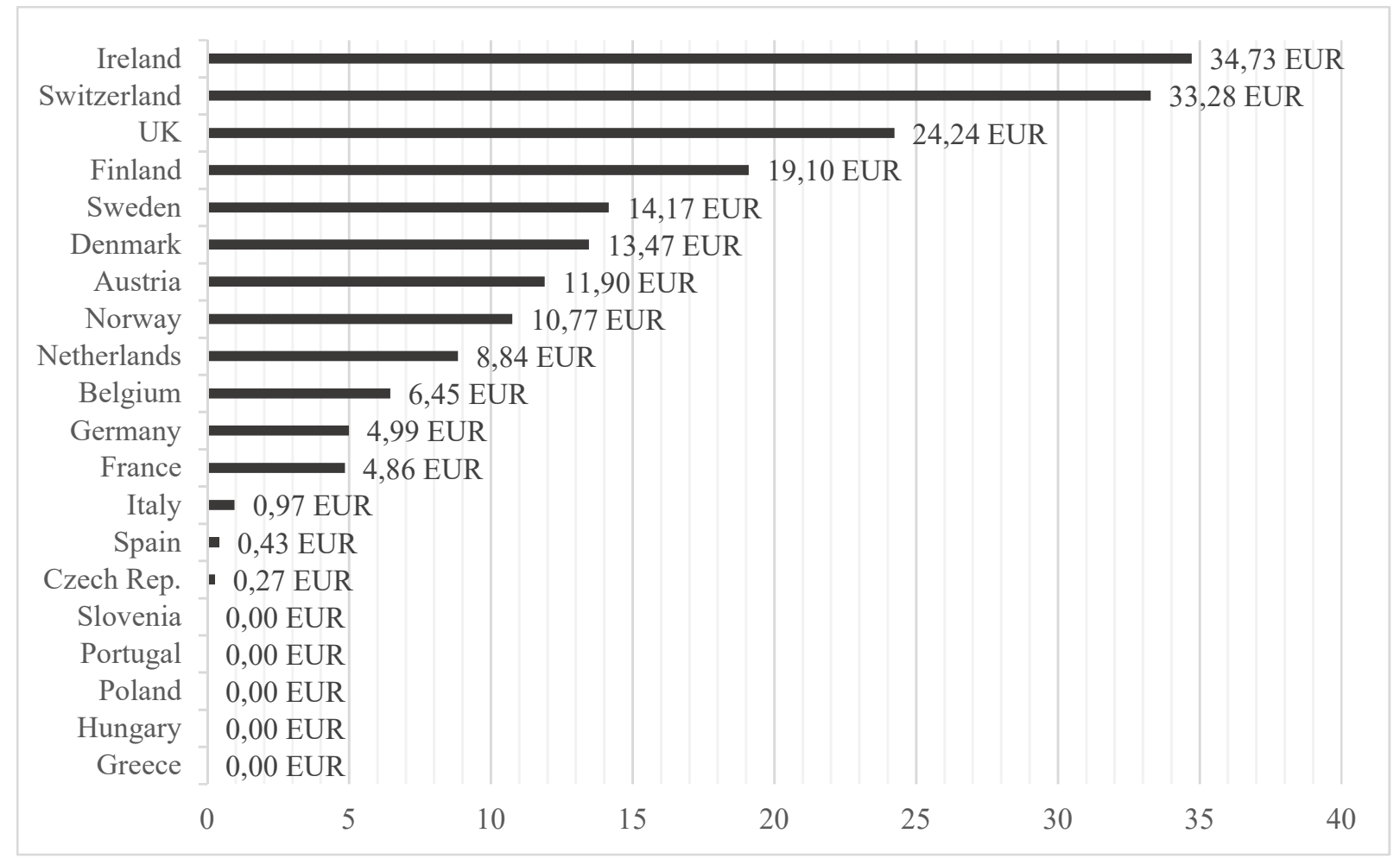

\subsubsection{Firms Societal Involvement}

The theoretical framework considers CSR as the comparative degree to which firms in a country are involved in activities which go beyond mere adherence to rules and regulations in their environmental, societal and ethical practices. Nevertheless, in difference to labelling schemes it relates to company activities. Therefore, sales data would not qualify as an indicator. Instead, a suitable indicator may reflect a combination of the companies' environmental performance, their conduct with respect to employees, involvement in community projects, and more.

A measure that gauges the magnitude to which companies are considerate of their responsible conduct per country is the "National Corporate Responsibility Index 2003" (NCRI). Developed and published by MacGillivray, Sabapathy, and Zadek (2003) for the NGO AccountAbility in the framework of developing a "Responsible Competitiveness Index", ${ }^{48}$ the index captures countrywide performances of companies in fields such as corporate governance, the dealing with employees, engagement with civil society and the environment, and the ethics of their business practices. ${ }^{49}$ Accordingly, it rests on a comprehensive assessment of the extent to

\footnotetext{
${ }^{48}$ See MacGillivray, Sabapathy, and Zadek 2003, 21-2.

49 The index covers 51 countries worldwide and relies on multiple sources including Freedom House, Transparency International, the World Bank and the World Economic Forum. The eventual index comprises 7 components, each of which builds upon 3 to 5 different indicators (MacGillivray, Sabapathy, and Zadek 2003, 25-6). The detailed composition is provided in Appendix A.5.
} 
which firms are dedicated to CSR in one country relative to the others. The index spreads from 0 to 100 , though the actually highest rating reaches Finland with 78, the lowest Indonesia with 39.

The 2003 index is available for all but two countries included in the analysis, ${ }^{50}$ and for these two an approximated index could be calculated by help of a later similar index. ${ }^{51}$ In the final sample, the values stretch from the 78 of Finland down to a rating of 52 for the Czech Republic and Poland. Figure 7 gives a picture of the comparative company performance in terms of Corporate Social Responsibility across the twenty European countries in question. Overall, the Northern and Middle European countries perform comparatively well on the index, ranging between values of 75 and 65. The Southern and Central European countries in turn perform poorer, with the exceptions of Spain and Slovenia. They reach similar levels as in Ireland and Germany.

Figure 7. CSR in Europe (as Index Value for the Year 2003)

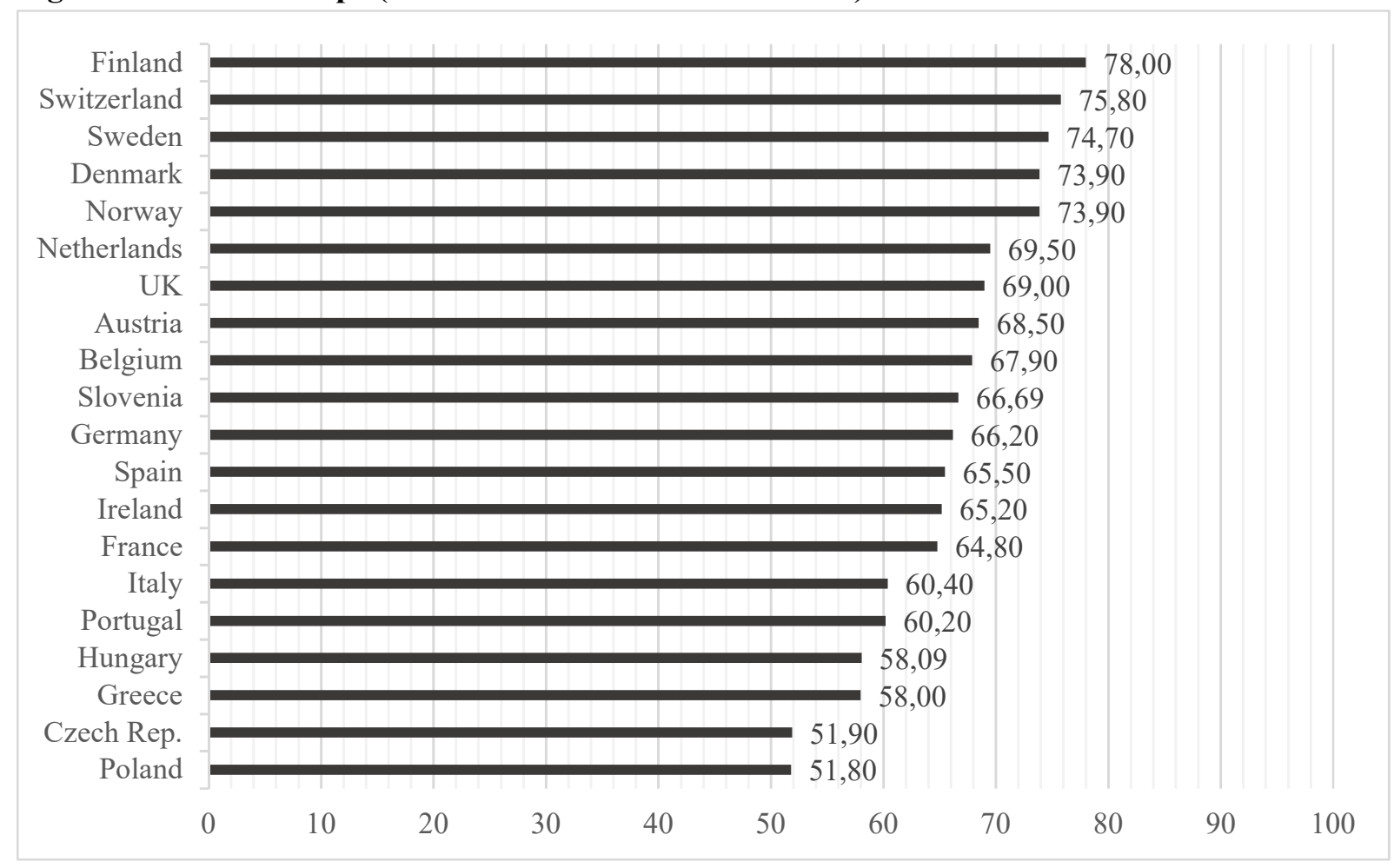

\footnotetext{
${ }^{50}$ Hungary and Slovenia; see MacGillivray, Sabapathy, and Zadek 2003, 28.

51 The later index was published in 2005 . The approximated index has been calculated as follows: Country Index $2003=$ Country Index 2005 (SLO/HUN) + [sum ((Country ${ }^{k}$ Index 2003 - mean Index 2003)-(Country ${ }^{k}$ Index 2005 - mean index 2005 of countries k))/no. of countries k] + [(Country Index 2005 (SLO/HUN)) - (mean Index 2005)], where $\mathrm{k}=$ countries with Index for 2003. Further information can be attained in Zadek, Raynard, and Oliveira 2005.
} 


\subsubsection{Overview of the Country Level Data Set}

To conclude this section, Table 4 provides an overview of the various variables with their sources. They provide for a comprehensive data set which covers multiple countries as well as all variables needed for testing the macro-level hypotheses. The range of countries is broad and they perform quite differently on the various variables. This allows for variance in the sample. In sum, although from varying sources, for all variables and country cases indicators are available.

Table 4. Overview of Country Level Variables

\begin{tabular}{|c|c|c|c|}
\hline Variable & Values & Main Data Source & Data Year \\
\hline Countries & $\begin{array}{l}\text { Austria, Belgium, Czech Republic, } \\
\text { Denmark, Finland, France, Germany, } \\
\text { Greece, Ireland, Italy, Hungary, } \\
\text { Netherlands, Norway, Poland, Portu- } \\
\text { gal, Slovenia, Spain, Sweden, Swit- } \\
\text { zerland, the UK }\end{array}$ & $\begin{array}{l}\text { Round 1, } \\
\text { European Social Survey }\end{array}$ & $2002 / 03$ \\
\hline $\begin{array}{l}\text { Political } \\
\text { Consumerism }\end{array}$ & $\begin{array}{l}\text { Percentage of individuals/country } \\
\text { involved in boycotting, buycotting, } \\
\text { boy- and buycotting, non-political } \\
\text { consumerism }\end{array}$ & $\begin{array}{l}\text { Round 1, } \\
\text { European Social Survey }\end{array}$ & $2002 / 03$ \\
\hline Concept of the State & Cooperative, Liberal, Mixed & $\begin{array}{l}\text { Varieties of Capitalism, } \\
\text { Hall and Soskice (2001) }\end{array}$ & 2001 \\
\hline Labelling Schemes & $\begin{array}{l}\text { Per capita retail sales of Fairtrade- } \\
\text { labelled goods in a country/year }\end{array}$ & Fairtrade International & 2011 \\
\hline $\begin{array}{l}\text { Corporate Social } \\
\text { Responsibility }\end{array}$ & $\begin{array}{l}\text { Index value }(0-100) \text { on the "National } \\
\text { Corporate Responsibility Index" }\end{array}$ & $\begin{array}{l}\text { Responsible Competi- } \\
\text { tiveness Index, } \\
\text { MacGillivray, Sabapa- } \\
\text { thy, and Zadek (2003) }\end{array}$ & 2003 \\
\hline
\end{tabular}

\subsection{Design of the Individual Level Study}

\subsubsection{Analytical Strategy and Method}

The individual level hypotheses state that the mode of political consumer behaviour varies with respect to the particular combination of concept of the state and degree of confidence in labelling schemes and CSR an individual has. Thus, the unit of analysis is the individual. Its examination needs recognising and comparing individuals' (1) political consumer behaviour; (2) their attitudes towards the roles of the state, the market and civil society; (3) and their level of confidence in the claims or promises attached to firm's voluntary societal involvement and in labelling schemes. 
Surveys constitute an efficient and practical approach to collect information on behaviour and attitudes of individuals. Consistent with the demands of the hypotheses, surveys provide a snap-shot of links at a point in time and therewith an impression of correspondences and tendencies (cf. e.g. Rea and Parker 2014, 7; Stein 2014, 142). Very few existing surveys consider individual attitudes toward labelling schemes, firms or the comparative roles of the state and the market. ${ }^{52}$ And of these, none could be acknowledged which provides suitable variables or indicators in a single data set. Likewise, the distinction drawn between buycotting of products and firms is rather novel and does not appear to have been covered in a general survey yet. As a consequence, the micro-level analyses rest on a newly conducted survey whose design was guided by four general objectives: the final sample should be large (i.e. in terms of the number of participants), representative of the general population, comprehensive, and deliver (random) variance in the key variables. At the same time, collecting the data should yet be practicable and effective.

Of key concern for successfully testing the micro-level hypotheses is the concept of the state. It is generally understood as a country-specific pattern. Thus, it refers to a conception as it is in aggregate. Consequently, within a country, on the individual level different views may persist (cf. Graeff 2014, 921, on the 'ecological fallacy'). In view of that, an efficient and yet adept approach is, instead of collecting data in various countries, recurring to quota sampling in a single country: as a non-probabilistic version of stratified sampling (Battaglia 2008, 523), quota sampling facilitates a broad, systematic coverage of socio-demographic backgrounds (cf. Häder and Häder 2014, 286). This permits to reflect a wide range of views and conceptions relatively easily even in smaller or restricted samples. Therewith, it delivers a preliminary idea of tendencies and, as intended, an impression of comparative variances (cf. Prein, Kluge, and Kelle 1994, 14; Rea and Parker 2014, 198).

The final data set for the micro-level analyses emanates from a quota-sample survey that was carried out in cooperation with the University of Siegen between $5^{\text {th }}$ and $18^{\text {th }}$ of March 2014 in Germany. ${ }^{53}$ The questionnaire was set up online and a random sample of individuals registered as participants at the German online panel of the market research institute Respondi

\footnotetext{
52 The International Social Survey Programme (ISSP) 2010 Module on Environment, for example, considers to what extent respondents agree in that (a) "private enterprise is the best way to solve the country's economic problems" vis-à-vis that (b) government should "reduce the differences in income between people [...]". Combining the two comes close to the idea underlying the concept of the state. Yet, the questionnaire does not include questions suiting the other key variables. Furthermore, in its entirety, the survey relates only to environmental considerations and therewith to a much narrower realm than the one considered in this dissertation (see ISSP Research Group 2012).

${ }^{53}$ More concrete, the survey was a cooperation-project with a research team at the Sociology Department of the University of Siegen (Germany), led by Prof. Sigrid Baringhorst and Dr. Mundo Yang.
} 
was invited to participate. Previously set quotas for each combination of age, gender and education level (i.e. 'stratum') demarcated the maximum number of individuals which each group should include. Certainly, this proceeding limits the generalisability of the findings (cf. Rea and Parker 2014). However, it secures the inclusion of each stratum (cf. Häder and Häder 2014, 286; Rea and Parker 2014, 185-6; see also Prein, Kluge, and Kelle 1994, 14-5) and allows for drawing comparisons among relevant strata within a respective context (cf. Prein, Kluge, and Kelle 1994, 18-9, ref. to Cook and Campbell 1979). This, in turn, is important for testing the hypotheses: they advance a set of explanations which centre on influences of boy- and buycotting behaviour across all strata. Nonetheless, they emanate from previous studies which have highlighted the influence of gender, age and education on involvement in political consumerism, though with ambiguous results (e.g. Baek 2010; Koos 2012a; Stolle and Micheletti 2005). Including all strata allows for detecting influences of gender, age and/or education and reliably testing and corroborating the hypotheses.

The survey and its questionnaire are guided by a dual purpose: On the one hand, it assesses the political consumer's political and social involvement. On the other hand, it strives to discern the differences and similarities between boycotter and buycotter. For that purpose, the questionnaire combines peoples' specifications about their political consumer behaviour with questions on their attitudes and behaviour in regard to three ambits: their interaction with co-citizens, their evaluation of the state and its politics, and their view of companies' behaviour and responsibilities. With some exceptions, all evaluative questions are set up such that respondents rate them on 7-point scales $(-3=$ not at all $;+3=$ very much $) .{ }^{54}$ Next to the respondents' specifications concerning their confidence in labelling schemes and CSR, additional questions consider the individuals' knowledge and activity levels surrounding labelling schemes, responsible production of products and firm behaviour.

The methodological approach deployed in testing the hypotheses involves a combination of bivariate correlation analysis with a generalised linear model (GLM) research design: the correlation examination permits to single out whether variables are at all noticeably related. Afterwards, regression analysis permits to study more accurately whether individuals' concept of the state and their confidence in labelling schemes and in CSR are linked to being more or less likely to consume politically in a specific way. Specifically, the hypotheses centre on probabilistic expectations and the outcome variables are binary i.e. dichotomous in nature. Consequently, the method centres on logistic regression analysis (cf. Kellstedt and Whitten 2009, 202ff.). Furthermore, with the intention to corroborate and reinforce the assertions derived from

\footnotetext{
${ }^{54}$ The questions used for the analyses are provided in Appendix A.1.
} 
the hypotheses tests, a second run of the analysis re-examines the findings. The novel nature of the variables recommends replicating the test for assessing the reliability of the measures and the explanatory power of the findings (Atteslander 2003, 255-6). This may uncover systematic distortions or patterns in responses affecting the results. There are no comparable tests which results can be compared to for appraising reliability, nor are there surveys embracing similar variables to be used. Conducting a second survey for running a new test was not viable in the framework of this project either. As an alternative, the test is performed a second time using the same sample as the first but split at random into two halves. This proceeding is inspired by the split-half method used for corroborating the internal reliability of indicators and multipleitem scales (cf. Atteslander 2003, 256; Bryman 2001, 71). The respective results may be put in comparison to each other as well as to the conclusions drawn based on the entire sample and therewith render information about the consistency of the findings. ${ }^{55}$ Further, the findings may be reviewed for the degree to which they appear to replicate and underpin observations found previously for the country level.

\subsubsection{Participants and Population}

After carrying out two pre-tests ${ }^{56}$, the respondents were recruited from the German online panel of the research institute Respondi. It covers 100.000 panellists who together constitute a cross-section of the citizens living in Germany as regards age, gender and education. The final sample should mirror the general distribution of the population in Germany according to three central socio-demographic parameters: age, gender and education. The German Microcensus $2012^{57}$ served for establishing corresponding quotas: maximum limits of numbers of participants per category were set and once these limits were reached, the respective groups of participants were sorted out by forwarding them directly to the questionnaire's last page. From the panel, $8.692^{58}$ individuals were invited to participate, 4.120 started doing so, yet 2.558 fell out because of full quotas and another 65 quit before the end. After adjusting the data set for invalid

\footnotetext{
${ }^{55}$ As in the procedure undertaken when applying a split-half method for corroborating the internal reliability of indicators and multiple-item scales (cf. Atteslander 2003, 256; Bryman 2001, 71), the proceeding here is to split the sample of respondents at random into two halves and carry out for each half the same line of analyses as for the entire sample (cf. e.g. Fredricks and Dossett 1983). The results for the two halves can then be compared (1) among each other and (2) to the entire sample. The degree to which the results are equivalent may further substantiate previous observations and might bolster up conclusions.

56 The first pre-test was paper-based and completed by 69 respondents (Dec. 2013/Jan. 2014). After adjusting a number of questions and their order, a second pre-test was carried out online and completed by 78 individuals (Feb. 2014). The second test run confirmed the applicability and functioning of the questionnaire and thus served in its tested setup for the actual survey.

${ }^{57}$ For the 2012 Microcensus, 688.900 individuals were interviewed (Statistisches Bundesamt 2013).

${ }^{58}$ Of these, 6.979 emanate from a random sample and 1.713 from an additional quota sample.
} 
responses $^{59}$, the entire sample ultimately covers 1.350 respondents, i.e. a response rate of 15.5 percent. Table 5 provides an overview of the sample's distributions.

The sample distributions mirror very well the German population as it was recorded in the Microcensus 2012 (cf. Table 5): the distribution of gender is identical, the age groups and education levels are, overall, very well reflected, too. Nonetheless, there are some discrepancies related to education and to age.

Table 5. Sample Distribution (Age, Gender and Education)

\begin{tabular}{|c|c|c|c|c|c|c|c|}
\hline \multirow{2}{*}{$\begin{array}{l}\text { Age } \\
\text { groups }\end{array}$} & \multicolumn{2}{|c|}{ Sample } & \multirow{2}{*}{$\frac{\text { Microcensus }}{\%}$} & \multirow{2}{*}{ Gender } & \multicolumn{2}{|c|}{ Sample } & \multirow{2}{*}{$\begin{array}{c}\text { Microcensus } \\
\%\end{array}$} \\
\hline & $\mathrm{N}$ & $\%$ & & & $\mathrm{~N}$ & $\%$ & \\
\hline $14-17$ & 82 & 6.1 & 5.5 & Female & 671 & 49.7 & 49.7 \\
\hline $18-24$ & 147 & 10.9 & 11.1 & Male & 679 & 50.3 & 50.3 \\
\hline $25-29$ & 112 & 8.3 & 8.5 & Total & 1350 & 100 & 100 \\
\hline $30-34$ & 105 & 7.8 & 8.5 & & & & \\
\hline $35-39$ & 112 & 8.3 & 8.0 & \multirow{2}{*}{ Highest degree } & \multicolumn{2}{|c|}{ Sample } & Microcensus \\
\hline $40-44$ & 137 & 10.1 & 10.6 & & $\mathrm{~N}$ & $\%$ & $\%$ \\
\hline $45-49$ & 166 & 12.1 & 11.8 & No/not yet a Degree & 81 & 6.0 & 9.5 \\
\hline $50-54$ & 143 & 10.6 & 11.0 & Certificate of Secondary & 424 & 31.4 & 29.2 \\
\hline $55-59$ & 128 & 9.5 & 9.5 & Education ( $9^{\text {th }}$ Grade) & & & \\
\hline $60-64$ & 104 & 7.7 & 8.6 & Certificate of Secondary & 426 & 31.6 & 30.7 \\
\hline $65-69$ & 114 & 8.4 & 7.0 & Education (10th Grade) & & & \\
\hline Total & 1350 & 100 & 100 & $\begin{array}{l}\text { Higher Education } \\
\text { Entrance Qualification }\end{array}$ & 206 & 15.3 & 16.1 \\
\hline & & & & University Degree & 203 & 15.0 & 14.1 \\
\hline & & & & Other Degree & 10 & 0.7 & 0.4 \\
\hline & & & & Total & 1350 & 100 & 100 \\
\hline
\end{tabular}

With respect to education, firstly, individuals (yet) without a degree are underrepresented in the sample (3.5 percentage points less than in the Microcensus) whereas the group with the lowest school certificate is slightly overrepresented (surplus of 2.2 percentage points). Of the survey participants (yet) without a degree, more than 95 percent pertain to one of the two youngest age groups. In contrast, in the Microcensus respondents without a degree make up between 3 and 4 percent in each one of all age groups. ${ }^{60}$ Thus, what is underrepresented and in part

\footnotetext{
${ }^{59}$ As invalid respondents count participants who completed the survey too fast, too little (that is, leaving out more than 4 questions i.e. 10 percent of the questions), and/or who ticked "don't know" in more than 8 cases. This is intended to minimise non-response biases and to single out 'click-through'- respondents i.e. those who may not have participated genuinely. These criteria lead to the exclusion of 147 respondents, thereby reducing the sample of 1.497 individuals who have completed the questionnaire to 1.350.

${ }^{60}$ See Statistisches Bundesamt 2013, 26.
} 
missing is individuals without an education degree across all age groups other than the youngest. To offset this bias by the help of statistical weights, individuals between 25 and 65 years of age without a degree would have to be up-weighted. However, for several of these groups there is not a single respondent in the sample (cf. Table 6) and thus no primary answer values which could actually be used as a base for the weights. As a result, up-weighting not (yet) a degree could not truly compensate for the gap since it would mainly base on the answers provided by the group of 14 to 24 years and thus a very different type of individuals than needed. ${ }^{61}$

Table 6. Percent of Age within the Level of Education

\begin{tabular}{ccccccc}
\hline \hline \multirow{2}{*}{$\begin{array}{c}\text { Age } \\
\text { groups } \\
(\%)\end{array}$} & $\begin{array}{c}\text { Ho/not yet } \\
\text { a Degree }\end{array}$ & $\begin{array}{c}\text { Certificate of } \\
\text { Sec. Ed. }\left(9^{\text {th }} \text { gr.) }\right.\end{array}$ & $\begin{array}{c}\text { Certificate of } \\
\text { Sec. Ed. }\left(10^{\text {th }} \text { gr.) }\right.\end{array}$ & $\begin{array}{c}\text { Higher Ed. En- } \\
\text { trance Qual. }\end{array}$ & $\begin{array}{c}\text { University } \\
\text { Degree }\end{array}$ & $\begin{array}{c}\text { Other } \\
\text { Degree }\end{array}$ \\
\hline $14-17$ & 85.2 & 0.7 & 1.4 & 1.9 & 0.0 & 0.0 \\
$18-24$ & 12.3 & 5.0 & 11.7 & 28.6 & 3.4 & 0.0 \\
$25-29$ & 1.2 & 2.8 & 5.4 & 19.4 & 17.2 & 10.0 \\
$30-34$ & 0.0 & 5.2 & 8.5 & 9.7 & 12.8 & 10.0 \\
$35-39$ & 0.0 & 5.4 & 10.3 & 8.7 & 12.8 & 10.0 \\
$40-44$ & 0.0 & 11.1 & 12.7 & 6.8 & 10.3 & 10.0 \\
$45-49$ & 0.0 & 12.5 & 16.4 & 8.7 & 10.8 & 30.0 \\
$50-54$ & 0.0 & 15.3 & 10.3 & 8.3 & 7.9 & 10.0 \\
$55-59$ & 1.2 & 12.7 & 10.3 & 4.9 & 9.4 & 0.0 \\
$60-64$ & 0.0 & 10.6 & 8.7 & 1.5 & 8.9 & 10.0 \\
$65-69$ & 0.0 & 18.6 & 4.2 & 1.5 & 6.4 & 10.0 \\
Total & 100 & 100 & 100 & 100 & 100 & 100 \\
\hline \hline
\end{tabular}

Instead, the probably closest group to the missing is the one comprising the lowest level of school leaving certificate. This group's distribution across age groups and gender matches very well the distribution in the Microcensus: the percentage of individuals in this category increases with increasing age and it is steadily a bit higher among men than among women except for the age group of 60 to 64 years (cf. Statistisches Bundesamt 2013, 26). Alone, it is overall slightly overrepresented, but in later analyses which focus on general tendencies and linear trends, this overrepresentation may in turn somewhat balance out the gap in the former group of education.

\footnotetext{
${ }^{61}$ In fact, 85 percent belong to the group of ages 14 to 17 , which is equivalent to 5 percent of the total sample and thus clearly above the 3.7 percent who were still enrolled in school according to the Microcensus. Thus, upweighting it could result in up-weighting an already overrepresented group and should be done with caution.
} 
In sum then, the bias clearly entails a minor limitation of the sample, but not one that should seriously distort the core examinations of the hypotheses. ${ }^{62}$

With respect to age, the youngest and the oldest age groups deviate from the Microcensus in two aspects. Firstly, gender is consistently roughly 50 percent across all age groups for male and female respondents, except for these two groups: 65 percent of the respondents between 14 and 17 are female, and in the group of 65 to 69 years of age, 81 percent are male. This can result in a female and male bias in the analyses, respectively. Nevertheless, testing whether within the age groups female and male participants differ in key characteristics such as level of education, occupation status, and social class, reveals no significant dissimilarity between the two sexes. Only for the youngest, women appear slightly more often than male respondents to not having yet an education diploma $(z=-2.091, p=.037)$. Yet, this again fits the Microcensus. ${ }^{63}$

Secondly, the percentages of respondents belonging to these two groups as of the total number of respondents in the sample differ from the fractions in the Microcensus: on the one hand, the youngest age group is slightly overrepresented (a divergence of 0.6 percentage points or 8 respondents more). On the other hand, the two oldest age groups are twisted: whereas the 60 to 64 year olds are underrepresented (-0.9 percentage points), the group of 65 to 69 year olds comprises 1.5 percentage points more in the sample than in the Microcensus. However, the two older age groups together form exactly the generation of those born directly after the end of the Second World War and so their growing up and formative years should not have been too different. That is, the formation of their views and behaviour should have followed a comparable line. ${ }^{64}$ As a result, the twist should somewhat cushion the bias in the later analysis centring on the concept of the state and confidence. But for analyses centring on direct links with sociodemographic characteristics, the two age groups should be comparable. Testing that, firstly, a

\footnotetext{
${ }^{62} \mathrm{~A}$ second observation with respect to education is that across age groups the younger respondents show a general tendency towards having completed higher education levels (in due consideration of the group without (yet) a degree, which for the major part comprises respondents at ages at which in Germany it is compulsory visiting a school). Nonetheless, this corresponds to the general trend among the more recent generations to strive for higher degrees of school diplomas. It is mentioned as well e.g. in a review published by the German Federal Agency for Civic Education evaluation of data on education from the Federal Office of Statistics' Statistical Yearbook 2013. They observe the increasing tendency among the younger generation between 15 and 35 years of age to less often complete lower level school degrees and instead middle to higher degrees (Bundeszentrale für Politische Bildung 2014). Consequently, this supports the representativeness of the present survey sample, i.e. it should not reflect a sampling error; cf. also Statistisches Bundesamt 2013, 13 \& 26.

${ }^{63}$ Specifically, it relates to a generally observed tendency across the younger age groups in Germany today that a larger fraction of women than of men, overall, completes higher degrees of education, what means that they finish school at a later age (see e.g. Weishaupt et al. 2012, 135; Statistisches Bundesamt 2012, 55; 2013, 26). Looking at the next older age group underlines this notion, with women there having completed higher education degrees $(z=-2.540, p=.011)$. The same is observable in the Microcensus as well (see Statistisches Bundesamt 2013, 26). Thus, in sum, the deviating fractions of gender should not affect the further analyses by singular underlying socio-demographic characteristics. Even so, the high fraction of women without a degree (yet) in the youngest age group may in the later analyses even out the higher levels of female education at higher ages. Any analysis of links with education levels should consider possible effects that could be a result of this high distortion.

${ }^{64}$ See also Hadjar and Becker 2009, 108.
} 
Mann-Whitney Test reveals a higher female fraction among the 60 to 64 year olds $(z=-4.367$, $p=.000)$. This is consistent with the above mentioned male overrepresentation in the oldest age group. Secondly, the 65 to 69 year olds disclose a comparatively low mean rank of level of education which deviates significantly from the general level of education of the other groups $\left(\chi^{2}(10)=289.776, p=.000\right){ }^{65}$ Thus, the oldest age group clearly deviates from the general distribution and cannot be regarded as comparable to the group of 60 to 64 year olds. Indeed, the theory wants to leave behind the focus on socio-demographics and proposes links that are basically unrelated to age, gender and education (cf. Chapter 2.1.2). Hence the bias should not markedly affect the later analyses. However, for the descriptive analyses specifically focusing on the socio-demographic distribution of political consumerism it recommends using weights to even out the distortion.

Thus, the sample is weighted for age, gender and education, with a focus mainly on levelling out discrepancies across age groups. It is one combined weight for the three indicators which ultimately reduces deviations from the participation ratios of the Microcensus to predominantly 0.1 percentage points (see Appendix A.2). The result is a sample which mirrors quite precisely the distribution in the Microcensus 2012 and thus builds a fairly representative basis for examining the prevalence of political consumerism in Germany. This in turn permits to draw more reliable conclusions about the extent to which the findings of the forthcoming analyses may be transferred on more general terms.

${ }^{65}$ More concrete, the male fraction has a very low level of education (69 percent of the men have a lower degree). Yet, this in turn matches the Microcensus (cf. Statistisches Bundesamt 2013, 26). 


\section{Political Consumerism on the Macro-Level}

5.1 Investigating the Aims Underlying Political Consumerism Cross-Nationally

The development of political consumerism on the macro-level is proposed to be closely related to the degree to which labelling schemes and CSR are available in a country. Their comparative dominance is in turn said to vary from country to country depending on the respective prevailing concept of the state. This chapter empirically examines these propositions by testing the previously presented hypotheses.

To begin with, the chapter analyses the hypotheses which formulate expectations on the prevalence of single varieties of political consumerism vis-à-vis the spreads of labelling schemes and CSR. The second part of the chapter then takes a closer look at these results and seeks to discern a systematic clustering of countries with a particular concept of the state. Finally, a third and concluding section considers the results overall and discusses more thoroughly the findings in relation to the preliminary expectations.

5.2 The Comparative Prevalence of Political Consumerism, CSR and Labelling Schemes

The first set of hypotheses considers the prevalence of single varieties of political consumer behaviour with respect to labelling schemes and CSR. The central assumption is that CSR and labelling schemes facilitate political consumerism. Stemming from that, the two initial hypotheses assume that the greater the prevalence of CSR (H1a) and/or labelling schemes (H1b) in a country, the lower the percentage of non-political consumers. Figure 8 illustrates the percentage of citizens per country who stated to not yet have consumed politically and its relationship with CSR (as index score) on the one hand, and the Fairtrade Label (in sales per capita) on the other hand.

Both graphs display a steady decrease of the percentage of citizens who have stated to not yet have consumed politically with rising scores on the CSR index as well as with rising per capita sales of the labelling scheme. Along with it, the correlation coefficients underpin the notion that the more widespread CSR or labelling schemes are, the lower is the percentage of non-political consumers. This inverse development of non-political consumerism in relation to the spreading of CSR and of labelling schemes corroborates H1a as well as H1b, respectively. 
Figure 8. The Spread of Non-Political Consumerism relative to CSR and Sales per Capita of Fairtrade labelled Products
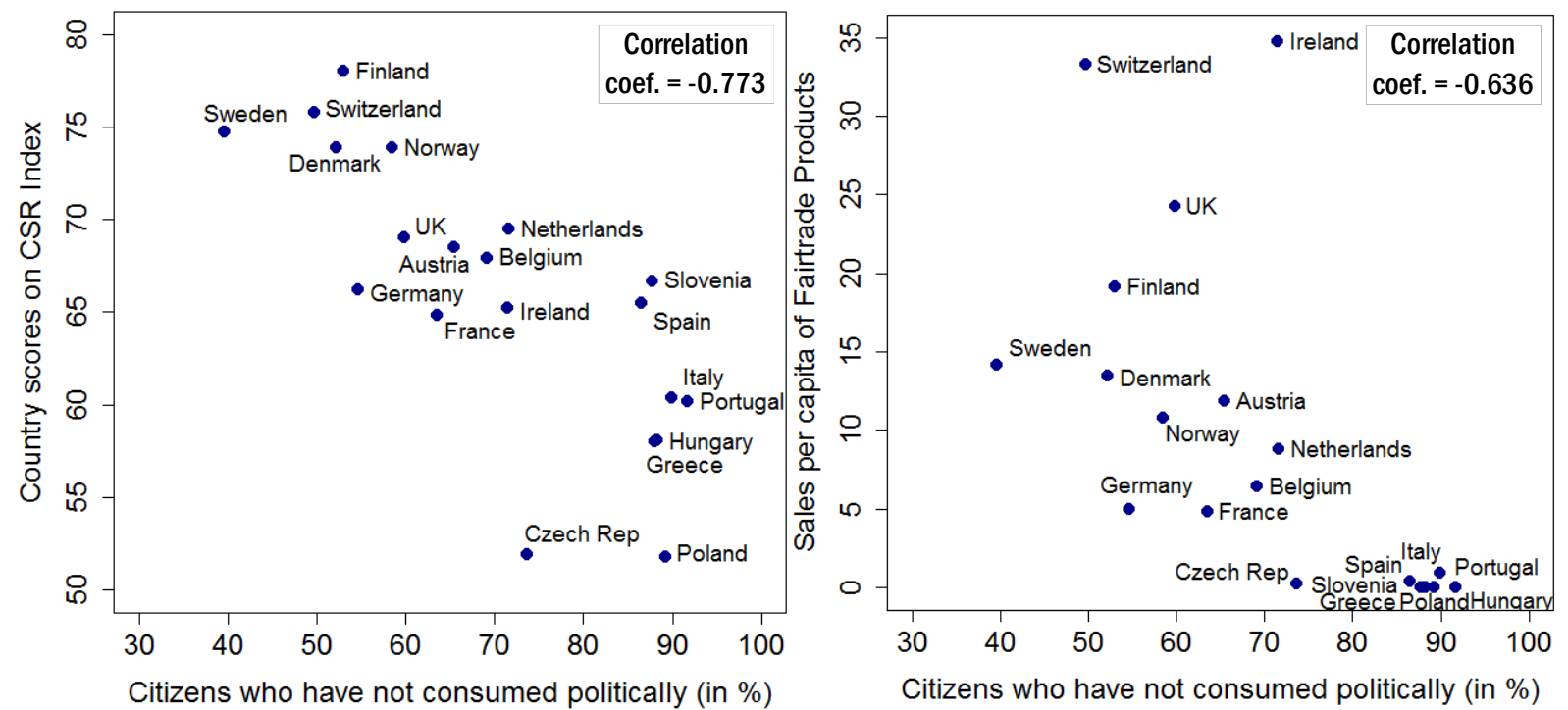

Measure of correlation: Pearson; $\mathrm{N}=20$; Significance level: $p<.01$ (2-tailed).

However, it further leads to the question whether the correlations are spurious and/or represent mere parallel developments. Or if they describe a factual connection into a certain direction. As noted in Chapter 3, deciding which is the dependent and which is the explanatory variable is not entirely unambiguous and both directions would be thinkable. ${ }^{66}$ For this reason, regression analyses consider the relationships in both directions. Besides, unless otherwise noted, all regression analyses include three control variables: the gross disposable income of private households, the net private household saving rate and retail store density. ${ }^{67}$ Table 7 displays the resulting figures.

\footnotetext{
${ }^{66}$ The central idea underlying the proposed process of political consumerism is that confidence in CSR and/or labelling schemes facilitates political consumerism. This suggests that non-political consumerism is rather the dependent than the independent variable. Nonetheless, it needs an impetus for the spreading of CSR and/or labelling schemes which boycotters i.e. active political consumers are said to give. From this perspective, a high percentage of non-political consumers would serve (also) as an explanatory factor for a low prevalence of CSR and/or labelling schemes; see also Chapter 3.3.2.1.

67 The gross disposable income of private households shall account for the theoretical amount which households in a country could spend for consumption (data for the year 2003; OECD 2015); the net private household saving rate considers the relative inclination of citizens in a country to consume their income (data for the year 2003; OECD 2012). Lastly, retail store density is included to take into consideration citizens' comparative accession to different stores and therewith the potential obtainability of product alternatives which may facilitate political purchasing decisions (in lack of figures for 2003, data for the year 2011 are used instead; Nielsen 2013, 26; 2015, 25); see also Appendix A.6.
} 
Table 7. OLS Regression of Non-Political Consumerism, Labelling Schemes and CSR

\begin{tabular}{lcccc}
\hline \multicolumn{1}{c}{$\begin{array}{c}\text { Dependent } \\
\text { Independent }\end{array}$} & $\begin{array}{c}\text { Labelling } \\
\text { Schemes }\end{array}$ & CSR & Non-Political Consumerism \\
\hline Non-Political Consumerism & $-.399^{*}(.152)$ & $-.261^{* *}(.082)$ & & \\
Labelling Schemes & & & $-.792^{*}(.301)$ & $-1.543^{* *}(.486)$ \\
CSR & & & .550 & .607 \\
\hline \hline$R^{2}$ & .509 & .690 & 4.586 & 5.780 \\
$F(1,15)$ & 3.887 & 8.340 & 20 & 20 \\
No. Observations & 20 & 20 & \\
\hline Data shown are unstandardized coefficients of OLS regressions with standard errors in parenthesis. \\
All models are controlled for gross disposable income, net private household saving rate and retail store density. \\
${ }^{*} p<.05, * * p<.01$.
\end{tabular}

The figures back the idea that the relationships are not spurious or random: high percentages of non-political consumerism appear to be linked in general with the (low) prevalence of labelling schemes and CSR. More specifically, with an increase in the spread of CSR and labelling schemes, the percentage of non-political consumers decreases. In turn, the effect in the reverse direction is much weaker, although the difference is more notable for CSR than for labelling schemes. Therewith, the result is a first sign in support of the consideration that CSR and labelling schemes serve as important underpinnings rendering possible political consumerism. Moreover, the smaller difference in the effects of non-political consumerism on labelling schemes and vice-versa backs the notion that especially labels not only act as guidelines. Instead, they also appear to serve as underlying 'motivators' in the sense that the desire to promote their appearance can foster involvement in political consumerism in the first place.

The presence of the two remarkable outliers Ireland and Switzerland for the Fairtrade Label (Figure 8) in turn raises the question for what may explain their existence. The theoretical framework links the availability and popularity of labelling schemes and CSR to the prevailing concept of the state. Accordingly, the outlying position of these countries for specifically the Fairtrade Label might be related to their concept of the state. This question will be addressed in the next section more in detail. For the present analysis on the general trend across all countries, the findings on the whole reiterate the positive correlations. Thus, they reinforce H1a as well as $\mathrm{H} 1 \mathrm{~b}$.

The succeeding two hypotheses focus on the consideration that CSR and labelling schemes constitute the basis on which buycotting can thrive. Based on that, they suggest that the greater the prevalence of CSR (H2a) and/or of labelling schemes (H2b), the higher the percentage of buycotter. Consistent with this view, Figure 9 depicts a similar relationship to that observed for non-political consumerism but with the structure reversed: on the one hand, the higher a country scores on the CSR index, the higher the percentage of citizens who buycott. On the other hand, 
in spite of some remarkable outliers (Ireland, Switzerland, the UK and to some extent Finland), overall labelling schemes and buycotting develop concurrently, too; that is, the higher the sales of labelled goods in a country, the higher the percentage of buycotter. The correlation coefficients endorse the two findings, being fairly high for buycotting and CSR, and somewhat weaker for buycotting and labelling schemes. Likewise, regression analyses underpin that the connections are both for CSR and for labelling schemes more than only random correspondences (Table 8). Therewith, the observations confirm $\mathrm{H} 2 \mathrm{a}$ as well as $\mathrm{H} 2 \mathrm{~b}$.

Figure 9. The Spread of Buycotting relative to CSR and Sales per Capita of Fairtrade labelled Products
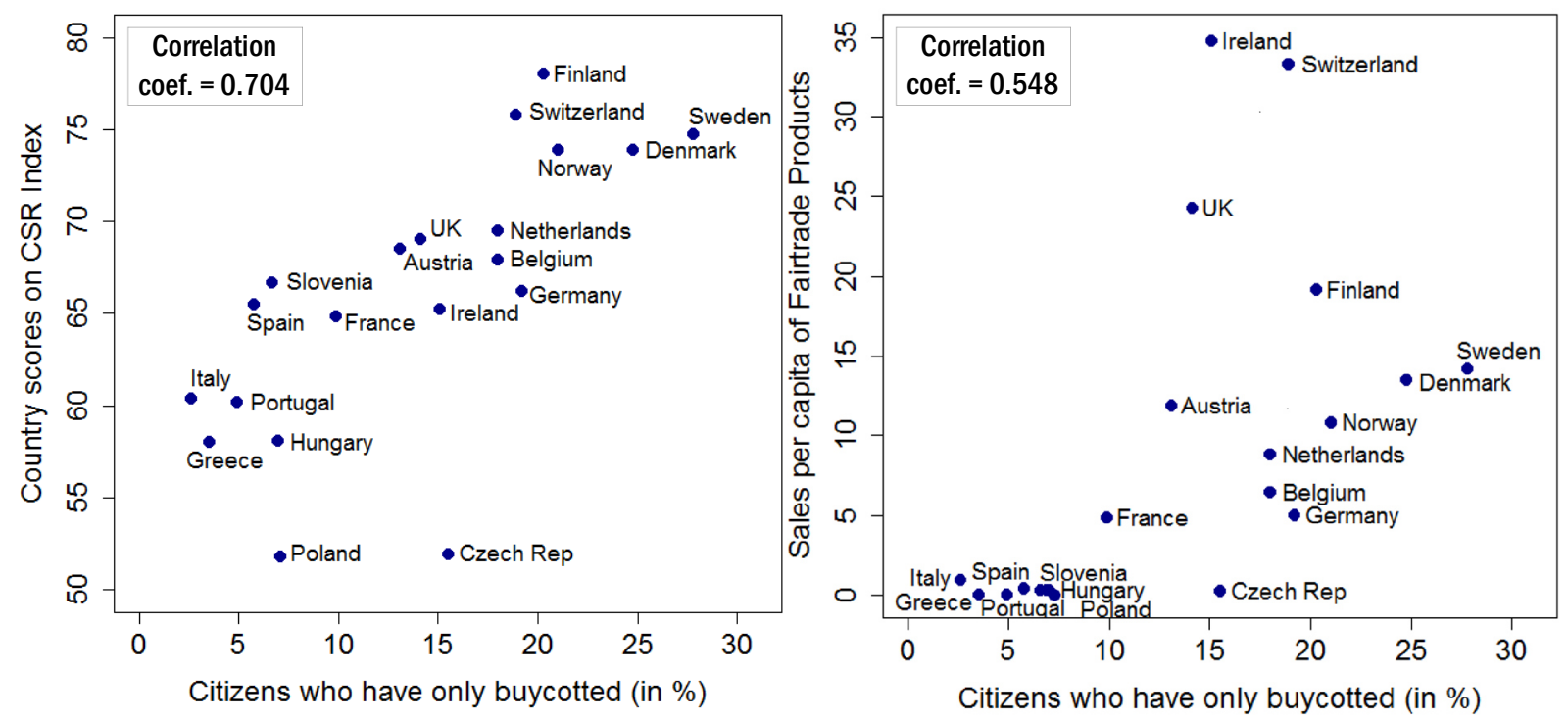

Measure of correlation: Pearson; $\mathrm{N}=20$; Significance level: $p<.01$ (2-tailed).

Table 8. OLS Regression of Buycotting, Labelling Schemes and CSR

\begin{tabular}{lcc}
\hline \hline & Dependent & \multicolumn{2}{c}{ Buycotting } \\
Independent & $.373^{*}(.152)$ & $.729^{* *}(.248)$ \\
\hline Labelling Schemes & & .510 \\
CSR & .448 & 3.904 \\
\hline \hline$R^{2}$ & 3.046 & 20 \\
$F(1,15)$ & 20 & \\
No. Observations & Data shown are unstandardized coefficients of OLS regressions with standard errors in \\
parenthesis. All models are controlled for disposable income, net private household \\
saving rate and retail store density. ${ }^{*} p<.05,{ }^{* *} p<.01$.
\end{tabular}

The theoretical framework posits that an impetus is needed for the spreading of labelling schemes and CSR, and that boycotter act as such 'pioneers' who set this spreading in motion. Accordingly, boycotting is related to the absence of labelling schemes and/or CSR (being the background in which citizens decide to boycott) as well as to their appearance i.e. presence 
(being the result of the boycotts). The expectations are that boycotting is neither systematically linked to CSR (H3a) nor to labelling schemes (H3b).

Figure 10 presents a scattered distribution of countries when accounting for the comparative prevalence of boycotting citizens, CSR and per capita sales of Fairtrade labelled products. The correlation coefficient for boycotting and CSR does not reach statistical significance. Regression analyses do not provide more telling results either (see Table 9). The coefficients are statistically insignificant, both when including and when excluding the control variables (Table 9, variants (1) and (2), respectively). Boycotting does not appear to be tied to the presence or absence of CSR in a specific way, irrespective of whether citizens have a larger or smaller financial leeway in deciding what to purchase. Thus, corresponding to $\mathrm{H} 3 \mathrm{a}$, boycotting and CSR exhibit no common link.

Figure 10. The Spread of Boycotting relative to CSR and Sales per Capita of Fairtrade labelled Products
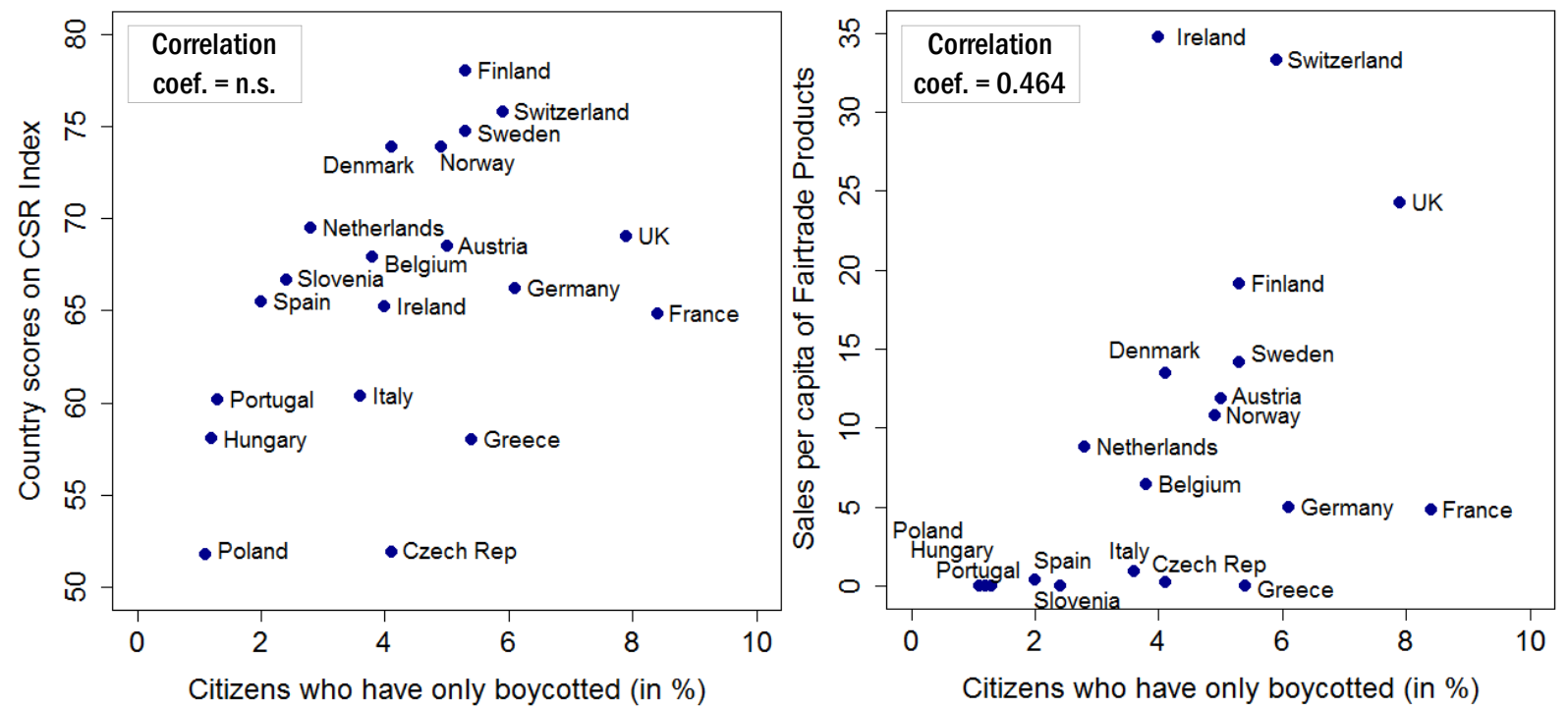

Measure of correlation: Pearson; $\mathrm{N}=20$; Significance level for Labelling: $p<.05$ (2-tailed).

For the relationship between boycotting and the labelling scheme, apart from the two prominent outliers Ireland and Switzerland, the remaining countries show a certain common development. Also, the correlation coefficient is statistically significant. This result becomes more expressive when disregarding the two outliers (Pearson's $r=.593, p<.01 ; 2$-tailed), whereby the findings clearly contradict H3b. The theoretical framework posits that the non-presence of guidelines like labelling schemes encourages boycotting and this in turn leads to the spread of labels. Therefore, the observation entails the question whether the link is stronger in one particular direction; according to the theoretical idea, the connection would be reciprocal.

Variant (1) in Table 9 displays the coefficients obtained for the link between boycotting and Fairtrade sales including the control variables; that is, the link as it is independent from 
differences across countries in the average private household income, the relative disposition to save that income and access to shopping facilities. None of the coefficients reaches statistical significance. ${ }^{68}$ In contrast, in variant (2) the average income disposable to private households as well as their net saving rate are not being accounted for. In this constellation, contrary to the expectation the impact of boycotting activities on the spread of labelling schemes is stronger than in the reverse. In fact, the difference between the coefficients is remarkable. This points to a well-defined link with a clearly larger influence in one particular direction. While labelling schemes have little bearing on whether involvement in boycotting is high or low, in the reverse, boycotting appears to promote the spreading of labelling schemes.

Table 9. OLS Regression of Boycotting, Labelling Schemes and CSR

\begin{tabular}{|c|c|c|c|c|c|c|c|c|}
\hline \multirow[b]{2}{*}{$\begin{array}{l}\text { Dependent } \\
\text { Independent }\end{array}$} & \multicolumn{4}{|c|}{ (1) With all Control Variables } & \multicolumn{4}{|c|}{$\begin{array}{l}\text { (2) Without Controls } \\
\text { for Income \& Saving }\end{array}$} \\
\hline & $\begin{array}{l}\text { Labelling } \\
\text { Schemes }\end{array}$ & CSR & Boyc & tting & $\begin{array}{l}\text { Labelling } \\
\text { Schemes }\end{array}$ & CSR & Boyc & tting \\
\hline Boycotting & $\begin{array}{c}.940 \\
(1.713)\end{array}$ & $\begin{array}{c}.157 \\
(1.000)\end{array}$ & & & $\begin{array}{l}2.479^{*} \\
(1.158)\end{array}$ & $\begin{array}{l}1.366 \\
(.697)\end{array}$ & & \\
\hline $\begin{array}{l}\text { Labelling } \\
\text { Schemes }\end{array}$ & & & $\begin{array}{l}.021 \\
(.038)\end{array}$ & & & & $\begin{array}{l}.086^{*} \\
(.040)\end{array}$ & \\
\hline CSR & & & & $\begin{array}{l}.010 \\
(.067)\end{array}$ & & & & $\begin{array}{l}.135 \\
(.069)\end{array}$ \\
\hline$R^{2}$ & .296 & .482 & .552 & .543 & .215 & .388 & .225 & .198 \\
\hline$F(1,15) /(1,17)$ & 1.575 & 3.490 & 4.612 & 4.461 & 2.326 & 5.383 & 2.468 & 2.094 \\
\hline No. Observations & 20 & 20 & 20 & 20 & 20 & 20 & 20 & 20 \\
\hline
\end{tabular}

To better understand the relationship and its tie with income, Figure 11 depicts the predicted percentages of boycotter in a country differentiated according to whether households dispose of an income lying above or below the median income in the entire set of countries. In eight countries, per capita sales of Fairtrade labelled goods are zero or close to zero, and in seven of these, private households dispose of incomes below the median. Simultaneously, it is the countries where boycotting activity is lowest (cf. Figure 11). This suggests that in countries where households have less disposable income to be spent on consumption, citizens' priorities at the moment of purchasing may be others than the desire to express discontent with market practices for political reasons. Boycotting can come with sacrifices, e.g. when rejecting to buy cheap products for ethical reasons (see e.g. Hoffmann 2008, $46 \& 77-8$ ). If income is low, citizens

${ }_{68}$ The coefficients are non-significant also when disregarding the two outliers Ireland and Switzerland. 
may not have the liberty to reject such buys (see also Koos 2012a, 51-2). Nonetheless, not in all countries with a low income, sales of labelled products and boycotting are low, too. In Ireland, for example, in spite of the low median income per capita, sales of Fairtrade labelled goods are outstandingly high. Consequently, income alone does not seem to suffice as explanation. This puts forward that involvement in boycotting is related to underlying country characteristics further than income. ${ }^{69}$

The presence of labelling schemes is no prerequisite for boycotting; instead, boycotting furnishes the spreading of labelling schemes. In sum, these findings actually endorse a more clear-cut impact than expected of boycotting as the 'pioneering' activity which sets in motion political consumerism and the spreading of labelling schemes in particular. Therewith, although with limitations, the results contradict the expectation of $\mathrm{H} 3 \mathrm{~b}$, which has to be rejected. $\mathrm{H} 3 \mathrm{a}$ in turn is supported.

Figure 11. Predicted Percentages of Citizens who have boycotted depending on the Gross Disposable Income of Private Households

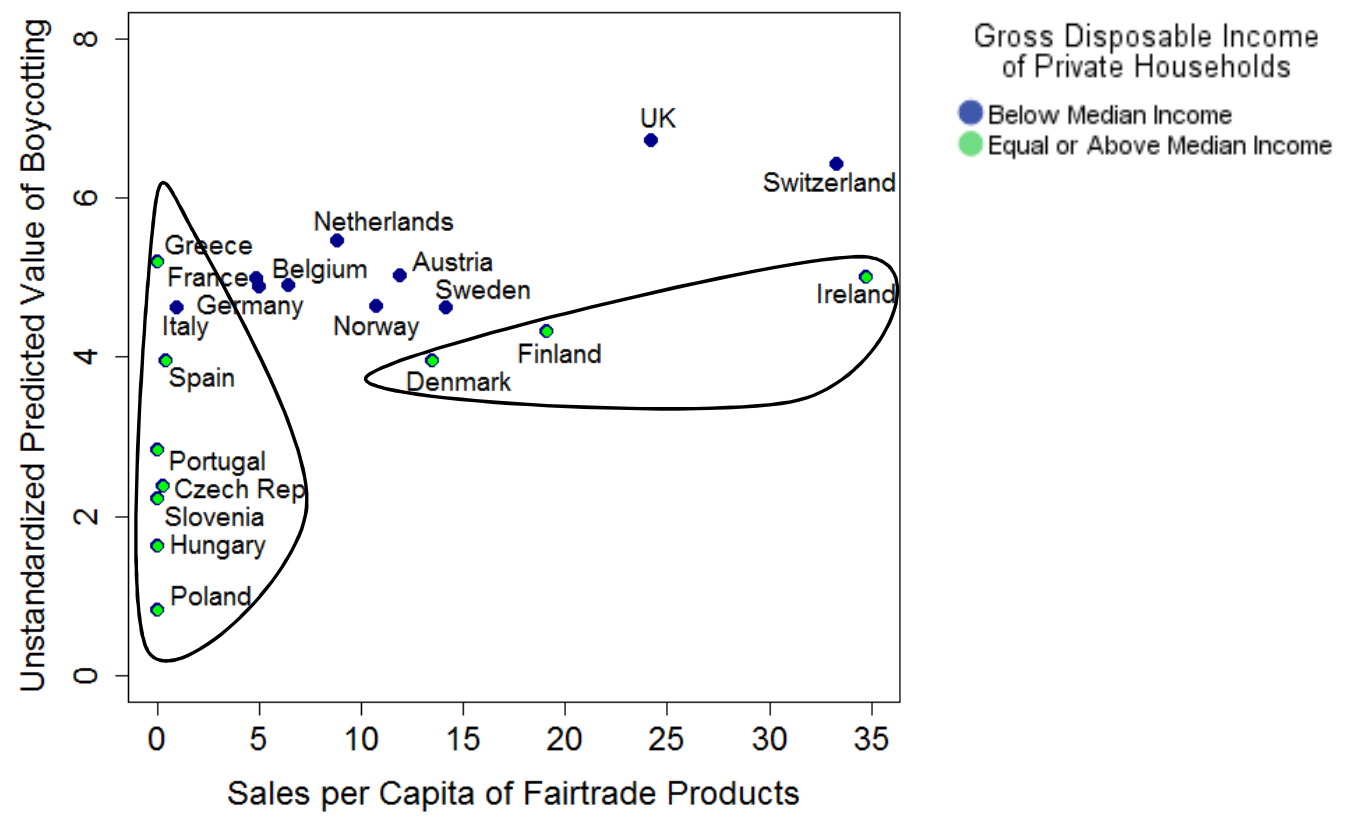

The last two hypotheses for the bivariate relationships consider involvement in both boyand buycotting vis-à-vis the prevalence of CSR and labels. Specifically, they suggest that the percentage of citizens involved in this variety of political consumerism is the higher, the greater the spread of CSR (H4a) and/or labelling schemes (H4b) is in a country. The spreading of

\footnotetext{
${ }^{69}$ The results point to two ideas. First, that the concept of the state inspires the individuals' sense of duty to adjust their own consumption preferences and to get involved in boycotting; and second, that boycotter may be driven by the desire to advance the availability of labelling schemes (cf. Chapter 3.3.2.3). Chapter 6.4.1.4 examines these ideas empirically.
} 
countries as depicted in Figure 12 endorse the propositions, and the correlation coefficients further substantiate the observation.

What is more, the distribution of countries in the graphs shows an almost perfect mirror image to that obtained for the relationship of non-political consumerism with CSR and labelling schemes (see Figure 8). Key to the theoretical framework is the conjecture that citizens broaden their involvement in political consumerism step by step with the expanding availability of CSR and/or labelling schemes. In line with it, these mirror images depict non-political consumerism and being involved in both boycotting and buycotting as being two opposite poles. That is, it depicts them as being the two opposite 'extremes' of political consumer commitment. Moreover, the inverse structure of the links matches the idea that the predominance of either extreme is subject to whether the prevalence of CSR and/or labelling schemes is low or high in a country. ${ }^{70}$

Figure 12. The Spread of Boy- and Buycotting relative to CSR and per Capita Sales of Fairtrade labelled Products
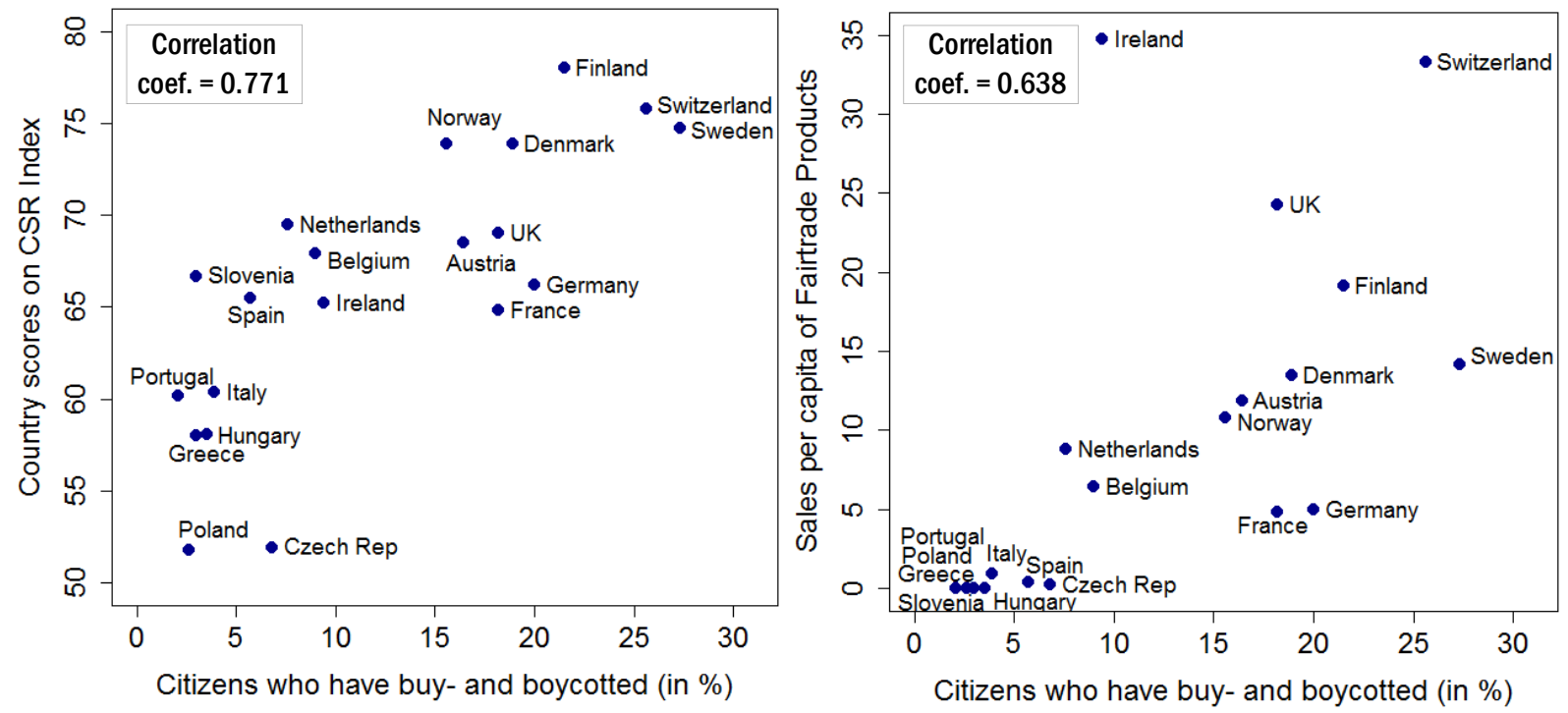

Measure of correlation: Pearson; $\mathrm{N}=20$; Significance level: $p<.01$ (2-tailed).

The regression results confirm the notion (Table 10). They put forward a tight mutual linkage where the presence of labelling schemes and/or CSR facilitates involvement in both boyand buycotting, while involvement fosters a growing spread of CSR and/or labelling schemes. However, the sizes of the effects vary. Labelling schemes appear to more strongly be fostered

\footnotetext{
${ }^{70}$ In line with this observation, the correlation coefficient between non-political consumerism and being involved in both boy- and buycotting is very high and negative $(r=-.968, p<.01)$. In contrast, the correlation of non-political consumerism and being involved in only boycotting is weaker $(r=-.679, p<.01)$, whereas the correlation coefficient with only buycotting is similar $(r=-.914, p<.01)$. Boycotting and non-political consumerism are thus no 'opposite poles' of involvement. Instead, boycotting appears to be a first step followed by 'something else', which may be the (additional) involvement in buycotting.
} 
by involvement in boy- and buycotting than to serve as its promoter. On the opposite, CSR seems to first and foremost serve as a basis for boy- and buycotting. Therewith, the findings match the observations obtained for buycotting and for boycotting. Political consumer involvement expedites the spreading of labelling schemes, whereas CSR primarily acts as a guideline facilitating involvement. With these results, $\mathrm{H} 4 \mathrm{a}$ and $\mathrm{H} 4 \mathrm{~b}$ are supported as well.

Table 10. OLS Regression of Boy- and Buycotting, Labelling Schemes and CSR

\begin{tabular}{|c|c|c|c|c|}
\hline $\begin{array}{l}\text { Dependent } \\
\text { Independent }\end{array}$ & Labelling Schemes & CSR & \multicolumn{2}{|c|}{ Boy- and Buycotting } \\
\hline Boy- and Buycottıng & $.769 *(.297)$ & $.518^{* *}(.158)$ & & \\
\hline Labelling Schemes & & & $.401 *(.155)$ & \\
\hline CSR & & & & $.807 * *(.246)$ \\
\hline$R^{2}$ & .503 & .698 & .548 & .620 \\
\hline$F(1,15)$ & 3.796 & 8.674 & 4.542 & 6.110 \\
\hline No. Observations & 20 & 20 & 20 & 20 \\
\hline
\end{tabular}

Lastly, the again remote positions in the figure of Ireland, Switzerland and to a lesser extent the UK accentuate the different dispersal of labelling schemes and CSR from country to country in spite of similar levels of boy- and buycotter. Labelling schemes are by far more widespread in Ireland, Switzerland and the UK than in the other countries. While at comparable levels of boy- and buycotting involvement, CSR is more widely disseminated in e.g. Sweden and Finland. This reinforces the proposition that underlying country characteristics give rise to distinct preferences for either labelling schemes or CSR. The next section reviews whether the relative differences stand in connection with the prevailing concept of the state.

\subsection{Varieties of Political Consumerism}

The prevalence of boycotting and buycotting varies in relation to the spread of CSR and labelling schemes. The second set of macro-level hypotheses turns to the question whether there is a systematic alignment of equal spreads in countries with similar concepts of the state. Additionally, the outliers in Figure 8 and Figure 12 present a further question about the remarkable outliers such as Switzerland, Ireland and the UK for the Fairtrade Label.

The theoretical framework proposes that countries with similar concepts of the state exhibit similar spreads of buycotting with respect to the availability of labelling schemes and CSR. The reason for it is that the concept of the state influences individuals' preferences for each of the two and thereby affects their decision on whether and on how to consume politically. According 
to the respective hypotheses, labelling schemes exhibit a greater relative importance for buycotting than CSR in countries where a liberal concept of the state prevails (H5). The reverse is proposed for countries where a cooperative or a mixed concept of the state prevails. That is, in countries with a cooperative concept of the state, CSR is expected to be more closely associated with buycotting than labelling schemes (H6). In countries with a mixed concept of the state, on the whole both labelling schemes and CSR are expected to be less present than in countries where a cooperative or a liberal concept of the state prevails $(\mathrm{H} 7 \mathrm{a})$. But relative to each other, CSR is expected to be more important than labelling schemes in countries with a mixed concept of the state and thus to exhibit a closer association with buycotting ( $\mathrm{H} 7 \mathrm{~b})$.

Figure 13 and Figure 14 display the results obtained from conducting two corresponding cluster-analyses for the link between buycotting and labelling schemes on the one hand, and for buycotting and CSR on the other hand. Using hierarchical cluster analysis, the countries are clustered step by step according to close patterns in the relationships of buycotting with labelling schemes and with CSR (see Chapter 4.1.1). Correspondingly, the criterion for clustering is the distance between patterns and the aim is to keep this distance among countries within a same cluster minimal. ${ }^{71}$ The resulting cluster confirm the four expectations.

As Figure 13 illustrates, the spread of the labelling scheme is relatively high in Ireland and the UK compared to countries with similar percentages of citizens who have buycotted but which are classified as cooperative or mixed economies. Thus, it appears to be of particular relevance for buycotters in precisely the two liberal countries. Still, a major exception is Switzerland: the country exhibits a comparable amount of sales per capita of the Fairtrade Label as the UK and Ireland even though being classified by Hall and Soskice as cooperative market economy. However, a comparison with its classification in other studies and theories displays Switzerland's ambiguous position.

\footnotetext{
${ }^{71}$ The hierarchical cluster analyses rely on Ward's method. Beginning with 20 cluster with each comprising one 'member' i.e. country, the method joins countries step by step according to proximities (i.e. similarities). At each merger of two cluster, the aim is to keep the increase of within-cluster sum of squared errors minimal. The clustering process is terminated as soon as a subsequent merger implies a sudden 'jump' in distance coefficients (cf. Everitt et al. 2010,95-6). To equalise the effect of the variables measured on different scales, the method uses zscore standardisation of the variables and squared Euclidian distances as the measure (cf. Brosius 1998, 695-7 \& 715).
} 
Figure 13. The Relative Spreads of Buycotting and Labelling Schemes across Countries

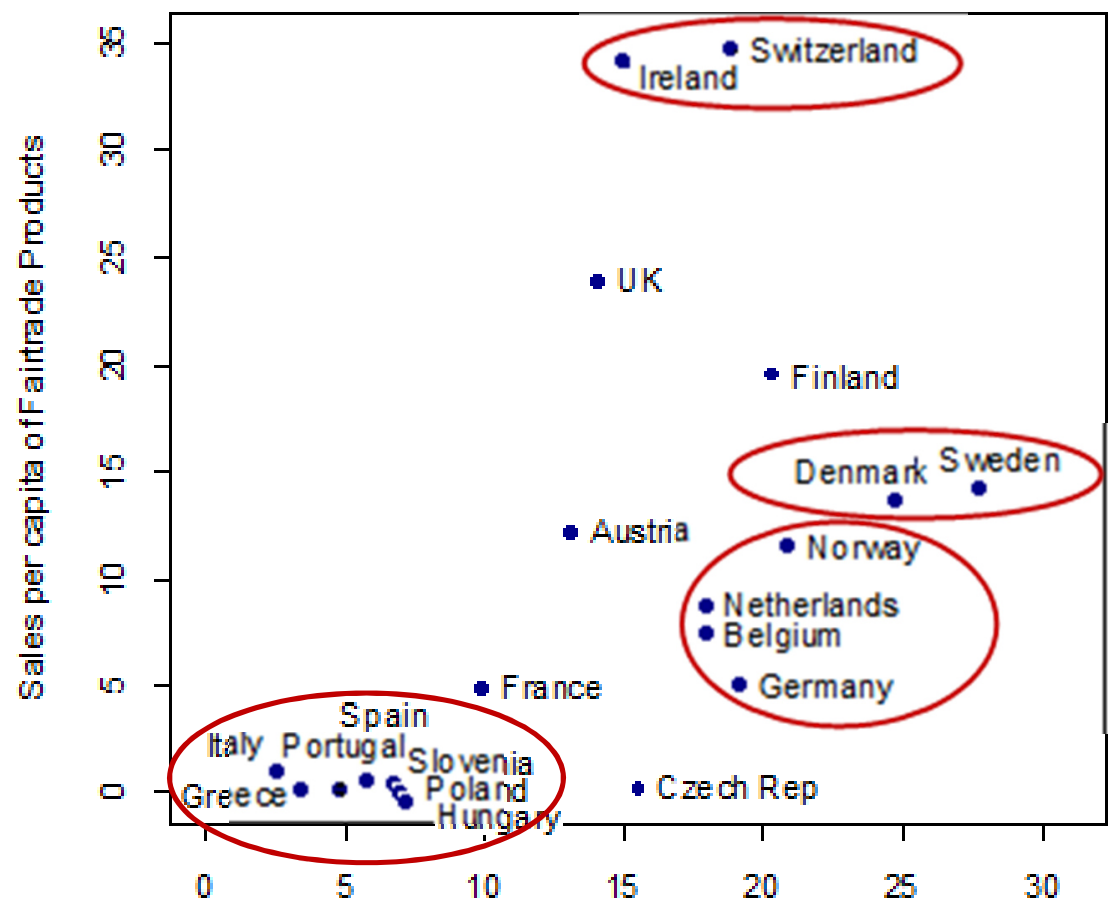

Citizens who have only buycotted (in \%)

Notes: Method: Hierarchical cluster-analysis, Ward-Method

Figure 14. The Relative Spreads of Buycotting and CSR across Countries

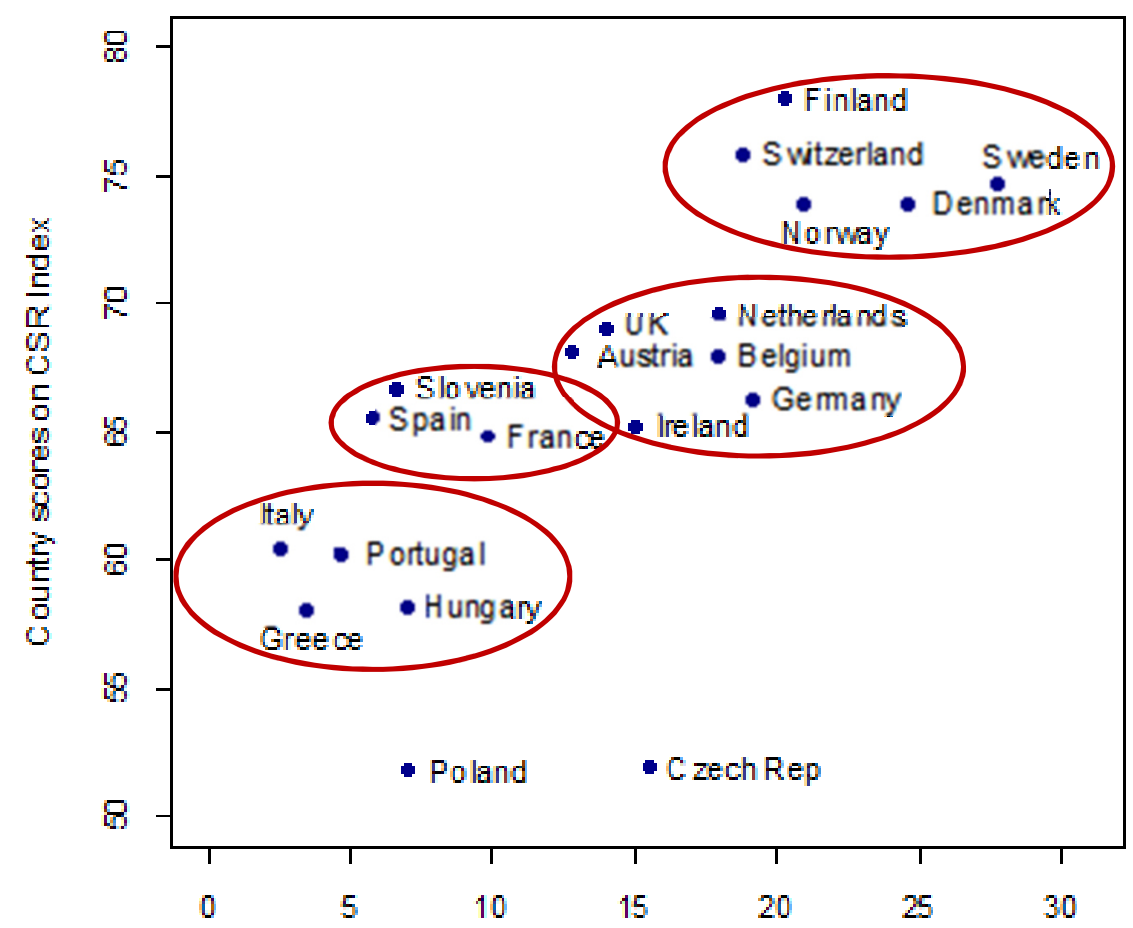

Citizens who have only buycotted (in \%)

Notes: Method: Hierarchical cluster-analysis, Ward-Method 
Esping-Andersen, for example, in his theory on the "Three Worlds of the Welfare State" (1990), classifies this country as liberal, while in a later revision he only partly discerns liberal features for Switzerland and refrains from classifying the country (Esping-Andersen 1999, 856; see also Schröder 2013, 32-6). Similarly, Hicks and Kenworthy (2003) as well as Schröder (2013, 124-6) discern liberal features as well as features that relate to the cooperative dimension for Switzerland. Taken together, this might mean that the fractions of citizens having a liberal and citizens having a cooperative concept of the state are similar, with the result that, on the country level, labelling schemes are as well accepted as CSR.

Turning to Figure 14, this suggestion is in fact further substantiated: Switzerland ranks among the highest scores on the CSR index, too. Besides to this positive finding, the clusters discerned in the figure for the bond between buycotting and CSR confirm the systematic differences between countries with certain concepts of the state. Nearly all countries classified as cooperative market economies score higher on CSR than the UK and Ireland. And, likewise, in cooperative countries with a similar score, more people buycott than in the UK and Ireland. Thus, in cooperative countries CSR is more closely related to buycotting than in the liberal countries. This is additionally underscored by the fact that, whereas the UK and Ireland rank highest for labelling schemes, it is the cooperative countries which rank highest for CSR. Accordingly, also the relative importance of labelling schemes for buycotting activity appears to be indeed higher in liberal countries. CSR in turn shows to be of higher relative importance for buycotting in cooperative countries. These results endorse H5 and H6.

Lastly, the mixed economies actually score low both on CSR and labelling compared to the other two country categories. This matches the expectation. However, also as advocated, they fare differently in CSR and labelling. More specifically, the comparison of the two shows that the former is much more prevalent. When taking into account the lower percentages of citizens who buycott in these countries, it becomes apparent that CSR plays a comparable role there for buycotting like in countries classified as cooperative market economies: the absolute percentages of citizens who buycott and of companies engaged in CSR may be higher in cooperative countries. Yet, in proportional terms, the relation between buycotting and CSR is essentially the same in countries with a mixed and a cooperative concept of the state. Hence, also the last two expectations, i.e. H7a and H7b, are confirmed.

To conclude, the results provide a positive answer to the central concern of this set of hypotheses as well as a possible answer to the accompanying question asked above: there is a clear tendency of countries with similar concepts of the state to agglomerate in the same clusters. Additionally, this appears to also be the reason for the outliers' existence: the UK and 
Ireland are countries classified as liberal market economies and in line with the theory developed it is exactly in these countries where the labelling scheme is of particularly high relevance; much higher than in countries classified as cooperative or mixed economies. The explanation for Switzerland, in turn, is more intricate. The country ranks very high both on the CSR index as well as in the sales of Fairtrade labelled products. Yet, it also moves in a somewhat ambiguous position between elements of a liberal and a cooperative concept of the state. This position may have provided for an especially conducive basis on which further factors could thrive and instigate the parallel rise of CSR and labelling schemes in Switzerland.

\subsection{Discussion}

All hypotheses are supported except for one. Therewith, the findings back the central assumptions that, first, the less present CSR and/or labelling schemes are in a country, the higher is the tendency of citizens to abstain from using their consumption as a tool to express political attitudes, and vice-versa. Likewise, CSR and labelling schemes are both linked with buycotting and boy- and buycotting. Thus, second, this underpins the idea that CSR and labelling schemes serve as an orientation for citizens who desire to buycott. This link seems to be independent of income, inclination to spend one's income on consumption and access to stores. Third, the extent to which either of the two serves as orientation indeed seems to be distinct across countries depending on the prevailing concept of the state: in countries classified as cooperative or mixed market economies, CSR exhibits a greater relative importance for buycotting than labelling schemes; in liberal market economies, in turn, labelling schemes appear to be of greater weight.

This also confirms the three research questions risen in the introductory chapter for the country level. Affirming $Q 1$, specific 'patterns' in boycotting and buycotting involvement vary in conjunction with certain 'patterns' in the distribution of labelling schemes and/or Corporate Social Responsibility. And, in affirmation of $Q 5$ and $Q 6$, they vary alongside with each other as $(Q 5)$ boycotting and buycotting involvement and (Q6) labelling schemes and Corporate Social Responsibility are distributed differently across countries depending on the prevailing concept of the state.

Beyond these confirmations, the correlation between boycotting and the labelling scheme opposes the expectation of hypothesis $\mathrm{H} 3 \mathrm{~b}$ and the two are related. Boycotting appears to expedite the spreading of labelling schemes. In spite of refuting $\mathrm{H} 3 \mathrm{~b}$, this is a clear-cut indication for the idea that involvement in boycotts is in part driven by the desire to initiate and advance the spreading of permanent, supervised guidelines as it are labelling schemes. This is further substantiated by the observation that only the label is linked to the spread of boycotting, whereas 
CSR is only related to the deliberate decision to purchase. At the same time, comparing the percentages of citizens who boycott with those who buycott or both boy- and buycott reveals a notably lower figure for boycotting. An explanation for this may be that some boycotters eventually 'become' buycotters, too, and then fall into the category of boy- and buycotter. Therewith, the finding backs the proposed process according to which some boycotter eventually turn to buycott as well, basing their purchasing decisions on the guidelines promoted by means of the previous boycotts.

On the whole, the findings thus endorse the theorised process of political consumerism on the macro-level. The results suggest a (non-linear) growing effect where 'pioneers' make the first step and start using their consumption to express political endeavours. Their action puts companies and institutions under pressure to adapt practices and regulations. Depending on the prevailing concept of the state, this might rather result in the increasing availability of labelling schemes or in a greater magnitude to which firms engage in CSR. The broader availability of CSR or labelling schemes then, in turn, facilitates buycotting. It permits more citizens to get involved in political consumerism since allowing them to tell apart the 'good' products or firms from the 'bad' ones. Moreover, being the result of their own previous activities, firms' societal involvement or labelling schemes can serve boycotters as a guideline for getting involved in buycotting, too. As a result, some citizens get involved in boycotting and in buycotting at once. According to this process, the more citizens decide to buy based on criteria of political nature, the more firms might sense the pressure to get involved. This in turn serves as a foundation for further political consumer action. Like a snowball, over-all action may promote the steady spreading of labelling schemes or CSR in a country and this again the continuous rise of boycotting and buycotting activity. 


\section{Examining Political Consumerism on the Micro-Level}

6.1 Surveying Boycotting and Buycotting Behaviour

The main assumption of the theory developed in this dissertation is that there is not one type of political consumer, but several. Depending on certain conditions and influences, individuals who become active political consumers may decide to do so differently, either by way of boycotting, buycotting products, buycotting firms, or by a combination of the three. As the previous chapter has shown, relationships observed on the country level suggest that the concept of the state as well as the spread of labelling schemes and CSR are factors that influence the decision. This chapter considers the individual level and tests the corresponding hypotheses. The aim is to examine whether individuals with a certain concept of the state and level of trust and confidence tend towards particular varieties of political consumerism.

An own survey conducted specifically for this purpose among 1.350 citizens living in Germany builds the basis for the analysis. The sample well replicates the population in Germany as it is depicted in the Microcensus 2012 (see Chapter 4). Yet, previous research has highlighted the influence of single socio-demographic characteristics on being involved in political consumerism. Therefore, to gauge a more precise idea of the extent to which the findings of the forthcoming analyses may be transferred onto more general terms, the first part of the chapter firstly reviews the socio-demographic antecedents of political consumerism in the sample. It then proceeds by presenting the core variables and their measurement. Based on this, the examination of the hypotheses and a brief discussion of the findings follows in the second part of the chapter. The conclusions in turn build the point of departure for the third and final part, which intends to corroborate the findings.

\subsection{Socio-Demographic Antecedents of Political Consumerism}

For the descriptive analyses, the sample is weighted for age, gender and education. ${ }^{72}$ Examining the socio-demographic distribution of political consumerism reveals that more women than men are active political consumers. Yet, the difference is very small: 63 percent of the women, and 60 percent of the men. Of this subset of active political consumers, 81 percent of both the women and the men indicate to have boycotted in the past 12 months. For buycotting it is more differentiated, with 85 percent of the women and 77 percent of the men indicating to having done so.

\footnotetext{
${ }^{72}$ Specifically, as presented in Chapter 4.2.2, it is one combined weight for the three indicators which ultimately reduces deviations from the participation ratios of the Microcensus to predominantly 0.1 percent; see also Appendix A.2.
} 
Looking at the entire set of respondents, as for the women 52 percent boy- and 54 percent buycott, whereas of the men, 48 percent boycott and 46 percent buycott. The values are slightly higher than the percentages obtained in older studies (cf. Teorell, Torcall, and Montero 2007, 338-9; Koos 2012a). Yet, bearing in mind that the political aspects surrounding consumerism are gaining more and more attention, the figures are conceivable (cf. Otto Group 2011, 10; 2013, 13; Stolle, Hooghe, and Micheletti 2005, 247-8; Stolle and Micheletti 2013, 48ff.).

Women seem to slightly prefer to buycott, men to boycott. In fact, of the men who are political consumers, almost one quarter merely boycotts, whereas the next most popular political consumer activity for men with 13 percent is boy- and buycotting of products. In contrast, women more than men boy- and buycott firms (58 percent of the respondents doing so are female). At the same time, the buycott of firms is done by slightly more men (56 percent), the buycott of products more often by women (60 percent). These observations are interesting since the diverging associations of buycotting alone on the one hand, and combined with boycotting on the other hand, suggest that men and women might attach their boycotting activities to different characteristics. The later analyses allow developing on that idea further. Overall, women display no clear tendency towards a specific type of political consumerist activity, while men tend to boycott. But the men's preference for boycotts appears to be due to another aspect than their gender.

When looking at age, the fraction of political consumerism is 72 percent for the youngest and around 60 to 65 percent among middle to older age groups. With 50 percent, only slightly fewer individuals are active in the oldest generation as well as in the group between 55 and 59 . Simultaneously, a larger fraction of the older than of the younger political consumers has not yet boycotted $\left(\chi^{2}(10)=18.821, p=.043\right)$. Though beyond that, age does not appear to be linked to any particular variety of political consumerism.

Education shows to be of greater relevance. Lower levels of education go hand in hand with lower fractions of individuals being involved in political consumerism, and degrees of higher education with a higher percentage of political consumers. This holds for boycotting and for buycotting products. ${ }^{73}$ The buycotting of firms in turn does not appear to be of smaller prevalence among the lower levels of education. ${ }^{74}$ What is more, when looking alone at the fraction

\footnotetext{
${ }^{73}$ In detail, boycotting and buycotting of products is noticeably more prevalent among higher levels of education both in the case when looking at the entire sample as well as when looking at the subset of political consumers ( $p=.000$ and .003 for boycotting, respectively; and, equally, for buycotting of products it is $p=.000$ and .003 , respectively; measure of correlation is Gamma; calculations based on unweighted data).

${ }_{74}$ Testing the difference across levels of education in a Kruskal-Wallis Test reveals a significant difference between higher and lower levels of education when looking at the entire sample $\left(\chi^{2}(5)=36.077, p=.000\right.$; for comparison: $\chi^{2}(5)$ is 66.133 for boycotting and 67.544 for the buycotting of products). Yet, when considering only the subset of political consumers, this statistically significant difference vanishes (the calculations are based on unweighted data).
} 
of political consumers, buycotting of firms is even more prevalent among the lower compared to the higher levels of education. Specifically, the fraction of individuals who only buycott firms is almost twice as high among those with no degree (yet) or the lowest school diploma than among the other higher levels of education (12 and 14 percent, respectively, compared to 5 to 8 percent among the other levels of education; $N=77, p=.004)$. Instead, with rising education, the tendency is to combine the entire three, i.e. to boycott, buycott products and buycott firms. This puts forward the notion that not only the percentage of active individuals is higher for higher education levels but also their 'intensity of activity'.

The basic socio-demographic statistics of the survey mirror the findings of previous studies, that is, women, the highly educated as well as the younger generations, tend to be the ones who are particularly active in political consumerism (see for example Acik 2013, 9-11; Copeland 2014b, 14; Micheletti and Stolle 2004; Newman and Bartels 2011, 810-2; Strømsnes 2005; Tobiasen 2005; Koos 2012a, 47; Krystallis and Chryssohoidis 2005, 322-3; Padel and Foster 2005, 608; Stolle and Micheletti 2005, 46; 2013, 68-70). Nonetheless, men have become very active, reaching almost same levels of involvement as women. Similarly, the variation in the levels of involvement in political consumerism across age groups is not very high. ${ }^{75}$ Besides, individuals with higher levels of education appear to not only get involved more often in political consumerism but also more intensively. On the whole, single types of political consumerism appear not to be strikingly characterised by gender, age or education. Thus, these variables offer no substantial response to the question for why some individuals decide to merely buycott, some to alone boycott, and some to combine the two. Instead, the results back the idea that there are additional factors which come into play at the time of deciding on how to consume politically. The theoretical framework recommends the concept of the state combined with confidence in labelling schemes or firms' societal involvement. The next section first provides a rough sketch of the questionnaire and reviews the hypotheses to recapitulate the core concepts of the theory. It then proceeds to presenting the measures used for these concepts for the later analysis.

\footnotetext{
${ }^{75}$ In the ESS 2002/03 for example, the fraction of political consuming men was significantly lower than for women, for both boycotting and buycotting $(z=-3.628, p=.000$ and $z=-9.010, p=.000$, respectively; cf. European Social Survey 2002b). Ten years later, this difference had vanished. And in line with it, the present survey confirms this for boycotting; nevertheless, buycotting is still somewhat more popular among women $(z=-3.101$, $p=.002$; calculated based on unweighted data).
} 


\subsection{The Questionnaire}

\subsubsection{Background and Characterisation}

The questionnaire contains 42 questions of which 39 are closed and three are open-ended questions. ${ }^{76}$ The closed questions are followed by 7-point scales for the most part or they provide several options and the respondents are asked to check the applicable one or, in some cases, one or more possibilities. The 7-scale items are partly agglomerated under an identical answering option. In total, there are nine such matrix questions. Three of them are randomly shuffled across participants with the aim of averting answering biases which could be caused due to a specific order in which the questions are posed..$^{77} 23$ questions are compulsory to be answered and three are contingent questions, i.e. they are only presented to the respondent if answered in a certain way beforehand. ${ }^{78}$

1.497 persons have completed the entire questionnaire. Yet, 147 cases are excluded from the analysis because they were completed e.g. too quickly or the respondents ticked (8 questions or 5 percent of all questions) with "don't know" too often. The average duration of completing the questionnaire was 11 minutes $(S D=4$ minutes $)$.

\subsubsection{Core Aspects of Political Consumer Behaviour}

The theoretical framework departs from the idea that there are different types or combinations of political consumer activity and it asks why individuals engage in these different combinations. Hypotheses h1a to h1c refer to non-political and political consumerism as the dependent variable. Hypotheses 2 a to h6 refer to single varieties, i.e. boycotting, buycotting products, buycotting firms and boy- and buycotting products. Accordingly, the questionnaire needs to allow for gathering political consumerism as a practice by individuals of different combinations of varieties of political consumer behaviour.

Individuals' tendency to practice one or the other combination of political consumerism is supposed to vary depending on four factors. General trust and the concept of the state are proposed to influence the tendency to be involved in political consumerism or not (hypotheses hlac), as well as the tendency to boycott (h5a-b). Besides, depending on their concept of the state, individuals are also suggested to be more or less likely to buycott products, firms or to boy- and

\footnotetext{
${ }^{76}$ Yet, for two of these open-ended questions, the answer options are in fact limited, too, since they ask for numeric information. One assesses the number of days in the week on which the respondent reads a newspaper, and the second asks for the number of children living in the household that are younger than 15 years.

77 These are questions on (1) Good Citizenship, (2) Involvement Types, (3) Digital Natives/Aliens Typology.

${ }^{78}$ These are on (1) Political Consumerism online, (2) Type of Employment (this question succeeded the more general question on employment status, and so if being e.g. a student or a pensioner, this question was not presented), (3) Classification within the Middle Class.
} 
buycott (hypotheses h2a-b, h4 and h6). A third factor rests on the idea that having more confidence in labelled than in non-labelled products guides the decision to boycott or to buycott products (h3a-b, h5a, h5c). Lastly, having more confidence in firms which are involved in CSR than in non-involved firms is expected to facilitate the buycotting of firms (h3b, h4). Consequently, the questionnaire needs to cover four aspects for the independent variables: (1) general trust in co-citizens, (2) the concept of the state, (3) confidence in labelled compared to nonlabelled products, and (4) confidence in firms that are involved in CSR compared to non-involved firms.

\subsubsection{Measuring Boycotting and Buycotting}

\section{Political consumerism is defined as}

the deliberate decision to buy or not to buy a specific product out of politically natured reasons. (ref. to Chapter 2.1.1)

It comprises the boycott and the buycott. Furthermore, the theory introduced the distinction between a buycott based on the nature of the product and a buycott based on the firm associated with the purchase. The crucial assumption is that individuals do not necessarily engage in boycotting and buycotting products and buycotting firms. Instead, each citizen may individually decide which of the three to use and which not. So, individuals may combine the three basic varieties of action differently.

The theory draws a framework that explains why individuals may convert attitudes into behavioural action differently. That is, how the individuals' perception of their environment (i.e. the macro-level), the norms they associate with it and the expectations they have of all actors involved influence the transfer of their fundamental values and attitudes into behavioural action. Accordingly, the theory considers individuals' tendency towards doing certain types of political consumer activities, not the intensity with which a participant is involved in it. ${ }^{79}$ In view of that, the measure for a precise dependent variable must adhere to two requirements: firstly, it has to be able to cover different combinations of the three basic varieties depending on whether an individual has ever engaged or not in each one of them. Secondly, the measure has to allow for clearly distinguishing between individuals who have ever done so and individuals who have never done so.

\footnotetext{
${ }^{79}$ In contrast to the tendency, the intensity is linked to what the individual expects from the self to do and how to behave given the own ideas and views concerning e.g. the environment or animal rights. Hence, it is linked to the individual's desired self-perception, i.e. the micro-level rather than the macro-level.
} 
The survey includes three questions that ask whether in the past 12 months the respondents have (1) boycotted, (2) buycotted products and (3) buycotted firms. The possible answers include three options: (1) never, (2) once or a few times, and (3) regularly (see Appendix A.1). To fulfil the second requirement of the measure, the two answer categories "have done so once or a few times" and "have done so regularly" count in the same way and are pooled for the dependent variable of the main model. Based on this the creation of a set which comprises the distinct varieties of political consumer involvement follows; combining the participants' answers to all of the three questions provides eight possible combinations or modes of political consumer involvement:

0) no political consumer activity

1) boycotting

2) buycotting products

3) buycotting firms

4) boycotting and buycotting products

5) boycotting and buycotting firms

6) buycotting products and firms

7) all three activities combined (i.e. boycotting as well as buycotting products and buycotting firms)

The resulting nominal variable for 'Political Consumerism' includes these eight varieties. Non-political consumerism is set as value 0 ; the others are numbered from 1 to 7 in the above consecutive order. Table 11 presents the number of respondents for the different combinations of political consumer activities as well as their percentage as of the total number of respondents.

As clearly observable, with more than one third of the respondents, the largest part is not consuming politically. Yet, after all, 60 percent state to consume politically. When differentiating between boycotting and buycotting, independent of whether they are combined or not, it is 50 percent of individuals who indicate to have done so for each. This clearly surpasses the figures obtained for Germany in studies a few years ago and illustrates the continuing rise of political consumerism. ${ }^{80}$ What is more, only a little bit less than another third states to have already done even all three types of political consumerism, i.e. boycotting as well as buycotting

\footnotetext{
${ }^{80}$ In the Citizenship, Involvement, Democracy Study conducted in 2000, 33 percent respondents in West- and 17.5 percent of respondents in East Germany indicated to be active political consumers. In West Germany, 23 percent had boycotted and 25 percent had buycotted. In East Germany, it was 11 and 13 percent, respectively. In the ESS conducted two years later (2002/03), it was 26 percent who had boycotted and 39 percent who had buycotted (West and East Germany together; European Social Survey 2002b; see also Koos 2012a, 46, and Micheletti, Stolle, and Berlin 2012, 151). Ten years later, in the $6^{\text {th }}$ wave of the ESS, the figure had risen to 36 percent who had boycotted (European Social Survey 2012; unfortunately, the survey did not assess buycotting in any wave after round 1). This reflects the continuous rise of political consumer activity in Germany. Finally, the figures obtained for boycotting in a study commissioned in 2014 by the German Federal Ministry for Economic Affairs - 45 percent boycotter in West- and 31 percent in East Germany - further underscore the soundness of the figures obtained in the present survey (cf. Holtmann et al. 2015, 47).
} 
products and buycotting firms. This scope underscores the meaning which political consumerism has reached in today's society and everyday life.

Table 11. Varieties of Political Consumer Behaviour

\begin{tabular}{|c|c|c|}
\hline Political Shopping Activities & $\mathbf{N}$ & $\%$ of total \\
\hline No political consumerism & 518 & 38.4 \\
\hline Boycotted (but not buycotted) & 157 & 11.6 \\
\hline $\begin{array}{l}\text { Buycotted (but not boycotted), } \\
\text { therefrom: }\end{array}$ & $158^{1}$ & 11.7 \\
\hline a. Buycotted Products only & 45 & 3.3 \\
\hline b. Buycotted Firms only & 77 & 5.7 \\
\hline c. Buycotted Products \& Firms & 36 & 2.7 \\
\hline $\begin{array}{l}\text { Boycotted } \\
\text { \& Buycotted Products }\end{array}$ & 107 & 7.9 \\
\hline $\begin{array}{l}\text { Boycotted } \\
\text { \& Buycotted Firms }\end{array}$ & 63 & 4.7 \\
\hline $\begin{array}{l}\text { Boycotted, Buycotted Products } \\
\text { \& Buycotted Firms }\end{array}$ & 346 & 25.7 \\
\hline Total N & 1350 & 100 \\
\hline \multicolumn{3}{|c|}{$\begin{array}{l}\text { Notes: Political shopping activities are here measured as binary variables, i.e. never done } \\
\text { on the one hand and, on the other hand, done once, several times or regularly and then } \\
\text { pooled in the one variable "Political Consumerism", with non-political consumerism set } \\
\text { as } 0 \text { and the others consecutively numbered from } 1 \text { to } 7 \text {; } \\
\text { The values are calculated based on the weighted data set. }\end{array}$} \\
\hline \multicolumn{3}{|c|}{$\begin{array}{l}{ }^{1} \text { This figure refers to the sum of participants who state to only have buycotted products, } \\
\text { to only have buycotted firms or to have buycotted products and firms. It depicts whether } \\
\text { a participant has alone buycotted in some way but never boycotted. The dependent varia- } \\
\text { ble does not cover this as a separate category given that in the theory one central idea is } \\
\text { precisely the further difference between buycotting products and buycotting firms. }\end{array}$} \\
\hline
\end{tabular}

Next to the two extremes, the remaining respondents are mainly spread out in similar fractions on three varieties: boycotted but not yet buycotted (11.4\%), buycotted but not yet boycotted $(11.7 \%)$ or both boycotted and buycotted products $(7.9 \%)$. This makes evident that there are indeed substantive different combinations of political consumerist activities. Only when further breaking down buycotting into buycotting firms and buycotting products, the percentages and thus the categories' relative importance drops. These results underscore the need for studying political consumerism not as a single entity but by treating and examining boy- and buycotting as distinct phenomena. The presented dissection of political consumerism into eight categories allows for doing so in the succeeding analyses. Each variant of political consumerism can be assessed individually for its relationship with the independent variables, and the individual relationships can be compared among each other. Furthermore, the categorical variable serves as dependent variable in a multinomial logistic regression. This permits to assess whether 
individuals, given a set of factors, are more likely to be involved in one or the other variety of political consumerism.

\subsubsection{The Concept of the State}

The concept of the state is defined as citizens' attitudes concerning the state, the market and civil society and their view about who is responsible for what, how the cooperation between the various actors involved should look like and which role each of them should take over (see Chapter 3.1.2 ref. to Almond and Verba 1996; Kim et al. 2012; North 1990; Pickel and Pickel 2006). It embraces five different ambits or actors towards which citizens may cultivate attitudes: (1) the 'market', (2) the state, (3) NGOs working in the sphere of consumer protection and representation, (4) firms, and (5) consumers.

The notion of the concept of the state is inspired by the theory on varieties of capitalism by Hall and Soskice, which is applied on entire countries. In contrast, the concept is applied here on individual citizens' views and it is attached explicitly to their attitudes towards aspects concerning market relationships and responsibilities. ${ }^{81}$ Therefore, the survey includes a set of five originally designed items each covering one of the five actors. Given that the concept of the state relates to the fundamental attitude on constitutive elements of the political and socio-economic processes in a country, the question considers regulating principles and spheres of responsibility. In concrete, comprising five items, the question asks survey participants for evaluating the relevance of five principles in economic- and consumer politics, with each item relating to one of the actors. By referring to the importance of free market competition between firms, the first item is designed to reflect the respondents' tendency to rely on the market. The second considers the extent to which the respondent seeks involvement of consumer associations in protecting consumers, whereas the third item is set to reveal a respondents' inclination to reckon the need for state intervention in consumer concerns. The fourth and the fifth items gauge the degree to which the respondent considers firms should take over societal responsibility voluntarily, and the extent to which a respondent deems consumers in charge to assume responsibility themselves, respectively. The evaluation ranges on a scale from -3 (not important at all) to +3 (very important).

\footnotetext{
${ }^{81}$ Previous studies generally attach the concept of the state alone to the country level and maintain this macro perspective along the study. In doing so, the studies commonly also base their conclusions on global, macrolevel observations and country level indicators, not from surveying individual citizens (cf. for example Akkermans, Castaldi, and Los 2009; Bair and Palpacuer 2012; Hall and Gingerich 2004; Pierson 2006; see also Lane and Myant 2007, 1-9).
} 
Resting on Hall and Soskice's theory on varieties of capitalism, hypotheses (h1a-c, h2a-b, $\mathrm{h} 4, \mathrm{~h} 5 \mathrm{~b}-\mathrm{c}$ and h6) refer to the concept understood as a binary classification model. Citizens may either prefer to solve challenges of socio- and economic-political relevance by following a strategy that focuses on cooperation and solidarity. Or, on the opposite, they might rather rely on the problem-solving capacity of free market competition and thus hold the view that there is no need for further intervention or assistance of others (e.g. the state or NGOs) for promoting the solution of given challenges. As a result, the variable used in testing the hypotheses should depict respondents' belonging to either a liberal or a cooperative concept of the state. Besides, the liberal or cooperative preferences relate to different ambits or actors, that is, the 'market', firms, the state, consumers, as well as NGOs working in the sphere of consumer protection and representation. The final classification model thus needs to consider respondents' attitudes towards each of the actors.

These two requirements placed on measuring the concept of the state recommend using a multiple-indicator measure in a first stage, and then merge the results into a single variable that reflects the liberal and the cooperative views as two opposite poles. This proceeding allows for covering citizens' attitudes towards the five actors without remaining on a too general level (cf. Bryman 2001, 67-9). Transferring the responses in a single measure afterwards permits to assign respondents as having one or the other concept of the state.

The survey question presented constitutes a corresponding multiple-item measure. It delivers five answers where a high rating denotes a high importance assigned to the principles embraced by the respective items. High importance assigned to items (1), (4) and (5) reflects a liberal position; high relevance given to the principles covered by items (2) and (3) points to a cooperative stance. The comparative evaluation of the five items indicates a person's relative inclination towards a liberal or cooperative view. To facilitate further analyses and avoid ambiguous interpretations, after conducting the survey the items are aligned; that is, they are rescaled so that for all five items low values relate to a 'cooperative' and high values to a 'liberal' attitude. ${ }^{82}$ A subsequent Principal Component Analysis (PCA) reveals one strong component. The three liberal indicators load positively on it, the two cooperative measures negatively (cf. Table 12). Given these antithetic loadings, the component reflects the extent to which a respondent puts weight on the liberal compared to the cooperative principles in economic- and consumer politics.

\footnotetext{
${ }^{82}$ As a standard setting in the survey system used (SoSci Survey; see www.soscisurvey.de), the scores are directly transferred from the -3 to +3 scale to a fully positive scale in the data set, i.e. the evaluation scores range from 1 to 7 . Accordingly, in the end a rating of 1 indicates a cooperative position concerning the issue reflected in an item, 7 a liberal position.
} 


\begin{tabular}{lc}
\hline \hline Item & Concept of the State \\
\hline (1) Protection of free competition between firms. & .632 \\
$\begin{array}{l}\text { (2) Influential representation of consumer interests, e.g. } \\
\text { consumer associations. }\end{array}$ & -.743 \\
$\begin{array}{l}\text { (3) Extensive state protection of consumer vis-à-vis } \\
\text { firms. }\end{array}$ & -.683 \\
(4) Voluntary takeover of responsibility by firms. & .703 \\
(5) Personal responsibility of consumers for what they \\
buy.
\end{tabular}

Method of Extraction: Principal component analysis with Promax rotation method. $\mathrm{KMO}=.758 ;$ Bartlett-Test $\mathrm{Chi}^{2}=1124.156 ; p=<.001$

To construct a measure for the concept of the state, each of the five items is multiplied with its corresponding factor loading and then added up with the others. Given the positive and negative factor loadings, the liberal items enter the equation with positive values and the cooperative with negative values. Thus, the latter are in fact subtracted from the former, resulting in a scale that spreads between the two extremes: ${ }^{83}$

Concept of the State $=($ Free Market Competition * 0.632 $)+($ Consumer Associations Participation * -0.743$)+($ State Intervention * $(-0.683)+($ Firms' Voluntary Takeover of Responsibility * 0.703$)+($ Personal Responsibility of Consumers * 0.676$)$

The upper end of the scale reflects a greater preference for liberal approaches, the lower end a greater preference for cooperative approaches. ${ }^{84}$ Figure 15 displays the distribution of the resulting values. Given the overhang of three liberal compared to two cooperative items, the

\footnotetext{
${ }^{83}$ An additional Principal Component Analysis conducted with the explicit requirement to extract two factors substantiates the measure: items (1), (4) and (5) load on one component, with loadings of .862, .591 and .734, respectively; items (2) and (3) load on a second component, with loadings being .750 and .942 (together, they explain $64 \%$ of variance; method of extraction is Promax rotation). This confirms that the respective items measure two different phenomena, that is, the two latent variables 'liberal' and 'cooperative' concept of the state. In addition, the components extracted serve for creating two variables to verify the single variable, one representing a 'liberal' and one a 'cooperative' attitude. They correlate with the concept of the state variable as intended: the correlation is positive of the liberal measure with the concept of the state variable $(r s=.884, p=.000)$, supporting that high values of the concept of the state variable depict a liberal view; and the correlation is negative with the cooperative measure $\left(r_{s}=-.815, p=.000\right)$, confirming that low values of the concept of the state variable depict a cooperative view. The correlation between the liberal and cooperative measures is negative and moderate $(r s=-.481, p=.000)$. This reinforces that the two measure distinct attitudes. Yet, it also underscores that the two merely represent tendencies, as respondents overall tend to rate all the items as being more or less important. ${ }^{84}$ The correlations of the concept of the state variable with the single items that underlie the measure confirm the links $\left(r_{s}=.662, .737\right.$ and .681 with the three liberal items, - .720 and -.670 with the two cooperative items; for all $p=.000)$
} 
upper end of the scale is sparsely populated. ${ }^{85}$ Also, a large fraction of respondents shows to be merely inclined towards having a cooperative or a liberal position; that is, they generally rate all items at least as being somewhat important but regard some to be slightly more important than others, comparatively. As a result, they are situated off the extremes. Albeit, approximately 20 percent of respondents are situated close to either of the two extremes.

\section{Figure 15. Distribution of Liberal and Cooperative Inclinations}

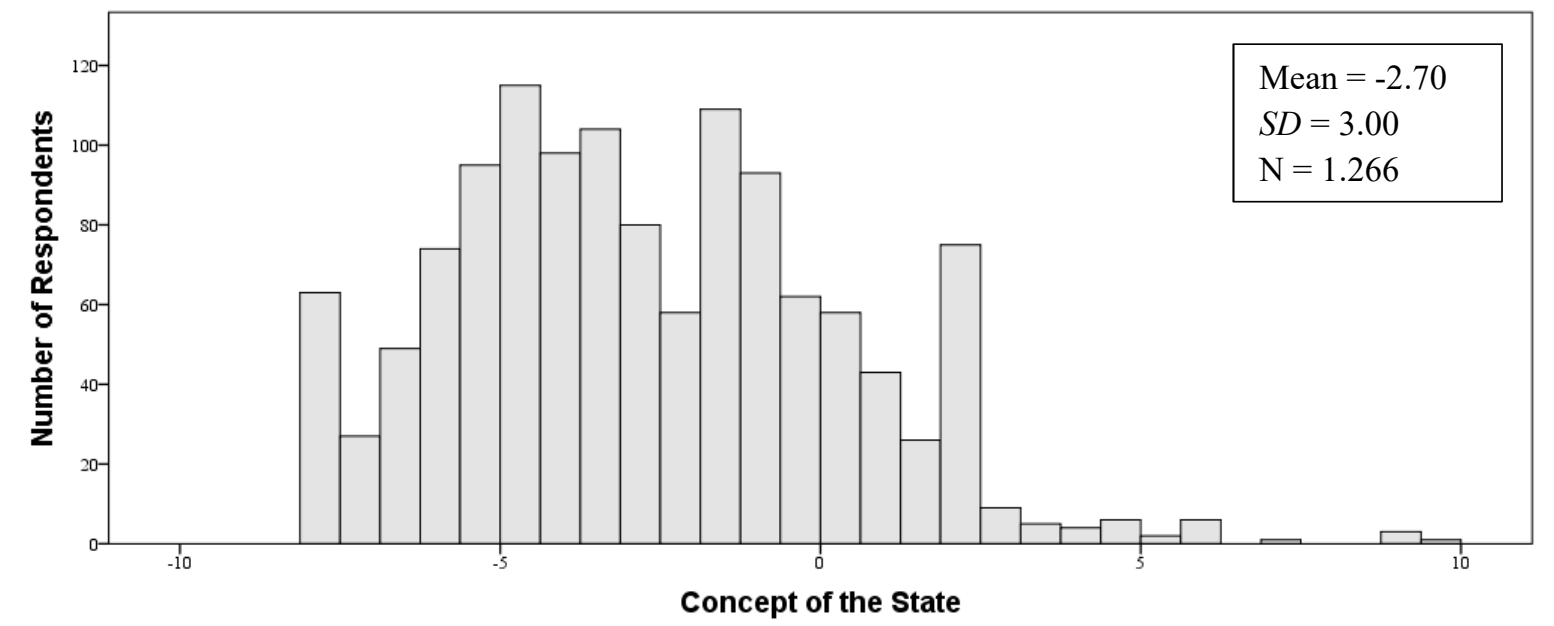

The theory on the concept of the state rests on the assumption that citizens have one or the other view, not on the 'intensity' of their view. Therefore, in a last step, the variable is split at the median into a binary variable, wherein 1 stands for the cooperative and 2 for the liberal concept of the state. In the end, the binary variable correlates very well with the continuous variable for the concept of the state $(r s=.866, p=.000) .{ }^{86}$ Correspondingly, it appears to appropriately reflect the concept of the state for the later analyses. ${ }^{87}$

\subsubsection{Confidence in Labelling Schemes}

The second independent variable at the heart of the theory considers confidence in labelled as compared to non-labelled products. Labelling schemes have been defined as symbols and marks that shall inform the consumer about a company's or a product's compliance with a certain standard or norm which is supervised by some (independent) institution other than the company itself (cf. Chapter 3.2, ref. to Lindén 2005). The idea drawn in the theory presented is

\footnotetext{
${ }^{85}$ Analogous, when considering the three liberal items as one variable and the two cooperative items as another, separate variable, the range for the liberal variable is 10.08 , whereas for the cooperative it is 8.56.

${ }^{86}$ The correlations of the binary variable for the concept of the state with the single measures for a liberal and a cooperative view are moderate $\left(r_{s}=.762, p=.000\right.$, and $r_{s}=-.673, p=.000$, respectively). But they are certainly acceptable, bearing in mind that the two variables' scale ranges are compressed into a binary scale comprising two values: 1 and 2 . In such a process, information is necessarily lost.

${ }^{87}$ The distribution of the concept of the state across age, gender and levels of education is provided in Appendix A.3.
} 
that in an environment in which individuals lack trust, labelling schemes may provide individuals with guidance on what is - from a relative vantage point - 'good' and what is not. 'Good' in this context refers to the adherence of aspects that are considered to be desirable from an ecological, ethical, social and/or other politically natured point of view. In sum, a labelling scheme is intended to inform the individual on whether buying a certain product supports and/or adheres to determined criteria. This information serves as a basis for evaluating which product can or should be buycotted.

In the very moment of deciding whether to buycott a product, the immediate comparison with products of the same category will be crucial since the decision commonly is not whether to buy a type of product; this is usually given, since the type of product is needed or desired. Instead, the question guiding the decision rather is which product to choose of the given type. At that point, viewing a labelled product and attaching to it a higher level of confidence than to the other products of the same type which are not labelled may be a decisive criterion promoting a positive buying decision.

Thus, a measure for confidence in labelling schemes as it is understood in the theory has to fulfil three criteria: firstly, it refers to labelling schemes as attempts to permit individuals to infer how a relatively anonymous counterpart behaves. Consequently, confidence applies rather than trust (see Chapter 3.2, ref. to Offe 1999, 43-4 \& 63). This means, a measure for confidence should consider the attitude towards labelling schemes generally rather than the attitude towards single concrete labels. This permits to gauge the respondents' confidence in an abstract image of labelling schemes. Otherwise, if the respondent is familiar with the particular label, the measure may be gauging the respondents' reliance and/or experiences concerning this specific label instead of the respondents' general impression of labelling schemes. Hence, the measure might be reflecting trust rather than confidence, and distort findings. Secondly, the measure has to assess the comparative level of confidence, that is, the confidence one has in labelled products as compared to the confidence the citizen has in products that are not labelled. Thirdly, the theory centres on a binary relationship. Therefore, the final variable should plainly depict whether respondents have or have not a higher level of confidence in labelling schemes (cf. De Vaus 2002, 190).

There is no existing measure known which generally gauges confidence in labelled as compared to non-labelled products. Instead, the measures commonly connect the question of confidence with particular labels. Therefore, the survey includes two questions which consider individual's attitude towards labelling schemes. The first goes along the lines of the common procedure and precedes a set of labelling schemes where respondents are asked whether they are 
familiar with each of the four labels or not. Afterwards, it asks to indicate on a scale from -3 (not at all) to +3 (fully) how much the respondent trusts such labelling schemes. ${ }^{88} \mathrm{~A}$ second question follows asking to indicate on a scale from -3 (not at all) to +3 (fully) whether the respondent generally has more confidence in products that are marked with a label than in products that are not labelled.

Thus, the first question measures the level of trust or distrust the respondent has in a quite specific set (or idea of a set) of labelling schemes. By presenting respondents to a specific set of labelling schemes, they construct a tangible idea of labelling schemes upon which to base their answer. This furnishes results that can be put into relation with former studies and serve to check for the study's external validity. In contrast, the second question measures whether the respondent has the same level of confidence in labelled and non-labelled products or whether the respondent has more confidence in the first than in the second. Thus, it unites the above compiled requirements to the measurement of the independent variable for the final model: it does not relate to specific labelling schemes but remains on a remote and 'anonymous' level; it asks for a comparative assessment and thus gauges the relative level of confidence in labelled as compared to non-labelled products; and it provides a suitable grounding for calculating a two-category option.

The two items for trust and confidence correlate quite highly, yet not as much as if they were measuring exactly the same underlying concepts $\left(r_{s}=.728, p=.000\right)$. Hence, they head into the same direction; that is, citizens having high values at one indicator tend to have a high level at the other, too, and the reverse at the lower end of the scale. Contrasting the two variables' mean values for the various types of political consumerism reveals a slightly higher mean level of absolute trust than of relative confidence (see Table 13). The only exception is the case of boycotters, where it is the reverse.

The last observation matches the findings of a study $(\mathrm{N}=300)$ on knowledge and trust in labelling schemes of consumers in Germany conducted by the University of Goettingen in 2012 (see von Meyer-Höfer and Spiller 2013): the study advocates a high level of trust in those labelling schemes which the respondents are actually familiar with. Whereas its findings propose that despite their trust in labelling schemes, citizens do not generally attach a more superior grade to the labelled products. Thus, in the comparative evaluation of labelled versus non-labelled products, the former do not score much higher than the latter.

${ }^{88}$ Alternatively, if respondents are unfamiliar with such labelling schemes, they could also indicate this instead of a rating. 
Table 13. Absolute and Relative Confidence across Types of Political Consumerism

\begin{tabular}{lcccc}
\hline \hline & \multicolumn{3}{c}{ Absolute Confidence } & \multicolumn{2}{c}{ Relative Confidence } \\
\cline { 2 - 5 } & Mean $(S D)$ & $\mathrm{N}$ & Mean $(S D)$ & $\mathrm{N}$ \\
\hline Boycotter & $3.73(1.70)$ & 156 & $3.86(1.87)$ & 155 \\
Buycotter of Products & $4.86(1.22)$ & 45 & $4.73(1.54)$ & 44 \\
Buycotter of Firms & $4.43(1.24)$ & 77 & $4.26(1.65)$ & 75 \\
Boy- and Buycotter of Products & $4.64(1.46)$ & 106 & $4.62(1.52)$ & 106 \\
Boy- and Buycotter of Firms & $4.57(1.35)$ & 63 & $4.47(1.63)$ & 63 \\
Buycotter of Products and Firms & $5.19(1.22)$ & 36 & $5.03(1.46)$ & 36 \\
Boy- and Buycotter of Prod. \& Firms & $5.05(1.39)$ & 344 & $5.03(1.54)$ & 345 \\
No Political Consumer & $3.89(1.60)$ & 506 & $3.62(1.65)$ & 505 \\
\hline Notes: The values are calculated based on the weighted data set. & \multicolumn{3}{l}{} \\
The levels of absolute and relative confidence all differ to a statistically significant extent \\
(paired t-test: $t(1322)=3.478, p=.001)$
\end{tabular}

The last step consists in creating a binary version that allows for clearly distinguishing individuals having a higher level of confidence from those who have not. In the survey, the respondents answered on a scale extending from -3 to +3 . Yet, within the final data set, the answer scores are actually coded on a fully positive scale ranging from 1 to $7 .{ }^{89}$ Hence, the mean value for the confidence in labelling schemes measure is $4.24(S D=1.73)$, its median is 5. ${ }^{90}$ This coincides with the underlying intention of the question design: the question is posed such that values above 4 equal a more of confidence in labelled versus non-labelled products. This match underscores the internal validity of the measure. Following this, the answers are pooled in a binary variable, with the median serving as reference value: all responses with a scale value equal to or higher than 5 are classified as having a higher level of confidence in labelled products than in non-labelled products; answers below as not having more confidence in labelled as compared to non-labelled products.

Finally, the first category (having more confidence) is assigned with the value 1 whereas the latter (not having more confidence) is set as 2 . The reason for this reverse order lies in the purpose to improve the interpretability of the chosen model when considering the wording of the hypotheses: the hypotheses (h3a and h5a) propose that more confidence is linked to being more likely to be a certain type of political consumer. In the ensuing assessment method, the last category serves as the baseline group to which the former categories are compared. Therefore, to set the group which does not have more confidence in labelled than in non-labelled products as the baseline provides results which can be interpreted exactly along the lines of the

\footnotetext{
${ }^{89}$ As mentioned above, this is a standard setting in the survey system used (SoSci Survey).

90 The values are calculated based on the unweighted sample.
} 
hypotheses: whether individuals with more confidence are more likely than individuals with not more confidence to be a certain type of political consumer. ${ }^{91}$

\subsubsection{Confidence in Corporate Social Responsibility}

The third key independent variable is confidence in firms that are involved in Corporate Social Responsibility, or in short 'CSR'. CSR refers to the different ethical, social, and environmental practices of companies and according to the typical understanding of the concept, firms commit themselves voluntarily to these practices (cf. Chapter 3.2, ref. to European Commission 2011; Lin-Hi 2008). Despite that, many a time their commitment goes hand in hand with responding to existing consumer concerns (European Commission 2011). The areas of commitment are manifold, including ecological production and environmental protection, 'fair' working conditions and projects that promote e.g. social welfare.

The idea drawn in the theory is that engaged firms differentiate themselves from non-engaged ones. In committing to CSR, firms offer individuals a guideline that allows them to distinguish whether buying from a particular firm supports concerns which from an ethical, social and/or ecological vantage point are considered to be important or sought after. Yet, a firm's CSR activities typically are not directed straight to the individual itself (cf. Friedman 1996, 443-4). This missing immediate interaction makes it difficult to evaluate a firm's intentions and motivations underlying its behaviour. Instead, the individual can only observe the firms' doings and based on that then construct a feeling or belief about what a firm's intentions might be and how it will behave. In the end, individuals may use the global experience with involvement in CSR for evaluating whether they can generally have more confidence in firms that are involved in CSR than in non-involved firms. In the very moment of a buy(cott)ing decision, they then can resort to this over-all conception (see Chapter 3.2, ref. to Muthuri, Matten, and Moon 2009; Offe 1999, 43-4 \& 63; Degli Antoni and Sacconi 2011).

Given this conceptual framework, an adequate measure for the concept has to fulfil four criteria: firstly, it has to be broad, i.e. cover the wide spectrum of activities that constitute CSR (ethical, social, environmental commitment, etc.). Secondly, it has to be general. More specifically, the definition rests on the notion that citizens infer from a general experience with CSR whether they can have confidence in it. Therefore, rather than attaching it to particular firms, the final measure needs to assess whether an individual does generally have a higher level of

${ }^{91}$ The distribution of confidence in labelling schemes across gender, age and education is presented in Appendix A.4. 
confidence in firms which are societally involved. Thirdly, the measure should gauge the comparative level of confidence, that is, the confidence a citizen has in firms which are involved in CSR as compared to firms which are not involved. And as a fourth and last requirement, the concept centres on the distinction between having and not having confidence, not on the height or intensity of confidence a respondent has. Accordingly, it should plainly depict whether respondents do or do not have a higher level of confidence.

CSR is commonly studied from the firm perspective in business studies and consumer psychology. The focus therein rests on the absolute level of trust that the potential customers have in CSR (cf. e.g. Becker-Olsen, Cudmore, and Hill 2006; Pivato, Misani, and Tencati 2008; Degli Antoni and Sacconi 2011). There is no measure known in previous studies which assesses the confidence in involved firms as compared to non-involved firms. Therefore, the survey includes a self-developed question which is not automatically presented to all respondents: in order to be able to answer the question, respondents need to be familiar with firm involvement in CSR. Unlike labelling schemes, which are put on a product and thus may be observed in the immediate buying decision, company involvement typically refers to a type of background knowledge. That is, an individual must have encountered information on firm involvement before getting into a shopping situation. The previously collected information may then be recalled and utilised in the immediate act of buy(cott)ing. Therefore, two approaches shall together ensure that the question is answered based on familiarity with involvement of firms in activities that constitute CSR. Firstly, all respondents are asked in a filtering question to indicate (i.e. yes or no) whether they are "familiar with a firm that is being involved socially, ecologically or societally". If the answer is 'yes', they are presented with the question on confidence in involved companies. This procedure secures that a respondent specifies the confidence one has only if having a reference point onto which the evaluation can be based. The second point involves the wording of the question. It asks to specify on a scale from -3 (not at all) to +3 (fully) whether respondents generally have more confidence in companies which are societally involved and behave in an ethically correct manner than in non-involved companies. Thus, the question is held general by referring to concepts that are universally understandable instead of using the technical term 'Corporate Social Responsibility'. This ensures that all respondents relate their answer to a comparable underlying idea of what is meant to be answered. Besides, societal involvement and ethical behaviour are wide-ranging and therewith allow for covering the broad spectrum of activities which underlie CSR. Taken together, the wording thus fits to the first as well as to the second requirement for the concept measurement. 
The third criterion of the measure is considered in the design of the answer. Respondents are asked to specify their level of confidence on a scale which ranges between -3 and +3 and where answers between +1 and +3 indicate that they have generally more confidence in involved compared to non-involved firms. Hence, in so doing, the question considers the comparative level of confidence.

The last requisite is the enabling of a clear distinction between having more confidence or not. As for the previous measure, within the survey respondents use a scale from -3 to +3 , but in the resulting data set the scores actually take on fully positive values between 1 and 7 . Hence, the mean level of confidence is $4.79(S D=1.53)$, the median is $5 .{ }^{92}$ This coincides again with the question design where values above four stand for having more confidence. Accordingly, the measure appears to measure what it shall, i.e. to be internally valid. Following this, the answers are split at the median and the respondents are pooled in two categories (cf. De Vaus 2002, 190): values equal to or higher than the median classify as having more confidence in involved firms, values below classify as attaching the same or at least not more confidence to involved firms.

In a last step, as for the previous variable the first category (having more confidence) is assigned with the value 1 whereas the latter (not having more confidence) is set as 2 . In the ensuing assessment, the latter category serves as the baseline category to which the former is compared. Therewith, the results can be interpreted in the exact line of the hypotheses; that is, whether individuals with more confidence are more likely than the baseline group to be a certain type of political consumer. ${ }^{93}$

\subsubsection{General Trust in Co-Citizens}

The fourth and last independent variable lying at the heart of the theory regards the level of trust individuals do generally have in their co-citizens. Trust denotes a phenomenon where an individual trusts another person out of the belief that the other will reciprocate this trust when interacting (cf. Chapter 3.2, ref. to Newton 2008, 242-3; Offe 1999, 2001 cit. in Seubert 2009, 112; Kaase 1999, 3 \& 12; Newton and Zmerli 2011, 171). What is peculiar about general trust, also called 'generalised' or 'social' trust (as opposed to personalised trust; cf. Uslaner 2002, 51-2), is that it relates to situations where individuals trust people who they have never met before and where trust is not necessarily coupled to reciprocity (Uslaner 2002, 27). Instead,

\footnotetext{
92 The values are calculated based on the unweighted sample.

${ }^{93}$ The distribution of confidence in CSR across gender, age and education is presented in Appendix A.3.
} 
individuals may infer from past experience whether they can generally put faith in a stranger not betraying them or whether they should better be careful when interacting with unknown people (cf. Zmerli, Newton, and Montero 2007, 38).

A suitable measure thus has to be held general enough to relate to a situation where an individual makes inferences about the behaviour of strangers. Yet, it also has to be concrete enough to resemble a typical shopping situation since in such situations individuals routinely resort to a general abstract image of the community around them to make presumptions about how others behave (cf. Sturgis and Smith 2010; Teyssier, Etile, and Combris 2012, 6). Lastly, in the proposed theory generalised trust comes in as a relative measure where individuals may have less or more trust compared to the other individuals. Accordingly, the concept rests on a more or less continuous understanding of trust instead of a binary high/low comprehension. A third prerequisite thus is that a measure for generalised trust provides an at least ordinal scaled variable for the final model.

One measure commonly used for assessing generalised trust is a question which asks respondents to indicate on a scale whether, generally speaking, they would rather say that "you can't be too careful in dealing with people" or that "most people can be trusted" (Uslaner 2002, 52; Zmerli, Newton, and Montero 2007, 38-9; see also Sturgis and Smith 2010, 76, ref. to Rosenberg 1956). Having been subject to intense debate and numerous studies considering the quality of its results, the question appears to have proven to be a relatively reliable measure for generalised trust (Uslaner 2002; Sturgis and Smith 2010, 76; see also Zmerli, Newton, and Montero 2007, 38-9). Examples of surveys using the measure include Almond and Verba's Civic Culture Study (1959-60), the Citizenship, Involvement, Democracy Study (1999-2002) or the European Social Survey (first round 2002, ongoing).

This question on generalised trust centres on individuals' notion of the extent to which they would need to be careful in interactions with strangers. Hence, it delivers a measure which is concrete enough by evoking the abstract picture of anonymous strangers with whom the individual is dealing with. But at the same time, it is general enough by referring to the generalised expectations about people, i.e. the broader general public. The question thus measures an abstract impression of people with whom the individual might have to interact and put trust in. It is held general but still refers to a public and thus evokes the picture of a community or of a blend of different communities. Lastly, the variable is not limited to two options or 'extremes' since it can in fact evoke the notion of more than one community or rather different sub-communities some of which may be trusted in, others not (Sturgis and Smith 2010, 76). In viewing 
then the 'sum of trust' in the various sub-communities, respondents may construe a more attenuated or intensified sense of generalised trust and reflect it correspondingly in their placement on the continuum off the extremes. In sum, the measure fulfils all criteria and is thus included in the survey for measuring generalised trust. Only one aspect differs from the question design in some previous studies including the above mentioned Citizenship, Involvement, Democracy Study or the European Social Survey: instead of ranging from 1 to 10, the scale is adapted to the general scale used in the survey such that it extends from -3 (you can't be too careful in dealing with people) to +3 (most people can be trusted). Yet, also for this variable, the final data set then covers a fully positive scale ranging from 1 to 7 .

In the end, the mean value is $3.78(S D=1.65)$, the median is $4 .{ }^{94}$ This value is lower than for the variables gauging confidence in labelling schemes and confidence in CSR. But it matches the values obtained e.g. in the Citizenship, Involvement, Democracy Study and in the European Social Survey. ${ }^{95}$ Altogether, the variable appears to fit its purpose of testing whether relatively high or low levels of generalised trust in co-citizens are linked to the involvement in specific varieties of political consumerism.

\subsection{Analysing Boycotting and Buycotting Behaviour}

The theoretical framework developed assumes that there is not one type of political consumer but several, and that getting involved in one or another type is related to different constellations between the concept of the state, general trust, confidence in labelling schemes and/or confidence in companies' societal involvement. Departing from this, Chapter 3 delineated 24 hypotheses on how these variables are connected to individuals' tendency towards getting involved in political consumerism in one or the other way. This section now turns to the examination of these hypotheses. The first part presents the statistical analyses and their results. In doing so, the analyses proceed step by step and consider the bivariate links and their directions among the covered variables for one hypothesis after another. In addition, where applicable supplementary models check for the robustness and/or for more precise explanations of the obtained results. The second part then takes a closer look at these results, and in contrasting them with the theory presented it discusses the findings.

\footnotetext{
94 The values are calculated based on the unweighted sample. The distribution of the variable across gender, age and education is provided in Appendix A.3.

${ }_{95}$ Based on scales ranging from 0 to 10 , the figures are in the Citizenship, Involvement, Democracy Study, for West Germany: $M=4.95, S D=2.55$, Median $=5$ and for East Germany: $M=4.15, S D=2.84$, Median $=4$; in the European Social Survey the values are: $M=4.67, S D=2.33$, Median $=5$.
} 


\subsubsection{Examination of the Hypotheses}

\subsubsection{Political and Non-Political Consumerism}

The first set of hypotheses (h1a to c) considers the question which individuals are most likely to be involved in political consumerism. Hypothesis hla proposes that citizens with a liberal concept of the state are more likely to be political consumers when having a relatively high level of general trust than when having a low level of general trust. Among citizens with a cooperative concept of the state, hlb in turn expects that having a high or a low level of general trust makes no difference. Emanating from this, lastly h1c suggests that it is in particular individuals with a liberal concept of the state and little general trust who are most likely to be non-political consumers.

The analysis begins with considering the bivariate correlations of the variables covered. The figures underscore the expected tendencies (Table 14): firstly, being a non-political consumer comes along with a liberal concept of the state. Secondly, being a non-political consumer also comes along with decreasing levels of general trust. And thirdly, it is specifically among individuals with a liberal concept of the state where this connection between non-political consumerism and general trust is of bearing, i.e. where lower levels of general trust are associated with non-political consumerism. For individuals with a cooperative concept of the state, being a political or a non-political consumer does not appear to simultaneously be connected to the level of general trust.

Table 14. Bivariate Correlations of Non-Political Consumerism with the Concept of the State and General Trust

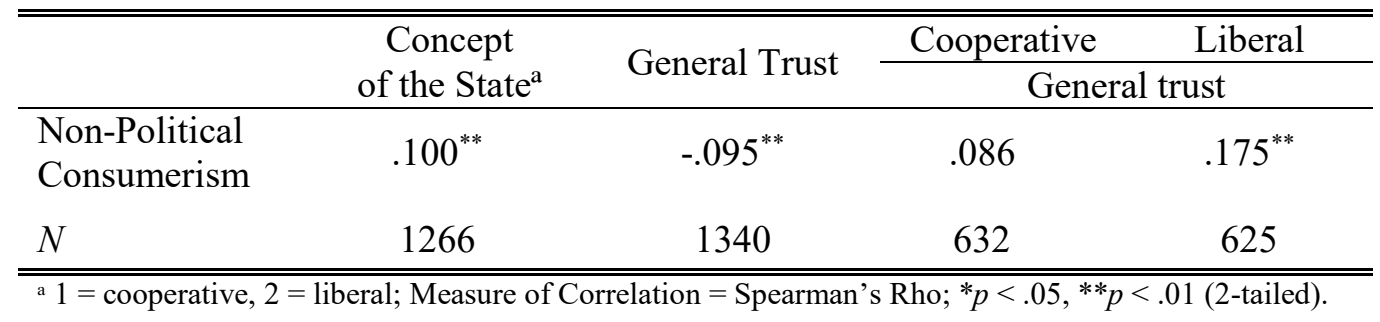

In the next step, these relations are examined more in detail in a logistic regression. The fundamental question underlying this first set of hypotheses differs from the ensuing in the three embracing a clearly two-sided option: either an individual is a political consumer or the individual is not. Therefore, the 8-scale political consumerism item is transformed into a binary variable which pools the 7 varieties of active political consumerism in one category. Therewith, 
the dependent variable clearly distinguishes between the option of belonging to the category of non-political consumers or not and allows for an efficient examination of the expectations. ${ }^{96}$

For ease of interpretation, in the first two models (model 1a and 1b) the variable takes on the value of " 1 " if an individual is a political consumer and a value of " 0 " if the individual is a non-political consumer. In the third model (model 1c), the variable takes on the value of " 1 " if an individual is a non-political consumer and a value of " 0 " if the individual is a political consumer. In the survey sample, 480 individuals are non-political consumers and 777 are political consumers. Table 15 displays the results of the regression analyses for hla and $1 \mathrm{~b}$, Table 16 depicts the results for hlc.

Table 15. Logistic Regression Analysis of Political Consumerism

\begin{tabular}{lcc}
\hline & Model 1a & Model 1b \\
\hline Predictors & & \\
$\quad$ Concept of the state & $.600^{* *}(.123)$ & $.456^{* *}(.301)$ \\
General trust & $1.073(.037)$ & $1.077^{*}(.037)$ \\
Concept of the state & & $1.077(.074)$ \\
$*$ general trust & $1.233(.246)$ & $1.222(.247)$ \\
Constant & & \\
Model fit & .075 & .076 \\
Nagelkerke $R^{2}$ & .055 & .056 \\
Cox and Snell & 1600,863 & 1599,863 \\
-2 Log Likelihood & 1257 & 1257 \\
$N$ & Note: Cell entries are odds ratios (Exp[B]), standard errors (SE), and model performance \\
statistics from a binary logistic regression using non-political consumerism as depend- \\
ent variable. All models include age, gender and education as control variables; \\
${ }^{*} p<.05 . * *<.01$
\end{tabular}

Model 1a puts forward that individuals with a liberal concept of the state are less likely to be political consumers than when having a cooperative concept of the state. In turn, having high or low general trust exerts no influence on the likelihood to be or not to be a political consumer. However, this picture changes in model $1 \mathrm{~b}$ when considering the conjoint effect of the concept of the state and general trust. The interaction term in the model describes how the effect of the concept of the state depends on the level of general trust. Matching the bivariate correlations, individuals having a liberal concept of the state are more likely to be political consumers with higher levels of general trust (row of general trust, model 1b). On the opposite, for individuals with a cooperative concept of the state, having high or low general trust makes no difference for whether they are more or less likely to be political consumers (row of the interaction term, model $1 \mathrm{~b})$. These results confirm h1a as well as $\mathrm{h} 1 \mathrm{~b}$.

\footnotetext{
${ }^{96}$ In using the 8-scale item, non-political consumerism would have to be compared to the 7 categories of active political consumerism. As a result, the two opposite poles could not be clearly put in comparison to each other, and so using this item would make it difficult to draw precise conclusions.
} 
Table 16. Logistic Regression Analysis of Non-Political Consumerism

\begin{tabular}{lc}
\hline & \multicolumn{1}{c}{ Model 1c } \\
\hline Predictors & $2.192 * *(.301)$ \\
Concept of the state & $.928^{*}(.037)$ \\
General trust & $.929(.074)$ \\
Concept of the state & $.819(.247)$ \\
$*$ general trust & \\
Constant & .076 \\
Model fit & .056 \\
Nagelkerke $R^{2}$ & 1599,863 \\
Cox and Snell & 1257 \\
-2 Log Likelihood & \\
$N$ & Note: Cell entries are odds ratios (Exp[B]), standard errors (SE), and model \\
performance statistics from a binary logistic regression using non-political \\
consumerism as dependent variable. All models include age, gender and edu- \\
cation as control variables; ${ }^{*} p<.05 . *{ }^{* *} p<.01$
\end{tabular}

Model 1c (Table 16) considers the reverse engagement, i.e. non-political consumerism. The figures suggest that someone with a liberal concept of the state is generally more likely to be a non-political consumer; yet, when having high levels of general trust they are less likely to be non-political consumers than when having little general trust. Considering this along with the findings in model $1 \mathrm{~b}$, it altogether puts forward that citizens with a liberal concept of the state and relatively low levels of general trust are indeed generally more likely than other citizens to be non-political consumers. Still, to facilitate a more accurate interpretation of the interaction effect, Figure 16 displays the mean predicted probabilities of non-political consumerism by the level of general trust depending on having a liberal or a cooperative concept of the state.

Figure 16. Mean Predicted Probability of Non-Political Consumerism

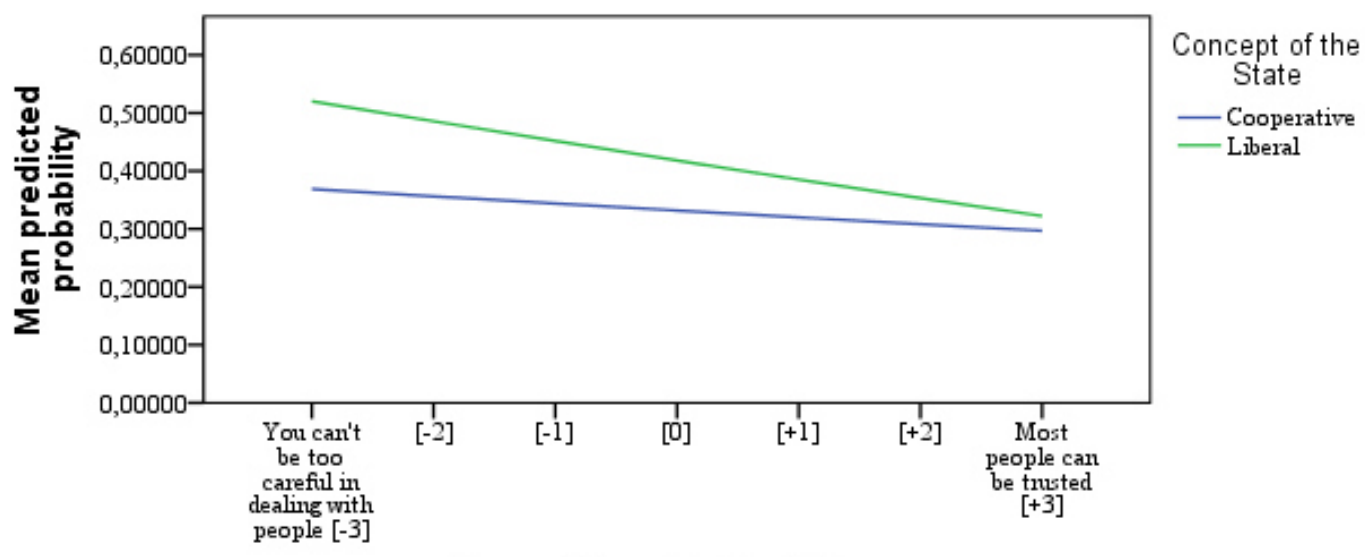

General Trust in Co-Citizens

The slopes describe the changing predicted probability to be a non-political consumer for individuals with a cooperative and a liberal concept of the state with increasing levels of general trust. The distance between the two slopes depicts the different likelihood to be non-political 
consumer for individuals holding a cooperative compared to a liberal view. As the two lines reaffirm, individuals with a cooperative concept of the state are generally less likely to be nonpolitical consumers, and their non-involvement depends little on their level of trust. A liberal concept of the state, in turn, is more strongly linked to the level of general trust. That is, with increasing general trust individuals are less likely to be non-political consumers. Nevertheless, at all levels of general trust they are still more likely to be non-political consumers than individuals with a cooperative concept of the state. Yet, this propensity changes with different degrees of general trust: individuals with a cooperative concept of the state and little general trust are considerably less likely to be non-political consumers than individuals with a liberal concept of the state and little general trust. In contrast, individuals with one and the other concept of the state are, when having high levels of general trust, almost equally as likely to be non-political consumers.

In conclusion, individuals with a liberal view and low levels of general trust appear to be more likely to be non-political consumers than individuals holding any other constellation of concept of the state and trust. This confirms hypothesis h1c. Besides, it underscores the relevance of the concept of the state as well as of general trust on the tendency to become or not become a political consumer.

\subsubsection{Buycotting Products}

Hypotheses $\mathrm{h} 2 \mathrm{a}$ and $3 \mathrm{a}$ consider the particular variety of buycotting products. They propose that individuals who have (h2a) a liberal concept of the state or (h3a) more confidence in labelled than in non-labelled products are particularly likely to do so.

For h2a, the bivariate correlation between buycotting products and the concept of the state is not statistically significant. Turning to the first mode of active political consumerism, the regression analysis uses the 8-scale political consumerism item delineated in Chapter 6.1.2.3. Correspondingly, the dependent variable is a nominal variable comprising 8 categories. A value of " 0 " indicates non-political consumerism, values from " 1 " to " 7 " relate to the different varieties of boycotting and buycotting. In accord with the bivariate correlations, the logistic regression does not reveal a significant connection of the concept of the state with the tendency to buycott products (Table 17, model 2a). In the view of this, h2a has to be rejected.

The bivariate correlation for $\mathrm{h} 3 \mathrm{a}$ between buycotting products and confidence in labelling schemes is statistically significant and in a congruent direction with the underlying assumption 
$\left(r_{s}(1329)=-.061^{97}, p=.025\right)$. That is, more individuals who have a high relative confidence in labelled products buycott products than individuals with no more confidence. The logistic regression analysis confirms the result as being more than only a parallel appearance: individuals who have more confidence in labelled than in non-labelled products are indeed more likely to be buycotter of products than individuals who do not have more confidence (Table 17, model 3a). This confirms hypothesis h3a.

Table 17. Logistic Regression Analysis of Buycotting Products

\begin{tabular}{lccc}
\hline & Model 2a & Model 3a & Model 3a(2) \\
\hline Predictors & & & \\
$\quad$ Concept of the state & $1.260(.323)$ & & $1.000(.542)$ \\
$\quad$ Confidence in LS & & $4.186^{* *}(.334)$ & $3.730^{* *}(.467)$ \\
$\quad$ Concept of the state & & & $1.129(.683)$ \\
$\quad$ * confidence in LS & & & $-3.807 * *(.708)$ \\
Constant & $-3.507^{* *}(.660)$ & $-3.984 * *(.664)$ & \\
Model fit & & & .187 \\
$\quad$ Nagelkerke $R^{2}$ & .093 & .161 & .181 \\
Cox and Snell & .090 & .156 & 2403,076 \\
-2 Log Likelihood & 1922,278 & 1944,391 & 1248 \\
$N$ & 1266 & 1329 & \\
\hline
\end{tabular}

Notes: Cell entries are odds ratios $(\operatorname{Exp}[\mathrm{B}])$, standard errors (SE), and model performance statistics from multinomial logistic regression using political consumerism as dependent variable and nonpolitical consumerism as reference category. Cell entry for the Constant is the beta coefficient [B]. All models are controlled for age, gender and education. ${ }^{*} p<.05 .{ }^{* *} p<.01$

To check the robustness of the findings, a last model examines whether the concept of the state in its link with buycotting products may be connected to confidence in labelling schemes. Therefore, Model 3a(2) includes the conjoint effect of confidence in labelling schemes and the concept of the state. The result further underscores the importance of the former and the irrelevance of the latter: overall, individuals who have more confidence in labelled than in non-labelled products are more likely to be buycotter of products than individuals who do not have more confidence in labelled products, and the concept of the state is inconsequential in it.

In sum, h3a is confirmed whereas $\mathrm{h} 2 \mathrm{a}$ has to be rejected; only having more confidence in labelled than in non-labelled products is linked with the tendency to buycott products.

\footnotetext{
97 The correlation coefficient (measure of correlation: Spearman's Rho) is negative since, as mentioned in the previous chapter, the variable used for the confidence in labelling schemes is reverse coded and so lower values indicate having more confidence (i.e. 1 = more confidence, $2=$ not more confidence). Accordingly, a negative coefficient represents an increase in confidence relative to another variable's increase.
} 


\subsubsection{Buycotting Firms}

The third set of hypotheses considers the buycotting of firms. They propose that individuals with (h2b) a cooperative concept of the state and those who have (h3b) more confidence in firms which are societally involved than in non-involved firms (or abbrev. CSR) are likely to buycott firms. Besides, h4 proposes that in particular individuals who have a cooperative view and more confidence in involved firms are most likely to buycott firms.

To begin with, the bivariate correlation for the assumption covered by hypothesis $h 2 b$ is in the suggested direction and significant: the coefficient is negative since the lower value, i.e. "1", represents a cooperative concept of the state, whereas a value of "2" stands for a liberal view. Accordingly, the buycotting of firms is positively related to having a cooperative concept of the state (Table 18, first column). The regression analysis in model $2 \mathrm{~b}$ (Table 19, model $2 \mathrm{~b}$ ) further underscores the connection between the two variables: the last category is the referent group, which is having a liberal concept of the state. Consequently, the positive odds ratio indicates that, compared to individuals with a liberal concept of the state, individuals with a cooperative concept of the state are more likely to buycott firms. More precisely, they are about twice as likely to buycott firms. Hence, this confirms hypothesis $2 b$ that individuals who have a cooperative view are more likely to buycott firms than individuals with a liberal view.

\begin{tabular}{|c|c|c|c|}
\hline & $\begin{array}{c}\text { Concept } \\
\text { of the state }\end{array}$ & $\begin{array}{l}\text { Confidence } \\
\text { in CSR }{ }^{b}\end{array}$ & $\begin{array}{l}\text { Confidence in } \mathrm{CSR}^{\mathrm{b}} \\
\text { /concept of the state }\end{array}$ \\
\hline Buycott Firms & $-.064 * \mathrm{c}$ & $-.058 * \mathrm{c}$ & $.055^{\mathrm{d}}$ \\
\hline$N$ & 1266 & 1262 & 1257 \\
\hline $\begin{array}{l}\mathrm{a} 1=\text { cooperative, } 2 \\
\text { more confidence; } \mathrm{t} \\
\text { represents an incre } \\
{ }^{c} \text { Measure of Corre } \\
{ }^{*} p<.05, * * p<.01\end{array}$ & 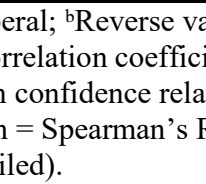 & $\begin{array}{l}\text { le, i.e. } 1=\text { havi } \\
\text { therefore is neg } \\
\text { to another varia } \\
\text { 'Measure of } \mathrm{Cc}\end{array}$ & $\begin{array}{l}\text { more confidence, } 2=\text { not } \\
\text { re. A negative coefficient } \\
\text { 's increase. } \\
\text { lation = Cramer's V; }\end{array}$ \\
\hline
\end{tabular}

Corresponding to $\mathrm{h} 3 \mathrm{~b}$, the bivariate correlations confirm as well the positive link of buycotting firms and having more confidence in involved than in non-involved firms (Table 18, column in the middle). As the second table (Table 19) displays, the link is not only a correlation but appears to follow a general pattern: according to model $3 \mathrm{~b}$, individuals who have more confidence in involved than in non-involved firms are more likely to buycott firms than individuals with not such more confidence. What is more, the high odds ratio points out that these individuals are even considerably more likely to buycott firms compared to the individuals who 
do not have more confidence in involved than in non-involved firms. This confirms hypothesis $\mathrm{h} 3 \mathrm{~b}$, and it underscores the relevance of confidence in CSR.

Table 19. Logistic Regression Analysis of Buycotting Firms

\begin{tabular}{|c|c|c|c|}
\hline & Model 2b & Model 3b & Model 4 \\
\hline \multicolumn{4}{|l|}{ Predictors } \\
\hline Concept of the state & $2.274 * *(.268)$ & & $2.133(.507)$ \\
\hline Confidence in CSR & & $3.923 * *(.291)$ & $3.775 * *(.460)$ \\
\hline $\begin{array}{l}\text { Concept of the state } \\
* \text { confidence in CSR }\end{array}$ & & & $.796(.612)$ \\
\hline Constant & $-2.070 * *(.494)$ & $-2.494 * *(.512)$ & $-2.748 * *(.593)$ \\
\hline \multicolumn{4}{|l|}{ Model fit } \\
\hline Nagelkerke $R^{2}$ & .093 & .194 & .208 \\
\hline Cox and Snell & .090 & .188 & .201 \\
\hline-2 Log Likelihood & 1922,278 & 1812,037 & 2233,540 \\
\hline$N$ & 1266 & 1262 & 1193 \\
\hline
\end{tabular}

Finally, for hypothesis h4 the picture becomes more diffuse: in considering the subsets of having a cooperative versus a liberal concept of the state, the bivariate correlation of buycotting firms and confidence in involved firms turns insignificant (Table 18, last column). Likewise, when corresponding to h4 the regression analysis considers the conjoint effect of the concept of the state and confidence in CSR (Table 19, model 4), the main effect of the concept of the state as well as the interaction term turn insignificant. Only confidence in CSR continues to exert a positive effect on buycotting firms, that is, individuals are more likely to buycott firms if they have more confidence in involved firms than in non-involved firms, independent of whether their concept of the state is cooperative or liberal. In line with that, for the last model the -2 Log Likelihood value increases notably whereas $\mathrm{R}^{2}$ improves only marginally, which points to an overall lower model fit compared to the previous.

Nevertheless, the effect in the row of confidence in CSR in model 4 suggests that individuals who both have a cooperative view as well as a higher level of confidence in involved than in non-involved firms are indeed generally more likely to buycott firms than individuals with a liberal concept of the state. The graphical representation of the interaction visualises it more clearly: first, as the slopes in Figure 17 show, the predicted probability of buycotting firms is higher for a cooperative as well as for a liberal view with having more confidence in societally involved firms i.e. CSR. Second, the difference in the lines indicates that the probability to buycott firms is overall higher for individuals having a cooperative view than for individuals with a liberal view. And third, the difference in the effect changes most strongly (1) from having no more confidence to having more confidence in CSR (2) for individuals with a cooperative 
concept of the state. So, on the whole, both for individuals with a liberal and a cooperative concept of the state, having confidence in CSR the propensity to buycott firms changes. Yet, the effect is stronger for those having a cooperative concept of the state.

Figure 17. Mean Predicted Probability of Buycotting Firms

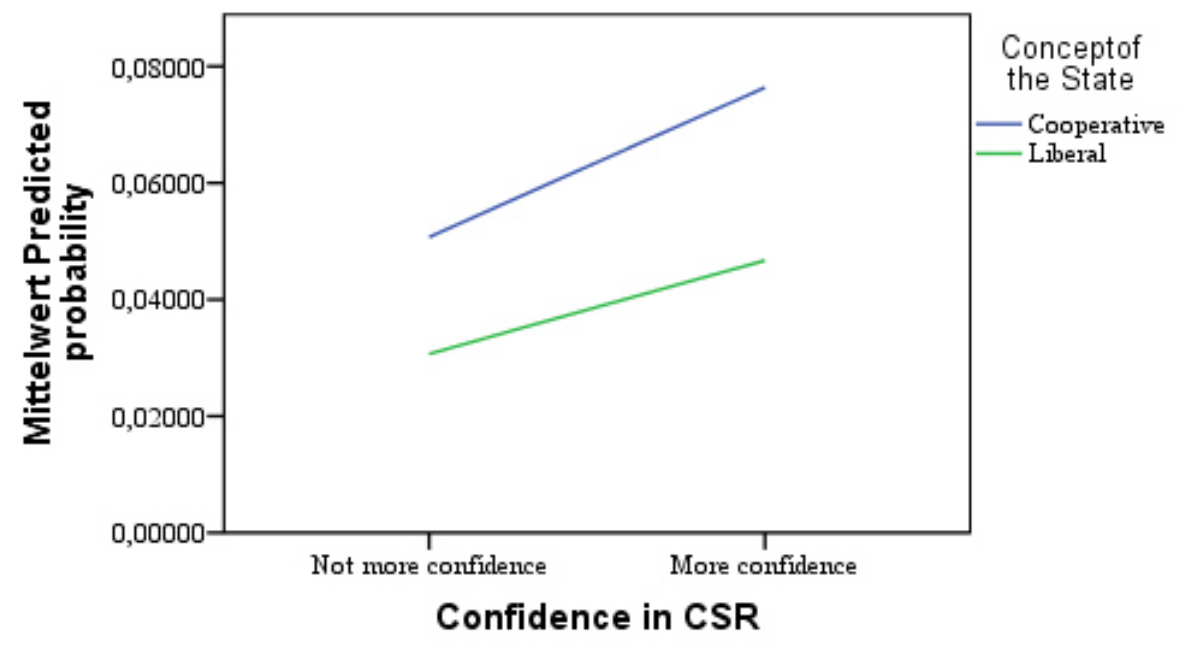

Corresponding to the idea of hypothesis h4, individuals with a cooperative concept of the state tend slightly more to be buycotter of firms when having confidence in firms that are societally involved than if not. Even so, the propensity to buycott firms is generally higher among individuals with a cooperative concept of the state. Likewise, confidence in CSR raises the likelihood to buycott firms both for a cooperative and a liberal concept of the state. This puts forward that rather than the combination of a particular concept of the state and confidence, the two factors influence separate aspects: depending on the concept of the state citizens are generally more or less probable to get involved; whereas the tendency to specifically buycott firms depends upon the level of confidence in CSR an individual has. Therefore, on the whole, rather than the combination of a particular concept of the state and confidence it is the influence of especially confidence in CSR which appears to be of capital importance for getting involved in buycotting firms.

To summarize, h2b, h3b as well as h4 are confirmed: individuals are more likely to buycott firms if they either have more confidence in involved than in non-involved firms or if they have a cooperative concept of the state. Moreover, it is individuals with both a cooperative concept of the state and more confidence in involved than in non-involved firms who are most likely to buycott firms. 


\subsubsection{Boycotting}

The next battery of hypotheses considers boycotting. They propose that individuals tend to be boycotter if they have either little generalised trust yet more confidence in labelled than in non-labelled products (h5a), a cooperative concept of the state $(\mathrm{h} 5 \mathrm{~b})$, or a liberal concept of the state and confidence in labelled products (h5c).

The analysis begins with considering the bivariate correlations of the variables covered in h5a: boycotting, general trust, and confidence in labelling schemes. However, the correlations are all statistically insignificant. The analysis in a logistic regression model confirms the insignificance of the proposed relationship: the specific constellation between generalised trust and confidence in labelling schemes does not appear to be related to an individuals' tendency to boycott products (Table 20, model 5a). Considering the two variables separately shows that for general trust the result remains the same, i.e. it is not generally related to the tendency to boycott (model 5a(2)). Only when dropping the idea that general trust matters and including alone confidence in labelling schemes in the model, the model fit improves notably and the result becomes more telling (see model 5a(3)). Specifically, it exerts a positive and statistically significant effect on boycotting. So, being a boycotter appears to be more likely for individuals who have more confidence in labelled than in non-labelled products than for individuals who do not have such more confidence. Even so, general trust appears to be irrelevant. Accordingly, the very first hypothesis which proposes an intertwined effect of general trust and confidence in labelling schemes on boycotting has to be rejected.

Table 20. Logistic Regression Analysis of Boycotting, hypothesis h5a

\begin{tabular}{lccc}
\hline & Model 5a & Model 5a(2) & Model 5a(3) \\
\hline $\begin{array}{l}\text { Predictors } \\
\text { General trust }\end{array}$ & $.923(.079)$ & $.980(.058)$ & \\
$\begin{array}{l}\text { Confidence in LS } \\
\text { General trust } \\
* \text { confidence in LS }\end{array}$ & $1.674(.479)$ & & $1.901 * *(.192)$ \\
$\begin{array}{l}\text { Constant } \\
\text { Model fit }\end{array}$ & $1.049(.119)$ & & \\
Nagelkerke $R^{2}$ & $-1.008 *(.434)$ & $-.953 *(.385)$ & $-1.203 * *(.347)$ \\
$\begin{array}{l}\text { Cox and Snell } \\
-2 \text { Log Likelihood }\end{array}$ & .172 & .083 & .161 \\
$N$ & .166 & .080 & .156 \\
\hline $\begin{array}{l}\text { Note: Cell entries are odds ratios }(\text { Exp[B]), standard errors }(\mathrm{SE}), \text { and model performance statistics from } \\
\text { multinomial logistic regression using political consumerism as dependent variable and non-political } \\
\text { consumerism as reference category. Cell entry for the Constant is the beta coefficient }[\mathrm{B}] . \text { All models }\end{array}$ \\
include age, gender and education as control variables; ${ }^{*} p<.05 . * * p<.01$
\end{tabular}

The second hypothesis (h5b) proposes that being a boycotter is rather linked to having a cooperative concept of the state than to having a liberal concept of the state. Yet, also in this 
case the bivariate correlations do not confirm the suggested idea. Along with it, the regression analysis for $\mathrm{h} 5 \mathrm{~b}$ (Table 21 , model $5 \mathrm{~b}$ ) suggests that having a cooperative view is not associated with being more likely to be a boycotter. The theoretical framework assumes that political consumerist activities are closely connected to the concept of the state and trust and confidence. Therefore, model 5b(2) considers as an additional check whether general trust may add explanatory power and bring about a relevant bearing of a cooperative view on the tendency to boycott. Nonetheless, the impact of the concept of the state remains insignificant. The same is the case when the model includes confidence in labelling schemes (model 5b(3)): the concept of the state is of no bearing. Hypothesis h5b thus has to be rejected. Yet, instead, model $5 \mathrm{~b}(3)$ reaffirms the positive effect of confidence in labelling schemes found in testing hypothesis h5a. Someone with confidence is more likely to be a boycotter than someone without. This leads over to h5c.

Table 21. Logistic Regression Analysis of Boycotting, hypotheses h5b and h5c

\begin{tabular}{lcccc}
\hline & Model $5 \mathrm{~b}$ & Model $5 \mathrm{~b}(2)$ & Model $5 \mathrm{~b}(3)$ & Model 5c \\
\hline Predictors & & & & \\
$\quad$ Concept of the state & $1.341(.197)$ & $1.915(.482)$ & $1.309(.200)$ & $1.916^{*}(.265)$ \\
General trust & & $.997(.091)$ & & \\
General trust & $.916(.122)$ & & \\
$*$ concept of the state & & & $1.860^{* *}(.202)$ & $2.870^{* *}(.280)$ \\
Confidence in LS & & & $.407^{*}(.400)$ \\
Concept of the state & & & & $-1.589^{* *}(.387)$ \\
$*$ confidence in LS & $-1.187^{* *}(.355)$ & $-1.255(.477)$ & $-1.372^{* *}(.370)$ & \\
Constant & & & .179 & .187 \\
Model fit & .093 & .107 & .173 & .181 \\
Nagelkerke $R^{2}$ & .090 & .104 & 2414,990 & 2403,076 \\
Cox and Snell & 1922,278 & 3254,133 & 1248 & 1248 \\
-2 Log Likelihood & 1266 & 1257 & 1248 \\
$N$ & & & & \\
\hline
\end{tabular}

Note: Cell entries are odds ratios (Exp[B]), standard errors (SE), and model performance statistics from multinomial logistic regression using political consumerism as dependent variable and non-political consumerism as reference category. Cell entry for the Constant is the beta coefficient [B]. All models are controlled for age, gender and education. $* p<.05$. ** $p<.01$

The third hypothesis considers the connection of boycotting with the concept of the state, too. Yet, it connects it further to the idea of having more confidence in labelled than in nonlabelled products. More concrete, h5c proposes that among the individuals with a liberal concept of the state, the ones who have more confidence in labelled than in non-labelled products are more likely to boycott than those with not more confidence. As for the bivariate correlations, among individuals who have a cooperative concept of the state, boycotting is inversely correlated with confidence in labelling schemes; that is, among the individuals with a cooperative concept of the state, more individuals with no higher confidence than with higher confidence 
in labelled products are also boycotter (Cramers $V(631)=.082, p=.040)$. On the opposite, when having a liberal concept of the state, the correlation is not statistically significant.

The logistic regression analysis of the interacting effect of both variables reveals a significant connection (Table 21, model 5c). The model fit is comparatively good, too. The interaction effect suggests that the effect on boycotting is opposite for confidence in labelling schemes when having a liberal view to when having a cooperative view. Given this intricate result, to facilitate a more precise interpretation Figure 18 displays the mean predicted probability for boycotting by the level of confidence in labelling schemes and by conditioning for having a liberal or a cooperative concept of the state.

Figure 18. Mean Predicted Probability of Boycotting

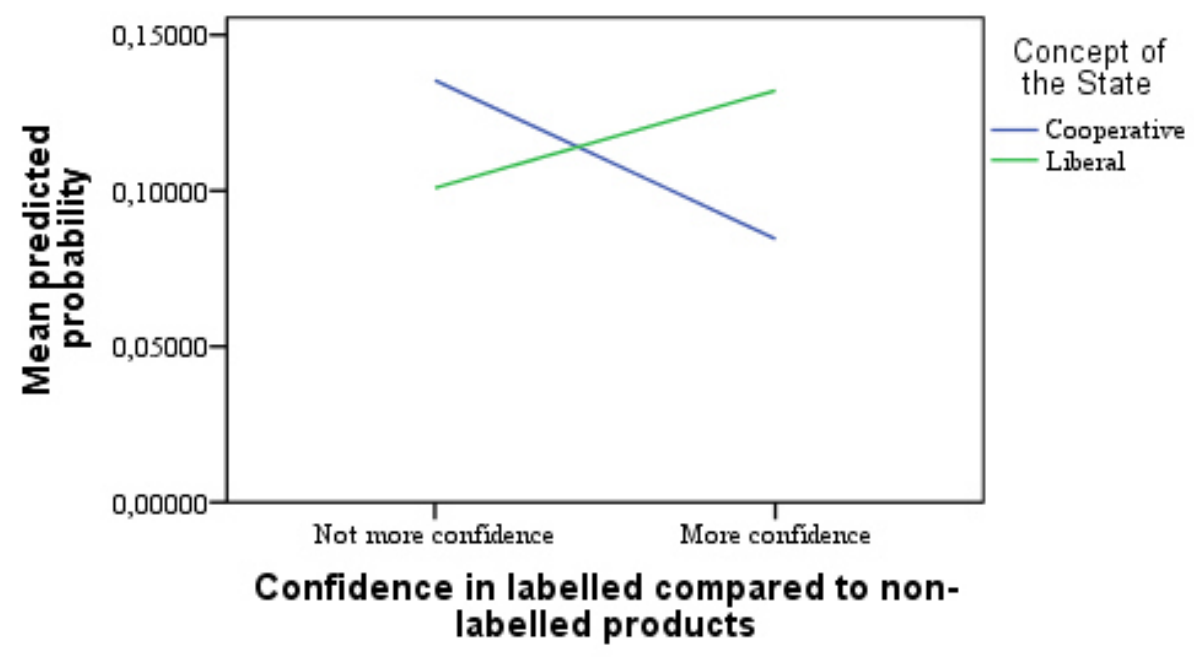

Figure 18 very well illustrates the antithetic effect: individuals with a cooperative concept of the state are less likely to be boycotter when having more confidence in labelling schemes than when not having more confidence. On the opposite, individuals with a liberal concept of the state are more likely to be boycotter when having more confidence in labelled than in nonlabelled products. This matches hypothesis h5c. In addition, the graph explains the results obtained in the previous models: given these antithetic effects, neither the level of general trust nor the concept of the state can alone predict the tendency to boycott since they alone exert no significant effect on it. The single effect of confidence in labelling schemes on the tendency to boycott is too strong and varying depending on the concept of the state which an individual has. In fact, individuals with a liberal as well as with a cooperative concept of the state can be more likely than the other to be boycotter - it all depends on their level of confidence in labelling schemes. The model also being the one with the highest $\mathrm{R}^{2}$-value further underscores the relevance of the interactive effect. 
To conclude, of the three hypotheses on boycotting only the third (h5c) is supported. According to it, individuals with a liberal view are more likely to be boycotter when having more confidence in labelled than in non-labelled products than if not.

\subsubsection{Boycotting and Buycotting Products}

Eventually, the theoretical framework assumes that there are individuals who only boycott, some who only buycott, and some who do a combination of both. Hypothesis h6 turns to the combination type of political consumerism and proposes that, in seeking the full bandwidth of cooperation, individuals with a cooperative concept of the state are more likely to both boycott and buycott products than individuals with a liberal concept of the state.

A first look at the bivariate correlation of boycotting and buycotting products with the concept of the state cannot underscore this proposition. Neither does the regression analysis confirm a connection between the two variables (Table 22, model 6a).

According to the analyses with regard to boycotting (h5c) and buycotting of products (h3a), confidence in labelling schemes is of capital importance. Thus, being involved in the two may be linked to confidence in labelling schemes, too. To check for this idea, model 6a(2) includes confidence in labelling schemes as an additional predictor and model $6 \mathrm{a}(3)$ the interaction term of the two variables. The results reveal a positive effect of having more confidence in labelled than in non-labelled products. That is, individuals are more likely to be boycotter and buycotter of products when having more confidence in labelled than in non-labelled products (model $6 a(2))$. However, as for boycotting, the effect is different depending on the concept of the state (model 6a(3)).

Table 22. Logistic Regression Analysis of Boycotting and Buycotting Products

\begin{tabular}{lccc}
\hline & Model 6a & \multicolumn{1}{c}{ Model 6a(2) } & \multicolumn{1}{c}{ Model 6a(3) } \\
\hline Predictors & & & \\
Concept of the state & $1.352(.227)$ & $2.039(.377)$ & $2.185^{*}(.332)$ \\
Confidence in LS & & $5.033^{* *}(.394)$ & $4.210^{* *}(.326)$ \\
Concept of the state & & & $.340^{*}(.461)$ \\
$*$ confidence in LS & $-1.380^{* *}(.484)$ & $-1.844 * *(.510)$ & $-2.139 * *(.534)$ \\
Constant & & & \\
Model fit & .093 & .179 & .187 \\
Nagelkerke $R^{2}$ & .090 & .173 & .181 \\
Cox and Snell & 1922,278 & 2414,990 & 2403,076 \\
-2 Log Likelihood & 1266 & 1248 & 1248 \\
$N$ &
\end{tabular}

Notes: Cell entries are odds ratios (Exp[B]), standard errors (SE), and model performance statistics from multinomial logistic regression using political consumerism as dependent variable and non-political consumerism as reference category. Cell entry for the Constant is the beta coefficient [B]. All models are controlled for age, gender and education. ${ }^{*} p<.05 .{ }^{* *} p<.01$ 
Figure 19 shows this very clearly: the slopes of the mean predicted probability for boycotting and buycotting products by confidence in labelling schemes are entirely opposite for the liberal concept of the state than for the cooperative one. Individuals with a liberal view are more likely to be boycotter and buycotter of products if they have more confidence in labelling schemes. Conversely, individuals with a cooperative view are less likely to be boycotter and buycotter of products if they have more confidence in labelling schemes than if they do not have more confidence. This shows that the concept of the state is indeed of matter, and similar to the proposed idea in hypothesis 6 . However, the interaction with confidence in labelling schemes is very strong, such that the concept of the state alone does not suffice to predict when an individual is likely to boycott and buycott products. In fact, the only small increase in the model fit when including the interaction term (as compared to model 6a(2)) underscores the particularly large relevance of confidence in labelling schemes. Altogether, the opposite effect may then explain the insignificant result when considering the concept of the state alone.

\section{Figure 19. Mean Predicted Probabilities of Boycotting and Buycotting Products}

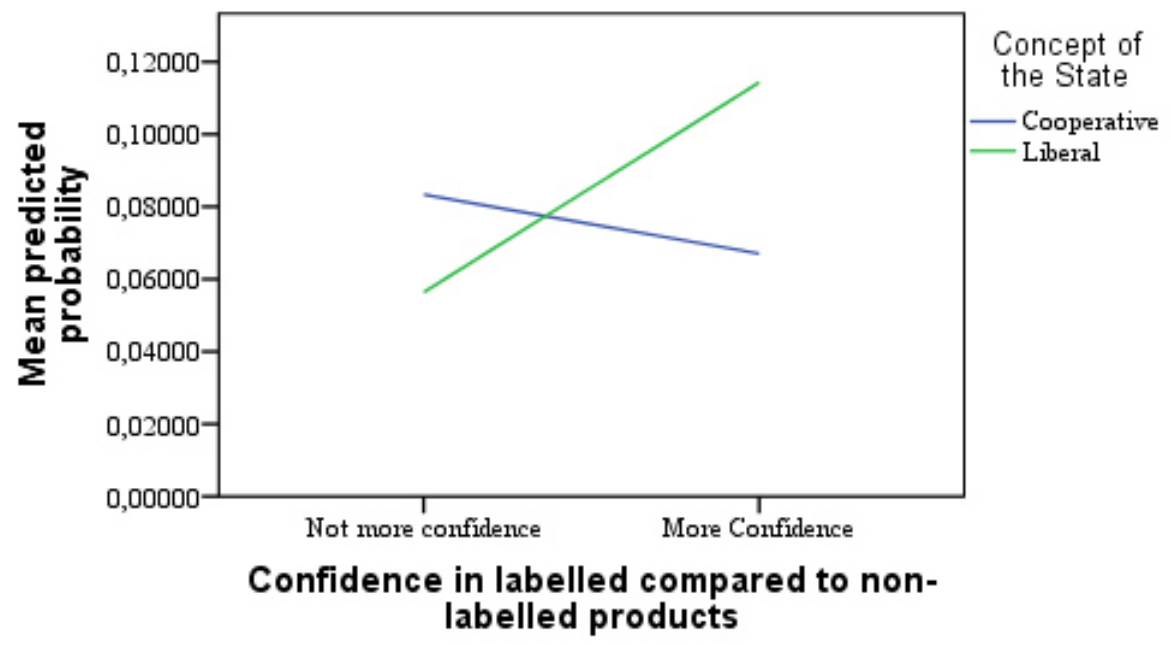

In conclusion, the concept of the state exerts an influence on the group of individuals who have more confidence in labelled than in non-labelled products. This influence is remarkable seeing that the liberal and cooperative views appear to have completely opposing effects. Even so, on the one hand, the relationship concerns only a subset of political consumers. On the other hand, it requires the interaction with confidence in labelling schemes to actually exert an effect. The boycotting and buycotting of products is thus only partially linked to the concept of the state. In the view of this, h6 cannot be supported. 


\subsubsection{Discussing the Findings}

\subsubsection{General Observations}

Table 23 presents an overview of the results for all hypotheses. Of the 12 hypotheses, 8 could be supported. All four factors proposed, i.e. the concept of the state, general trust as well as confidence in labelling schemes and in societally involved firms, appear to be relevant. Yet, their influences seem to be less intertwined than theorised.

\section{Table 23. Overview of Results of Hypotheses Tests}

Political and non-Political Consumerism:

Citizens are...

(h1a) when having a liberal concept of the state and high general trust more likely to be political consumers than when having low general trust $(+)$

(h1b) when having a cooperative concept of the state and high general trust equally as likely to be political consumers as when having low general trust $(+)$

(h1c) most likely to be non-political consumers with a liberal concept of the state and low general trust $(+)$

Buycotting Products:

Citizens are likely to buycott products with...

(h2a) a liberal concept of the state (-)

(h3a) more confidence in labelled than in non-labelled products $(+)$

Buycotting Firms:

Citizens are likely to buycott firms with...

(h2b) a cooperative concept of the state $(+)$

(h3b) more confidence in involved than in non-involved firms $(+)$

(h4) a cooperative concept of the state and more confidence in involved than in non-involved firms $(+)$

Boycotting:

Citizens are likely to boycott with...

(h5a) little general trust yet more confidence in labelled products (-)

(h5b) a cooperative concept of the state (-)

(h5c) a liberal concept of the state and more confidence in labelled than in non-labelled products $(+)$

Boycotting and Buycotting Products:

Citizens are likely to boycott AND to buycott products with...

(h6) a cooperative concept of the state (-)

Note: $(+)$ is supported, (-) is rejected.

More specifically, the results entail two major observations: firstly, the findings for buycotting products, buycotting firms and boycotting put forward that the factors which influence the decision for getting involved in one or another variety of political consumerism are mainly 
the different types of confidence. As proposed in the theory, product related confidence in labelling schemes increases the likelihood that an individual is involved in political consumerism by means of buycotting products (hypothesis h3a). Company related confidence in companies' social responsibility in turn increases the chances that an individual is involved in political consumerism by means of buycotting firms ( $\mathrm{h} 3 \mathrm{~b}$ ). Besides, in line with the theory's proposition that boycotter intend to put pressure for more regulation via tools such as labelling schemes, getting involved as a boycotter appears to be linked to the respective type of confidence, too (h5c). This also answers research question $Q 4$ raised in the introductory chapter: Indeed, having high levels of confidence in labelling schemes and/or CSR is related to individuals' being involved in boycotting and/or buycotting, and low levels of confidence are related to not being involved in any of the two variants.

Secondly, opposite to the theoretical propositions, the concept of the state is not linked to specific subtypes of political consumerism. In its place, it appears to be closely linked to being involved in political consumerism at all or not. Correspondingly, responding to research questions $Q 2$ and $Q 3$, having a specific concept of the state is related to the individuals' general inclination to be involved in boycotting and/or buycotting $\left(Q^{2}\right)$; but it is not related to the tendency to purchase based on labelling schemes or CSR (Q3). More precisely, a liberal concept of the state is more closely linked to non-political consumerism than a cooperative concept of the state (hypotheses hla-c). Hence, in place of an intertwined effect, the findings suggest effects at different stages: on a first stage, being a political consumer or not is linked to the concept of the state. Then, on a second stage, the variety of political consumerist activity is linked to confidence in labelling schemes or in societally involved firms.

To examine the statistical substance of this claim more precisely, Table 24 presents results of three additional logistic regression models with regard to the suggested first stage: in the first model, the dependent variable is having boycotted whereas in the second model, the dependent variable is having buycotted. However, in distinction to the former analyses, the two variables are not restricted to the exclusive involvement in either boycotting or buycotting, respectively. Instead, the former variable depicts individuals who boycott and possibly as well buycott; the latter depicts individuals who buycott and possibly as well boycott. This allows for covering all respondents who are involved in any of the varieties of (active) political consumerism, while 
still permitting to make the distinction between boycotting and buycotting involvement. ${ }^{98}$ The third model recollects the figures for non-political consumerism.

The three models compare the effect of the concept of the state on political versus nonpolitical consumerism. The effects on the two types of political consumerism (boycotting and buycotting) are in fact opposite to that on non-political consumerism: individuals with a liberal concept of the state are more likely to be non-political consumers than those with a cooperative concept of the state; and individuals with a cooperative concept of the state are in turn more likely to be boycotter or buycotter than individuals with a liberal view. Thus, in fact a person having a cooperative concept of the state is more likely to be a political consumer than a person with a liberal view.

Table 24. Logistic Regressions comparing Political and Non-Political Consumerism

\begin{tabular}{lccc}
\hline & (1) Boycotted & (2) Buycotted & $\begin{array}{c}\text { (3) Non-political } \\
\text { consumer }\end{array}$ \\
\hline $\begin{array}{l}\text { Predictors } \\
\text { Concept of the state }\end{array}$ & $1.396^{* *}(.118)$ & $1.649^{* *}(.117)$ & $.593^{* *}(.1 .22)$ \\
$\begin{array}{l}\text { Constant } \\
\text { Model fit }\end{array}$ & $.895^{* *}(.020)$ & $.732(.217)$ & $.744(.225)$ \\
$\quad$ Nagelkerke $R^{2}$ & .075 & .056 & .069 \\
Cox and Snell & .056 & .042 & .51 \\
-2 Log Likelihood & 1681,748 & 1700,036 & 1617,339 \\
$N$ & 1266 & 1266 & 1266 \\
\hline $\begin{array}{l}\text { Note: Cell entries are odds ratios (Exp[B]), standard errors (SE), and model performance statistics from a } \\
\text { binary logistic regression. All models include age, gender and education as control variables; }{ }^{*} p<.05 . \\
* * p<.01\end{array}$
\end{tabular}

With regard to the suggested second stage, the assertion is that the comparative effects of confidence in labelling schemes and confidence in firms' societal involvement on the single varieties of political consumerism differ in their applicability and strength. To allow for a comparison of these relative effects, Table 25 recaps the global results of the previous multinomial logistic regression models. The figures confirm the theoretical idea: the product relation of the former and the firm relation of the latter indeed match with the product or firm relation of single varieties of political consumerism. That is, confidence in labelling schemes shows to be related to all the varieties entailing the buycotting of products whereas confidence in CSR is steadily related to varieties which involve the buycotting of firms.

There is only one exception, which is the variety of boycotting and buycotting firms. There, none of the two types of confidence exhibits a significant effect. The insignificant finding here

\footnotetext{
98 The variable for boycotting comprises a total of 669 respondents, of which 154 have only boycotted and 515 who have as well buycotted. The variable for buycotting comprises a total of 673 respondents, of which 158 have only buycotted and 515 who have as well buycotted. Consequently, 515 respondents are involved in any of the following varieties which may otherwise have been excluded: boycotting and buycotting products; boycotting and buycotting firms; buycotting products and buycotting firms; boycotting, buycotting products and buycotting firms.
} 
underlines the peculiar and ambiguous nature of this variety and endorses that the reasons underlying it are different from that of combining boycotting and buycotting products. This observation leads over to another core conclusion which the overall results point to: in line with one central idea developed in the theoretical framework, boycotting appears to be closely connected to labelling schemes, but differently than buycotting products. The effect of having more confidence in labelling schemes is weakest on boycotting, that is, the sway of having more confidence is bigger on buycotting than on boycotting. Taken together, in the end this fits to the theoretical idea that boycotter have confidence in labelling schemes, but not enough to buycott (yet) or not the labels that are available to them.

Table 25. Comparative Effects of Confidence in Labelling Schemes and Confidence in CSR

\begin{tabular}{|c|c|c|c|c|c|c|}
\hline & Boycotted & $\begin{array}{l}\text { Buycotted } \\
\text { Products }\end{array}$ & $\begin{array}{l}\text { Buycotted } \\
\text { Firms }\end{array}$ & $\begin{array}{l}\text { Boycotted } \\
\text { \& Buyc. } \\
\text { Prod. }\end{array}$ & $\begin{array}{c}\text { Boycotted } \\
\text { \& Buyc. } \\
\text { Firms }\end{array}$ & $\begin{array}{c}\text { Buycotted } \\
\text { Prod. \& } \\
\text { Firms }\end{array}$ \\
\hline Predictors & & & & & & \\
\hline $\begin{array}{l}\text { Confidence } \\
\text { in LS }\end{array}$ & $\begin{array}{r}1.831 * * \\
(.223)\end{array}$ & $\begin{array}{r}3.648 * * \\
(.378)\end{array}$ & $\begin{array}{l}1.685 \\
(.289)\end{array}$ & $\begin{array}{r}2.453 * * \\
(.261)\end{array}$ & $\begin{array}{l}1.481 \\
(.309)\end{array}$ & $\begin{array}{r}3.047 * * \\
(.427)\end{array}$ \\
\hline $\begin{array}{l}\text { Confidence } \\
\text { in CSR }\end{array}$ & $\begin{array}{l}1.323 \\
(.222)\end{array}$ & $\begin{array}{l}1.180 \\
(.374)\end{array}$ & $\begin{array}{r}3.309 * * \\
(.322)\end{array}$ & $\begin{array}{r}1.384 \\
(.264)\end{array}$ & $\begin{array}{l}1.780 \\
(.313)\end{array}$ & $\begin{array}{r}3.720 * * \\
(.501)\end{array}$ \\
\hline Constant & $\begin{array}{r}-1.311 * * \\
(.365)\end{array}$ & $\begin{array}{r}-3.903 * * \\
(.682)\end{array}$ & $\begin{array}{r}-2.707 * * \\
(.527)\end{array}$ & $\begin{array}{r}-1.953 * * \\
(.425)\end{array}$ & $\begin{array}{r}-2.814 * * \\
(.551)\end{array}$ & $\begin{array}{r}-3.768 * * \\
(.738)\end{array}$ \\
\hline $\begin{array}{l}\text { Model fit } \\
\text { Nagelkerke } R^{2} \\
\text { Cox and Snell } \\
-2 \text { Log Likelihood } \\
N\end{array}$ & $\begin{array}{l}.224 \\
.216 \\
2233,089 \\
1256\end{array}$ & & & & & \\
\hline
\end{tabular}

Nevertheless, the effects so far result the assessment of how likely individuals are to be a boycotter or a boycotter and buycotter of products instead of being a non-political consumer. However, in the theorised model of the two-stage process, the choice is actually rather a choice between different varieties of active political consumerism. In accordingly extending the comparison to other types of political consumerism, as Figure 20 displays, the picture changes.

In assessing whether individuals with confidence in labelling schemes are more or less likely to be (1) boycotter or (2) boycotter and buycotter of products instead of any other type 
of political consumer, the results for the two are entirely opposite. Boycotting is closer associated with not having more confidence in labelled products than with having more confidence, whereas boycotting and buycotting products is closer associated with having more confidence. ${ }^{99}$

Figure 20. The Effect of Confidence in Labelling Schemes on Boycotting and on Boycotting and Buycotting Products
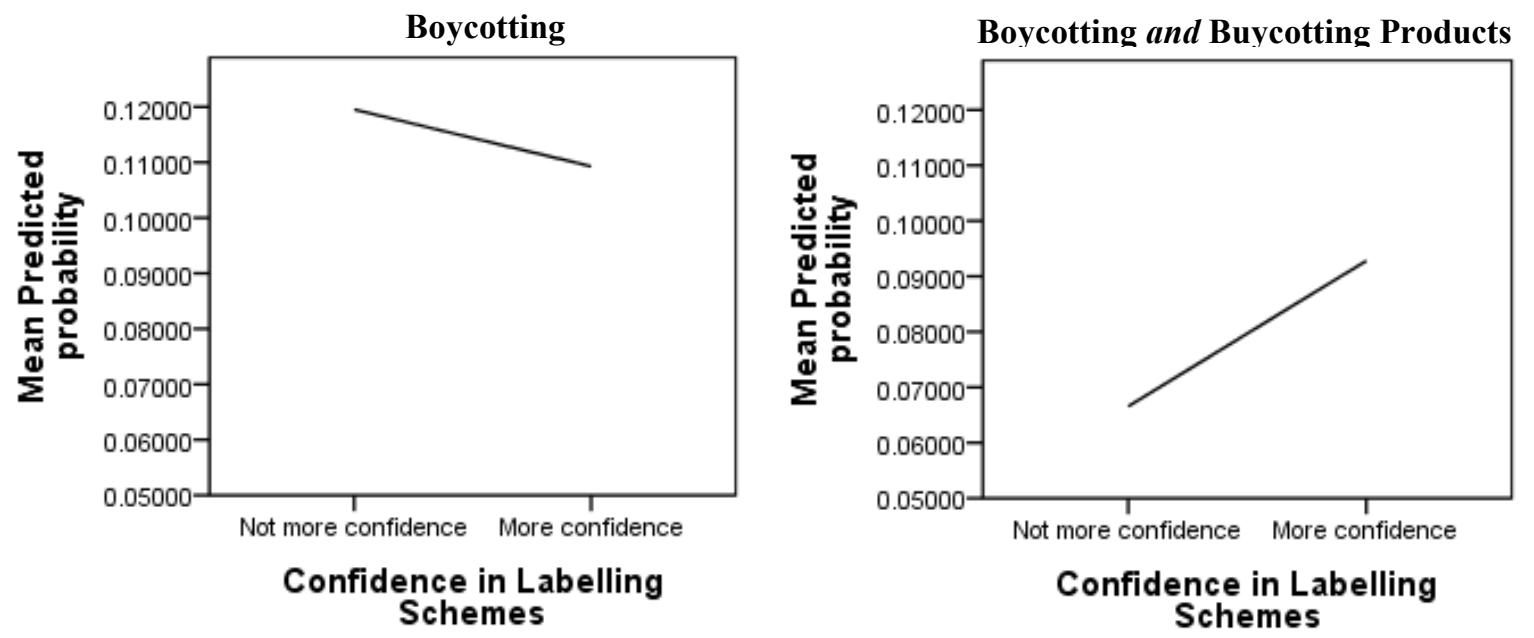

Nonetheless, the slope as well as the levels of the lines are different. The slope is particularly pronounced for boy- and buycotting products, i.e. individuals having more confidence in labelled than in non-labelled products are notably more likely to be involved in boycotting and buycotting than individuals with no more confidence. The propensity to boycott in turn is only slightly different for individuals who have more confidence from those who have not. However, the probability of being involved in boycotting is overall higher. Thus, when compared with one another, individuals are generally more likely to only boycott than to boycott and buycott products. Put differently, the distinct levels suggest that the 'threshold' is higher for doing both boy- and buycotting products; and with it, the chances of being involved in this variety are generally smaller than for boycotting.

Altogether, this indeed further backs the theory on a stepwise process. When comparing it to the option of non-political consumerism, individuals with confidence in labelling schemes may tend to boycott. Nevertheless, when contrasting it to types of political consumerism, the individuals who have high confidence in labelling schemes rather tend to be involved in another type of political consumerism than in boycotting. Hence, in line with the theoretical claim that

\footnotetext{
99 The results base on one binary logistic regression on boycotting and one on boycotting and buycotting products, each assessing the likelihood of being involved in the respective activity compared to all other varieties of political consumerism. Yet, important to note is that for boycotting and buycotting products, the results do not reach statistical significance. Thus, the results only allow for a vague impression and clearly have to be considered with caution. This is also why the text merely talks of associations, not of likelihoods.
} 
confidence is associated with the willingness to do an 'investment' in transactions with relatively anonymous counterparts, boycotters appear to be not as willing to make an investment as buycotter. They theoretically have confidence but are missing something besides which permits them to translate this confidence in positive buying i.e. buycotting. Accordingly, the findings sustain the idea that boycotters have confidence in the usefulness of labelling schemes but not in the yet existing ones. So, they strive to promote the creation of further labels. Once they have succeeded, they may also buy the labelled products.

\subsubsection{Conclusions for the Theoretical Framework}

The theoretical framework rests on two main pillars: The first pillar is the theory of the concept of the state and the assumption that citizens' understanding of how cooperation between government, the market and civil society should look like is one guiding factor when deciding whether to boycott and/or to buycott. The second pillar is the assumption that political consumer behaviour is guided by labelling schemes and corporate social responsibility which individuals can confide in, and that individuals who both boycott and buycott get involved in it gradually depending on the extent to which such guidelines are available. That is, first some individuals become boycotter with the aim of expressing discontent and to promote the introduction of tools which permit to better distinguish the 'good' from the 'bad' purchases. And then, in the following, the resulting tools may guide buycotting activities.

The assessment of the findings in the previous section mainly sustains both assumptions, notwithstanding some adjustments. According to the theory on the concept of the state, a cooperative view entails the preference of non-market forms of cooperation between the three actors state, market and civil society as means to deal with matters of socio- and economic-political relevance. Hence, an individual with a cooperative view should per se regard it as a responsibility to get involved as a political consumer. Either in supporting i.e. cooperating with the firms which behave in line with certain criteria that are considered to be important from a political point of view; or in putting pressure on firms which do not behave as expected. In contrast, the liberal view is not directly associated with the perceived 'obligation' to get involved. Instead, individuals with a liberal view rely on free market competition. In line with it, they use the information provided by the market actors to evaluate 'the best offer' to buy. Yet, this requires being capable (or willing) to trust in the offer actually being the 'best offer'. The global findings for the hypotheses sustain this idea: hypotheses hlb and h1c put forward that individuals with 
a cooperative concept of the state are generally more likely to be political consumers than individuals with a liberal concept of the state. Furthermore, for individuals with a cooperative view, trust and having confidence in the information provided by such means as labelling schemes and CSR is not a prerequisite for being involved in political consumerism in general (h1b), and buycotting firms more in particular (h2b). In contrast, for individuals with a liberal view not only trust but also confidence in labelling schemes are decisive (h1a, h5c). It suggests that they seek formal information to be provided by the market actors which they may rely on, and then use it for their (political) purchasing decisions. In sum, the concept of the state may not be directly related to the decision on whether to boycott and/or buycott in a peculiar combination. Instead, it is related to the very important initial question of whether or not to become a political consumer at all. This shows that the theory on the concept of the state is indeed a central element influencing political consumer behaviour.

The second pillar involves the idea that political consumer activity is a stepwise process related to confidence in guidelines for consumers. According to it, certain individuals get involved into political consumerism step by step, that is, they begin with boycotting and once there is a sufficient extent of information available (i.e. labelling schemes), they also start to buycott. As noted above, boycotting and boycotting and buycotting products equally exhibit peculiar links with the concept of the state and confidence in labelling schemes. This is regarded as a sign that the two are connected. Still, the theoretical framework assumes that preferences translate differently into political shopping behaviour depending on the individuals' level of trust and confidence. It proposes that the effect of confidence is somewhat different between the two varieties because boycotters are still too wary to buycott. The findings back this assumption: confirmed in hypothesis 5a, when having confidence in labelling schemes, individuals are indeed more likely to be boycotter than non-political consumers. Yet, as Table 25 illustrates, when comparing it to other types of political consumers, individuals with confidence in labelling schemes appear to tend to be involved in another variety of political consumer activity rather than in a boycott. Thus, boycotter seem to differ from buycotter in their confidence in labelling schemes, which underpins the theoretical proposition that boycotter theoretically have confidence in labelling schemes, yet considering the labelling schemes that are available to them so far, they do not have more confidence in products labelled with these than in the nonlabelled products. Therefore, they boycott in order to encourage the introduction of labelling schemes which they can have confidence in. And once these are introduced, they become buycotter, too. In sum then, even though a final statement requires further corroboration, it all points 
towards a stepwise model of getting involved in boycotting and buycotting activities. Figure 21 depicts the resulting framework on political consumerism.

Succeeding analyses will now have to consider more in detail the exact causal mechanism underlying the step from boycotting to doing both boycott and buycott. In spite of this remaining level of uncertainty, as the graph visualises, all taken together the findings ultimately confirm political consumerism as a dynamic, gradually evolving process building on confidence, information and the individual understanding of responsibility in the market place.

Figure 21. The Process of Political Consumerism

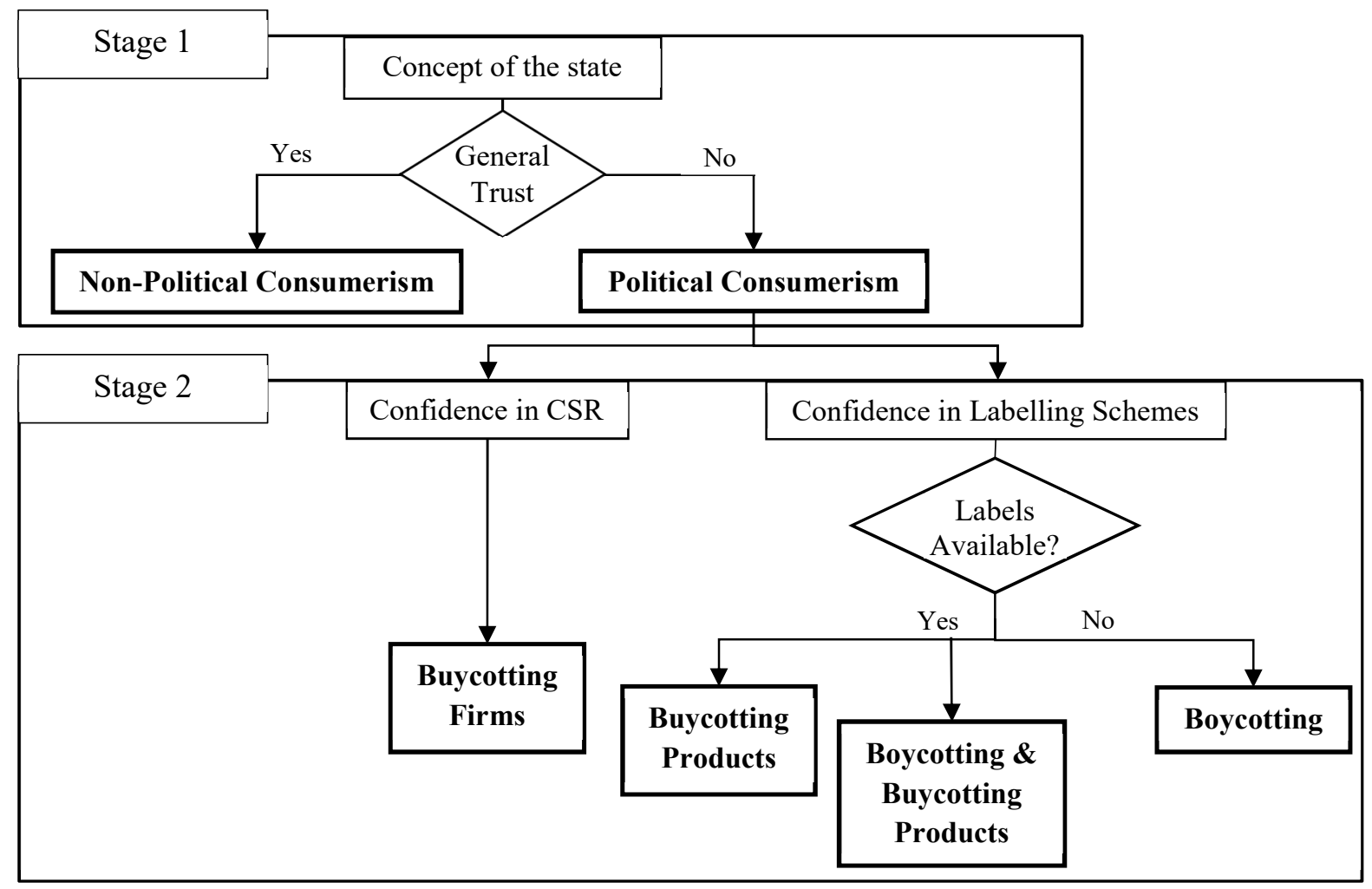

6.5 Corroborating the Final Interpretation

The previous section closed with the observation that political consumerism can be viewed as a two-stage process: in a first stage, the concept of the state and general trust influence the tendency to become a political consumer. Following this, in a second stage, labelling schemes and information about the societal involvement of firms serve the political consumer as reference points for deciding how to consume politically, i.e. what to buycott and when to boycott. Having confidence in labelling schemes aids the buycotting of products, having confidence in firm related information serves buycotting firms. Boycotting, in turn, appears to rather be the 
result of a lack of labelling schemes which individuals have confidence in and the resulting desire to encourage the introduction of such.

This section strives to corroborate these findings and conclusions. For doing so, the employed survey sample is split at random in two, and for each of the resulting data sets the previous analyses are reiterated and the results then compared. The first part of the section briefly presents the examination strategy applied. Further, it checks for the basic underlying structure and thus the comparability of the two sets. Following this, in line with the final conclusion, the analysis begins with examining the relationships on the first stage and then proceeds to the second stage of the process of political consumerism. That is, the analysis first reviews individuals' tendency to be political or non-political consumers. Once done so, it then turns to the second stage and considers the links between confidence in labelling schemes and confidence in CSR with the single varieties of active political consumerism.

\subsubsection{Re-Examination of the Model on Political Consumerism}

\subsubsection{Examination Strategy and Structure of the Deployed Data}

To divide the survey sample into two halves, respondents are assigned in turns to sample A or B (see also Chapter 4.2.1): every second respondent in the sample is assigned to sample B (i.e. even case numbers), all others to sample A (i.e. uneven case numbers). The alternate allocation permits to bring together two random groups of individuals and thereby allows for circumventing differences in the socio-demographic distributions of individuals who participated at earlier stages of the survey and those who participated later. ${ }^{100}$ Each of the two samples is then examined following the same line of analyses as for the entire sample. As in the previous chapter, the examination starts with considering the bivariate correlations between the respective variables and then proceeds to checking the links of multiple variables in a regression analysis.

Splitting the survey sample provides two data sets with each covering 675 respondents. Looking at the primary indicators age group, gender and level of education shows that the sociodemographic distributions of the two halves are indeed comparable to each other. Besides, they also overall mirror the distribution in the complete sample. ${ }^{101}$ Consequently, deviations in the

\footnotetext{
${ }^{100}$ Such differences could arise due to the quota sampling technique: once single quotas were filled, respondents with the respective socio-demographic characteristics could not participate anymore in the survey (see Chapter 4.2.2). As a result, respondents from strata which were more difficult to reach (e.g. individuals at higher ages and/or with lower levels of education) could agglomerate in the last segment of the sample.

${ }^{101}$ The largest deviations from the entire survey sample are, firstly, 1.93 percent more individuals with a Higher Education Entrance Qualification in set A and 1.93 percent less of them in set B; and, secondly, 1.7 percent less individuals at the age of 50 to 54 in set $\mathrm{A}$ and 1.7 percent more in set B. The remainder varies mainly between 0.1 and 0.5 percent of deviation to the distribution in the general sample.
} 
results of subsequent analyses are not expected to be linked to these underlying socio-demographic features.

The final model rests on four core concepts: general trust, confidence in labelling schemes, confidence in CSR and the concept of the state. In comparing the distributions of these variables in the two sets, the mean levels of general trust and confidence in CSR show to be almost equal. Confidence in labelling schemes, in turn, is somewhat lower in set A than in set B, yet according to a Mann-Whitney-U Test this difference is not statistically significant. Likewise, the individuals in set A exhibit a slightly higher tendency towards a liberal concept of the state than in set $\mathrm{B}$, but not to a statistically significant extent either. Thus, all taken together the underlying structure of the split-sample halves appears to be comparable to each other as well as to the entire sample. So they seem to be apt for the ensuing review.

\subsubsection{Reassessing the First Stage}

In the proposed model on the process of political consumerism, for the first stage the core variables are non-political consumerism, the concept of the state and general trust. Consistent with the correlation in the entire sample, in set A as well as in set B non-political consumerism goes hand in hand with having lower levels of general trust (cf. Table 26). The correlation of non-political consumerism with the concept of the state in turn slightly differs: only in set B they are correlated, not in set A. Nonetheless, in set B the correlation observed in the entire sample is replicated, that is, non-political consumerism appears to be linked to a liberal concept of the state. Finally, the analysis of the entire sample concludes that the concept of the state and level of general trust interact, and depending on their peculiar combination their link with nonpolitical consumerism varies. In view of that, Table 26 further includes the correlation of these two variables. Nevertheless, again only set B mirrors the entire sample where individuals with a liberal concept of the state tend to also have lower levels of general trust. 
Table 26. Bivariate Correlations of Non-Political Consumerism with the Concept of the State and General Trust in Set A vs. Set B

\begin{tabular}{|c|c|c|c|c|c|c|c|}
\hline & \multicolumn{3}{|c|}{ Set A } & \multirow{2}{*}{$\begin{array}{c}\text { Set B } \\
\begin{array}{c}\text { Concept of } \\
\text { the State }^{\mathrm{a}}\end{array}\end{array}$} & \multicolumn{2}{|c|}{ Entire Set } \\
\hline & & $\begin{array}{c}\text { General } \\
\text { Trust } \\
\end{array}$ & $\begin{array}{l}\text { Concept of } \\
\text { the State }^{\mathrm{a}}\end{array}$ & $\begin{array}{c}\text { General } \\
\text { Trust }\end{array}$ & & $\begin{array}{c}\text { General } \\
\text { Trust } \\
\end{array}$ & $\begin{array}{l}\text { Concept of } \\
\text { the State }^{\mathrm{a}}\end{array}$ \\
\hline Non-Political & Corr. Coefficient & $-.115^{* *}$ & .073 & $-.077 *$ & $.128^{*}$ & $-.095^{* *}$ & $.100 * *$ \\
\hline Consumerism & $N$ & 672 & 639 & 668 & 627 & 1340 & 1266 \\
\hline $\begin{array}{l}\text { Concept of } \\
\text { the State }\end{array}$ & $\begin{array}{l}\text { Corr. Coefficient } \\
N\end{array}$ & $\begin{array}{r}-.078 \\
636\end{array}$ & & $\begin{array}{r}-.160 * * \\
621\end{array}$ & & $\begin{array}{r}-.120 * * \\
1257\end{array}$ & \\
\hline
\end{tabular}

a 1 = cooperative, 2 = liberal; Measure of Correlation = Spearman's Rho; ${ }^{*} p<.05,{ }^{* *} p<.01$ (2-tailed).

Given this differing underlying correlative structure, the effects in the regression analysis may vary, too. And as the figures in Table 27 display, indeed they do: when including the interaction term of the concept of the state and general trust, only set A replicates the results obtained for the entire survey sample. Hence, this set's analysis supports the assertion that individuals with a liberal concept of the state and higher levels of trust are less likely to be nonpolitical consumers than individuals with a liberal concept of the state and low levels of general trust (set A, Model 1). The consideration of only the main effects (set A, Model 2) further backs the result, indicating that having a liberal concept of the state increases the likelihood of an individual being a non-political consumer, whereas having higher general trust decreases it.

Table 27. Reviewing the Link between the Concept of the State and General Trust with Non-Political Consumerism

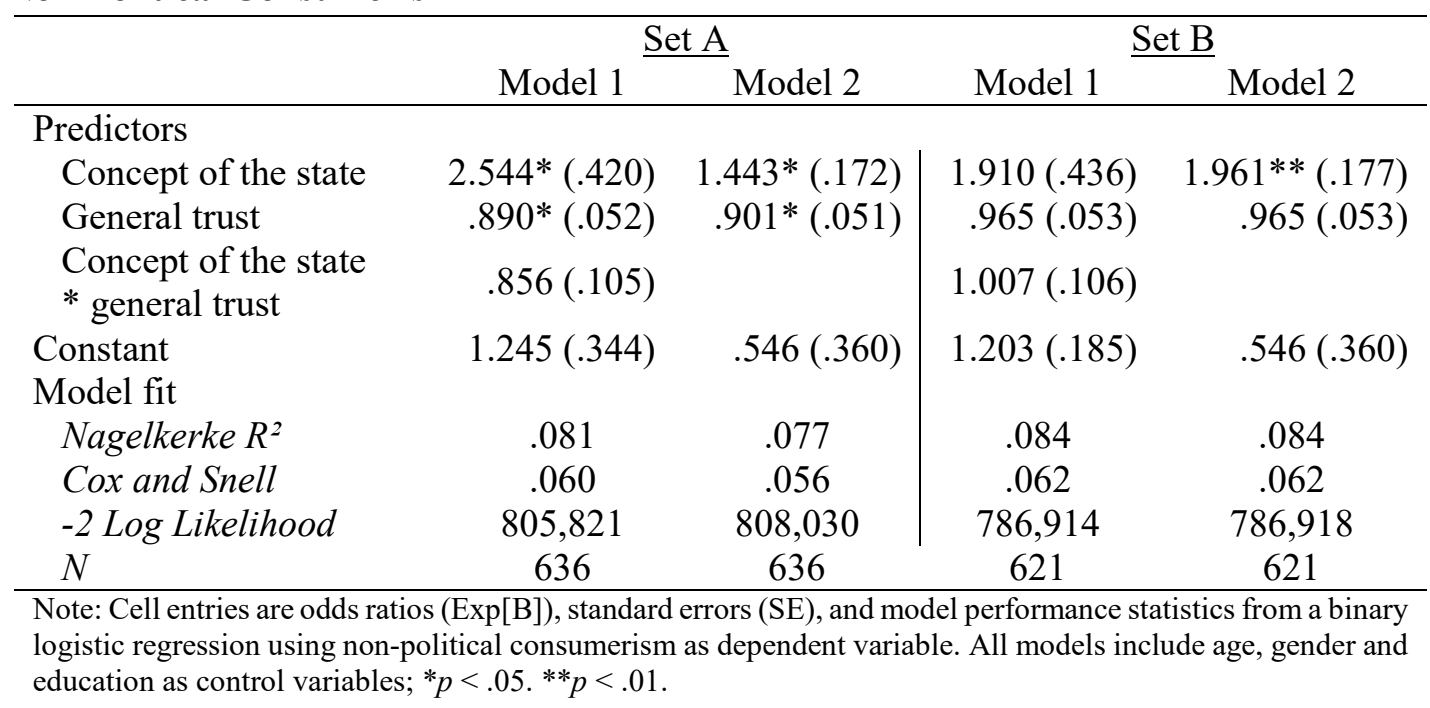

In contrast, in set B general trust does not reach statistical significance at all whereas the concept of the state does so only when excluding the interaction term (cf. set B Models 1 and 2 ). The interaction term of the concept of the state and general trust is non-significant as well. 
The three charts in Figure 22 clarify the differing results graphically: in set A, the concept of the state and general trust are together linked to non-political consumerism in a similar style as in the entire sample (middle and upper charts, respectively). Only the relevance of general trust is more pronounced in set A than when considering the entire sample. What is important, it corroborates the fundamental notion that at lower levels of general trust an individual's mean predicted probability to be a non-political consumer is much higher when having a liberal than when having a cooperative concept of the state. At high levels of general trust, in turn, the propensity to be a non-political consumer is not more different for someone with a liberal than with a cooperative view.

The lower chart displaying the result for set B shows a somewhat different picture. There, individuals with a liberal concept of the state are generally more probable to be non-political consumers than individuals with a cooperative view, and the level of general trust does not change much in this relative tendency. Even so, the impact of the concept of the state is faintly stronger at lower levels of general trust than at high levels. Thus, the trend is not entirely against the observations in the other two sets. In fact, the effect of general trust in the entire sample appears to move exactly in between the two split-samples. In line with that, in both the entire sample and in set B a liberal view is correlated with having lower levels of general trust (ref. to Table 26). This may cause a "hidden effect" in the underlying structure of the data where general trust works through its link with the concept of the state and so levels out the direct effect of general trust (at least to some degree). The almost identical model fit for including and not including the interaction term in set B backs this notion (set B Model 1 and 2, respectively). Considering this, in sum the findings then primarily emphasize the relevance of the concept of the state. But they also reaffirm the role that general trust plays, too, though to a less consistent extent. That is, only in the context of certain conditions being given. 
Figure 22. Mean Predicted Probabilities of Non-Political Consumerism in the Entire Sample and the Split-Half Samples
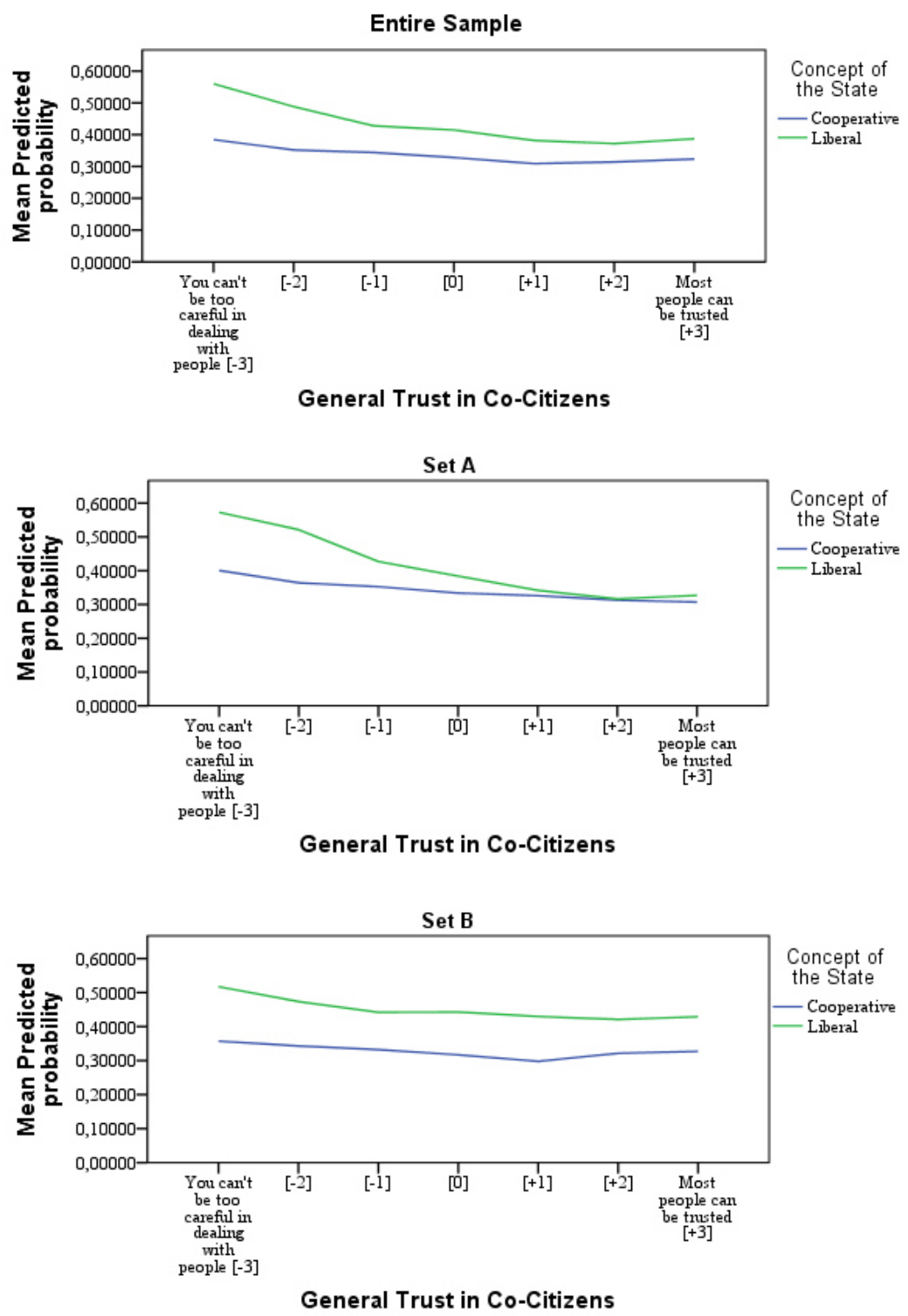

\subsubsection{Reassessing the Second Stage}

The second stage of the model proposes a link (1) between buycotting firms with confidence in CSR, between (2) buycotting products and (3) boycotting and buycotting products with confidence in labelling schemes, and (4) between boycotting with confidence in labelling schemes, too, though to a lesser extent. Considering the bivariate links, in all except for two cases the variables are not correlated. Only in set B the buycotting of products, and in set A the buycotting of products and firms are connected to having more confidence in labelling schemes (Cramer's $V=.081, p=.036$ and Cramer's $V=.102, p=.009$, respectively). 
The regression analysis sheds further light on this finding (see Table 28). It displays the comparative effects of the two types of confidence on the different varieties of political consumerism in set A and B: the buycotting of firms is persistently interconnected with having confidence in CSR. This backs the theory. Equally does the stable link of boycotting and buycotting products with confidence in labelling schemes underline the conclusions drawn based on the entire sample. And, lastly, for the boycotting and buycotting of firms, the results mirror that of the entire sample, too. That is, neither confidence in labelling schemes nor confidence in the societal involvement of firms are linked to the tendency to be involved in this variety of political consumerism.

For boycotting as well as for the buycotting of products the results are less clear: in set A, neither of them is related to any type of confidence. In contrast, in set B the results match those for the entire sample, that is, both boycotting as well as the buycotting of products appear to be linked to confidence in labelling schemes. The beta coefficient for boycotting in set B is comparable to that obtained for the entire sample $(\operatorname{Exp}[B]=1.831, S E=.223)$. Hence, the conflicting observations seem to merely fit in with the theoretical conclusion that the link between boycotting and confidence in labelling schemes is ambiguous. However, for the buycotting of products the beta coefficient as well as its standard error is very high in set $\mathrm{B}$, pointing towards large discrepancies in the answers across the respondents belonging to this category. This advocates that the underlying structure of the two sample-halves may be biased in an aspect related to this variety of political consumerism. And in fact, the number of buycotter of products is very small, with 26 in set A and 20 in set B. ${ }^{102}$ Thus, the finding reinforces the connection between product related purchasing and labelling schemes. Yet, the small number of respondents makes the analysis susceptible even to small disparities and thus limited in its validity. The same shortcoming applies to the variety of buycotting products and firms: there, the results partly deviate from the analysis of the entire sample, revealing instead of a link with the two types of confidence only a link with confidence in labelling schemes in set A and a link with confidence in CSR in set B. Still, in line with its dual character it maintains the tie to both labelling schemes and CSR. However, only 13 respondents belong to this category in set A and 23 in set B. As a result, it does not provide an adequate basis for drawing substantial conclusions about deeper implications of this finding.

\footnotetext{
${ }^{102}$ For comparison, in the category of boycotting it is $\mathrm{n}=71$ in set $\mathrm{A}$ and $\mathrm{n}=83$ in set $\mathrm{B}$.
} 
Table 28. Comparative Effects of Confidence in Labelling Schemes and in CSR in Sets A and B

\begin{tabular}{|c|c|c|c|c|c|c|}
\hline Set A & Boycotted & $\begin{array}{c}\text { Buycotted } \\
\text { Products }\end{array}$ & $\begin{array}{c}\text { Buycotted } \\
\text { Firms }\end{array}$ & $\begin{array}{l}\text { Boycotted \& } \\
\text { Buyc. Prod. }\end{array}$ & $\begin{array}{l}\text { Boycotted \& } \\
\text { Buyc. Firms } \\
\end{array}$ & $\begin{array}{c}\text { Buycotted } \\
\text { Prod.\& Firms }\end{array}$ \\
\hline Predictors & & & & & & \\
\hline $\begin{array}{l}\text { Confidence } \\
\text { in LS }\end{array}$ & $\begin{array}{l}1.478 \\
(.327)\end{array}$ & $\begin{array}{l}2.355 \\
(.488)\end{array}$ & $\begin{array}{l}1.818 \\
(.382)\end{array}$ & $\begin{array}{r}2.095^{*} \\
(.366)\end{array}$ & $\begin{array}{r}.929 \\
(.446)\end{array}$ & $\begin{array}{r}6.958^{*} \\
(.850)\end{array}$ \\
\hline $\begin{array}{l}\text { Confidence } \\
\text { in CSR }\end{array}$ & $\begin{array}{l}1.376 \\
(.321)\end{array}$ & $\begin{array}{l}1.910 \\
(.507)\end{array}$ & $\begin{array}{r}3.434 * * \\
(.421)\end{array}$ & $\begin{array}{l}2.039 \\
(.378)\end{array}$ & $\begin{array}{l}1.659 \\
(.417)\end{array}$ & $\begin{array}{l}2.980 \\
(.855)\end{array}$ \\
\hline Constant & $\begin{array}{r}-1.353 * * \\
(.519)\end{array}$ & $\begin{array}{r}-3.569 * * \\
(.871)\end{array}$ & $\begin{array}{r}-3.098^{* *} \\
(.712)\end{array}$ & $\begin{array}{r}-1.426^{*} \\
(.562)\end{array}$ & $\begin{array}{r}-2.295 * * \\
(.774)\end{array}$ & $\begin{array}{r}-4.648^{* *} \\
(1.273)\end{array}$ \\
\hline \multicolumn{7}{|l|}{ Model fit } \\
\hline Nagelkerke $R^{2}$ & .254 & & & & & \\
\hline Cox and Snell & .246 & & & & & \\
\hline $\begin{array}{l}-2 \text { Log Likelihood } \\
N\end{array}$ & $\begin{array}{l}1366,784 \\
625\end{array}$ & & & & & \\
\hline
\end{tabular}

\begin{tabular}{lrrr|rrr}
\hline Set B & Boycotted & $\begin{array}{c}\text { Buycotted } \\
\text { Products }\end{array}$ & $\begin{array}{c}\text { Buycotted } \\
\text { Firms }\end{array}$ & $\begin{array}{r}\text { Boycotted \& } \\
\text { Buyc. Prod. }\end{array}$ & $\begin{array}{r}\text { Boycotted \& } \\
\text { Buyc. Firms }\end{array}$ & $\begin{array}{c}\text { Buycotted } \\
\text { Prod. \& Firms }\end{array}$ \\
\hline Predictors & & & & & & \\
$\quad$ Confidence & $2.203^{*}$ & $7.118^{* *}$ & 1.563 & $3.027^{* *}$ & 2.234 & 2.095 \\
in LS & $(.311)$ & $(.611)$ & $(.444)$ & $(.382)$ & $(.458)$ & $(.514)$ \\
Confidence & 1.253 & .613 & $3.042^{*}$ & .875 & 1.956 & $3.993^{*}$ \\
$\quad$ in CSR & $(.311)$ & $(.556)$ & $(.501)$ & $(.378)$ & $(.489)$ & $(.624)$ \\
Constant & $-1.296^{*}$ & $-4.504^{* *}$ & $-2.302^{* *}$ & $-2.864^{* *}$ & $-3.580^{* *}$ & $-3.191^{* *}$ \\
& $(.518)$ & $(1.101)$ & $(.796)$ & $(.670)$ & $(.836)$ & $(.947)$ \\
Model fit & & & & & & \\
Nagelkerke R $R^{2}$ & .248 & & & & & \\
$\quad$ Cox and Snell & .239 & & & & & \\
-2 Log Likelihood & 1316,904 & & & & & \\
$\quad N$ & 631 & & & & & \\
\hline
\end{tabular}

Note: Cell entries are odds ratios (Exp[B]), standard errors (SE), and model performance statistics from multinomial logistic regression using political consumerism as dependent variable and non-political consumerism as reference category. Cell entry for the Constant is the beta coefficient [B]. All models are controlled for age, gender and education; ${ }^{*} p<.05,{ }^{* *} p<.01$.

In sum, the observations for the second stage are mixed, yet imprecise conclusions arise primarily in relation to small numbers of respondents in the respective categories. Beyond that, the results support the conclusions drawn based on the analysis of the entire sample and the resulting model established on the process of political consumerism: buycotting firms is connected to confidence in firms' societal involvement, the boycotting and buycotting of products to confidence in labelling schemes, and for boycotting the results remain vague but suggest that it is somehow connected to confidence in labelling schemes, too.

\subsubsection{Summing up the Findings}

This chapter strived to test whether the model on the process of political consumerism also holds in a setup different to that of the survey sample employed in the main analysis. Splitting 
the survey sample provided two data sets which differ to a certain degree, yet not to such an extent that an underlying deviation in socio-demographic characteristics would be the root of variations in the findings. Grounded on these two data sets, the reassessment of the model mainly endorses the conclusions drawn based on the entire sample. Some assertions cannot fully be ascertained, yet none of the ideas is contradicted or rejected. Figure 23 displays which of the links are confirmed and which not.

\section{Figure 23. Results for the Process of Political Consumerism}

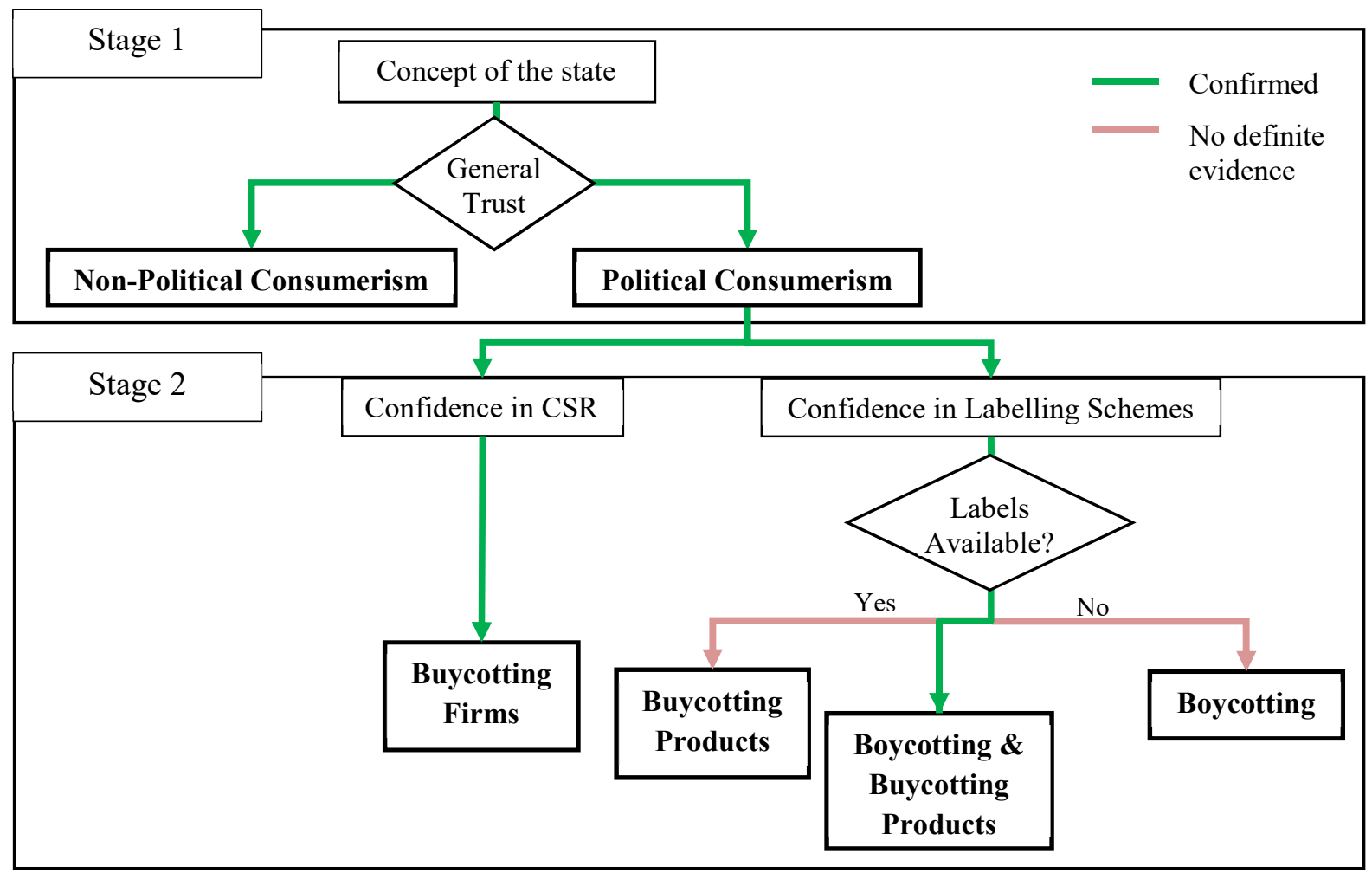

As the graph illustrates, the re-examination corroborates the idea that political consumerism should be regarded as a stepwise process: the decision to become or not become a political consumer is linked to the individuals' understanding of how cooperation and the distribution of responsibilities between government, the market and civil society should look like, combined with their concurrent level of general trust in co-citizens. The decision on the approach taken to consume politically is in turn guided by the availability of labelling schemes and information on firms' societal involvement and the individuals' level of confidence in these reference points. Having more confidence in firms which are societally involved than in non-involved firms facilitates the buycotting of firms whereas having more confidence in labelled than in non-labelled products enables the product-related varieties of political consumerism. Lastly, the precise mechanism underlying the decision to become a boycotter could not be explored more in 
depth than in the preceding section. Nevertheless, the results replicate the same ambiguous link with confidence in labelling schemes. In view of that, the findings underpin the idea that boycotter theoretically have a certain level of confidence in labelling schemes, yet they are lacking a 'mediator' (i.e. reference points like labelling schemes) which permits them to translate their basically positive attitude towards buycotting into behavioural action. Therefore, they recur to the denying of purchasing specific products with the aim of putting pressure on government, firms, consumer associations, etc. to introduce more reliable reference points that allow for distinguishing the 'good' from the 'bad' products and firms. 


\section{Conclusion}

7.1 Investigating the Aims underlying Boycotting and Buycotting

There is not one type of political consumer but several, and citizens seem to make a distinction between them. But why are boycotter not automatically buycotter, and vice versa? The central idea investigated in this dissertation was that boycotting and buycotting represent two opposite and yet complementary modes of political consumerism, which together constitute a process. This process of political consumerism develops on the individual and the country levels in parallel and interacting, therein being influenced by two facets: the concept of the state and political shopping guidelines like labelling schemes and firms' societal involvement i.e. Corporate Social Responsibility (CSR). Stemming from three key observations, the first chapter raised six research questions to investigate this idea. First, depending on their concept of the state, citizens have distinct preferences for how political concerns ought to be tackled, and the fundamental proposition was that these preferences influence their choice of whether and on how they get involved in political consumerism. Second, similar to boycotting and buycotting, labelling schemes and CSR are different in nature and relate to distinct underlying intentions. And third, boycotting and buycotting as well as the two types of guidelines are spread differently across countries. This put forward that boycotting and buycotting involvement interacts differently with CSR and labelling schemes, and across countries depending on the concept of the state.

The later chapters set out to answer the research questions. Chapters 2 and 3 drafted a theoretical framework, which Chapters 4, 5 and 6 then considered empirically. A cross-country study of 20 European countries and a survey conducted among 1.350 individual citizens living in Germany built the core of the examination. This concluding chapter finalises the investigation by bringing together the findings of the respective studies. Coming back to one research question after another offers a point of departure for a systematic presentation of the discoveries delivered. In so doing, the chapter centres on three purposes. The first is to answer the research questions. In getting back to the questions, the chapter compares the results gained in the country and the individual level studies with the ideas presented at the outset of the work, and it elaborates on what findings and ideas the dissertation delivers. A second aim consists in reviewing the degree to which the findings obtained in the micro-level study replicate and complement the findings obtained in the macro-level study, and vice-versa. Finally, the chapter strives to reflect on the study and on its position in the broader field of research on political consumerism. A sketch of the consequences of the global conclusions and an outlook for future endeavours to investigate political consumerism complete the dissertation. 
7.2 Answering the Research Questions

\subsubsection{Patterns at the Macro-Level}

The main goal of the dissertation was to examine the relationship of boycotting and buycotting behaviour with labelling schemes compared to CSR. The assumption was that their relationship varies, this variation being linked to distinct preferences on how socio-political concerns ought to be tackled among individuals as well as prevailing across countries. Three research questions sought to better understand this relationship at the country level $(Q 1, Q 5$ and $Q 6)$, another three questions regarded the bond at the individual level ( $Q 2, Q 3$ and $Q 4)$. Stemming from the observation that the prevalence of boycotting, buycotting, CSR and labelling schemes is different across countries, the first question started by considering the country level. Therefore, the section begins with answering the macro-level questions, of which the first read:

(Q1) Do specific 'patterns' in boycotting and buycotting involvement vary in conjunction with certain 'patterns' in the distribution of labelling schemes and/or Corporate Social Responsibility?

Chapters 2 and 3 reflected upon the question and its backgrounds from a theoretical vantage point. Chapter 2 conceptualised boycotting and buycotting and presented varying perspectives on the concept offered by different disciplines of the social sciences. The sociological narrative in section 2.2 unfolded a citizen-consumer hybrid which unifies own consumption desires with self-transcending societal interests and acts based on the global appraisal of the respective concerns. As a result, the section closed with suggesting that patterns in boycotting and buycotting involvement may be related to factors from both the consumer and the political spheres. The socio-psychological perspective assumed in section 2.3 then sketched out two broad classes of conceivably relevant factors: underlying values and/or norms that relate to fundamental issues in life and therefore are comparatively stable over time; and familiarity with and confidence in information providing phenomena, as reliance on information provided can promote a feeling of security.

Chapter 3 elaborated further on these ideas and placed them in context. Boycotting and buycotting involvement arise a profoundly evolving macro-environment in which the share of duties and responsibilities between the state and 'the market' have shifted. Firms have become key actors and addressees of political concerns. Besides, macro-level conditions are assimilating across countries. From this perspective, boycotting and buycotting involvement might be expected to follow similar patterns across countries, too. However, views on duties and responsibilities as well as preferences for how arising socio-political and economic concerns ought to 
be tackled differ from country to country, and across individuals. Therefore, comparable developments may have very different effects on individual behaviour depending on the national contexts and/or personal backgrounds. Inspired by the theory on 'varieties of capitalism' (Hall and Soskice 2001), section 3.1.2 therefore described a distribution of distinct patterns of orientation among the actors in a country towards how cooperation problems should be tackled. As the section concludes, this can translate in certain patterns of boycotting and buycotting involvement. Finally, section 3.2 added the notion of confidence in the sphere of the citizenconsumer furnished by information providing means as it are labelling schemes and CSR. Therewith, it provided a theoretical answer to $Q 1$ : analogous to boycotting and buycotting, labelling schemes and CSR relate to different styles of solving socio-political concerns moving at the interface of politics and the 'market'. Prevailing preferences for such styles of solving socio-political concerns vary from country to country. This may affect their comparative prevalence across countries, with the result that boycotting and buycotting involvement and labelling schemes and CSR are distributed differently across countries, yet following a common pattern.

The first section of Chapter 5 substantiated the answer with empirical data. The study conducted in section 5.2 compared a selection of 20 European liberal democracies on the basis of their boycotting and buycotting involvement, sales of Fairtrade labelled goods and the firms' CSR performance for the year 2003. The methodological approach centred on OLS regression analyses to appraise whether labelling schemes and CSR relate to single varieties of political consumerism in a certain sequential mode. As the results revealed, the spread of non-political consumerism is inversely related to the spreading of CSR and of labelling schemes (Figure 8). On the opposite, buycotting as well as boy- and buycotting involvement increase analogous to a rising prevalence of CSR and labelling schemes (Figures 9 and 12, respectively). Boycotting in turn is linked to labelling schemes only by serving as their promoter, while it does not exhibit a systematic bond with CSR. However, across countries, political consumerism has started to develop at different times. They are at different stages and may therefore exhibit different spreads of boycotting: At early stages, a low incidence of CSR and labelling schemes may come along with relatively high numbers of individuals who only boycott. However, citizens may not stop boycotting as soon as first labelling schemes and CSR have spread out in the country. Hence, at later stages, a large magnitude of boycotting involvement can come along with a high incidence of CSR and/or labelling schemes. The result is a different prevalence of boycotting compared to CSR and labelling schemes depending on the stage at which the country under 
consideration is. To summarise the response to $Q 1$, patterns in boycotting and buycotting involvement, labelling schemes and CSR vary in conjunction. The less present CSR and/or labelling schemes are in a country, the higher is the tendency of citizens to abstain from using their consumption as a tool to express political attitudes, and vice-versa.

The other two macro-level research questions considered these common patterns more in detail. More specifically, they pondered whether common patterns of orientation were related to the prevailing concept of the state in a country, i.e. predominant views on how economicand socio-political challenges ought to be dealt with. So, they asked:

(Q5) Is boycotting and buycotting involvement distributed differently across countries depending on the prevailing concept of the state?

(Q6) And are labelling schemes and Corporate Social Responsibility distributed differently across countries depending on the prevailing concept of the state?

Hall and Soskice (2001) distinguish three groups of countries: coordinated, liberal and mixed market economies. In 'coordinated market economies', non-market forms of cooperation between the state, market and civil society prevail as means to deal with tasks of socio- and economic-political significance. In 'liberal market economies', actors rely on free market competition and that this will most effectively lead to the fulfilment of the intended objective. Finally, in 'mixed' countries, structures are described as favouring cooperative approaches in the sphere of interfirm relation and rather liberal approaches in concerns affecting other actors in society than firms. Besides, they comprise the presence of a strong state.

Chapter 4 provided the comparative distribution of boycotting and buycotting involvement across countries (Figure 5) and thus a first answer to Q5. As the figure illustrated, overall involvement is highest in the countries classified as 'cooperative' market economies. The 'liberal' countries are placed in the middle, and in the 'mixed' countries involvement is lowest. The country study in section 5.3 underscored the observations by presenting a similar picture of country clusters for the distribution of specifically buycotting (Figures 13 and 14). In countries where a cooperative conception prevails, citizens rely on cooperation and solidarity and they are presumed to deem it their duty to actively participate in solving challenges of socio- and economic-political relevance. In line with this thought, in these countries citizens show to be particularly inclined to get involved in political consumerism. On the opposite, citizens living in mixed countries are described as being used to primarily focus on issues that concern the private realm. Moreover, the state is suggested to already control a large part of business activities whereby citizens may feel less in charge to intervene and put firms under pressure to 
change practices. In line with this perception, only few citizens are involved in political consumerism there.

Nonetheless, the discrepancy between liberal and cooperative countries is not entirely clearcut. Section 3.3.1 offered an explanation for it. In their presence, CSR and labelling schemes convey information concerning company conduct and/or product characteristics. Therewith, they allow for distinguishing which purchase may support a political endeavour and make sending political signals easier. Their existence can expedite involvement by easing buycotting. Involvement then is not generally distributed differently in countries with a liberal or a cooperative concept of the state. Instead, depending on the prevailing concept of the state, involvement is related differently (i.e. more closely) to either labelling schemes or CSR, whereas involvement varies liable to the prevalence of the preferred guidelines in a country. Consequently, instead of boycotting and buycotting involvement being each individually and immediately linked to the concept of the state, the section put forward that labelling schemes and CSR act as intermediaries facilitating political consumer involvement. The cluster analyses carried out in section 5.3 corroborate this interpretation. This leads over to the next research question.

The interpretation of the findings obtained in response to $Q 5$ also drafted a theoretical explanation in answer to $Q 6$. Labelling schemes reflect market-based approaches, whereas CSR involves rather informal collaborative approaches. Both labelling schemes and/or CSR facilitate buycotting. As a result, in countries with a liberal concept of the state the former are more closely related to buycotting, in cooperative countries the latter. Finally, in mixed countries citizens are used to rely on informal networks in interactions that take place in the economic sphere; therefore, citizens who decide to buycott prefer the more informal CSR to labelling schemes. The analyses presented in section 5.3 substantiated the answers empirically. Using hierarchical cluster analysis, the section discerned a systematic variation of singular patterns in buycotting involvement, CSR and labelling schemes relative to the prevailing concept of the state. More specifically, as visualised in Figures 13 and 14, the comparative prevalence of labelling schemes and CSR varies across countries depending on the concept of the state, and relative to it, the prevalence of buycotting is different. In countries where a cooperative or mixed concept of the state prevails, CSR is more widespread and exhibits a greater relative importance for buycotting than labelling schemes; in countries where a liberal concept of the state prevails, labelling schemes are more pervasive.

To summarise, responding to $Q 5$, all in all involvement varies systematically relative to the concept of the state. Yet, this variation primarily is a function of distinct preferences for labelling schemes or CSR prevailing across countries. Hence, this also answers Q6. Labelling 
schemes and CSR are distributed differently across countries depending on whether a liberal or a cooperative/mixed concept of the state prevails, respectively.

\subsubsection{Political Consumerism at the Micro-Level}

The macro-level patterns of orientation reflect a sum of individual level choices. In view of that, a second set of research questions regarded the relationship of boycotting, buycotting, labelling schemes and CSR at the individual level. Analogous to $Q 5$ and $Q 6$, the first two questions asked:

(Q2) Is having a specific concept of the state related to the individuals' involvement in boycotting and/or buycotting?

(Q3) And is having a specific concept of the state related to individuals purchasing based on labelling schemes or Corporate Social Responsibility?

Section 3.3.2.1 drafted a theoretical framework in response to $Q 2$. The central proposition was that depending on their concept of the state, citizens have distinct preferences on how to approach political concerns. And given that political consumerism is an act of political participation, the citizens' strategy followed when using their consumption for political participation should be guided by these same preferences, too. Individuals focused on broad cooperation between the different parts of society in solving challenges of socio- and economic-political relevance are presumed to follow a collaborative strategy in political consumerism. Individuals relying on free market competition and on its ability to yield optimal outcomes are assumed to rely on that one will automatically choose the 'right' products as long as the market provides for the 'right' choices. Accordingly, the former were expected to be more likely than the latter to deem it their duty to get involved in boycotting and/or buycotting.

Chapter 6 reviewed the ideas empirically, proceeding in two steps. The first step (section 6.4) consisted in evaluating a survey conducted online in Germany among 1.350 individuals in March 2014. The methodological approach used involved a combination of bivariate correlation and logistic regression analyses. The second step consisted in reassessing the findings applying a split-half method on the sample (section 6.5). Therein, the sample was split at random into two halves and the tests were performed for a second time. The results obtained in both steps suggest that, indeed, having a cooperative concept of the state is related to individuals being more likely to be involved in boycotting and/or buycotting i.e. to be political consumers. As Figure 16 in section 6.4.1.1 visualised and the tests in 6.5.1.2 corroborated, a person having a cooperative concept of the state is generally more likely to be a political consumer than a 
person with a liberal concept of the state. In addition, unlike citizens with a cooperative concept of the state, to be willing to get involved in political consumerism citizens with a liberal view require having high levels of general trust. Their liberal understanding implies them relying on the market. Therefore, they need to be able to rely on co-citizens acting alike so to together be able to incite a noticeable shift in demand and thereby sending a signal to producers. Still, even with high levels of general trust, individuals having a liberal concept of the state are less likely to be political consumers than individuals with a cooperative view. A supplementary test of the bond between having one or the other concept of the state with boycotting, buycotting and nonpolitical consumerism (Table 24) further underscored the finding. Having a specific concept of the state is related to the individuals' involvement in boycotting and/or buycotting i.e. political versus non-political consumerism. By contrast, it is not related differently to being involved in either boycotting or buycotting.

Q3 asks whether having a specific concept of the state is related to purchasing based on labelling schemes or CSR. Section 3.2 approached the question from a theoretical angle and introduced a key distinction. The different backgrounds of labelling schemes and CSR put forward that a preference for one or the other also translates into distinct decisions for what or for whom to buycott. Labelling schemes are related to the nature and production backgrounds of the product (e.g. organic, eco-friendly, etc.). Accordingly, buying based on labelling schemes means to buycott a product. In contrast, CSR is company related; so, if a citizen decides to buy something because the producing company is acting responsibly it is based on the aim to support the particular firm. In other words, the citizen is buycotting a firm. Finally, in the absence of labelling schemes and CSR which individuals rely in, they may desire to express their discontent and seek to encourage or pressure firms to implement it. To achieve that, individuals may decide to boycott. Then, once labelling schemes are introduced, they may boycott and buycott the labelled products. In short, the chapter provided a theoretical framework distinguishing five main variants of involvement: non-political consumerism, boycotting, buycotting products, buycotting firms, and boy- and buycotting products.

Section 6.4 considered for each variant its relationship with the concept of the state. Only purchasing based on CSR (i.e. buycotting firms; section 6.4.1.3) showed to be related to having a specific concept of the state. Specifically, individuals with a cooperative view are generally more likely to buycott firms than individuals with a liberal concept of the state. In contrast, purchasing based on labelling schemes exhibits no common bond with a specific concept of the state when considering the pair of variables alone. Instead, the link varies with an individuals' 
level of confidence, and the impact of this additional variable is notable: the likelihood to buycott based on labelling schemes turns opposite for a liberal versus a cooperative concept of the state as the level of confidence changes from being low to high. Yet in sum, in answer to $Q 3$, the concept of the state is not related to purchasing based on labelling schemes or CSR. This leads to the last research question, which wondered:

(Q4) Is having high or low levels of confidence in labelling schemes and/or in Corporate Social Responsibility related to the individuals' involvement in boycotting and/or buycotting?

Departing from the notion that trust between individuals and firms is vanishing, section 3.2 introduced the conceptual distinction between trust and confidence in the sphere of the citizenconsumer. Labelling schemes and CSR constitute means which aim at furnishing confidence. So, the chapter proposed that although trust in firms might be vanishing, individuals can resort to labelling schemes or CSR and use it as a basis for political purchasing decisions. The theoretical answer to $Q 4$ advanced in 3.3.2 was that having a high level of confidence in labelling schemes increases the likelihood that an individual buycotts products or, if no labels are available (yet), the individual boycotts in order to instigate the spreading of labelling schemes. Equally, high levels of confidence in CSR increase the chances that an individual is involved in political consumerism by means of buycotting firms.

The empirical analyses for buycotting products (section 6.4.1.2), buycotting firms (section 6.4.1.3) and boycotting (section 6.4.1.4) underscore the importance of confidence. All in all, individuals having high levels of confidence in labelling schemes and/or CSR are generally more likely to boycott and/or to buycott than when having low levels of confidence. Moreover, the type and level of confidence influence the deliberate choice for one or the other variant of political consumerism. Having a high level of confidence in CSR is related to the buycotting of firms. High levels of confidence in labelling schemes are related to boycotting, buycotting products or involvement in both boycotting and buycotting products.

To recapitulate the findings in response to $Q 2, Q 3$ and $Q 4$, having a specific concept of the state is related to the individuals' general inclination to be involved in boycotting and/or buycotting. But it is not related to the tendency to purchase based on labelling schemes or CSR. Instead, this tendency shows to be a function of the level of confidence in labelling schemes and/or CSR an individual has. When having high levels of confidence in one and/or the other type of guideline, individuals are more likely to be involved in boycotting and/or buycotting. Likewise, having high levels of confidence in labelling schemes or in CSR is related to individuals purchasing based on labelling schemes or CSR, respectively. 


\subsection{Integrating the Micro- and the Macro-level Findings}

The macro-level analysis closes with three central conclusions. First, the less present CSR and/or labelling schemes are in a country, the higher is the tendency of citizens to abstain from using their consumption as a tool to express political attitudes, and vice-versa. Likewise, CSR and labelling schemes are both linked with buycotting and boy- and buycotting. Thus, second, CSR and labelling schemes serve as an orientation for citizens who desire to buycott. And as the tests highlight, this is independent of income, inclination to spend one's income on consumption and access to stores. Third, the extent to which either of the two serves as orientation differs across countries depending on the prevailing concept of the state: in countries classified as cooperative or mixed market economies, CSR exhibits a greater relative importance for buycotting than labelling schemes; in liberal market economies, labelling schemes appear to be of greater weight. In sum, the results obtained in the country level study can best be described as a mutually reinforcing, circular process of political consumerism wherein boycotter act as promoter of labelling schemes. By deliberately rejecting to buy certain products or from certain firms, boycotts articulate discontent, put pressure to change prevailing practices and instigate the proliferation of labelling schemes. The resulting guidelines then serve as a basis for buycotts. This involvement in turn fosters a growing dispersion of CSR and/or labelling schemes, and their dispersion then, again, facilitates involvement in buycotting or both boy- and buycotting. Still, the patterns of political consumer involvement, labelling schemes and CSR differ from country to country. Which patterns develop depends on the prevailing concept of the state.

The results obtained in the micro-level analyses corroborate the findings for the most part. Individual political consumer involvement is related to whether the guidelines which a citizen is looking for are available in a country, and to whether the individual has confidence in these guidelines. Thus, CSR and labelling schemes facilitate political consumer involvement by serving as an orientation for the citizen, and this is independent of the citizen's age, education and gender. This matches the first two conclusions drawn for the country level. In addition, the effect of having confidence in labelling schemes is larger on buycotting than on boycotting. The finding puts forward that boycotter generally have confidence in the usefulness of labelling schemes, but they do not have sufficient confidence in the existing labels or in those available to them. They lack the basis which permits them to translate their basically positive attitude towards buycotting into behavioural action. Therefore, they boycott to nurture the introduction of labelling schemes which they can have confidence in. Once the guidelines aimed for are available, they can (also) get involved in buycotting. From this perspective, the micro-level 
study, too, can best be described as a circular process of political consumerism in which boycotting and buycotting involvement, labelling schemes and CSR constitute mutually reinforcing phenomena.

Yet, contrary to the third conclusion drawn for the country level, at the individual level having a specific concept of the state is not related to purchasing based on either labelling schemes or CSR. Instead, it influences the decision to become or not become a political consumer. However, it matches the underlying understanding of the concept of the state as it is delineated in section 3.1.2. The concept of the state in its guise as a nation-specific conception builds the fundament on which general response-patterns in the country for coping with socioeconomic and political matters develop; in its guise as a person-specific conception it builds the basis on which an individual acts in socio-economic and political concerns. Correspondingly, for the individual having a cooperative conception brings about a sense of duty to assume responsibility and be willing to engage in a collaborative problem-solving process. If perceiving products or firm behaviour to oppose certain values or political principles, the individual senses the need to adjust the own consumption practices respectively. In contrast, the individual with a liberal view relies on free market competition and its ability to yield optimal outcomes. This implies a reliance on that one will automatically choose 'right' if the market provides for it. As a consequence, the citizen having a cooperative view is generally more likely to engage in the deliberate politisation of purchasing decisions than the citizen with a liberal view. At the country level in turn, the concept of the state affects the firms' and other institutions' views on who and in what manner ought to solve socio-political challenges. Correspondingly, it influences which variant of guidelines spreads, resulting in an increasing availability of labelling schemes or in a greater magnitude to which firms engage in CSR.

To summarize, the central finding which this dissertation delivers is that boycotting and buycotting constitute two complementary modes in a process which develops on two levels in parallel and interacting. Getting involved in boycotting and buycotting constitutes a stepwise process in which individual behaviour is directly influenced by the framework provided for political consumerism in a country, and vice-versa. At the beginning of this process, boycotters act as the 'pioneers' who put pressure for change. Their activities resonate on the country level and instigate the proliferation of labelling schemes and/or CSR. The resulting guidelines then facilitate individual buycotting involvement. Eventually, the more citizens decide to buy based on political considerations, the more firms might sense the pressure to change practices. CSR and labelling schemes continue spreading and this serves as foundation for further political 
consumer action. Hence, like a snowball, over-all action promotes the steady spreading of labelling schemes or CSR in a country and this, again, fosters the continuous rise of boycotting and buycotting activity - in a country as well as of individuals.

\subsection{Putting the Findings into Perspective}

\subsubsection{Reflecting the Understanding of Political Consumerism in Political Science}

A remaining concern is where the findings position in relation to prevalent understandings and previous studies on political consumerism. The dissertation set out in Chapter 2 with delineating perspectives on political consumerism offered by different disciplines concerned with the phenomenon. Thereof, three core insights inspired the later analyses. This section reflects upon the extent to which the findings tie in with these inaugurating ideas. Also, it considers where results enhance existing insights, where they challenge prevailing understandings and it briefly discusses implications for the study of political consumerism.

The first insight originates from the field of political science. As outlined in section 2.1, ambiguous findings obtained in previous studies on political consumerism put forward that boycotting and buycotting are two distinct modes of political consumer involvement. They ground on different conceptions and underlying aims, whereby individuals can regard the two as tools suited for very different purposes. Baek (2010), Copeland (2014a), Koos (2012a) and Stolle and Micheletti (2005), among others, study the influence of various micro- and macrolevel factors on the likelihood to boycott compared to buycott. Their analyses reveal important differences, showing that the demographic and socioeconomic backgrounds of buycotters and boycotters are not necessarily the same. What is more, Neilson (2010) finds that while individuals with low levels of trust appear to rather be boycotter than to not consume politically at all, it is when having high levels of trust that citizens tend to be buycotter rather than non-political consumers. These findings suggested that both the dispositions as well as the underlying intentions of boycotter and buycotter head into entirely opposite directions. The section concluded that attaining a better understanding of political consumer involvement requires studying the two as separate modes. Based on this consideration, the ensuing study investigated whether and why individuals would be involved in one but not in the other.

The answers delivered in response to research questions $Q 2$ and $Q 5$ make evident that drawing a distinction between the two modes is in fact essential. The findings do not parallel Neilson's observation that dispositions head into opposite directions. Nonetheless, buycotters show to have much higher levels of confidence than boycotter (cf. Table 13, section 6.3.2.3). Similarly, the likelihood of an individual being a boycotter or a buycotter varies contingent 
upon the peculiar combination of particular factors and parameter values. At the individual level, the likelihood of an individual to boycott, to buycott or to boy- and buycott can be reverse depending on the degree of confidence and the concept of the state the individual has (illustrated e.g. in Figures 18, 19 and 20, sections 6.4.1 and 6.4.2). At the country level, buycotts show to be expedited and to furnish labelling schemes and CSR. For boycotts in turn, the regression coefficients obtained reveal a clearly larger impact of boycotting activities on the spread of labelling schemes than in the reverse. This presents boycotts, in contrast to buycotts, as rooted in an environment in which individuals do not yet have access to political shopping guidelines. Therefore, they can only have confidence in a theoretical notion of guidelines. Hence, tying in with the individual level observations, confidence may be lower among boycotters because they do not have access to existing guidelines that provide for a concrete and palpable basis on which they may ground confidence. This interpretation is partly suppositional, and the bond between labelling schemes and the decision to get involved in boycotting requires to be explored more in depth. Even so, in sum, the study confirms and clearly underscores previous studies which have highlighted that the distinction of boycotting and buycotting matters.

In addition, the dissertation expands the repertoire of political consumer involvement. Specifically, the individual level study puts emphasis on another distinction which has not yet been considered in research: the distinction between buycotting products and buycotting firms. As shown in section 6.4.2.1, the comparative effects of confidence in labelling schemes and confidence in firms' societal involvement on the single varieties of political consumerism differ in their applicability and strength. The former is persistently tied to the varieties which involve products, while confidence in CSR is steadily related to varieties centring on firms. Thus, depending on whether citizens address firms or products, drivers of their behaviour can diverge considerably. Likewise, the outcomes on the country level can be very different, as distinct actors are addressed by the buycotts. This reinforces the multi-layered character of political consumer involvement. Besides, with this original distinction the dissertation further refines the reigning understanding of political consumerism.

The findings entail a dual implication for approaching political consumerism in the realm of political science research. First, the relationship between boycotting, buycotting and labelling schemes shows that a same variable can lead to very different variants of behaviour depending on the peculiar configuration, value or underlying rationale. If the ambition is to better understand where modes are alike and where they diverge, and why individuals get involved in one or another variety of political consumerism, studies need to be considerate of these subtle differences. Second, the dissertation delivers expressive evidence for political consumerism 
being an even more fragmented collection of varieties than so far considered. Citizens appear to clearly make a distinction between whether they buycott products due to their nature or the firms behind the products. Therefore, when studying political consumerism in its own guise these varieties deserve further merit. Otherwise, analyses may conceal differences across the distinct modes or equivocally assign explanations to being valid for all politically consuming citizens in general when, in fact, they may only be valid for a singular mode of involvement.

\subsubsection{Counterbalancing Problematics Expounded by Social Psychology Research}

The second insight stems from behavioural psychology research. Past investigations striving to clear up differences and similarities of buycotter and boycotter focusing on the expression of values or socio-demographic characteristics provide inconclusive findings. Sociology and political science research suggest that political consumerism is in particular tightly connected to values, norms and attitudes (cf. Andorfer 2015). However, section 2.3 described the ambiguous interplay between attitudes and behaviour, and the influence of psychological facets in this process. Contextual factors intervene and may alter attitude judgements towards an issue or object, as well as behavioural choices. So, frequently, individuals state having positive attitudes towards politically considerate purchasing. But these favourable attitudes do not translate into corresponding behaviour. In short, there is an 'attitude-behaviour gap', as for instance Kollmuss and Agyeman (2002), Padel and Foster (2005) or Vermeir and Verbeke (2006) point out. Equally, different observations put forward that citizens recognize political consumerism not only as a way to express values but also as a strategy to abridge decision making or to feel better (e.g. Boström and Klintman 2009; Mazar and Zhong 2010). In response, Hines, Hungerford, and Tomera (1987) offer a model which brings together individuals' attitudes with their capabilities and knowledge, the latter being rendered through information. Merging the various thoughts, the chapter concluded that in basing explorations of political consumer involvement on values and attitudes only, research would risk leaving out an important fraction of explanatory variables. Individuals may be using political shopping guidelines for example as heuristics, that is, as simplified rules which facilitate and expedite decision-making in an ambivalent (consumer) context (cf. Bohner and Wänke 2002; Schoen 2006; Valor 2007). To circumvent such underlying influences, the dissertation put forward looking at the level of relative confidence which individuals have in information providing phenomena (section 6.3.2.3).

Research question $Q 4$ considered the relation of confidence with the tendency to purchase based on either one or another type of guideline. The evidence delivered in response to the question was expressive. Together with the country level observations, the findings endorse the 
bearing of contextual features and their interplay with subtle mechanisms which can influence decision-making also subconsciously. The presence of labelled products and/or involved firms is tightly entwined with political consumer involvement. The spread of such purchasing options can expedite political purchasing, their absence hamper it. Nevertheless, the key factor capable to predict individual involvement in one or another variant of political consumerism is the individual's comparative appraisal of these vis-à-vis other purchasing options. So, individuals do not necessitate having high levels of trust in labelling schemes or CSR. But they require having at least more confidence in them than in non-labelled products or firms which are not involved. This excess of confidence suffices as 'anchor' for getting involved in either a product buycott or the buycotting of firms.

Hines, Hungerford, and Tomera (1987), Kollmuss and Agyeman (2002) as well as Valor (2007) have described how in politically infused purchasing situations individuals recur to different neutralisation strategies. Thereby, individuals intend to reduce ambivalences or dissonances between a felt obligation and what they actually want or can do. Tying in with this, the dissertation presents expressive evidence in support of the idea that having more confidence in an option which is labelled or sold by a certain firm than in other options can serve for selecting a purchase based on a criterion that is easily ascertainable and yet relatively reliable. Alike heuristics, it can serve as a cognitive shortcut easing and/or abridging decision-making. All in all, this underscores the suggested influence of unconscious processes on the evaluation of purchasing options.

This entails an important implication for the study of political consumerism in the realm of political science research. Attaining a conclusive comprehension of political consumer decision making requires bridging the 'attitude-behaviour gap'. Comparable insights from social psychology research are yet scarcely considered in existing political science research on political consumerism. The predictive power of having comparatively high or low levels of confidence in political shopping guidelines highlights the proficiency and appeal of the variable. Political consumerism deeply relies on moral, ethics and (other) politically infused attitudes which individuals hold and base their consumer decisions on. Looking at the relative degree of confidence in informative shopping guidelines can serve as counterpart to the fickleness of attitudes. The variable focuses on an abstract image of labelling schemes and CSR rather than on the individuals' reliance in a particular label or firm. Thus, it reflects attitudes towards guidelines generally and is able to seize the impact of surrounding influences and across varying contexts. In so doing, it offers an approach apt to 'adjust' to different contexts without losing its explanatory 
power and reliability. Moreover, it can 'absorb' the underlying processes which guide and impair decisions in the very moment of purchasing. In conclusion, contemplating the comparative degree of confidence in political shopping guidelines can allow for untangling the explanatory links at work when making a decision, also subconsciously. Correspondingly, it may deserve closer attention in the study of boycotting and buycotting involvement.

\subsubsection{From Varieties of Capitalism to Varieties of Political Consumerism}

The third and last key insight which inspired the dissertation emerges an interdisciplinary lens. The politically consuming citizen faces socio-political concerns moving at the interface of politics and the 'market'. The act of deciding to boycott or to buycott is influenced by processes that develop and are developed both 'within' as well as 'outside' the individual and in multiple spheres of life. Thus, individual preferences are likely to influence decision making. Yet, these preferences can be influenced by ones' social, political and economic surroundings. In the reverse, Bair and Palpacuer (2012) as well as Boström and Klintman (2006) demonstrate in their analyses how different national institutional constellations and political cultures influence the rise of peculiar macro-level environments for political consumerism. Hence, these social, political and economic surroundings are again influenced by individuals' behaviour. The dissertation elaborated these ideas one step further. In their theory on varieties of capitalism, Hall and Soskice (2001) delineate how macro- and the micro-levels are tightly entwined in there being "systemic differences in [behavioural] strategy across nations" which "parallel the overarching institutional structures [...]" (Hall and Soskice 2001, 15). This set the basis for the notion of the concept of the state, which ties in two aspects: prevailing styles applied in the mode of operation of a country's market economy and political culture; and the inhabitants' views on what balance between the state, the market and civil society is considered to be desirable. Emanating from this, the dissertation delineated a model in which political consumerism develops at the individual level in relation to the peculiar macro-level environments arising national institutional constellations and political cultures; and at the same time reciprocally, with the two levels influencing each other.

The integrated picture of the micro- and the macro-level findings underlines the explanatory power of the proposed model and the informative value contributed by the concept of the state. Boycotting and buycotting involvement and the spreading of informative guidelines in a country evolve in a stepwise and interrelated process; this process in turn develops differently across countries depending on the prevailing concept of the state. The conclusions therewith replicate the observations advanced by Bair and Palpacuer (2012) and Boström and Klintman (2006), 
who describe the impact of prevailing views and national institutional patterns on the development of singular patterns of political consumer involvement. At the same time, the present study extends upon these previous examinations. First, by delivering with the concept of the state a notion which connects the two levels; and second, by connecting the peculiar macro-level constellations with micro-level conduct in an interactive bond. Prevailing preferences as depicted by the concept of the state build the grounding on which macro-societal developments translate into individual behavioural choices and vice-versa. Furthermore, the conceptions vary systematically across countries, yet they should be relatively stable among individuals and within a single country. With this, the dissertation presents a model which can explain why political consumerism develops differently across countries, but with a common pattern of involvement among the individuals within singular countries.

In sum, the findings clearly evidence the explanatory power reposing in looking at prevailing views and the individual understanding of responsibility in the market place for appraising political consumer involvement. The conclusions drawn for the micro-level originate a survey conducted in one country only, i.e. Germany. This certainly confines the degree to which the findings can be generalised. Even so, within a same country, on the individual level different views may persist (cf. Graeff 2014), and the survey expressly relied on quota sampling to reflect a wide range of views and conceptions in spite of being limited to one country. The measure for the concept of the state used corroborates this thought. It allows for attaining an idea of tendencies and, as intended, an impression of comparative variances (cf. section 4.2.1 ref. to Prein, Kluge, and Kelle 1994; Rea and Parker 2014). Therewith, the survey provides a preliminary glimpse on the bearing of the concept of the state in individuals' political purchasing decisions. To appraise to what extend the findings apply also on individuals living in other cultural, economic and/or political circumstances than in Germany, equivalent analyses need to be conducted now in further countries. Covering countries both with similar and with different backgrounds will permit for comparing patterns across countries and discern whether the bond between the concept of the state and political consumer involvement may be assumed to apply generally. Overall, the results describe political consumerism as a process whose development at any of the two levels cannot be understood in isolation from the other. The concept of the state permits responding to this need. Besides, it allows for analysing attitudes regarding concerns at precisely this crossing point of politics and the market where political consumerism is taking place. Therewith, the concept of the state renders a framework for studying the varieties of political consumerism at the two levels in parallel, and at the same time each level on its own and in due consideration of its multi-layered nature. 
7.5 On the Future of Political Consumerism

"The publicity the issue has been getting has led to pressure from consumers and activists on importers and wholesalers to be more diligent in identifying their suppliers [...], but [t] he most potent advocates for change may be educated consumers."

(New York Times Editorial Board, 20.02.2016)

A concise summary of the conclusion of this dissertation is that the 'educated consumer' indeed plays a vital role in advancing the spreading of political consumerism and responsible market practices. Yet, the findings also highlight the need for an environment providing consumers with reference points and the necessary information on the political backgrounds of purchases. The model presented in this study implies several consequences, of which two for policy makers and one vital consequence for political science research shall be highlighted.

Policy makers, consumer associations and other political practitioners may be seeking to raise awareness on politically considerate purchasing and to promote responsible market practices. As the study shows, individuals are more or less likely to contemplate getting involved in political consumerism depending on their concept of the state. Equally, preferences for labelling schemes and CSR vary across countries with respect to the prevailing view. Thus, contingent on which preferences prevail in a country context, market-based approaches may be the first best tactic for furnishing political consumer involvement (i.e. whenever a liberal conception predominates). While in other country contexts, such changes may best be accomplished by relying on firms' voluntary assumption of societal responsibility (if a cooperative understanding prevails). Accordingly, as a first consequence for political implementations, whenever striving to facilitate political purchasing and induce responsible market practices, political practitioners should devise policies fitting to the views predominant among the actors who are sought to alter conduct. As a second consequence, the availability of political shopping guidelines which citizens have confidence in constitutes a crucial facet in the process of political consumerism described. Their absence can hinder, their presence promote politically considerate purchasing. Therefore, consumers may be "potent advocates for change" as the New York Times notes; nevertheless, a key task in advancing conscientious market practices is incumbent on political practitioners. They can and they need to provide for an environment in which citizens have access to reference points informing about the political backgrounds of a purchase. Weaving the logics of these two consequences means that, in countries where a cooperative view prevails, political measures may best be focused on nurturing an environment conducive to involvement in CSR. To accomplish advances on the firm side, sponsored programmes, well targeted grants or subsidies and bringing firm's conduct to the public agenda can generate a context which 
promotes, encourages and at the same time imparts the expectation for firms to assume societal responsibility. Analogous, on the citizen-consumer side, raising awareness and disseminating information about firm conduct constitute the cornerstones to facilitate political consumerism. Concerted initiatives and action groups offer suitable stages for stirring and steering public discussion. They can bring together the various actors who are sought to alter behaviour and, in line with the cooperative conception, foster their collaboration in solving socio-political challenges. Where market reliance predominates, political practitioners may instead focus on promoting and/or creating labelling schemes. On the citizen-consumer side, such schemes can serve as distinctive product features and enable individuals to integrate political rationales in their purchasing decisions. This can in turn lead the way to the context prompting and pressuring firms to adjust market practices to what is demanded by the citizen-consumers - and strived for by the political actors.

From the perspective of political science research, one crucial question lingers on the relationship between boycotting and buycotting involvement with political shopping guidelines. In the process of political consumerism described, confidence acts as a bonding mechanism between attitudes and the inclination to boycott and/or to buycott. The idea put forward is that boycotter put pressure for labelling schemes, and once these are available they become boyand buycotter. Nonetheless, evaluating a cross-sectional survey conducted at one point in time (as it was the case with this study) does not allow for drawing conclusions about the causal mechanism underlying this step. To appraise the causality in this process, future investigations may consider applying experimental approaches. Experimental techniques allow for deliberately extricating the effect of singular factors and control for other variables and thereby approach the causal mechanisms underlying human behaviour in complex settings. What is more, as for instance Mazar and Zhong (2010) illustrate, experiments allow for gauging external as well as internal psychological reward mechanisms. Hence, studies can gain insights on motivations and drivers of human behaviour unknown even to their beholder. And as shown in the course of this dissertation, such underlying influences can be pivotal elements leading to an incongruent translation of politically considerate attitudes and acting intentions into actual behaviour. Furthermore, research in social psychology has shown individuals maintaining a consistent self-image easier when acting immorally takes place in the form of passive omission rather than of active commission (cf. Mazar and Hawkins 2015; see also Mazar and Ariely 2006). Such insights put into question to what extent boycotter are in fact driven by political rationales. Alternatively, some boycotter may merely be driven by the desire to skirt ambivalent situations and evade the risk of experiencing negative (emotional, cognitive and/or physical) 
consequences. That is, they decide to not purchase at all rather than risk a purchase which possibly turns out to be supporting production processes or firm operations which, from a political vantage point, they in fact despise. In comparing various testing groups and thereby control for all but one influencing variable, such possible explanations can be extricated and the actual processes at work in deciding disentangled. A possible approach may combine different ideas. For instance, in a laboratory setting, de Vries, Aarts, and Midden (2011) first trigger acting and non-acting habits for switching off light. Thereupon, they examine whether the habit of acting facilitates executing an intention to act but hinders the intention to abstain from acting. Another set of studies demonstrates how writing about emotionally salient stories can rouse attitudes like pro-social behaviour (Gailliot et al. 2008) or the need for distinctiveness versus similarity (Slotter, Duffy, and Gardner 2014), and writing pre-given statements or deliberately reflecting about reasons for an attitude can stir new or attenuate previously held attitudes, respectively (Alquist, Ainsworth, and Baumeister 2013; Fernbach et al. 2013). Combined, such approaches embody an elegant approach to extricate the causal mechanism underlying the suggested process from boycotting to boy- and buycotting. Having established a habit of boycotting and being endowed with a certain level of confidence e.g. through writing about a related story, if then provided with labelling schemes results may render an answer to whether boycotter become buycotter.

The concept of the state fundamentally influences how political consumerism develops. Looking beyond and ahead on the future of political consumerism, equally, the concept of the state may bear on a phenomenon which has been gaining popularity. In Germany, France and the U.K., among others, a focus moving to the fore among political consumers is to centre purchases on locally, regionally and/or nationally produced products (cf. Co-operative Group 2012; Otto Group 2013). The weight of this phenomenon may be comparatively small. Nonetheless, the underlying considerations of these purchases involve aspects like the desire to reduce the complexity which globalisation has furnished, anticapitalistic sentiments and nationalistic expressions (see also Stolle and Micheletti 2013, 267ff.). These are of genuinely political character. What is more, the expansion of this type of political consumerism mirrors a growing popular support for right-wing parties which advocate the reduction of global ties across countries. A prime example renders France, where on the one hand, the Food Assembly 'La Ruche Qui Dit Oui' ("the hive that says yes") has been rapidly spreading across the country since its foundation in 2010 (Food Assembly 2016a). The association strives to bring together local consumers with local producers, and a basic rule in the project is that buyer and seller must be living within a $150 \mathrm{~km}$ radius (Food Assembly 2016b). In parallel, the right-wing party Front 
National earned 27 percent of the votes in the regional elections 2015, up from 11 percent of the votes in 2010 (Ministère de l'Intérieur 2015). These developments may not be causally connected. But they may be two versions of coping with same trends citizens are unhappy or uncomfortable with.

Political, economic and societal concerns have become inextricably intertwined, and political consumerism echoes citizens' response to this changing political landscape. It reflects and captivates the complexity in which citizens are immersed today. The emphasis on buying nationally produced goods seems to reflect a general change in sentiments concerning key attributes embodying the richness of modern democracies: openness, tolerance and deliberative problem-solving. Political science is dedicated to uncovering and understanding the opportunities and risks involved in political participatory processes. Paying regard to such political consumer phenomena can give access to political attitudes in citizens' everyday life and thus make them relatively easily and early ascertainable. In view of that, observing micro-phenomena like the deliberate choice to purchase locally, regionally and/or nationally produced products may provide for an early detection of modifications in politically pertinent attitudes in society. It offers an efficient basis for understanding and evaluating current as well as future developments in citizens' attitudes towards politics and the polity. Therefore, if the ambition is to carry on in learning to understand political participation with all its light and dark facets, future research will have to continue quarrying deeper into the variegated, multi-layered nature of the varieties of political consumerism. 


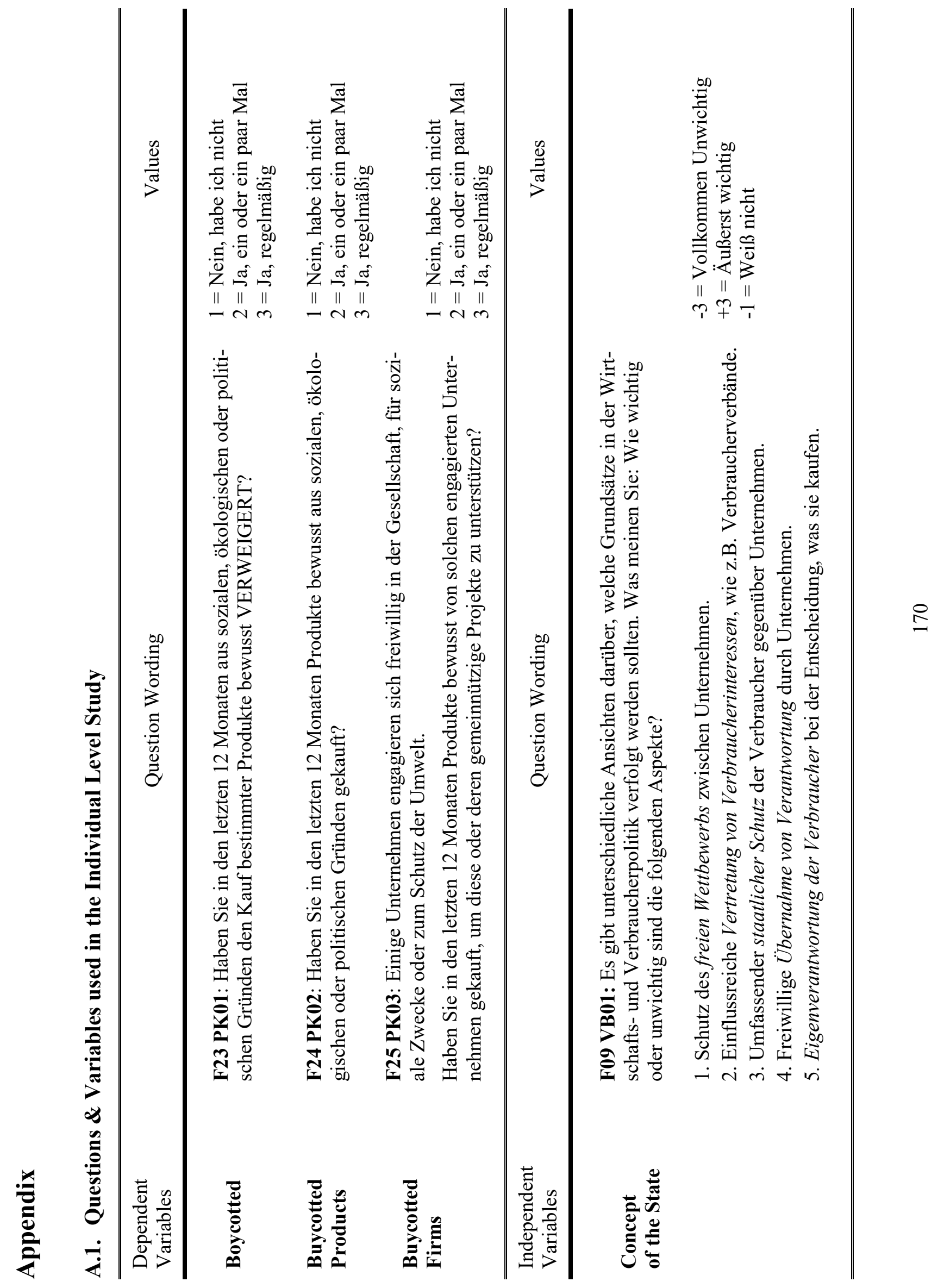



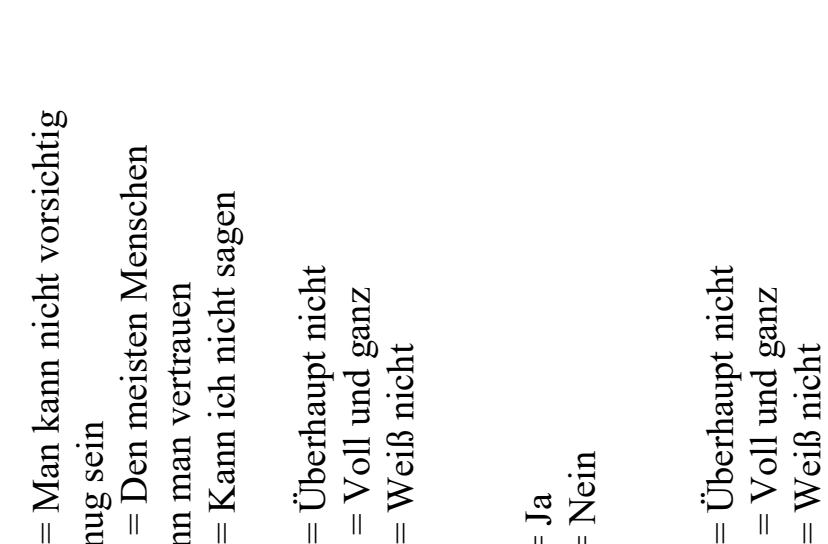

"

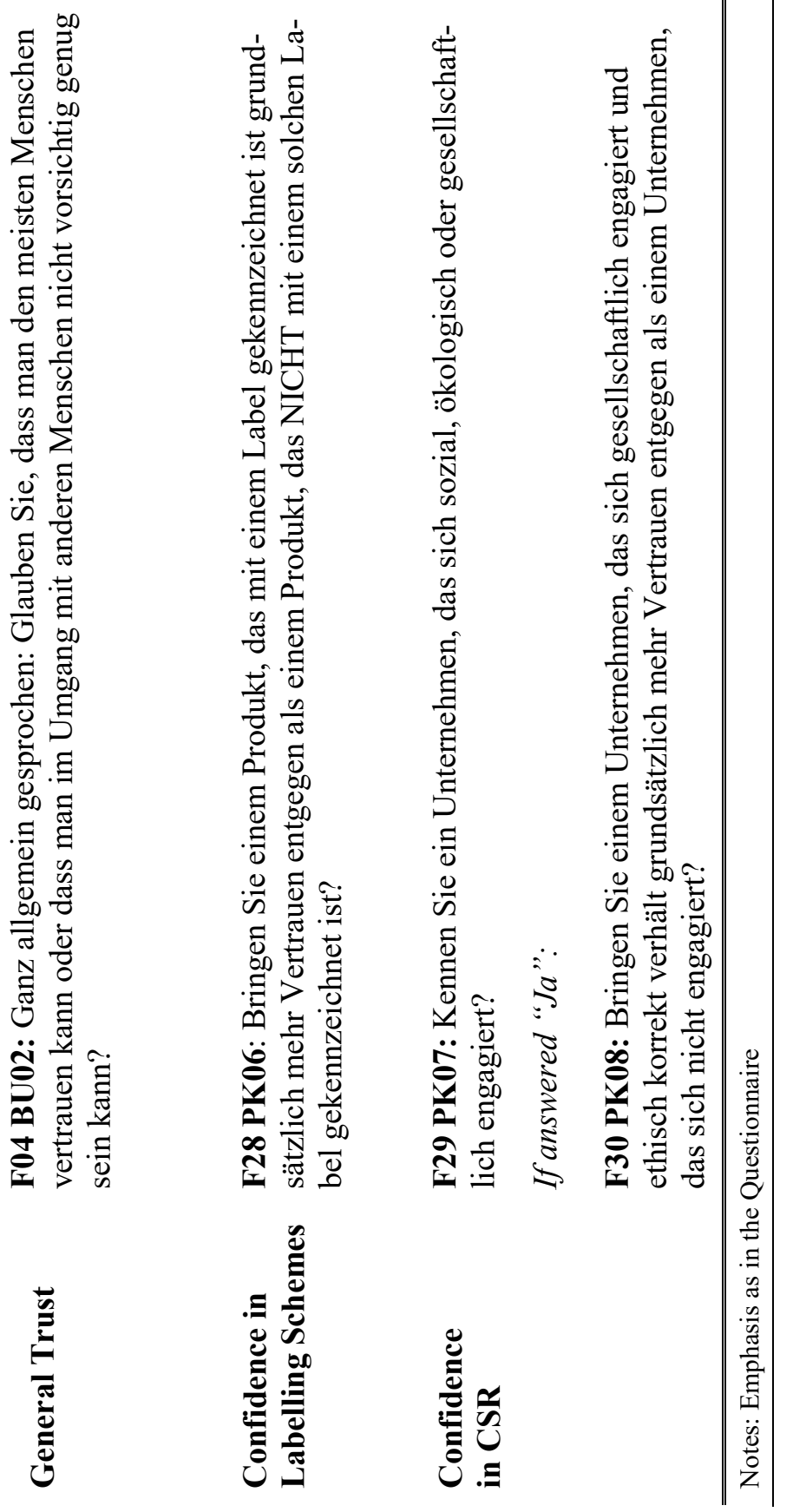




\section{A.2. Comparison of the Weighted and the Unweighted Samples with the Microcensus}

\begin{tabular}{|c|c|c|c|c|c|c|}
\hline \multirow[b]{2}{*}{ Age groups } & \multicolumn{3}{|c|}{ Sample } & \multirow{2}{*}{$\begin{array}{c}\begin{array}{c}\text { Micro- } \\
\text { census }\end{array} \\
\%\end{array}$} & \multicolumn{2}{|c|}{$\begin{array}{c}\text { Difference } \\
\text { Sample - Microcensus }\end{array}$} \\
\hline & $\begin{array}{l}\mathrm{N} \text { with } \\
\text { weights }\end{array}$ & $\begin{array}{l}\% \text { with } \\
\text { weights }\end{array}$ & $\begin{array}{c}\% \text { origi- } \\
\text { nally }\end{array}$ & & $\begin{array}{l}\text {...without } \\
\text { weights }\end{array}$ & $\begin{array}{l}\ldots \text { with } \\
\text { weights }\end{array}$ \\
\hline $14-17$ & 80 & 5.9 & 6.1 & 5.5 & 0.6 & 0.4 \\
\hline $18-24$ & 151 & 11.2 & 10.9 & 11.1 & -0.2 & 0.1 \\
\hline $25-29$ & 113 & 8.4 & 8.3 & 8.5 & -0.2 & -0.1 \\
\hline $30-34$ & 113 & 8.4 & 7.8 & 8.5 & -0.7 & -0.1 \\
\hline $35-39$ & 108 & 8.0 & 8.3 & 8.0 & 0.3 & -0.1 \\
\hline $40-44$ & 142 & 10.5 & 10.1 & 10.6 & -0.5 & -0.1 \\
\hline $45-49$ & 158 & 11.7 & 12.1 & 11.8 & 0.5 & -0.1 \\
\hline $50-54$ & 147 & 10.9 & 10.6 & 11.0 & -0.4 & -0.1 \\
\hline $55-59$ & 128 & 9.5 & 9.5 & 9.5 & -0.1 & 0.0 \\
\hline $60-64$ & 115 & 8.5 & 7.7 & 8.6 & -0.9 & 0.0 \\
\hline \multirow[t]{2}{*}{$65-69$} & 94 & 7.0 & 8.4 & 7.0 & 1.5 & 0.0 \\
\hline & \multicolumn{3}{|c|}{ Sample } & Microcensus & \multicolumn{2}{|c|}{ Sample - Microcensus } \\
\hline Gender & $\begin{array}{l}\mathrm{N} \text { with } \\
\text { weights }\end{array}$ & $\begin{array}{l}\% \text { with } \\
\text { weights }\end{array}$ & $\begin{array}{c}\% \text { origi- } \\
\text { nally }\end{array}$ & $\%$ & $\begin{array}{c}\text {...without } \\
\text { weights }\end{array}$ & $\begin{array}{l}\ldots \text { with } \\
\text { weights }\end{array}$ \\
\hline Women & 669 & 49.6 & 49.7 & 49.7 & 0.0 & -0.1 \\
\hline \multirow[t]{2}{*}{ Men } & 681 & 50.4 & 50.3 & 50.3 & 0.0 & 0.1 \\
\hline & \multicolumn{3}{|c|}{ Sample } & Microcensus & \multicolumn{2}{|c|}{ Sample - Microcensus } \\
\hline Education & $\begin{array}{l}\mathrm{N} \text { with } \\
\text { weights }\end{array}$ & $\begin{array}{l}\% \text { with } \\
\text { weights }\end{array}$ & $\begin{array}{c}\% \text { origi- } \\
\text { nally }\end{array}$ & $\%$ & $\begin{array}{c}\text {...without } \\
\text { weights }\end{array}$ & $\begin{array}{l}\text {...with } \\
\text { weights }\end{array}$ \\
\hline No/not yet a Degree & 93 & 6.9 & 6.0 & 9.5 & -3.5 & -2.6 \\
\hline $\begin{array}{l}\text { Certificate of Secondary } \\
\text { Education }\left(9^{\text {th }} \text { Grade }\right)\end{array}$ & 406 & 30.0 & 31.4 & 29.2 & 2.2 & 0.8 \\
\hline $\begin{array}{l}\text { Certificate of Secondary } \\
\text { Education }\left(10^{\text {th }} \text { Grade }\right)\end{array}$ & 428 & 31.7 & 31.6 & 30.7 & 0.9 & 1.0 \\
\hline $\begin{array}{l}\text { Higher Education } \\
\text { Entrance Qualification }\end{array}$ & 220 & 16.3 & 15.3 & 16.1 & -0.8 & 0.2 \\
\hline University Degree & 198 & 14.7 & 15.0 & 14.1 & 0.9 & 0.6 \\
\hline Other Degree & 6 & 0.4 & 0.7 & 0.4 & 0.3 & 0.0 \\
\hline
\end{tabular}


A.3. Distribution of the Concept of the State across Age Groups, Gender and Education Levels

\begin{tabular}{lcccc}
\hline \hline \multirow{2}{*}{$\begin{array}{l}\text { Age } \\
\text { groups }\end{array}$} & \multicolumn{2}{c}{ Cooperative } & \multicolumn{2}{c}{ Liberal } \\
\cline { 2 - 5 } & $\mathbf{N}$ & $\mathbf{\%}$ & $\mathbf{N}$ & $\mathbf{\%}$ \\
\hline $14-17$ & 29 & 40.3 & 43 & 59.7 \\
$18-24$ & 58 & 43.0 & 77 & 57.0 \\
$25-29$ & 45 & 44.1 & 57 & 55.9 \\
$30-34$ & 37 & 37.0 & 63 & 63.0 \\
$35-39$ & 50 & 49.0 & 52 & 51.0 \\
$40-44$ & 55 & 43.3 & 72 & 56.7 \\
$45-49$ & 76 & 47.8 & 83 & 52.2 \\
$50-54$ & 75 & 54.3 & 63 & 45.7 \\
$55-59$ & 69 & 58.0 & 50 & 42.0 \\
$60-64$ & 64 & 63.4 & 37 & 36.6 \\
$65-69$ & 78 & 70.3 & 33 & 29.7 \\
Total & 636 & 50.2 & 630 & 49.8 \\
\hline \hline
\end{tabular}

\begin{tabular}{|c|c|c|c|c|}
\hline \multirow[t]{2}{*}{ Gender } & \multicolumn{2}{|c|}{ Cooperative } & \multicolumn{2}{|c|}{ Liberal } \\
\hline & $\mathbf{N}$ & $\%$ & $\mathbf{N}$ & $\%$ \\
\hline Female & 309 & 49.9 & 310 & 50.1 \\
\hline Male & 327 & 50.5 & 320 & 49.5 \\
\hline Total & 636 & 50.2 & 630 & 49.8 \\
\hline \multirow{2}{*}{ Highest degree } & \multicolumn{2}{|c|}{ Cooperative } & \multicolumn{2}{|c|}{ Liberal } \\
\hline & $\mathbf{N}$ & $\%$ & $\mathbf{N}$ & $\%$ \\
\hline No/not yet a Degree & 29 & 39.7 & 44 & 60.3 \\
\hline $\begin{array}{l}\text { Certificate of Secondary } \\
\left.\text { Education ( } 9^{\text {th }} \text { Grade }\right)\end{array}$ & 207 & 52.7 & 186 & 47.3 \\
\hline $\begin{array}{l}\text { Certificate of Secondary } \\
\text { Education }\left(10^{\text {th }} \text { Grade }\right)\end{array}$ & 195 & 48.5 & 207 & 51.5 \\
\hline $\begin{array}{l}\text { Higher Education } \\
\text { Entrance Qualification }\end{array}$ & 95 & 49.7 & 96 & 50.3 \\
\hline University Degree & 105 & 52.8 & 94 & 47.2 \\
\hline Other Degree & 5 & 62.5 & 3 & 37.5 \\
\hline Total & 636 & 50.2 & 630 & 49.8 \\
\hline
\end{tabular}


A.4. Distribution of Confidence in Labelling Schemes, Confidence in CSR and General Trust across Age Groups, Gender and Education Levels

\begin{tabular}{|c|c|c|c|c|c|c|}
\hline \multirow[b]{2}{*}{ Age groups } & \multicolumn{2}{|c|}{$\begin{array}{l}\text { Confidence in La- } \\
\text { belling Schemes }\end{array}$} & \multicolumn{2}{|c|}{$\begin{array}{l}\text { Confidence } \\
\text { in CSR }\end{array}$} & \multicolumn{2}{|c|}{ General Trust } \\
\hline & Mean (SD) & $\mathrm{N}$ & Mean (SD) & $\mathrm{N}$ & Mean (SD) & $\mathrm{N}$ \\
\hline $14-17$ & $5.00(1.56)$ & 82 & $5.29(1.19)$ & 77 & $3.71(1.44)$ & 82 \\
\hline $18-24$ & $4.60(1.49)$ & 144 & $5.05(1.43)$ & 136 & $3.88(1.35)$ & 146 \\
\hline $25-29$ & $4.48(1.66)$ & 110 & $4.88(1.52)$ & 106 & $3.87(1.63)$ & 111 \\
\hline $30-34$ & $4.21(1.73)$ & 103 & $4.68(1.38)$ & 98 & $3.89(1.52)$ & 102 \\
\hline $35-39$ & $4.25(1.75)$ & 110 & $5.01(1.55)$ & 106 & $3.68(1.60)$ & 110 \\
\hline $40-44$ & $4.30(1.65)$ & 134 & $4.70(1.48)$ & 125 & $3.75(1.66)$ & 136 \\
\hline $45-49$ & $3.98(1.73)$ & 164 & $4.65(1.44)$ & 154 & $3.76(1.57)$ & 166 \\
\hline $50-54$ & $4.12(1.83)$ & 141 & $4.80(1.55)$ & 135 & $3.63(1.75)$ & 143 \\
\hline $55-59$ & $3.94(1.78)$ & 125 & $4.35(1.76)$ & 118 & $3.75(1.76)$ & 127 \\
\hline $60-64$ & $4.24(1.82)$ & 103 & $4.92(1.55)$ & 102 & $3.71(1.81)$ & 103 \\
\hline $65-69$ & $3.81(1.80)$ & 113 & $4.56(1.72)$ & 105 & $4.00(1.93)$ & 114 \\
\hline Gender & Mean (SD) & $\mathrm{N}$ & Mean (SD) & $\mathrm{N}$ & Mean (SD) & $\mathrm{N}$ \\
\hline Women & $4.45(1.71)$ & 660 & $4.94(1.48)$ & 619 & $3.71(1.65)$ & 665 \\
\hline Men & $4.04(1.73)$ & 669 & $4.65(1.56)$ & 643 & $3.86(1.64)$ & 675 \\
\hline Education & Mean (SD) & $\mathrm{N}$ & Mean (SD) & $\mathrm{N}$ & Mean (SD) & $\mathrm{N}$ \\
\hline No/not yet a Degree & $4.81(1.68)$ & 81 & $5.23(1.16)$ & 77 & $3.81(1.41)$ & 80 \\
\hline $\begin{array}{l}\text { Certificate of Secondary } \\
\left.\text { Education ( } 9^{\text {th }} \text { Grade }\right)\end{array}$ & $3.88(1.70)$ & 414 & $4.39(1.60)$ & 384 & $3.52(1.77)$ & 421 \\
\hline $\begin{array}{l}\text { Certificate of Secondary } \\
\text { Education }\left(10^{\text {th }} \text { Grade }\right)\end{array}$ & $4.14(1.77)$ & 419 & $4.75(1.58)$ & 400 & $3.67(1.61)$ & 423 \\
\hline $\begin{array}{l}\text { Higher Education } \\
\text { Entrance Qualification }\end{array}$ & $4.63(1.58)$ & 204 & $5.06(1.34)$ & 194 & $4.03(1.47)$ & 203 \\
\hline University Degree & $4.58(1.70)$ & 201 & $5.25(1.39)$ & 197 & $4.34(1.55)$ & 203 \\
\hline Other Degree & $4.30(1.77)$ & 10 & $4.10(1.59)$ & 10 & $2.80(1.32)$ & 10 \\
\hline
\end{tabular}




\section{A.5. Composition of the Corporate Social Responsibility Index}

MacGillivray, Sabapathy, and Zadek (2003, 26)

\begin{tabular}{ll}
\hline \hline Component & Details \\
\hline Corporate Governance & $\begin{array}{l}\text { Transparency, disclosure, auditing and accounting } \\
\text { standards, independence of boards }\end{array}$ \\
Ethical Business Practices & $\begin{array}{l}\text { Corruption, bribe payers, anti-dumping measures } \\
\text { against a country, corporate ethics }\end{array}$ \\
Progressive Policy Formulation & $\begin{array}{l}\text { Ratification Kyoto Protocol, environmental standards, } \\
\text { adverse environmental gains, firms signed up at UN } \\
\text { Global Compact }\end{array}$ \\
Building Human Capital & $\begin{array}{l}\text { Employee protection legislation, employment laws in- } \\
\text { dex, staff training, fatal accidents/100.000 workers }\end{array}$ \\
Engagement with Civil Society & $\begin{array}{l}\text { Consumer groups and sophistication, public trust in } \\
\text { business, civic freedom, customer orientation of firms }\end{array}$ \\
Contributions to Public Finance & $\begin{array}{l}\text { Corporate tax levels, irregular payments in tax collec- } \\
\text { tion, public spending on education }\end{array}$ \\
Environmental Management & $\begin{array}{l}\text { Compliance with environmental regulations, environ- } \\
\text { mental management systems, emissions of carbon diox- } \\
\text { ide per unit of GDP, Dow Jones Sustainability Index } \\
\text { ratings }\end{array}$ \\
\hline \hline
\end{tabular}




\section{A.6. Control Variables used in the Macro-Analysis}

\begin{tabular}{|c|c|c|c|}
\hline Country & $\begin{array}{l}\text { Household Disposable } \\
\text { Income }(2003)^{1}\end{array}$ & $\begin{array}{c}\text { Household Net } \\
\text { Saving Rates }(2003)^{2}\end{array}$ & $\begin{array}{l}\text { Retail Stores per } 1 \mathrm{mil} \text {. } \\
\text { Inhabitants }(2011)^{3}\end{array}$ \\
\hline Austria & 25.161 & 9.10 & 445 \\
\hline Belgium & 23.783 & 12.20 & 249 \\
\hline Czech Republic & 14.335 & 2.40 & 152 \\
\hline Denmark & 20.226 & 2.40 & 371 \\
\hline Finland & 19.451 & 1.40 & 225 \\
\hline France & 23.770 & 12.50 & 201 \\
\hline Germany & 24.384 & 10.30 & 340 \\
\hline Greece & 21.636 & -6.20 & 171 \\
\hline Hungary & 12.201 & 4.30 & 129 \\
\hline Ireland & 20.606 & 2.40 & 216 \\
\hline Italy & 22.847 & 10.30 & 232 \\
\hline Netherlands & 24.362 & 7.60 & 224 \\
\hline Norway & 24.518 & 8.90 & 496 \\
\hline Poland & 10.418 & 7.70 & 140 \\
\hline Portugal & 16.148 & 3.70 & 178 \\
\hline Slovenia & 16.046 & 7.60 & 302 \\
\hline Spain & 20.175 & 6.00 & 217 \\
\hline Sweden & 21.708 & 7.20 & 247 \\
\hline Switzerland & 25.805 & 9.40 & 202 \\
\hline United Kingdom & 25.050 & 0.40 & 108 \\
\hline
\end{tabular}




\section{References}

Abrams, Dominic. 1999. "Social Identity, Social Cognition, and the Self: The Flexibility and Stability of Self-categorization." In Social Identity and Social Cognition, edited by Dominic Abrams, Michael A. Hogg, 197-229. Oxford: Blackwell Publishers.

Abramson, Paul R., and John H. Aldrich 1982. "The Decline of Political Participation in America", American Political Science Review 76 (3): 502-521.

Acik, Necla. 2013. "Reducing the Participation Gap in Civic Engagement: Political Consumerism in Europe." European Sociological Review 0 (0): 1-14.

Agresti, Alan, and Barbara Finlay. 1997. Statistical Methods for the Social Sciences. 3rd ed. Upper Saddle River: Prentice Hall.

Aguilera, Ruth V., Deborah E. Rupp, Cynthia A. Williams, and Jyoti Ganapathi. 2007. "Putting the S Back in Corporate Social Responsibility: A Multilevel Theory of Social Change in Organizations." Academy of Management Review 32 (3): 836-863.

Ahn, T.K., and Elinor Ostrom. 2008. "Social Capital and Collective Action." In The Handbook of Social Capital, edited by Dario Castiglione, Jan W. van Deth, and Guglielmo Wolleb, 70-100. Oxford: Oxford University Press.

Ajzen, Icek. 1991. "The Theory of Planned Behavior." Organizational Behavior and Human Decision Processes 50: 179-211.

Ajzen, Icek. 2008. “Consumer Attitudes and Behavior.” In Handbook of Consumer Psychology, edited by Curtis P. Haugtvedt, Paul M. Herr, and Frank. R. Kardes, 525-548. New York: Taylor \& Francis.

Akkermanns, Dirk, Carolina Castaldi, and Bart Los. 2009. "Do 'Liberal Market Economies' really innovate more radically than 'Coordinated Market Economies'? Hall and Soskice reconsidered.” Research Policy 38: 181-191.

Allison, Gareth. 2009. "Pursuing Status through Ethical Consumption?" In Proceedings of the Australian and New Zealand Marketing Academy (ANZMAC) Sustainable Management and Marketing Conference, edited by Dewi Tojib, Monash University, Melbourne, 30 November-2 December.

Almond, Gabriel A. 1990. A Discipline Divided: Schools and Sects in Political Science. Newbury Park, CA: Sage Publications.

Almond, Gabriel A., and Sidney Verba. 1963. The Civic Culture. Political Attitudes and Democracy in Five Nations. London: Sage Publications.

Almond, Gabriel A., and Sidney Verba (eds.). 1980. The Civic Culture Revisited. London: Sage Publications.

Almond, Gabriel A., and Sidney Verba. 1996. "Five Political Cultures." In Comparing Nations and Cultures: Readings in a Cross-Disciplinary Perspective, edited by Alex Inkeles, and Masamichi S. Sasaki, 425-429. Englewood Cliffs: Prentice-Hall.

Alquist, Jessica L., Sarah E. Ainsworth, and Roy F. Baumeister. 2013. "Determined to conform: Disbelief in Free Will increases Conformity." Journal of Experimental Social Psychology, 49 (1): 80-86.

Andorfer, Veronika A. 2015. "Ethical Consumers." In International Encyclopedia of the Social \& Behavioral Sciences, edited by James D. Wright, 2nd ed., 25-30. Oxford: Elsevier. 
Ariely, Dan, Anat Bracha, and Stephan Meier. 2009. "Doing Good or Doing Well? Image Motivation and Monetary Incentives in Behaving Prosocially." American Economic Review 99 (1): 544-555.

Ariely, Dan, and Michael I. Norton. 2008. "How Actions create - not just reveal - Preferences." Trends in Cognitive Sciences 12 (1): 13-16.

Ariely, Dan, and Michael I. Norton. 2009. "Conceptual Consumption.” Annual Review of Psychology 60: 475-499.

Arrow, Kenneth J. 1985. "Informational Structure of the Firm." American Economic Review 75 (2): 303-307.

Atkinson, Lucy, and Sonny Rosenthal. 2014. "Signalling the Green Sell: The Influence of Eco-Label Source, Argument Specificity, and Product Involvement on Consumer Trust." Journal of Advertising 43 (1): 33-45.

Atteslander, Peter. 2003. Methoden der empirischen Sozialforschung. 10th ed. Berlin: Walter de Gruyter.

Baek, Young Min. 2010. "To Buy or Not to Buy: Who are Political Consumers? What do they Think and How Do they Participate?" Political Studies 58: 1065-1086.

Bair, Jennifer, and Florence Palpacuer. 2012. "From Varieties of Capitalism to Varieties of Activism: The Antisweatshop Movement in Comparative Perspective." Social Problems 59 (4): 522-543.

Banerjee, S. B. 2007. Corporate Social Responsibility. The Good, the Bad and the Ugly. Cheltenham, UK: Edward Elgar.

Barnett, Clive, Philip Cafaro, and Terry Newholm. 2005. "Philosophy and Ethical Consumption." In The Ethical Consumer, edited by Rob Harrison, Terry Newholm, and Deirdre Shaw, 11-24. London: Sage Publications.

Battaglia, Michael P. 2008. "Nonprobability Sampling." In Encyclopedia of Survey Research Methods, edited by Paul J. Lavrakas, 523-26. Thousand Oaks: Sage Publications.

Bauman, Zygmunt. 2008. "Exit Homo Politicus, Enter Homo Consumens." In Citizenship and Consumption, edited by Kate Soper, and Frank Trentmann, 139-153. Basingstoke: Palgrave Macmillan.

Bazerman, Max H., and Deepak Malhotra. 2006. "Economics Wins, Psychology Loses, and Society Pays.” In Social Psychology and Economics, edited by David De Cremer, Marcel Zeelenberg, and Mahwah J. Keith Murnighan, 263-280. New Jersey: Lawrence Erlbaum Associates, Inc.

Becker-Olsen, Karen L., B. Andrew Cudmore, and Ronald Paul Hill. 2006. "The Impact of Perceived Corporate Social Responsibility on Consumer Behaviour." Journal of Business Research 59: 46-53.

Belk, Russell W. 1988. "Possessions and the Extended Self." Journal of Consumer Research 15: 139-168.

Bellows, Anne C., Benjamin Onyango, Adam Diamond, and William K. Hallman. 2008. "Understanding Consumer Interests in Organics: Production Values vs. Purchasing Behavior.” Journal of Agricultural \& Food Industrial Organization 6 (1): Article 2. 
Bennett, W. Lance. 2003. "Branded Political Communication: Lifestyle Politics, Logo Campaigns, and the Rise of Global Citizenship." In Politics, Products, and Markets: Exploring Political Consumerism Past and Present, edited by Michele Micheletti, Andreas Føllesdal, and Dietlind Stolle, 101-126. New Brunswick, NJ: Transaction Publishers.

Bennett, W. Lance. 2012. "The Personalization of Politics: Political Identity, Social Media, and Changing Patterns of Participation." The ANNALS of the American Academy of Political and Social Science 644 (1): 20-39.

Berger, Ida, Peggy H. Cunningham, and Minette E. Drumwright. 2004. “Social Alliances: Company/Nonprofit Collaboration.” California Management Review, 47 (1): 58-90.

Berry, Hannah, and Morven McEachern. 2005. "Informing Ethical Consumers." In The Ethical Consumer, edited by Rob Harrison, Terry Newholm, and Deirdre Shaw, 69-87. London: Sage Publications.

Bettman, James R., Mary Frances Luce, John W. Payne. 2008. "Consumer Decision Making: A Choice Goals Approach." In Handbook of Consumer Psychology, edited by Curtis P. Haugtvedt, Paul M. Herr, and Frank. R. Kardes, 589-610. New York: Taylor \& Francis.

Bhattacharya, C.B., and Sankar Sen. 2004. "Doing Better at Doing Good: When, Why, and How Consumers Respond to Corporate Social Initiatives." California Management Review 47 (1): 9-24.

Blais, André. 2010. "Political Participation." In Comparing Democracies: Elections and Voting in the $21^{\text {st }}$ Century, edited by Lawrence LeDuc, Richard G. Niemi, and Pippa Norris, 165-183. London: Sage Publications.

Bohner, Gerd, and Michaela Wänke. 2002. Attitudes and Attitude Change. Hove: Psychology Press.

Bossy, Sophie. 2014. "The Utopias of Political Consumerism: The Search of Alternatives to Mass Consumption." Journal of Consumer Culture 0 (0): 1-20.

Boström, Magnus, Andreas Føllesdal, Mikael Klintman, Michele Micheletti, and Mads P. Sørensen. 2005. "Studying Political Consumerism." In Political Consumerism: Its motivations, power, and conditions in the Nordic countries and elsewhere, edited by Magnus Boström, Andreas Føllesdal, Mikael Klintman, Michele Micheletti, and Mads P. Sørensen, 9-24. TemaNord 2005:517, Copenhagen: Nordic Council of Ministers.

Boström, Magnus, and Mikael Klintman. 2006. "State-Centered versus Nonstate-Driven Organic Food Standardization: A Comparison of the US and Sweden." Agriculture and Human Values 23: 163-180.

Boström, Magnus, and Mikael Klintman. 2009. "The Green Political Food Consumer: A Critical Analysis of the Research and Policies." Anthropology of food S5.

Bourdieu, Pierre. 1987. Die feinen Unterschiede: Kritik der gesellschaftlichen Urteilskraft. Frankfurt/Main: Suhrkamp.

Brehm, John, and Wendy Rahn. 1997. "Individual Level Evidence for the Causes and Consequences of Social Capital.” American Journal of Political Science 41 (3): 999-1023.

Brosius, Felix. 1998. SPSS 8: Professionelle Statistik unter Windows. Bonn: MITP-Verlag.

Bryman, Alan. 2001. Social Research Methods. Oxford: Oxford University Press.

Bundeszentrale für Politische Bildung. 2014. Bildungsstand der Bevölkerung, http://www.bpb.de/nachschlagen/zahlen-und-fakten/soziale-situation-in-deutschland/61656/bildungsstand (accessed 09.02.2015) 
Chaudhuri, Arjun. 2006. Emotion and Reason in Consumer Behavior. Oxford: ButterworthHeinemann.

Clouder, Scott, and Rob Harrison. 2005. "The Effectiveness of Ethical Consumer Behaviour". In The Ethical Consumer, edited by Rob Harrison, Terry Newholm, and Deirdre Shaw, 89-104. London: Sage Publications.

Co-operative Group. 2012. Ethical Consumer Markets Report 2012, http://www.co-operative.coop/corporate/Investors/Publications/Ethical-Consumerism-Report/ (accessed 13.11.2015)

Coleman, James S. 1990. Foundations of Social Theory. Cambridge, MA: Belknap Press.

Cook, Thomas D., and Donald T. Campbell. 1979. Quasi-Experimentation: Design and Analysis for Field Settings. Chicago: Rand McNally.

Copeland, Lauren. 2014a. "Conceptualizing Political Consumerism: How Citizenship Norms Differentiate Boycotting from Buycotting." Political Studies 62: 172-186.

Copeland, Lauren. 2014b. "Value Change and Political Action: Postmaterialism, Political Consumerism, and Political Participation." American Politics Research 42 (2): 257-282.

Cox, Robert. 1997. "Economic Globalization and the Limits to Liberal Democracy." In The Transformation of Democracy? Globalization and Territorial Democracy, edited by Anthony McGrew, 49-72. Cambridge: Polity Press.

Crane, Andrew. 2005. "Meeting the Ethical Gaze: Challenges for Orienting to the Ethical Market". In The Ethical Consumer, edited by Rob Harrison, Terry Newholm, and Deirdre Shaw, 219-232. London: Sage Publications.

Crouch, Colin. 2004. Post-Democracy. Cambridge: Polity Press.

Dalton, Russell J. 2006. Citizenship Norms and Political Participation in America: The Good News Is ... the Bad News Is Wrong. CDACS Occasional Paper 2006-01, Center for Democracy and Civil Society Georgetown University, 1-14.

Dalton, Russell J. 2008. "Citizenship Norms and the Expansion of Political Participation." Political Studies 56: 76-98.

Dalton, Russell J. 2010. "Ideology, Partisanship, and Democratic Development." In Comparing Democracies: Elections and Voting in the $21^{\text {st }}$ Century, edited by Lawrence LeDuc, Richard G. Niemi, and Pippa Norris, 143-164. London: Sage Publications.

De Vaus, David A. 2002. Surveys in Social Research. 5th ed. New York: Taylor \& Francis.

De Vries, Peter, Henk Aarts, and Cees J. H. Midden. 2011. "Changing Simple Energy-Related Consumer Behaviors: How the Enactment of Intentions is thwarted by Acting and NonActing Habits." Environment and Behavior 43 (5): 612-633.

Degli Antoni, Giacomo, and Lorenzo Sacconi. 2011. "Does a Virtuous Circle Between Social Capital and CSR Exist? A "Network of Games" Model and Some Empirical Evidence." EconomEtica Working Papers 28. Centro interuniversitario per l'etica economica e la responsabilità sociale di impresa promosso dalla Fondazione Italiana Accenture.

Dichter, Ernest. 1964. Handbuch der Kaufmotive: Der Sellingappeal von Waren, Werkstoffen und Dienstleistungen. Wien, Düsseldorf: Econ-Verlag.

Dittmar, Helga. 2008. Consumer Culture, Identity and Well-being: The Search for the 'Good Life' and the 'Body Perfect'. Hove: Psychology Press. 
Dmitrović, Tanja, and Mateja Bodlaj. 2013. "Retailing in Slovenia: Current Landscape and Trends.” In European Retail Research, 27 (II), edited by Thomas Foscht, Dirk Morschett, Thomas Rudolph, Peter Schnedlitz, Hanna Schramm-Klein, and Bernhard Swoboda, 93123. Wiesbaden: Springer Gabler.

Eisenstadt, S. N. 1996. "Frameworks of the Great Revolutions: Culture, Social Structure, History, and Human Agency." In Comparing Nations and Cultures. Readings in a Cross-Disciplinary Perspective, edited by Alex Inkeles, and Masamichi Sasaki, 450-466. Englewood Cliffs: Prentice-Hall.

Ersson, Svante, and Jan-Erik Lane. 2008. "Political Culture." In Comparative Politics, edited by Daniele Caramani, 419-444. Oxford: Oxford University Press.

Esping-Andersen, Gøsta. 1990. The Three Worlds of Welfare Capitalism. Cambridge: Polity Press.

Esping-Andersen, Gøsta. 1999. Social Foundations of Postindustrial Economies. Oxford: Oxford University Press.

Esser, Hartmut. 2008. "The two Meanings of Social Capital". In The Handbook of Social Capital, edited by Dario Castiglione, Jan W. van Deth, and Guglielmo Wolleb, 22-49. Oxford: Oxford University Press.

European Commission. 2011. A renewed EU strategy 2011-14 for Corporate Social Responsibility. $C O M(2011) 681$ final. Communication from the Commission to the European Parliament, the Council, the European Economic and Social Committee and the Committee of the Regions, Brussels: European Commission.

European Social Survey. 2002a. ESS1 Source Main Questionnaire, Round 1 2002/3. Norwegian Social Science Data Services.

European Social Survey. 2002b. Data Round 1. Norwegian Social Science Data Services, http://ess.nsd.uib.no/ess/round1/

European Social Survey. 2012. Data Round 6. Norwegian Social Science Data Services, http://ess.nsd.uib.no/ess/round6/

European Social Survey. 2014. ESS Appendix A3 Variables and Questions edition 6.4. Norwegian Social Science Data Services.

Eurostat. 2014. Real GDP growth, 2004-14 (\% change compared with the previous year; average 2004-14), http://ec.europa.eu/eurostat/statistics-explained/index.php/File:Real_GDP_growth,_2003-13_\%28\%25_change_compared_with_the_previous_year; average_2003-13\%29_YB14-de.png (accessed 01.09.2015)

Eurostat. 2015a. Census Hub: Census 2011 (Residence - nations/Sex), https://ec.europa.eu/CensusHub2/query.do?step=selectHyperCube (accessed 02.09.2015)

Eurostat. 2015b. Population Change - Demographic balance and crude rates at national level, http://appsso.eurostat.ec.europa.eu/nui/show.do (accessed 01.09.2015)

Everitt, Brian S., Sabine Landau, Morven Leese, and Daniel Stahl. 2010. Cluster Analysis. 5th ed. Chichester: Wiley.

Everson, Michelle, and Christian Joerges. 2008. "Consumer Citizenship in Post-national Constellations?" In Citizenship and Consumption, edited by Kate Soper, and Frank Trentmann, 154-171. Basingstoke: Palgrave Macmillan.

Faber, Malte, Thomas Petersen, and Johannes Schiller. 2002. "Homo Oeconomicus and Homo Politicus in Ecological Economics.” Ecological Economics 40: 323-333. 
Fafchamps, Marcel. 2004. "Social Capital and Development." Economic Series Working Papers 214. University of Oxford, Department of Economics.

Fairtrade International. 2012. For Producers, with Producers, Annual report 2011-2012, http://www.fairtrade.net/fileadmin/user_upload/content/2009/resources/2011-12_AnnualReport_web_version_small_FairtradeInternational.pdf (accessed 03.06.2013)

Fairtrade International. 2013. Unlocking the Power, Annual report 2012-2013, http://www.fairtrade.net/fileadmin/user_upload/content/2009/resources/2012-13_AnnualReport_FairtradeIntl_web.pdf (accessed 13.07.2015)

Fairtrade International 2014. Strong Producers, Strong Future, Annual report 2013-2014, http://www.fairtrade.net/fileadmin/user_upload/content/2009/resources/2013-14_AnnualReport_FairtradeIntl_web.pdf (accessed 25.08.2015)

Fairtrade International 2015. Monitoring the Scope and Benefits of Fairtrade, Sixth Edition 2014. Bonn: Fairtrade International.

Fairtrade Labelling Organizations International. 2011. What is Fairtrade? http://www.fairtrade.net/what-is-fairtrade.html (accessed 13.07.2015)

Fehr, Ernst, and Urs Fischbacher. 2004. "Social norms and human cooperation." Trends in Cognitive Sciences 8 (4): 185-190.

Fernbach, Philip M., Todd Rogers, Craig R. Fox, and Steven A. Sloman. 2013. "Political Extremism is supported by an Illusion of Understanding." Psychological Science, 24 (6): 939-946.

Festinger, Leon. 1957. A Theory of Cognitive Dissonance. Evanston: Row, Peterson.

Fishbein, Martin, and Icek Ajzen. 1975. Belief, Attitude, Intention and Behaviour: An Introduction to Theory and Research. Reading: Addison-Wesley.

Flatters, Paul, and Michael Willmott. 2009. "Understanding the Post-Recession Consumer." Harvard Business Review, July-August.

Food Assembly. 2016a. Über Uns, https://laruchequiditoui.fr/de/p/history (accessed 22.02.2016)

Food Assembly. 2016b. Regional und Fair, https://laruchequiditoui.fr/de/p/short-distances (accessed 22.02.2016)

Fraj, Elena, and Eva Martinez. 2006a. "Environmental Values and Lifestyles as Determining Factors of Ecological Consumer Behaviour: An Empirical Analysis." Journal of Consumer Marketing 23 (3): 133-144.

Fraj, Elena, and Eva Martinez. 2006b. "Influence of Personality on Ecological Consumer Behaviour." Journal of Consumer Behaviour 5: 167-181.

Fraj, Elena, and Eva Martinez. 2007. "Ecological Consumer Behaviour: An Empirical Analysis." International Journal of Consumer Studies 31: 26-33.

Freedom House. 2015. Freedom in the World 2015. Washington: Freedom House.

Fredricks, Arlene J., and Dennis L. Dossett. 1983. "Attitude-Behavior Relations: A Comparison of the Fishbein-Ajzen and the Bentler-Speckart Models." Journal of Personality and Social Psychology 45 (3): 501-512.

Friedman, Monroe. 1996. "A Positive Approach to Organized Consumer Action: The "Buycott" as an Alternative to the Boycott." Journal of Consumer Psychology 19: 439-451. 
Friedman, Monroe. 2003. "Using Consumer Boycotts to Stimulate Corporate Policy Changes: Marketplace, Media, and Moral Considerations." In Politics, Products, and Markets, edited by Michele Micheletti, Andreas Føllesdal, and Dietlind Stolle, 45-62. New Brunswick: Transaction Publishers.

Friedrichsen, Jana, and Dirk Engelmann. 2013. "Who Cares for Social Image? Interactions between Intrinsic Motivation and Social Image Concerns." Paper presented at the CESifo Area Conference on Behavioural Economics, Munich, 25-26 October.

Fournier, Susan. 2009. "Lessons Learned about Consumers' Relationships with their Brands." In Advertising and Consumer Psychology: Handbook of Brand Relationships, edited by Deobarh J. MacInnis, C. Whan Park, and Joseph Priester, 5-23. New York: Society for Consumer Psychology.

Gailliot, Matthew T., Tyler F. Stillman, Brandon J. Schmeichel, Jon K. Maner, and E. Ashby Plant. 2008. "Mortality Salience increases Adherence to Salient Norms and Values." Personality \& Social Psychology Bulletin, 34 (7): 993-1003.

Gallup. 2013. "Worldwide Median Household Income.” December 16, http://www.gallup.com/poll/166211/worldwide-median-household-income-000.aspx (accessed 09.09.2015)

Giddens, Anthony. 1991. Modernity and Self-Identity: Self and Society in the Late Modern Age. Stanford: Stanford University Press.

Gil de Zúñiga, H., Lauren Copeland, and Bruce Bimber. 2013. "Political Consumerism: Civic Engagement and the Social Media Connection." New Media and Society 16 (3): 488-506.

Goul Andersen, Jørgen, and Mette Tobiasen. 2003. "Who are these Political Consumers anyway? Survey Evidence from Denmark." In Politics, Products, and Markets, edited by Michele Micheletti, Andreas Føllesdal, and Dietlind Stolle, 203-221. New Brunswick: Transaction Publishers.

Graeff, Peter. 2014. „Aggregatdaten.” In Handbuch Methoden der empirischen Sozialforschung, edited by Nina Baur, and Jörg Blasius, 915-924. Wiesbaden: Springer VS Verlag.

Häder, Michael, and Sabine Häder. 2014. "Stichprobenziehung in der quantitativen Sozialforschung." In Handbuch Methoden der empirischen Sozialforschung, edited by Nina Baur, and Jörg Blasius, 283-296. Wiesbaden: Springer VS Verlag.

Hadjar, Andreas, and Rolf Becker. 2009. "Bildungsexpansion und politisches Engagement Unkonventionelle politische Partizipation im Zeitverlauf”. In: Bürgergesellschaft als Projekt - Eine Bestandsaufnahme zu Entwicklung und Förderung zivilgesellschaftlicher Potenziale in Deutschland, edited by Ingo Bode, Adalbert Evers, and Ansgar Klein, 101124. Wiesbaden: VS Verlag.

Hall, Peter A. 2007. "The Evolution of Varieties of Capitalism in Europe.” In Debating Varieties of Capitalism: A Reader, edited by Bob Hancké. Oxford: Oxford University Press.

Hall, Peter, and Daniel W. Gingerich. 2004. "Varieties of Capitalism and Institutional Complementarities in the Macro-Economy: An Empirical Analysis.” Discussion Paper 04/5, Cologne, Max Planck Institute for the Study of Societies.

Hall, Peter A., and David Soskice. 2001. Varieties of Capitalism: The Institutional Foundations of Comparative Advantage. Oxford: Oxford University Press.

Hancké, Bob, Martin Rhodes, and Mark Thatcher. 2009. "Beyond Varieties of Capitalism." In Debating Varieties of Capitalism: A Reader, edited by Bob Hancké. Oxford: Oxford University Press. 
Harrison, Rob, Terry Newholm, and Deirdre Shaw (eds.). 2005. The Ethical Consumer. London: Sage Publications.

Haufler, Virginia. 2001. A Public Role for the Private Sector. Industry Self-Regulation in a Global Economy. Washington D.C.: Carnegie Endowment for International Peace.

Heidbrink, Ludger, and Alfred Hirsch (eds.). 2008. Verantwortung als marktwirtschaftliches Prinzip. Zum Verhältnis von Moral und Ökonomie. Frankfurt/New York: Camps Verlag.

Held, David. 1997. “Democracy and Globalization.” MPIfG Working Paper 97/5.

Hicks, Alexander, and Lane Kenworthy. 2003. "Varieties of Welfare Capitalism." Socio-Economic Review 1: 27-61.

Hines, Jody M., Harold R. Hungerford, and Audrey N. Tomera. 1987. "Analysis and Synthesis of Research on Responsible Environmental Behavior: A Meta-Analysis." The Journal of Environmental Education 18 (2): 1-8.

Hoffmann, Stefan. 2008. Boykottpartizipation: Entwicklung und Validierung eines Erklärungsmodells durch ein vollständig integriertes Forschungsdesign. Wiesbaden: Gabler

Hoffmann, Stefan. 2014. "Does National Culture impact Consumer Boycott Prevalence? A multi-country Study." European Journal of International Management 8 (2): 141-159.

Hofstede, Geert. 1996. "The Cultural Relativity of Organizational Practices and Theories." In Comparing Nations and Cultures. Readings in a Cross-Disciplinary Perspective, edited by Alex Inkeles, and Masamichi Sasaki, 387-401. Englewood Cliffs: Prentice-Hall.

Hogg, Michael A., and Dominic Abrams. 1999. "Social Identity and Social Cognition: Historical Background and Current Trends." In Social Identity and Social Cognition, edited by Dominic Abrams, and Michael A. Hogg, 1-25. Oxford: Blackwell Publishers.

Holtmann, Everhard, Oscar W. Gabriel, Jürgen Maier, Michaela Maier, Melanie Leidecker, and Tobias Jaeck. 2015. Deutschland 2014: Sind wir ein Volk? 25 Jahre Friedliche Revolution und Deutsche Einheit. Berlin: Bundesministerium für Wirtschaft und Energie.

Hooghe, Marc, Bengü Hosch-Dayican, and Jan W. van Deth. 2014. "Symposium. Conceptualizing Political Participation." Acta Politica 49 (3): 337-348.

Hooghe, Marc, and Sofie Marien. 2012. "How to Reach Members of Parliament? Citizens and Members of Parliament on the Effectiveness of Political Participation Repertoires." Parliamentary Affairs: 1-25.

Inglehart, Ronald. 1977. The Silent Revolution: Changing Values and Political Styles among Western Publics. Princeton: Princeton University Press.

Inglehart, Ronald. 1988. "The Renaissance of Political Culture." American Political Science Review 82 (4): 1203-1230.

Inglehart, Ronald. 1990. Culture Shift in Advanced Industrial Society. Princeton: Princeton University Press.

Inglehart, Ronald, and Paul R. Abramson. 1994. "Economic Security and Value Change." American Political Science Review 88 (2): 336-354.

Inglehart, Ronald, and Wayne E. Baker. 2000. "Modernization, Cultural Change and the Persistence of Traditional Values." American Sociological Review 65 (1): 19-51.

Inglehart, Ronald, and Gabriela Catterberg. 2002. "Trends in Political Action: The Developmental Trend and the Post-Honeymoon Decline." International Journal of Comparative Sociology 43 (3-5): 300-316. 
ISSP Research Group. 2012. International Social Survey Programme: Environment III - ISSP 2010. GESIS Data Archive, Cologne. ZA5500 Data file Version 2.0.0, doi:10.4232/1.11418

Jäckel, Michael. 2006. Einführung in die Konsumsoziologie. Fragestellungen - Kontroversen - Beispieltexte. 2nd ed. Wiesbaden: VS Verlag für Sozialwissenschaften.

Jensen, Hans Rask. 2005. "What Does Political Consumerism Mean for Marketers?" In Political Consumerism: Its motivations, power, and conditions in the Nordic countries and elsewhere, edited by Magnus Boström, Andreas Føllesdal, Mikael Klintman, Michele Micheletti, and Mads P. Sørensen, 439-454. TemaNord 2005:517, Copenhagen: Nordic Council of Ministers.

Johnston, Josée. 2008. "The Citizen-Consumer Hybrid: Ideological Tensions and the Case of Whole Foods Market.” Theory and Society 37: 229-270.

Jones, Christopher R. M., and Russell H. Fazio. 2008. "Associative Strength and Consumer Choice Behavior.” In Handbook of Consumer Psychology, edited by Curtis P. Haugtvedt, Paul M. Herr, and Frank. R. Kardes, 437-459. New York: Taylor \& Francis.

Jordan, Andrew, Rüdiger K.W. Wurzel, Anthony R. Zito, and Lars Brückner. 2003. "Consumer Responsibility-Taking and Eco-Labeling Schemes in Europe.” In Politics, Products, and Markets. Exploring Political Consumerism Past and Present, edited by Michele Micheletti, Andreas Føllesdal, and Dietlind Stolle, 161-180. New Brunswick, NJ: Transaction Publishers.

Jubas, Kaela. 2007. "Conceptual Confusion in Democratic Societies Understandings and Limitations of Consumer-Citizenship." Journal of Consumer Culture 7 (2): 231-254.

Kaase, Max. 1999. "Interpersonal Trust, Political Trust and Non-institutionalised Political Participation in Western Europe." West European Politics 22 (3): 1-21.

Kahneman, Daniel. 2003. "Maps of Bounded Rationality: Psychology for Behavioral Economics." American Economic Review 93(5): 1449-1475.

Kahneman, Daniel, and Amos Tversky. 1979. "Prospect Theory: An Analysis of Decision under Risk." Econometrica 47 (2): 263-292.

Kallgren, Carl A., Raymond R. Reno, and Robert B. Cialdini. 2002. "A Focus Theory of Normative Conduct: When Norms Do and Do Not Affect Behavior." Personality and Social Psychology Bulletin 26 (8): 1002-1012.

Kang, Nahee, and Jeremy Moon. 2012. "Institutional Complementarity between Corporate Governance and Corporate Social Responsibility: A Comparative Institutional Analysis of Three Capitalisms" Socio-Economic Review 10: 85-108.

Katona, George. 1967. "What is Consumer Psychology?” American Psychologist 22 (3): 219226.

Kellstedt, Paul M., and Guy D. Whitten. 2009. The Fundamentals of Political Science Research. Cambridge: Cambridge University Press.

Kim, Young Mae. 2012. "The Shifting Sands of Citizenship: Toward a Model of the Citizenry in Life Politics." The ANNALS of the American Academy of Political and Social Science 644 (1): 147-158.

Kim, Chung Hee, Kenneth Amaeshi, Simon Harris, and Chang-Jin Suh. 2012. "CSR and the National Institutional Context: The Case of South Korea." Journal of Business Research 66 (12): 2581-2591. 
Kogut, Bruce. 1991. "Country Capabilities and the Permeability of Borders." Strategic Management Journal, Summer Special Issue 12: 33-48.

Kollmuss, Anja, and Julian Agyeman. 2002. "Mind the Gap: Why Do People Act Environmentally and What Are the Barriers to Pro-Environmental Behavior?" Environmental Education Research 8 (3): 239-260.

Koos, Sebastian. 2012a. "What Drives Political Consumption in Europe? A Multi-Level Analysis on Individual Characteristics, Opportunity Structures and Globalization." Acta Sociologica 55 (1): 37-57.

Koos, Sebastian. 2012b. "The Institutional Embeddedness of Social Responsibility: A Multilevel Analysis of Smaller Firms' Civic Engagement in Western Europe.” Socio-Economic Review 10: 135-162.

Kroeber-Riel, Werner, and Andrea Gröppel-Klein. 2013. Konsumentenverhalten. München: Franz Vahlen Verlag.

Krystallis, Athanasios, and George Chryssohoidis. 2005. "Consumer's Willingness to Pay for Organic Food: Factors That Affect It and Variation Per Organic Product Type." British Food Journal 107 (5): 320-343.

Kurz-Milcke, Elke, and Gerd Gigerenzer. 2007. "Heuristic Decision Making." Marketing: Journal of Research and Management 3 (1): 48-60.

Lane, David Stuart, and Martin Myant. 2007. Varieties of Capitalism in Post-Communist Countries. Basingstoke: Palgrave Macmillan.

Leary, Mark R., and June Price Tangney. 2012. "The Self as an Organizing Construct in the Behavioral and Social Sciences." In Handbook of Self and Identity, edited by Mark R. Leary, and June Price Tangney, 2nd ed., 1-18. New York: Guilford Press.

LeDuc, Lawrence, Richard G. Niemi, and Pippa Norris (eds.). 2010. Comparing Democracies: Elections and Voting in the $21^{\text {st }}$ Century. London: Sage Publications.

Lin-Hi, Nick. 2001. Social Capital: A Theory of Social Structure and Action. Cambridge: Cambridge University Press.

Lin-Hi, Nick. 2008. “Corporate Social Responsibility: An Investment in Social Cooperation for Mutual Advantage." Discussion Paper 2008-6, Lutherstadt Wittenberg, Wittenberg Center for Global Ethics.

Lindén, Anna-Lisa. 2005. "Private Food Strategies and Political Consumerism." In Political Consumerism: Its motivations, power, and conditions in the Nordic countries and elsewhere, edited by Magnus Boström, Andreas Føllesdal, Mikael Klintman, Michele Micheletti, and Mads P. Sørensen, 203-224. TemaNord 2005:517, Copenhagen: Nordic Council of Ministers.

Llopis-Goig, Ramon. 2013. "Dimensions of Cosmopolitanism and their Influence on Political Consumption: An Analysis focused on Spanish Consumers." International Journal of Consumer Studies 37: 481-489.

Lüdemann, Christian. 1997. Rationalität und Umweltverhalten. Wiesbaden: Deutscher Universitäts-Verlag.

MacGillivray, Alex, John Sabapathy, and Simon Zadek. 2003. "Responsible Competitiveness Index 2003. Aligning Corporate Responsibility and the Competitiveness of Nations." AccountAbility and the Copenhagen Centre, http://www.accountability.org/images/content/ 1/0/105/RCI\%202003\%20-\%20Full\%20Report.pdf (accessed 03.06.2013) 
Matten, Dirk, and Andrew Crane. 2005. "Corporate Citizenship: Towards an Extended Theoretical Conceptualization." Academy of Management Review 30: 166-179.

Mazar, Nina, and Dan Ariely. 2006. "Dishonesty in Everyday Life and its Policy Implications." Working Paper Series, Federal Reserve Bank of Boston, 06-3.

Mazar, Nina, and Scott A. Hawkins. 2015. "Choice Architecture in Conflicts of Interest: Defaults as Physical and Psychological Barriers to (Dis)honesty." Journal of Experimental Social Psychology 59 (July), 113-117.

Mazar, Nina, and Chen-Bo Zhong. 2010. "Do Green Products Make Us Better People?" Psychological Science 21 (4): 494-498.

McGrew, Anthony. 1997. "Globalization and Territorial Democracy: An Introduction.” In The Transformation of Democracy? Globalization and Territorial Democracy, edited by Anthony McGrew, 1-24. Cambridge: Polity Press.

Micheletti, Michele. 2003. Political Virtue and Shopping: Individuals, Consumerism, and Collective Action. New York: Palgrave Macmillan.

Micheletti, Michele. 2008. „The Moral Force of Consumption and Capitalism: Anti-slavery and Anti-sweatshop." In Citizenship and Consumption, edited by Kate Soper, and Frank Trentmann, 121-136. Basingstoke: Palgrave Macmillan.

Micheletti, Michele, and Andreas Føllesdal. 2007. "Shopping for Human Rights. An Introduction to the Special Issue." Journal of Consumer Policy 30: 1649-175.

Micheletti, Michele, Andreas Føllesdal, and Dietlind Stolle (eds.). 2003. Politics, Products, and Markets. Exploring Political Consumerism Past and Present. New Brunswick, NJ: Transaction Publishers.

Micheletti, Michele, and Dietlind Stolle. 2004. "Swedish Political Consumers: Who they are and why they use the market as an arena for politics". In Political Consumerism: Its motivations, power, and conditions in the Nordic countries and elsewhere, edited by Magnus Boström, Andreas Føllesdal, Mikael Klintman, Michele Micheletti, and Mads P. Sørensen, 145-164. TemaNord 2005:517, Copenhagen: Nordic Council of Ministers.

Micheletti, Michele, and Dietlind Stolle. 2010. "Vegetarianism - A Lifestyle Politics?” In Creative Participation: Responsibility-Taking in the Political World, edited by Michele Micheletti, and Andrew S. McFarland, 125-145. Boulder: Paradigm.

Micheletti, Michele, and Dietlind Stolle. 2012. "Sustainable Citizenship and the New Politics of Consumption." The ANNALS of the American Academy of Political and Social Science 644 (88): 88-120.

Micheletti, Michele, Dietlind Stolle, and Daniel Berlin. 2012. "Habits of Sustainable Citizenship: The Example of Political Consumerism." In The Habits of Consumption, COLLeGIUM of Studies Across Disciplines in the Humanities and Social Sciences 12, edited by Alan Warde, and Dale Southerton, 142-164. Helsinki: Helsinki Collegium for Advanced Studies.

Milgrom, Paul, and John Roberts. 1988. "An Economic Approach to Influence Activities in Organizations.” American Journal of Sociology 94, Supplement: 154-179.

Milgrom, Paul, and John Roberts. 1992. Economics, Organizations, and Management. Englewood Cliffs: Prentice-Hall.

Ministère de 1'Intérieur. 2015. Résultats des Élections Régionales, http://www.interieur.gouv.fr/Elections/Les-resultats/Regionales (accessed 21.02.2016) 
Molina, Oscar, and Martin Rhodes. 2007. "The Political Economy of Adjustment in Mixed Market Economies: A Study of Spain and Italy" In Debating Varieties of Capitalism: A Reader, edited by Bob Hancké, 223-252. Oxford: Oxford University Press.

Morgan, Robert M., and Shelby D. Hunt. 1994. "Theory of Relationship Marketing." Journal of Marketing 58 (3): 20-38.

Muthuri, Judy N., Dirk Matten, and Jeremy Moon. 2009. "Employee Volunteering and Social Capital: Contributions to Corporate Social Responsibility.” British Journal of Management 20 (1): 75-89.

Neilson, Lisa A. 2010. “Boycott or Buycott? Understanding Political Consumerism.” Journal of Consumer Behaviour 9: 214-227.

Nelson, Kim. A. 2004. "Consumer Decision Making and Image Theory: Understanding Value-Laden Decisions.” Journal of Consumer Psychology 14 (1\&2): 28-40.

New York Times Editorial Board. 2016. "Slave Labor on the High Seas." New York Times Sunday Review, February 20, http://www.nytimes.com/2016/02/21/opinion/sunday/slavelabor-on-the-high-seas.html?emc=edit_ee_20160221\&nl=todaysheadlines-europe\&nlid $=55931791 \&$ referer $=\& \_r=0($ accessed 21.02 .2016$)$

Newman, Benjamin J., and Brandon L. Bartels. 2011. "Politics at the Checkout Line: Explaining Political Consumerism in the United States." Political Research Quarterly 64 (4): 803-817.

Newton, Ken. 2008. "Trust and Politics." In The Handbook of Social Capital, edited by Dario Castiglione, Jan W. van Deth, and Guglielmo Wolleb, 241-272. Oxford: Oxford University Press.

Newton, Ken, and Sonja Zmerli. 2011. "Three Forms of Trust and Their Association.” European Political Science Review 3 (2): 169-200.

Nielsen. 2013. Deutschland 2013. Handel, Verbraucher, Werbung. Frankfurt: Nielsen.

Nielsen. 2014. "Global Consumers are Willing to Put Their Money Where Their Heart is When it Comes to Goods and Services From Companies Committed to Social Responsibility." June 17, http://www.nielsen.com/ca/en/press-room/2014/global-consumers-arewilling-to-put-their-money-where-their-heart-is.html (accessed 01.11.2015)

Nielsen. 2015. Deutschland 2015. Handel, Verbraucher, Werbung. Frankfurt: Nielsen.

Noel, Hayden. 2010. Konsumverhalten. München: Stiebner Verlag.

Nölke, Andreas, and Arjan Vliegenthart. 2009. "Enlarging the Varieties of Capitalism: The Emergence of Dependent Market Economies in East Central Europe." World Politics 61 (04): 670-702.

Norris, Pippa. 2011. Democratic Deficit: Critical Citizens Revisited. New York: Cambridge University Press.

North, Douglass C. 1990. Institutions, Institutional Change and Economic Performance. Cambridge: Cambridge University Press.

OECD. 2012. Ersparnis der privaten Haushalte. Die OECD in Zahlen und Fakten 2011-2012: Wirtschaft, Umwelt, Gesellschaft. OECD Publishing.

OECD. 2015. "Gross household adjusted disposable income per capita, US dollars, current prices and current PPPs." National Accounts at a Glance, 5 (Household), https://stats.oecd.org/Index.aspx?DataSetCode=NAAG (accessed 02.09.2015) 
Offe, Claus. 1999. "How can we Trust our Fellow Citizens?" In Democracy and Trust, edited by Mark E. Warren, 42-87. Cambridge: Cambridge University Press.

Offe, Claus. 2000. "Civil Society and Social Order: Demarcating and Combining Market, State and Community." European Journal of Sociology 41: 71-94.

Offe, Claus. 2001. "Wie können wir unseren Mitbürgern vertrauen?” In Vertrauen. Die Grundlagesozialen Zusammenhalts, edited by Martin Hartmann, and Claus Offe, 241294. Frankfurt/New York: Camps Verlag.

Onyx, Jenny, and Paul Bullen. 2000. "Measuring Social Capital in Five Communities." Journal of Applied Behavioral Science 36 (1): 23-42.

Otto Group/Trendbüro. 2011. Trendstudie 2011: Verbrauchervertrauen. Hamburg: Otto Group.

Otto Group/Trendbüro. 2013. Trendstudie 2011: Lebensqualität. Hamburg: Otto Group.

Ozcaglar-Toulouse, Nil. 2007. 'Living for 'Ethics': Responsible Consumption in Everyday Life." Consumer Culture Theory 11: 421-436.

Padel, Susanne, and Carolyn Foster. 2005. "Exploring the Gap between Attitudes and Behaviour: Understanding why Consumers buy or do not buy Organic Food." British Food Journal 107 (8): 606-625.

Palazzo, Guido. 2009. Der aktuelle Stand der internationalen wissenschaftlichen Forschung zur Corporate Social Responsibility (CSR). Gutachten für das Bundesministerium für Arbeit und Soziales Abteilung VI - Referat GS3 Gesellschaftliche Verantwortung von Unternehmen/ Corporate Social Responsibility.

Papadopoulos, Yannis. 2013. Democracy in Crisis? Politics, Governance and Policy. Basingstoke: Palgrave Macmillan.

Petersen, Trond. 1993. "The Economics of Organization: The Principal-Agent Relationship." Acta Sociologica 36: 277-293.

Pickel, Susanne, and Gert Pickel. 2006. Politische Kultur- und Demokratieforschung. Grundbegriffe, Theorien, Methoden. Eine Einführung. Wiesbaden: VS Verlag.

Pierson, Christopher. 2006. Beyond the Welfare State? The New Political Economy of Welfare. 3rd ed. Cambridge: Polity Press.

Pivato, Sergio, Nicola Misani, and Antonio Tencati. 2008. "The Impact of Corporate Social Responsibility on Consumer Trust: the Case of Organic Food." Business Ethics: A European Review 17 (1): 3-12.

Poffenberger, Albert T. 1942. Principles of Applied Psychology. New York: Appleton-Century.

Prein, Gerald, Susann Kluge, and Udo Kelle. 1994. "Strategien zur Sicherung von Repräsentativität und Stichprobenvalidität bei kleinen Samples.” Working Paper 18, Bremen, Sfb186.

Putnam, Robert D. 1993. Making Democracy Work. Civic Traditions in Modern Italy. Princeton: Princeton University Press.

Putnam, Robert D. 2000. Bowling Alone: the Collapse and Revival of American Community. New York: Simon and Schuster.

Quintelier, Ellen. 2014. "The Influence of the Big 5 Personality Traits on Young People's Political Consumer Behaviour" Young Consumers 15 (4): 342-352. 
Quintelier, Ellen, and Jan W. van Deth. 2014. "Supporting Democracy: Political Participation and Political Attitudes. Exploring Causality Using Panel Data." Political Studies 62 (1934): 153-171.

Rasmussen, Tove Arendt. 2014. "Experience and Sustainable Consumption." Journal of Transdisciplinary Environmental Studies 13 (1): 2-15.

Rea, Louis M., and Richard A. Parker. 2014. Designing and Conducting Survey Research: A Comprehensive Guide. 4th ed. San Francisco: Jossey-Bass.

Reisinger, William M. 1995. "The Renaissance of a Rubric: Political Culture as Concept and Theory." International Journal of Public Opinion Research 7 (4): 328-352.

Ritzer, George. 2007. (ed.) The Blackwell Companion to Globalization. Oxford: Blackwell Publishers.

Roberts, John H., and Gary L. Lilien. 1993. "Explanatory and Predictive Models of Consumer Behaviour." In Handbooks in Operations Research and Management Science, Vol. 5, edited by Jehoshua Eliashberg, and Gary L. Lilien, 27-82. Amsterdam: Elsevier.

Rokeach, Milton. 1973. The Nature of Human Values. New York: Free Press

Rosenberg, Morris. 1956. "Misanthropy and Political Ideology." American Sociological Review 21: 690-695.

Rossteutscher, Sigrid. 2008. "Social Capital and Civic Engagement: A Comparative Perspective." In The Handbook of Social Capital, edited by Dario Castiglione, Jan W. van Deth, and Guglielmo Wolleb, 208-240. Oxford: Oxford University Press.

Rousseau, Sandra, and Liesbet Vranken. 2013. "Green Market Expansion by Reducing Information Asymmetries: Evidence for Labeled Organic Food Products." Food Policy 40: 3143.

Sabbati, Guilio, and Ivana Katsarova. 2015. "Organic Food.” European Parliamentary Research Service, 20.05.2015, http://epthinktank.eu/2015/05/20/organic-food/

Sagoff, Mark. 1988. The Economy of the Earth: Philosophy, Law, and the Environment. First Edition, Cambridge: Cambridge University Press.

Sassatelli, Roberta. 2006. "Virtue, Responsibility and Consumer Choice. Framing Critical." In Consuming Cultures, Global Perspectives, edited by John Brewer, and Frank Trentmann, 219-250. Basingstoke: Palgrave Macmillan.

Sassatelli, Roberta. 2008. "Representing Consumers: Contesting Claims and Agendas." In The Politics and Pleasures of Consuming Differently: Better Than Shopping, edited by Kate Soper, Martin Ryle, and Lyn Thomas, 25-42. Basingstoke: Palgrave Macmillan.

Saunders, Eileen. 2009. "Youth Engagement, Civic Education, and New Vehicles of Political Participation." In Activating the Citizen: Dilemmas of Participation in Europe and Canada, edited by Joan DeBardeleben, and Jon H. Pammett, 257-275. Hampshire: Palgrave.

Scharpf, Fritz W. 1997. “Globalisierung als Beschränkung der Handlungsmöglichkeiten nationalstaatlicher Politik.” MPIfG Discussion Paper 97/1.

Scherer, Andreas Georg, and Guido Palazzo. 2011. "The New Political Role of Business in a Globalized World: A Review of a New Perspective on CSR and its Implications for the Firm, Governance, and Democracy." Journal of Management Studies 48 (4): 899-931.

Scherer, Andreas Georg, Guido Palazzo, and Dirk Matten. 2009. "Introduction to the Special Issue: Globalization as a Challenge for Business Responsibilities." Business Ethics Quarterly 19 (3): 327-347. 
Scherer, Andreas Georg, and Marc Smid. 2000. "The downward spiral and the U.S. model principles. Why MNEs should take responsibility for the improvement of world-wide social and environmental conditions." Management International Review 40: 351-71.

Schimank, Uwe. 2005. Die Entscheidungsgesellschaft. Komplexität und Rationalität der Moderne. Wiesbaden: VS Verlag für Sozialwissenschaften.

Schlozman, Kay Lehman. 2012. "Creative Participation: Concluding Thoughts from the Land of the Boston Tea Party." In Creative Participation: Responsibility-Taking in the Political World, edited by Michele Micheletti, and Andrew S. McFarland, 171-185. Boulder: Paradigm.

Schoen, Harald. 2006. "Der demokratische Musterbürger als Normalfall? Kognitionspsychologische Einblicke in die black box politischer Meinungsbildung." Politische Vierteljahresschrift 47 (1): 89-101.

Schröder, Martin. 2013. Integrating Varieties of Capitalism and Welfare State Research: A Unified Typology of Capitalisms. Basingstoke, Hampshire: Palgrave Macmillan.

Schudson, Michael. 2007. "Citizens, Consumers, and the Good Society." The ANNALS of the American Academy of Political and Social Science 611: 236-249

Schumpeter, Joseph A. 1947. Capitalism, Socialism, and Democracy. 2nd ed. New York: Harper \& Brothers.

Seubert, Sandra. 2009. Das Konzept des Sozialkapitals. Frankfurt/New York: Camps Verlag.

Shapiro, Arthur. 2000. Everybody Belongs: Changing Negative Attitudes Towards Classmates with Disabilities. London: Routledge.

Shaw, Deirdre. 2005. "Modelling Consumer Decision Making in Fair Trade.” In The Ethical Consumer, edited by Rob Harrison, Terry Newholm, and Deirdre Shaw, 137-153. London: Sage Publications.

Shaw, Deirdre, and Iain Black. 2010. "Market Based Political Action: a Path to Sustainable Development?" Sustainable Development 18: 385-397.

Shaw, Deirdre, Emma Grehan, Edward Shiu, Louise Hassan, and Jennifer Thomson. 2005. "An Exploration of Values in Ethical Consumer Decision Making." Journal of Consumer Behaviour 4 (3): 185-200.

Shreck, Aimee. 2002. "Just Bananas? Fair Trade Banana Production in the Dominican Republic.” International Journal of Sociology of Agriculture and Food 10 (2): 13-23.

Simon, Herbert A. 1978. "Rational Decision-Making in Business Organizations." Nobel Memorial Lecture, 8 December.

Sirgy, M. Joseph. 1982. "Self-Concept in Consumer Behavior: A Critical Review." Journal of Consumer Research 9: 287-300.

Slotter, Erica B., Caitlin W. Duffy, and Wendi L. Gardner. 2014. "Balancing the Need to be "Me" with the Need to be "We": Applying Optimal Distinctiveness Theory to the Understanding of Multiple Motives within Romantic Relationships." Journal of Experimental Social Psychology, 52: 71-81.

Smith, N. Craig. 2008. "Consumers as Drivers of Corporate Social Responsibility." In The Oxford Handbook of Corporate Social Responsibility, edited by Andrew Crane, Abagail McWilliams, Dirk Matten, Jeremy Moon, and Donald S. Siegel, 281-302. Oxford: Oxford University Press.

Solomon, Robert C. 1992. Ethics and Excellence. Oxford: Oxford University Press. 
Sommer, Rudolf. 2007. Consumer's Mind. Die Psychologie des Verbrauchers. Frankfurt: Deutscher Fachverlag.

Soper, Kate. 2008. "'Alternative Hedonism` and the Citizen-Consumer." In Citizenship and Consumption, edited by Kate Soper, and Frank Trentmann, 191-205. Basingstoke: Palgrave Macmillan.

Soper, Kate, and Frank Trentmann. 2008. "Introduction". In Citizenship and Consumption, edited by Kate Soper, and Frank Trentmann, 1-16. Basingstoke: Palgrave Macmillan.

Sørensen, Mads P. 2005. "Liberal Democratic Society and Political Consumerism - a Problematic Combination". In Political Consumerism: Its motivations, power, and conditions in the Nordic countries and elsewhere, edited by Magnus Boström, Andreas Føllesdal, Mikael Klintman, Michele Micheletti, and Mads P. Sørensen, 59-76. TemaNord 2005:517, Copenhagen: Nordic Council of Ministers.

Spaargaren, Gert, and Susan Martens. 2005. "Globalisation and the Role of Citizen-Consumers in Environmental Politics". In Political Consumerism: Its motivations, power, and conditions in the Nordic countries and elsewhere, edited by Magnus Boström, Andreas Føllesdal, Mikael Klintman, Michele Micheletti, and Mads P. Sørensen, 25-58. TemaNord 2005:517, Copenhagen: Nordic Council of Ministers.

Statistisches Bundesamt. 2012. Bildungsstand der Bevölkerung. Wiesbaden: Statistisches Bundesamt

Statistisches Bundesamt. 2013. Bildungsstand der Bevölkerung. Wiesbaden: Statistisches Bundesamt

Stein, Petra. 2014. "Forschungsdesigns für die quantitative Sozialforschung". In Handbuch Methoden der empirischen Sozialforschung, edited by Nina Baur, and Jörg Blasius, 135151. Wiesbaden: Springer VS Verlag.

Stokke, Olaf Schram, Lars H. Gulbrandsen, Alf Håkon Hoel, and Jonette Braathen. 2005. "Ecolabelling and Sustainable Management of Forestry and Fisheries: Does it work?" In Political Consumerism: Its motivations, power, and conditions in the Nordic countries and elsewhere, edited by Magnus Boström, Andreas Føllesdal, Mikael Klintman, Michele Micheletti, and Mads P. Sørensen, 291-317. TemaNord 2005:517, Copenhagen: Nordic Council of Ministers.

Stolle, Dietlind, Marc Hooghe, and Michele Micheletti. 2003. "Political Consumerism - A New Phenomenon of Political Participation? An Exploratory Study in Canada, Belgium and Sweden." Paper presented at the ECPR Joint Sessions, Edinburgh, 28 March - 2 April.

Stolle, Dietlind, Marc Hooghe, and Michele Micheletti. 2005. "Politics in the Supermarket: Political Consumerism as a Form of Political Participation." International Political Science Review 26 (3): 245-269.

Stolle, Dietlind, and Michele Micheletti. 2003. "The Gender Gap Reversed: Political Consumerism as a Women-Friendly Form of Civic and Political Engagement: An Exploratory Study in Canada, Belgium and Sweden." Paper presented at the Gender and Social Capital Conference, St. John's College, University of Manitoba, 2-3 May.

Stolle, Dietlind, and Michele Micheletti. 2005. "Warum werden Käufer zu ,politischen Verbrauchern'?” Forschungsjournal Neue Soziale Bewegungen 18 (4): 41-52.

Stolle, Dietlind, and Michele Micheletti. 2013. Political Consumerism. Global Responsibility in Action. Cambridge: Cambridge University Press. 
Stolle, Dietlind, Michele Micheletti, and Daniel Berlin. 2010. "Young People and Political Consumerism.” Fokus 10. En analys av ungas inflytande. Stockholm: Swedish National Board for Youth Affairs.

Stratenschulte, Eckart D. 2014. "Warum Europa?” Bundeszentrale für politische Bildung, Dossier Die Europäische Union: 6-10.

Strømsnes, Kristin. 2005. "Political Consumption in Norway: Who, why - and does it have any effect?" In Political Consumerism: Its motivations, power, and conditions in the Nordic countries and elsewhere, edited by Magnus Boström, Andreas Føllesdal, Mikael Klintman, Michele Micheletti, and Mads P. Sørensen, 165-182. TemaNord 2005:517, Copenhagen: Nordic Council of Ministers.

Sturgis, Patrick, and Patten Smith. 2010. “Assessing the Validity of Generalized Trust Questions: What Kind of Trust are we Measuring?" International Journal of Public Opinion Research 22 (1): 74-92.

Swidler, Ann. 1986. "Culture in Action: Symbols and Strategies." American Sociological Review 51: 273-286.

Tajfel, Henri, and John C. Turner. 1979. "An Integrative Theory of Intergroup Conflict.” In The Social Psychology of Intergroup Relations, edited by Stephen Worchel, and William G. Austin, 33-48. Monterey: Brooks/Cole.

Tallontire, Anne, Erdenechimeg Rentsendorj, and Mick Blowfield. 2001. "Ethical Consumers and Ethical Trade." Policy Series 12, Natural Resources Institute. Chatham, UK.

Teorell, Jan. 2006. "Political Participation and Three Theories of Democracy: A Research Inventory and Agenda." European Journal of Political Research 45 (5): 787-810.

Teorell, Jan, Mariano Torcall, and José Ramón Montero. 2007. "Political Participation: Mapping the Terrain." In Citizenship and Involvement in European Democracies: A Comparative Analysis, edited by Jan W. van Deth, José Ramón Montero, and André Westholm, 334-357. London: Routledge.

Teyssier, Sabrina, Fabrice Etilé, and Pierre Combris. 2012. "Social- and Self-Image Concerns in Fair-Trade Consumption: Evidence from Experimental Auctions for Chocolate." Paris School of Economics Working Paper 2012-33.

Thompson, Grahame. 1997. "Multinational Corporations and Democratic Governance." In The Transformation of Democracy? Globalization and Territorial Democracy, edited by Anthony McGrew, 171-200. Cambridge: Polity Press.

Tobiasen, Mette. 2005. "Political Consumerism in Denmark." In Political Consumerism: Its motivations, power, and conditions in the Nordic countries and elsewhere, edited by Magnus Boström, Andreas Føllesdal, Mikael Klintman, Michele Micheletti, and Mads P. Sørensen, 113-144. TemaNord 2005:517, Copenhagen: Nordic Council of Ministers.

Trentmann, Frank. 2007. “Citizenship and Consumption.” Journal of Consumer Culture 7 (2): 147-158.

Trumbull, Gunnar. 2006. Consumer Capitalism. New York: Cornell University Press.

Turner, John C. 1985. "Social Categorization and the Self-Concept: A Social Cognitive Theory of Group Behavior.” In Advances in Group Processes, edited by E. J. Lawler, Vol. 2, 77-122. Greenwich: JAI Press.

Turner, John, and Penny Oakes. 1986. "The Significance of the Social Identity Concept for Social Psychology with Reference to Individualism, Interactionism and Social Influence." British Journal of Social Psychology 25 (3): 237-252. 
Turner, John C., Michael A. Hogg, Penelope J. Oakes, Stephen D. Reicher, and Margaret S. Wetherell. 1987. Rediscovering the Social Group: A Self-Categorization Theory. Oxford: Basil Blackwell.

Tversky, Amos, and Daniel Kahneman. 1981. "The Framing of Decisions and the Psychology of Choice." Science 211 (4481): 453-458.

United Nations Development Programme. 2014. Human Development Report 2014. New York: UNDP.

Uslaner, Eric M. 2002. The Moral Foundations of Trust. Cambridge: Cambridge University Press.

Uslaner, Eric M. 2008. “Trust and Consequences.” In Social Capital, Volume 2, edited by K.R. Gupta, Gunnar Lind Haase Svendsen, and Prasenjit Maiti, 58-87. New Delhi: Atlantic Publishers.

Vallerand, Robert J., Luc G. Pelletier, Paul Deshaies, Jean-Pierre Cuerrier, and Claude Mongeau. 1992. "Ajzen and Fishbein's Theory of Reasoned Action as Applied to Moral Behaviour: A Confirmatory Analysis." Journal of Personality and Social Psychology 62 (1): 98-109.

Valor, Carmen. 2007. "The Influence of Information about Labour Abuses on Consumer Choice of Clothes: A Grounded Theory Approach.” Journal of Marketing Management 23 (7-8): 675-695.

van Deth, Jan W. 1995. "Introduction: The Impact of Values." In The Impact of Values, edited by Jan W. van Deth, and Elinor Scarbrough, 1-18. Oxford: Oxford University Press.

van Deth, Jan W. 2001. "The Proof of the Pudding: Social Capital, Democracy, and Citizenship." Paper presented at the EURESCO Conference Social Capital: Interdisciplinary Perspectives, Exeter, United Kingdom.

van Deth, Jan W. 2008. “Introduction: Social Capital and Democratic Politics.” In The Handbook of Social Capital, edited by Dario Castiglione, Jan W. van Deth, and Guglielmo Wolleb, 199-207. Oxford: Oxford University Press.

van Deth, Jan W. 2012. "New Modes of Participation and Norms of Citizenship." In New Participatory Dimensions in Civil Society. Professionalization and Individualized Collective Action, edited by Jan W. van Deth, and William A. Maloney, 115-138. London: Routledge.

van Deth, Jan W. 2013. "Citizenship and the Civic Realities of Everyday Life." In Civic Education and Competences for Engaging Citizens in Democracies, edited by Murray Print, and Dirk Lange, 9-21. Rotterdam: Sense Publishers.

van Deth, Jan W. 2014. “A Conceptual Map of Political Participation.” Acta Politica 49 (3): 349-367.

van Deth, Jan W., and Elinor Scarbrough. 1995. "The Concept of Values." In The Impact of Values, edited by Jan W. van Deth, and Elinor Scarbrough, 21-47. Oxford: Oxford University Press.

Verba, Sidney, and Norman H. Nie. 1972. Participation in America: Political Democracy and Social Equality. New York: Harper \& Row.

Vermeir, Iris, and Wim Verbeke. 2006. "Sustainable Food Consumption: Exploring the Consumer 'Attitude - Behavioral Intention' Gap." Journal of Agricultural and Environmental Ethics 19: 169-194. 
Vogel, David. 2008. "Private Global Business Regulation." Annual Review of Political Science 11: 261-282.

von Meyer-Höfer, Marie, and Achim Spiller. 2013. "Anforderungen an eine nachhaltige Land- und Ernährungswirtschaft: Die Rolle des Konsumenten.” KTBL-Schrift 500 Steuerungsinstrumente für eine nachhaltige Land- und Ernährungswirtschaft, Stand und Perspektiven, Darmstadt, Kuratorium für Technik und Bauwesen in der Landwirtschaft e.V.

Wahlström, Mattias, and Abby Peterson. 2005. "Between the State and the Market: The Political Struggle between the Animal Rights Movement and the Swedish Fur Industry." In Political Consumerism: Its motivations, power, and conditions in the Nordic countries and elsewhere, edited by Magnus Boström, Andreas Føllesdal, Mikael Klintman, Michele Micheletti, and Mads P. Sørensen, 225-254. TemaNord 2005:517, Copenhagen: Nordic Council of Ministers.

Weishaupt, Horst, Martin Baethge, Hans-Peter Füssel, Heinz-Werner Hetmeier, Thomas Rauschenbach, Ulrike Rockmann, Susan Seeber, and Andrä Wolter (eds.). 2012. Bildung in Deutschland 2012: Ein indikatorengestützter Bericht mit einer Analyse zur kulturellen Bildung im Lebenslauf. Bielefeld: W. Bertelsmann Verlag.

Westholm, Anders, José Ramón Montero, and Jan W. van Deth. 2007. "Introduction: Citizenship, Involvement, and Democracy in Europe." In Citizenship and Involvement in European Democracies: A Comparative Analysis, edited by Jan W. van Deth, José Ramón Montero, and André Westholm, 1-32. London: Routledge.

Wheeler, Kathryn. 2012. Fair Trade and the Citizen-Consumer. Shopping for Justice? Basingstoke: Palgrave Macmillan.

Willer, Helga, and Julia Lernoud (eds.). 2015. The World of Organic Agriculture. Statistics and Emerging Trends 2015. FiBL- IFOAM Report. Bonn: Research Institute of Organic Agriculture (FiBL), Frick, and IFOAM Organics International.

Woodward, Ian, Zlatko Skrbis, and Clive Bean. 2008. "Attitudes towards Globalization and Cosmopolitanism: Cultural Diversity, Personal Consumption and the National Economy." British Journal of Sociology 59 (2): 207-226.

Woolridge, Jeffrey M. 2003. Introductory Econometrics: A Modern Approach. 2nd ed. Mason: Thomson.

World Bank Group. 2015. Country and Lending Groups, http://data.worldbank.org/about /country-and-lending-groups\#High_income (accessed 09.10.2015)

World Trade Organization. 2015. World Trade and the WTO: 1995-2014. International Trade Statistics 2015. Geneva: World Trade Organization.

Wyer, Robert S. 2008. "The Role of Knowledge Accessibility in Cognition and Behavior: Implications for Consumer Information Processing." In Handbook of Consumer Psychology, edited by Curtis P. Haugtvedt, Paul M. Herr, and Frank. R. Kardes, 31-76. New York: Taylor \& Francis.

Ybarra, Oscar, David Seungjae Lee, and Richard Gonzalez. 2012. "Supportive Social Relationships Attenuate the Appeal of Choice." Psychological Science 23 (10): 1186-1192.

Zadek, Simon, Peter Raynard, and Cristiano Oliveira. 2005. "Responsible Competitiveness Reshaping Global Markets through Responsible Business Practices." AccountAbility, http://www.accountability.org/images/content/1/1/110/Full\%20Report\%20\%28Compressed\%29.pdf (accessed 03.06.2013) 
Zakaras, Alex. 2009. Individuality and Mass Democracy: Mill, Emerson, and the Burdens of Citizenship. Oxford: Oxford University Press.

Zaki, Mohammed, and Wagner Meira, Jr. 2014. Data Mining and Analysis: Fundamental Concepts and Algorithms. Cambridge: Cambridge University Press.

Zmerli, Sonja, Kenneth Newton, and José Ramón Montero. 2007. "Trust in People, Confidence in Political Institutions, and Satisfaction with Democracy." In Citizenship and Involvement in European Democracies: A Comparative Analysis, edited by Jan W. van Deth, José Ramón Montero, and André Westholm, 35-65. London: Routledge. 
